RAFAEL SANTAREM MORASSI

\title{
ESTUDO COM CFD SOBRE A FAIXA OPERATIVA DA CÂMARA DE DISSIPAÇÃO PARA VÁLVULAS DISPERSORAS
}

São Paulo 


\title{
RAFAEL SANTAREM MORASSI
}

\section{ESTUDO COM CFD SOBRE A FAIXA OPERATIVA DA CÂMARA DE DISSIPAÇÃO PARA VÁLVULAS DISPERSORAS}

\author{
Dissertação apresentada à Escola \\ Politécnica da Universidade de São \\ Paulo para obtenção do título de Mestre \\ em Ciências
}

Área de Concentração: Engenharia Mecânica de Energia e Fluidos

Orientador: Prof. Dr. Jayme Pinto Ortiz

\section{SÃO PAULO}


Este exemplar foi revisado e corrigido em relação à versão original, sob responsabilidade única do autor e com a anuência de seu orientador.

São Paulo de de

Assinatura do autor

Assinatura do orientador:

Morassi, Rafael

ESTUDO COM CFD SOBRE A FAIXA OPERATIVA DA CÂMARA DE DISSIPAÇÃO PARA VÁLVULAS DISPERSORAS / R. Morassi -- versão corr. -São Paulo, 2016.

$122 \mathrm{p}$.

Dissertação (Mestrado) - Escola Politécnica da Universidade de São Paulo. Departamento de Engenharia Mecânica.

1.dissipação de energia 2.câmara de dissipação 3.válvula dispersora 4.CFD 5.turbulência I.Universidade de São Paulo. Escola Politécnica. Departamento de Engenharia Mecânica II.t. 


\section{RESUMO}

O dimensionamento das câmaras dissipadoras para válvulas dispersoras demanda um estudo sobre a interação da operação destes elementos, não somente para um ponto de operação, mas também para a faixa operativa do conjunto, que compreende a faixa de operação da válvula e da câmara de dissipação.

Os limites sobre responsabilidade assumem um cenário onde as dimensões da câmara podem não ser adequadas à operação da válvula, e vice-versa. Isto porque durante o processo de dissipação de energia, ocorrem grandes turbulências que podem gerar erosão na estrutura dissipadora.

A interação entre a operação das válvulas dispersoras e as dimensões da câmara dissipadora é complexa porque o dimensionamento de um elemento está associado ao outro. Assim, as dimensões necessárias para dissipação de energia na câmara dependem de dados da válvula, resultando em uma interdependência de dados para a dissipação de energia adequada.

O dimensionamento do conjunto deve levar em consideração a interdependência de operação dos elementos, caso contrário o funcionamento do sistema poderá ser inadequado devido às turbulências e altas velocidades, que podem gerar cavitação e erosão das estruturas dissipadoras. Os danos na estrutura dissipadora podem causar paradas de geração de energia das usinas hidrelétricas e acidentes nas regiões localizadas a jusante desta estrutura.

O dimensionamento adequado do conjunto válvula e câmara dissipadora e o conhecimento de sua faixa operativa admissível pode ser feito com auxílio de simulações numéricas e ensaios em modelo reduzido de forma a prever o comportamento adequado do protótipo. Desta forma, as simulações numéricas em $C F D$ possibilitam maior seletividade dos casos que serão ensaiados em modelo reduzido, proporcionando maior assertividade nestes ensaios.

Palavras-chave: dissipação de energia, câmara de dissipação, válvula de jato oco, $C F D$, válvula dispersora, turbulência, cavitação. 


\begin{abstract}
The sizing of valves and chambers for dissipating purpose demands a study about the interaction between these elements, not only from an operation point of view but also the whole operating range of the set, which comprehends the operating range of the valve and the dissipating chamber.
\end{abstract}

The limits of liability assume a scenario where the dimensions of the chamber may be not suitable for operation of the valve, and vice-versa. This is because during dissipating energy process, major turbulences occur which may cause erosion in the dissipating structure.

The interaction between the dissipating valve and the dissipating chamber dimensions is complex because the sizing of an element is associated to other. Thus, the required dimensions to dissipate energy on the chamber rely on valve data, resulting in data interdependency required for adequate energy dissipation.

The set sizing must consider the operation interdependency of both elements otherwise the system operation may be inadequate due to turbulence high flow velocities, which may cause cavitation and erosion of the dissipating structures. Damages on the dissipating structure may cause energy generation interruption of hydroelectric power plants and accidents on the regions located downstream this structure.

The adequate sizing of the set valve and dissipating chamber as well as the information regarding its operating range can be done with the aid of numerical simulations and physical model tests in order to predict the behavior of the prototype. Therefore, numerical simulations in $C F D$ allow more selectivity of the cases which will be tested in a physical model, proportioning higher assertiveness on those tests.

Keywords: energy dissipation, stilling basin, CFD, dissipating valve, Hollow-Jet valve, turbulence, cavitation. 


\section{LISTA DE FIGURAS:}

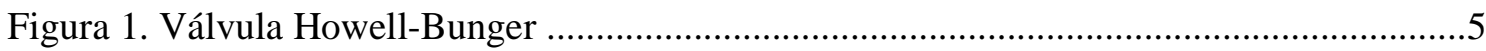

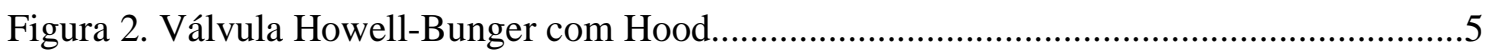

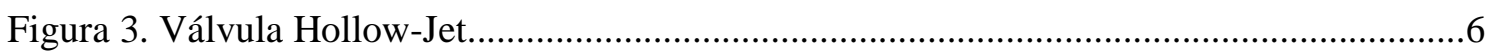

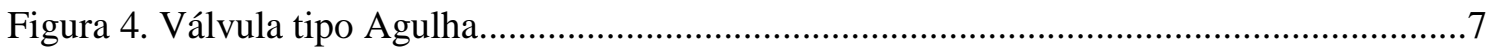

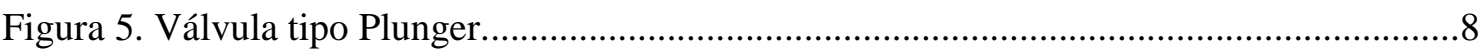

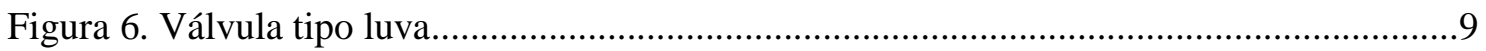

Figura 7. Coeficiente de descarga da válvula Hollow-Jet..................................................11

Figura 8. Dimensões da válvula Hollow-Jet para as simulações numéricas............................12

Figura 9. Cavitação a jusante de um degrau de $6 \mathrm{~mm}$ de altura............................................18

Figura 10. Vista esquemática de uma câmara dissipadora para válvulas Hollow-Jet...............22

Figura 11. Vista esquemática das paredes convergentes.................................................23

Figura 12. Dimensões gerais da câmara dissipadora para válvulas Hollow-Jet.......................26

Figura 13. Definição da profundidade de água ideal em função da queda líquida, diâmetro e

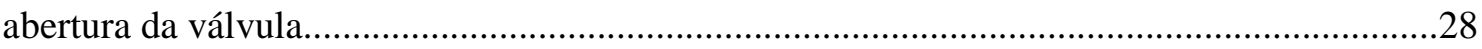

Figura 14. Definição da profundidade de água mínimo em função da queda líquida, diâmetro e abertura da válvula.

Figura 15. Definição do comprimento de soleira em função da queda líquida, diâmetro e abertura da válvula.

Figura 16. Definição da largura câmara em função queda líquida, diâmetro e abertura da válvula. .30

Figura 17. Posição dos piezômetros na cone e corpo da válvula...........................................43

Figura 18. Diagrama de fator pressão no cone da válvula..................................................45

Figura 19. Diagrama de fator pressão no corpo da válvula.................................................46

Figura 20. Dimensões da câmara dissipadora de Falcon Dam...............................................47 
Figura 21. Posição dos piezômetros no fundo da câmara dissipadora .48

Figura 22. Perfil longitudinal de carga de pressão estática no fundo da câmara dissipadora...49

Figura 23. Perfil longitudinal de nível de água da câmara dissipadora. .50

Figura 24. Perfil transversal de nível de água no fim da parede divisória e final da câmara

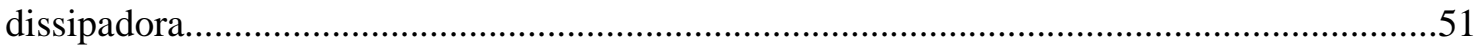

Figura 25. Exemplo de estratégia de aplicação de malha........................................................53

Figura 26. Malha aplicada em camadas de prisma nas superfícies seguida de tetraedros........54

Figura 27. Condições de Contorno utilizadas durante o setup................................................56

Figura 28. Distribuição de pressão ao longo da válvula para abertura de $100 \%$, obtido por CFD .59

Figura 29. Fração de Volume ao longo da válvula para abertura de 100\%, obtido por CFD. .60

Figura 30. Distribuição de pressão ao longo da válvula para abertura de $50 \%$, obtido por CFD. 61

Figura 31. Fração de Volume ao longo da válvula para abertura de 50\%, obtido por CFD 61

Figura 32. Coeficiente de descarga da válvula Hollow-Jet obtido por CFD..........................62

Figura 33. Diagrama de fator pressão no cone da válvula obtido por CFD.............................63

Figura 34. Diagrama de fator pressão no corpo da válvula obtido por CFD...........................63

Figura 35. Vista isométrica: fração de volume da câmara, 2 válvulas a $64,76 \mathrm{~m} 3 / \mathrm{s}$ cada....... .65

Figura 36. Perfil de linha d'água no eixo de simetria, 2 válvulas a $64,76 \mathrm{~m}^{3} / \mathrm{s}$ cada..............65

Figura 37. Perfil de linha d'água na parede lateral, 2 válvulas a $64,76 \mathrm{~m}^{3} / \mathrm{s}$ cada..................66

Figura 38. Comparação de perfil de linha d’água na parede lateral, 2 válvulas a $64,76 \mathrm{~m}^{3} / \mathrm{s}$ .66 
Figura 39. Comparação de perfil de linha d'água no eixo de simetria, 2 válvulas a $64,76 \mathrm{~m}^{3} / \mathrm{s}$ 67

Figura 40. Perfil de linha d'água na parede lateral, 2 válvulas a $36,30 \mathrm{~m} 3 / \mathrm{s}$ cada .67

Figura 41. Perfil de linha d'água no eixo de simetria, 2 válvulas a $36,30 \mathrm{~m} 3 / \mathrm{s}$ cada..............68

Figura 42. Vista isométrica: fração de volume da câmara, 1 válvula a 68,0 m³/s.................69

Figura 43. Perfil de linha d'água na parede lateral, 1 válvula a $68,00 \mathrm{~m}^{3} / \mathrm{s} . \ldots \ldots \ldots \ldots \ldots \ldots \ldots \ldots \ldots . . . .69$

Figura 44. Perfil de linha d'água no final da câmara dissipadora, 1 válvula a $68,00 \mathrm{~m} 3 / \mathrm{s} \ldots \ldots . .70$

Figura 45. Perfil de linha d'água no final da parede divisória, 1 válvula a $68,00 \mathrm{~m} 3 / \mathrm{s} \ldots \ldots \ldots \ldots . .71$

Figura 46. Comparação de perfil de linha d'água na parede lateral, 1 válvula a $68,0 \mathrm{~m} 3 / \mathrm{s} . . . . .71$

Figura 47. Comparação de perfil de linha d'água no final da câmara dissipadora, 1 válvula a $68,00 \mathrm{~m}^{3} / \mathrm{s}$ .72

Figura 48. Comparação de perfil de linha d'água no final da parede divisória, 1 válvula a $68,00 \mathrm{~m}^{3} / \mathrm{s}$ .72

Figura 49. Pressão no fundo da câmara para linha dos piezômetros 1, 2 e 3, para 2 válvulas a $64,76 \mathrm{~m}^{3} / \mathrm{s}$ .73

Figura 50. Pressão no fundo da câmara para linha dos piezômetros 4,5 e 6, para 2 válvulas a $64,76 \mathrm{~m}^{3} / \mathrm{s}$ .74

Figura 51. Pressão no fundo da câmara para linha dos piezômetros 7, 8 e 9, para 2 válvulas a $64,76 \mathrm{~m}^{3} / \mathrm{s}$ .74

Figura 52. Pressão no fundo da câmara para linha dos piezômetros 1, 2 e 3, para 2 válvulas a $45,45 \mathrm{~m}^{3} / \mathrm{s}$ .75

Figura 53. Pressão no fundo da câmara para linha dos piezômetros 4,5 e 6, para 2 válvulas a $45,45 \mathrm{~m}^{3} / \mathrm{s}$ .75

Figura 54. Pressão no fundo da câmara para linha dos piezômetros 7, 8 e 9, para 2 válvulas a $45,45 \mathrm{~m}^{3} / \mathrm{s}$ .76 
Figura 55. Pressão no fundo da câmara para linha dos piezômetros 1, 2 e 3, para 1 válvula a $68 \mathrm{~m}^{3} / \mathrm{s}$ .76

Figura 56. Pressão no fundo da câmara para linha dos piezômetros 4, 5 e 6, para 1 válvula a $68 \mathrm{~m}^{3} / \mathrm{s}$ .77

Figura 57. Pressão no fundo da câmara para linha dos piezômetros 7, 8 e 9, para 1 válvula a $68 \mathrm{~m}^{3} / \mathrm{s}$ .77

Figura 58. Vista isométrica: fração de volume da câmara, 2 válvulas a $86,85 \mathrm{~m}^{3} / \mathrm{s}$ cada.........81

Figura 59. Perfil de linha d'água no eixo de simetria, 2 válvulas a $86,85 \mathrm{~m} 3 / \mathrm{s}$ cada...............81

Figura 60. Perfil de linha d'água na parede lateral, 2 válvulas a $86,85 \mathrm{~m} 3 / \mathrm{s}$ cada..................82

Figura 61. Perfil de linha d'água no eixo de simetria, 2 válvulas a 48,50 m³/s cada...............82

Figura 62. Perfil de linha d'água na parede lateral, 2 válvulas a 48,50 m³/s cada..................83

Figura 63. Vista isométrica: fração de volume da câmara, 1 válvula a 86,85

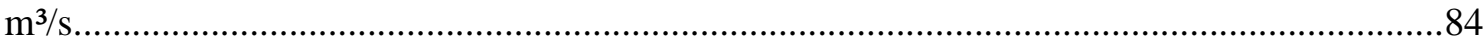

Figura 64. Perfil de linha d'água na parede lateral, 1 válvula a $86,85 \mathrm{~m}^{3} / \mathrm{s} . \ldots \ldots \ldots \ldots \ldots \ldots \ldots \ldots \ldots . . . . . \ldots 4$

Figura 65. Perfil de linha d'água no final da câmara dissipadora, 1 válvula a $86,85 \mathrm{~m}^{3} / \mathrm{s} \ldots \ldots . .85$

Figura 66. Perfil de linha d'água no final da parede divisória, 1 válvula a $86,85 \mathrm{~m}^{3} / \mathrm{s} \ldots \ldots \ldots \ldots . . .86$

Figura 67. Vista isométrica: fração de volume da câmara, 2 válvulas a 74,95 m³/s cada........88

Figura 68. Perfil de linha d'água no eixo de simetria, 2 válvulas a 74,95 m³/s cada..............89

Figura 69. Perfil de linha d'água na parede lateral, 2 válvulas a $74,95 \mathrm{~m}^{3} / \mathrm{s}$ cada..................89

Figura 70. Perfil de linha d'água no eixo de simetria, 2 válvulas a 41,95 m³/s cada..............90

Figura 71. Perfil de linha d'água na parede lateral, 2 válvulas a 41,95 m³/s cada.................90

Figura 72. Vista isométrica: fração de volume da câmara, 1 válvula a 74,95 m³/s................91

Figura 73. Perfil de linha d'água na parede lateral, 1 válvula a $74,95 \mathrm{~m}^{3} / \mathrm{s}$.........................92

Figura 74. Perfil de linha d'água no final da câmara dissipadora, 1 válvula a 74,95 m³/s......92

Figura 75. Perfil de linha d'água no final da parede divisória, 1 válvula a 74,95 m³/s...........93 
Figura 76. Vista isométrica: fração de volume da câmara, 2 válvulas a 53,0 m³/s cada.........96

Figura 77. Perfil de linha d'água no eixo de simetria, 2 válvulas a 53,0 m³/s cada...............96

Figura 78. Perfil de linha d'água na parede lateral, 2 válvulas a 53,0 m³/s cada...................97

Figura 79. Perfil de linha d'água no eixo de simetria, 2 válvulas a 29,67 m³/s cada............97

Figura 80. Perfil de linha d'água na parede lateral, 2 válvulas a $29,67 \mathrm{~m}^{3} / \mathrm{s}$ cada..................98

Figura 81. Vista isométrica: fração de volume da câmara, 1 válvula a 53,0 m³/s..................99

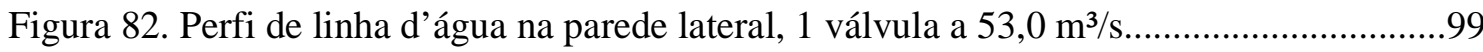

Figura 83. Perfil de linha d'água no final da câmara dissipadora, 1 válvula a 53,0 m³/s......100

Figura 84. Perfil de linha d'água no final da parede divisória, 1 válvula a 53,0 m³/s...........101

Figura 85. Fração de volume nas seções analisadas pelo número de Froude, $H / d=20 \ldots . .104$

Figura 86. Fração de volume nas seções analisadas pelo número de Froude, $H / d=15 \ldots . .104$

Figura 87. Fração de volume nas seções analisadas pelo número de Froude,

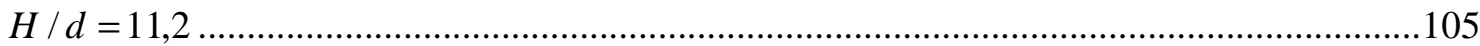

Figura 88. Fração de volume nas seções analisadas pelo número de Froude , $H / d=7,5 \ldots 105$

Figura 89. Velocidades de escoamento no fundo da câmara de dissipação , $H / d=20 \ldots \ldots 109$

Figura 90. Velocidades de escoamento no fundo da câmara de dissipação , $H / d=15 \ldots . . .109$

Figura 91. Velocidades de escoamento no fundo da câmara de dissipação , $H / d=11,2 \ldots 110$

Figura 92. Velocidades de escoamento no fundo da câmara de dissipação , $H / d=7,5 \ldots . .110$

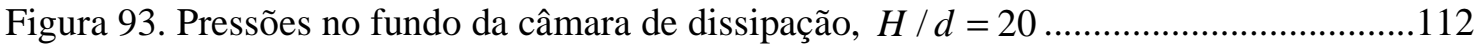

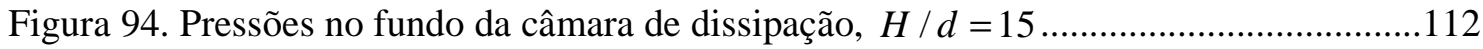

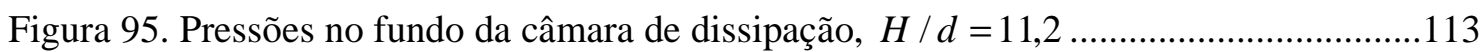

Figura 96. Pressões no fundo da câmara de dissipação, $H / d=7,5 \ldots \ldots \ldots \ldots \ldots \ldots \ldots \ldots \ldots \ldots \ldots \ldots \ldots \ldots \ldots \ldots \ldots \ldots \ldots \ldots \ldots . . . .113$

Figura 97. Linhas de corrente vetoriais no plano da válvula, $H / d=20 \ldots \ldots \ldots \ldots \ldots \ldots \ldots \ldots \ldots \ldots . . . . .115$

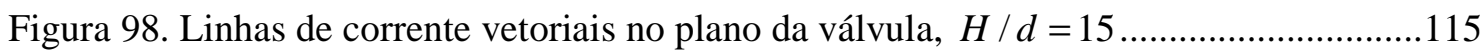

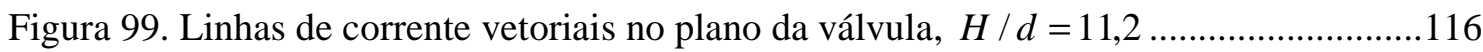


Figura 100. Linhas de corrente vetoriais no plano da válvula, $H / d=7,5 \ldots \ldots \ldots \ldots \ldots \ldots \ldots \ldots . . . .116$ Figura 101. Faixa operativa da câmara dissipadora, queda líquida versus vazão de cada

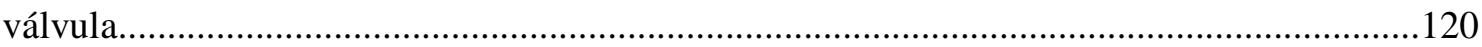




\section{LISTA DE TABELAS:}

Tabela 1. Dimensões da câmara dissipadora de Falcon Dam $(\mathrm{H} / \mathrm{d}=10,94, \mathrm{D} / \mathrm{d}=3,3, \mathrm{~L} / \mathrm{d}=12,53$

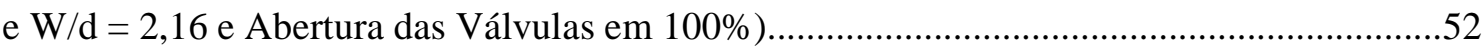

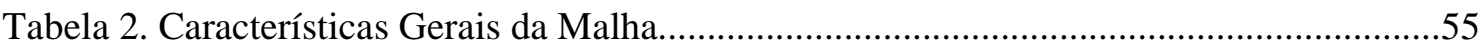

Tabela 3. Fatores de Pressão para os Piezômetros do Cone da Válvula.....................................57

Tabela 4. Diferenças de Fator de Pressão no Cone da Válvula entre o CFD e ensaio de

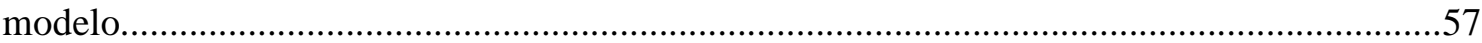

Tabela 5. Fatores de Pressão para os Piezômetros do Corpo da Válvula...................................58

Tabela 6. Diferenças de Fator de Pressão no Corpo da Válvula entre o CFD e ensaio de

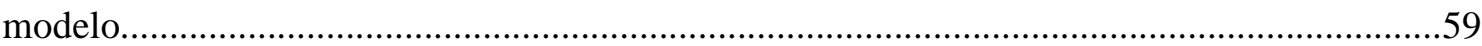

Tabela 7. Coeficientes de Descarga da Válvula Hollow-Jet .................................................62

Tabela 8. Cargas de pressão para os piezômetros de 1 a 9, obtidos por CFD para

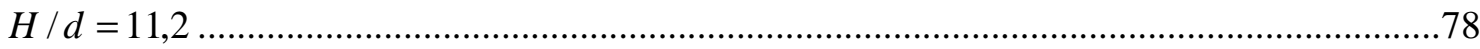

Tabela 9. Análise de Dissipação de Energia, obtido por CFD para $H / d=11,2 \ldots \ldots \ldots \ldots \ldots \ldots \ldots . . .79$

Tabela 10. Cargas de pressão para os piezômetros de 1 a 9, obtidos por CFD para

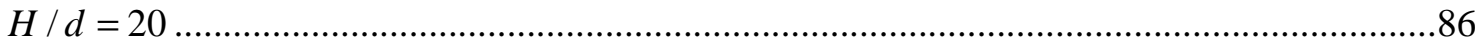

Tabela 11. Análise de Dissipação de Energia, obtido por CFD para $H / d=20 \ldots \ldots \ldots \ldots \ldots \ldots \ldots . . .87$

Tabela 12. Cargas de pressão para os piezômetros de 1 a 9, obtidos por CFD para

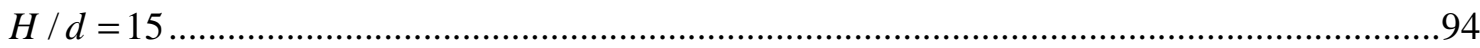

Tabela 13. Análise de Dissipação de Energia, obtido por CFD para $H / d=15 \ldots \ldots \ldots \ldots \ldots \ldots \ldots . . . .94$

Tabela 14. Cargas de pressão para os piezômetros de 1 a 9, obtidos por CFD para $H / d=7,5$ 101

Tabela 15. Análise de Dissipação de Energia, obtido por CFD para $H / d=7,5 \ldots \ldots \ldots \ldots \ldots \ldots . . . .102$

Tabela 16. Número de Froude ao longo da câmara de dissipação, $H / d=20 \ldots \ldots \ldots \ldots \ldots \ldots \ldots . . . . . .106$ 
Tabela 17. Número de Froude ao longo da câmara de dissipação, $H / d=15 \ldots \ldots \ldots \ldots \ldots \ldots \ldots \ldots . . . . .107$

Tabela 18. Número de Froude ao longo da câmara de dissipação, $H / d=11,2$...................107

Tabela 19. Número de Froude ao longo da câmara de dissipação, $H / d=7,5 \ldots \ldots \ldots \ldots \ldots \ldots \ldots . . . .108$ 


\section{LISTA DE SÍMBOLOS:}

\begin{tabular}{|c|c|c|}
\hline$\alpha_{q}$ & fração da fase q contida no volume de controle & {$[-]$} \\
\hline$\frac{\partial}{\partial t}\left(\alpha^{q} \rho^{q} Y_{i}^{q}\right)$ & aceleração do fluido & {$\left[\mathrm{kg} / \mathrm{m}^{2} / \mathrm{s}^{2}\right]$} \\
\hline$\vec{\nabla}\left(\alpha^{q} \rho^{q} u^{q} Y_{i}^{q}\right)$ & q) convecção do fluido na equação & {$\left[\mathrm{kg} / \mathrm{m}^{2} / \mathrm{s}^{2}\right]$} \\
\hline$\vec{\nabla} \cdot \alpha^{q} J_{i}^{q}$ & difusão do fluido na equação & {$\left[\mathrm{kg} / \mathrm{m}^{2} / \mathrm{s}^{2}\right]$} \\
\hline$\alpha^{q} R_{i}^{q}$ & dissipação homogênea do fluido & {$\left[\mathrm{kg} / \mathrm{m}^{2} / \mathrm{s}^{2}\right]$} \\
\hline$\alpha^{q} S_{i}^{q}$ & produção de turbulência do fluido & {$\left[\mathrm{kg} / \mathrm{m}^{2} / \mathrm{s}^{2}\right]$} \\
\hline$\sum_{p=1}^{n}\left(\dot{m}_{p^{i} q^{j}}-\dot{m}_{q^{i} p}\right.$ & $p^{j}$ dissipação heterogênea do fluido & {$\left[\mathrm{kg} / \mathrm{m}^{2} / \mathrm{s}^{2}\right]$} \\
\hline$A$ & área da seção transversal da entrada da válvula dispersora & {$\left[\mathrm{m}^{2}\right]$} \\
\hline$A_{\text {câmara }}$ & área da seção transversal do escoamento na saída da câmara & {$\left[\mathrm{m}^{2}\right]$} \\
\hline$A_{\text {jato }}$ & área da seção transversal do escoamento do jato da válvula & {$\left[\mathrm{m}^{2}\right]$} \\
\hline$b$ & espessura do jato da válvula dispersora & [m] \\
\hline$C_{\varepsilon 1}, C_{\varepsilon 2}, C_{3}$ & constantes das equações do modelo $k-\varepsilon$ RNG & {$[-]$} \\
\hline$C_{d}$ & coeficiente de descarga & {$[-]$} \\
\hline$C L_{\text {valve }}$ & elevação da linha de centro da válvula dispersora & {$[\mathrm{m}]$} \\
\hline$\delta_{i j}$ & delta de Kronecker & {$[-]$} \\
\hline$d$ & diâmetro nominal da válvula dispersora & {$[\mathrm{m}]$} \\
\hline$D_{H}$ & diâmetro hidráulico da seção de escoamento & {$[\mathrm{m}]$} \\
\hline$D$ & profundidade de água da câmara dissipadora de projeto & {$[\mathrm{m}]$} \\
\hline$D_{s}$ & profundidade de água mínima da câmara dissipadora & {$[\mathrm{m}]$} \\
\hline$E_{d}$ & eficiência de dissipação da câmara dissipadora & {$[-]$} \\
\hline$\varepsilon$ & dissipação de energia & {$\left[\mathrm{m}^{2} / \mathrm{s}^{3}\right]$} \\
\hline$F$ & fator de pressão da válvula dispersora & {$[-]$} \\
\hline$F_{q}$ & força externa ao escoamento & {$[\mathrm{N}]$} \\
\hline$F_{l i f t, q}$ & força de empuxo & {$[\mathrm{N}]$} \\
\hline$F_{v m, q}$ & força de massas virtuais & {$[\mathrm{N}]$} \\
\hline $\mathrm{Fr}$ & número de Froude & {$[-]$} \\
\hline
\end{tabular}




\begin{tabular}{|c|c|c|}
\hline$F r_{m}$ & número de Froude do modelo reduzido & {$[-]$} \\
\hline$F r_{p}$ & número de Froude do protótipo & {$[-]$} \\
\hline$g$ & aceleração da gravidade & {$\left[\mathrm{m} / \mathrm{s}^{2}\right]$} \\
\hline$h$ & profundidade de água local na câmara dissipadora & {$[\mathrm{m}]$} \\
\hline$H$ & queda líquida da válvula dispersora & {$[\mathrm{m}]$} \\
\hline$H_{\text {entrada }}$ & carga na entrada na válvula dispersora & {$[\mathrm{m}]$} \\
\hline$H_{e s t}$ & queda estática da válvula dispersora & {$[\mathrm{m}]$} \\
\hline$H_{f}$ & carga no final da câmara dissipadora & {$[\mathrm{m}]$} \\
\hline$H_{\text {jato }}$ & carga do jato ou saída da válvula dispersora & {$[\mathrm{m}]$} \\
\hline$H_{\text {perdas }}$ & perda de carga & {$[\mathrm{m}]$} \\
\hline$H W L$ & nível de montante (head water level) & {$[\mathrm{m}]$} \\
\hline$k$ & energia cinética & {$\left[\mathrm{m}^{2} / \mathrm{s}^{2}\right]$} \\
\hline Ks & coeficiente de perda de carga singular & {$[-]$} \\
\hline$l$ & comprimento & {$[\mathrm{m}]$} \\
\hline$L$ & comprimento da soleira da câmara dissipadora & {$[\mathrm{m}]$} \\
\hline$l_{m}$ & dimensão do modelo & {$[\mathrm{m}]$} \\
\hline$l_{p}$ & dimensão do protótipo & {$[\mathrm{m}]$} \\
\hline$\dot{m}_{p q} u_{q}$ & forças de troca de massa entre fases & {$[\mathrm{N}]$} \\
\hline$p$ & pressão estática & {$[\mathrm{Pa}]$} \\
\hline$P_{\varepsilon}$ & dissipação de turbulência & {$\left[\mathrm{kg} / \mathrm{m} / \mathrm{s}^{3}\right]$} \\
\hline$P_{\varepsilon b}$ & influência do empuxo na dissipação & {$\left[\mathrm{kg} / \mathrm{m} / \mathrm{s}^{3}\right]$} \\
\hline$p_{\text {entrada }}$ & pressão estática na entrada da válvula dispersora & {$[\mathrm{Pa}]$} \\
\hline$P_{k}$ & produção de turbulência & {$\left[\mathrm{kg} / \mathrm{m} / \mathrm{s}^{3}\right]$} \\
\hline$P_{k b}$ & influência do empuxo na energia cinética & {$\left[\mathrm{kg} / \mathrm{m} / \mathrm{s}^{3}\right]$} \\
\hline$p_{\text {saida }}$ & pressão estática na saída da válvula dispersora & {$[\mathrm{Pa}]$} \\
\hline$p_{m}$ & pressão estática do modelo & {$[\mathrm{Pa}]$} \\
\hline$p_{p}$ & pressão estática do protótipo & {$[\mathrm{Pa}]$} \\
\hline$p_{\text {vapor }}$ & pressão de vapor da água & {$[\mathrm{Pa}]$} \\
\hline
\end{tabular}




\begin{tabular}{|c|c|c|}
\hline$p_{x}$ & carga de pressão estática absoluta local em um ponto genérico & {$[\mathrm{m}]$} \\
\hline$Q$ & vazão volumétrica & {$\left[\mathrm{m}^{3} / \mathrm{s}\right]$} \\
\hline$Q_{\text {câmara }}$ & vazão volumétrica da câmara dissipadora & {$\left[\mathrm{m}^{3} / \mathrm{s}\right]$} \\
\hline$Q_{m}$ & vazão volumétrica do modelo & {$\left[\mathrm{m}^{3} / \mathrm{s}\right]$} \\
\hline$Q_{p}$ & vazão volumétrica do protótipo & {$\left[\mathrm{m}^{3} / \mathrm{s}\right]$} \\
\hline$Q_{\text {válvula }}$ & vazão volumétrica da válvula dispersora & {$\left[\mathrm{m}^{3} / \mathrm{s}\right]$} \\
\hline$R$ & raio interno do jato na saída da válvula dispersora & {$[\mathrm{m}]$} \\
\hline$R_{e}$ & raio externo na saída do corpo da válvula dispersora & {$[\mathrm{m}]$} \\
\hline$R_{p q}$ & termo de força que considera a interação entre fases & {$[\mathrm{N}]$} \\
\hline $\operatorname{Re}$ & número de Reynolds & {$[-]$} \\
\hline$\rho$ & massa específica & {$\left[\mathrm{kg} / \mathrm{m}^{3}\right]$} \\
\hline$\rho_{q}$ & massa específica da fase $q$ & {$\left[\mathrm{~kg} / \mathrm{m}^{3}\right]$} \\
\hline$-\rho \overline{u_{i}^{\prime} u_{j}^{\prime}}$ & tensão de Reynolds & {$[\mathrm{Pa}]$} \\
\hline$\sigma$ & número de cavitação & {$[-]$} \\
\hline$\sigma_{p}$ & constante de Schmidt & {$[-]$} \\
\hline$t$ & tempo & {$[\mathrm{s}]$} \\
\hline$T$ & temperatura & {$[\mathrm{K}]$} \\
\hline$T_{m}$ & tempo aplicado ao modelo & [s] \\
\hline$T_{p}$ & tempo aplicado ao protótipo & {$[\mathrm{s}]$} \\
\hline$\tau_{q}$ & tensor de tensão de cisalhamento (viscoso e turbulento) para a fase $q$ & {$[\mathrm{~Pa}]$} \\
\hline$u_{x}$ & velocidade de escoamento em direção genérica & {$[\mathrm{m} / \mathrm{s}]$} \\
\hline$u_{q}$ & velocidade de escoamento da fase $q$ & {$[\mathrm{~m} / \mathrm{s}$} \\
\hline$\overline{u_{i}}$ & velocidade média de escoamento & {$[\mathrm{m} / \mathrm{s}]$} \\
\hline$u_{i}^{\prime}$ & flutuação de velocidade de escoamento & {$[\mathrm{m} / \mathrm{s}]$} \\
\hline$\mu$ & viscosidade dinâmica & {$[\mathrm{Pa} . \mathrm{s}]$} \\
\hline$\mu_{t}$ & viscosidade turbulenta & {$[\mathrm{Pa} . \mathrm{s}]$} \\
\hline$v_{\text {câmara }}$ & velocidade média na saída da câmara dissipadora & {$[\mathrm{m} / \mathrm{s}]$} \\
\hline
\end{tabular}




$\begin{array}{ll}v_{\text {entrada }} & \text { velocidade média na entrada da válvula dispersora } \\ v_{\text {saida }} & \text { velocidade média na saída da válvula dispersora } \\ v_{\text {jato }} & \text { velocidade média do jato da válvula dispersora } \\ v_{m} & \text { velocidade de escoamento do modelo } \\ v_{p} & \text { velocidade de escoamento do protótipo } \\ V & \text { velocidade média na seção de escoamento } \\ x_{x} & \text { posição genérica no espaço } \\ y & \text { profundidade de escoamento para cálculo do número de Froude } \\ \gamma & \text { peso específico do fluido } \\ W & \text { largura da câmara dissipadora } \\ v & \text { viscosidade cinemática do fluido } \\ \nabla & \text { operador nabla }\end{array}$




\section{SUMÁRIO}

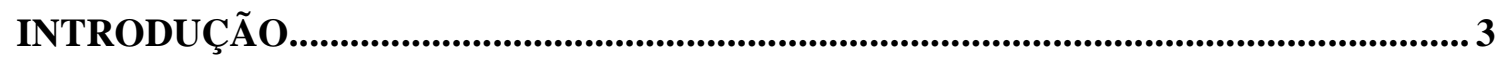

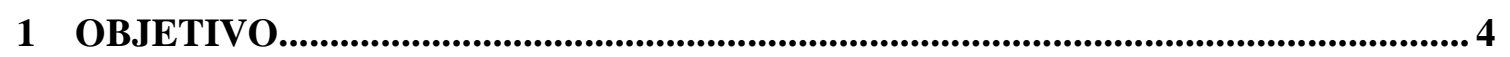

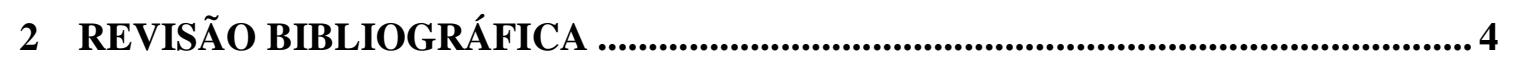

2.1 Tipos de Válvulas Aplicadas em Câmaras Dissipadoras .......................................... 4

2.1.1 Válvula de Cone Fixo (Howell-Bunger).................................................................. 4

2.1.2 Válvula de Jato Oco (Hollow-Jet) ……………….................................................. 6

2.1.3 Válvula Tipo Agulha (Needle Valve) ……………………………………….........

2.1.4 Válvula de Passo Anular (Plunger or Tube Valve) .................................................... 8

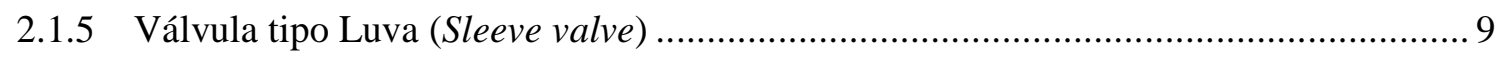

2.2 Dimensionamento das Válvulas Hollow-Jet ............................................................. 10

2.3 Turbulência, Escoamento Multifásico, Cavitação e Semelhança.......................... 13

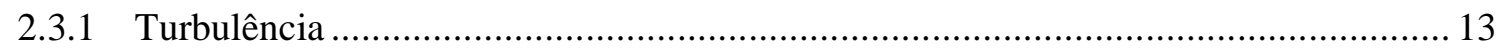

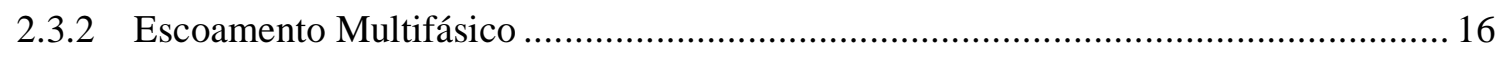

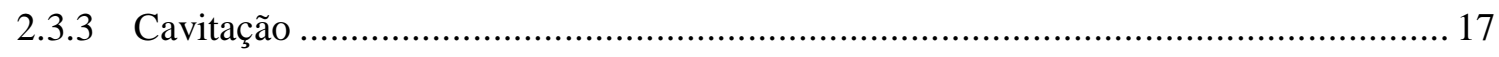

2.3.4 Semelhança de Froude entre Modelo e Protótipo ........................................................ 20

2.4 Dimensionamento Básico da Câmara Dissipadora para Válvulas Hollow-Jet com Base em Ensaio de Modelo Físico Reduzido................................................................... 21

2.4.1 Análise de Cavitação e Eficiência de Dissipação de Energia ......................................... 32

3 METODOLOGIA ............................................................................................................. 34 


\section{APLICAÇÃO DAS SIMULAÇÕES NUMÉRICAS E COMPARAÇÃO COM OS RESULTADOS DE ENSAIO DE MODELO E PROTÓTIPO.......................................... 35}

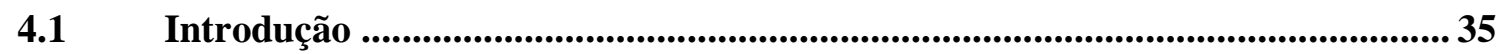

4.2 Modelo de Turbulência ................................................................................. 39

4.3 Calibração do Modelo Numérico …............................................................................... 43

4.4 Simulações Numéricas............................................................................52

4.5 Configuração da Malha e Setup...............................................................53

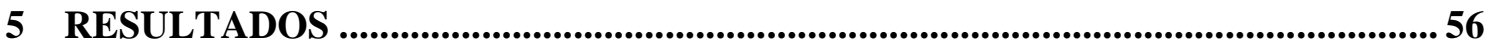

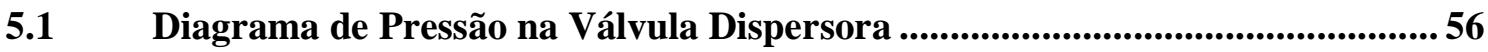

5.2 Simulações das Condições de Protótipo de Falcon Dam $(H / d=11,2)$............. 64

5.2.1 Perfil de Linha de Nível na Bacia Dissipadora com duas Válvulas em Operação ...... 64

5.2.2 Perfil de Linha de Nível na Bacia Dissipadora com uma Válvula em Operação ........ 68

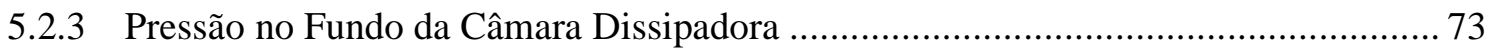

5.2.4 Análise e Cálculo de Eficiência de Dissipação de Energia .................................... 78

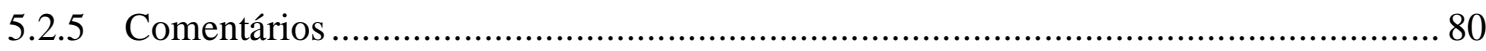

5.3 Simulações de Falcon Dam com $H / d=20$.......................................................... 80

5.3.1 Perfil de Linha de Nível na Bacia Dissipadora com duas Válvulas em Operação ...... 80

5.3.2 Perfil de Linha de Nível na Bacia Dissipadora com uma Válvula em Operação ........ 83

5.3.3 Pressão no Fundo da Câmara Dissipadora ….................................................. 86

5.3.4 Análise e Cálculo de Eficiência de Dissipação de Energia ........................................ 87

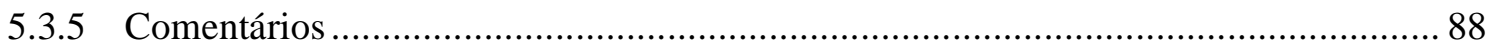

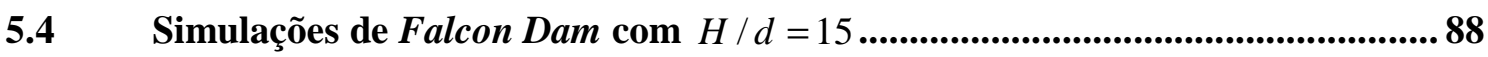

5.4.1 Perfil de Linha de Nível na Bacia Dissipadora com duas Válvulas em Operação ...... 88

5.4.2 Perfil de Linha de Nível na Bacia Dissipadora com uma Válvula em Operação ........ 91 
5.4.3 Pressão no Fundo da Câmara Dissipadora ........................................................ 93

5.4.4 Análise e Cálculo de Eficiência de Dissipação de Energia ....................................... 94

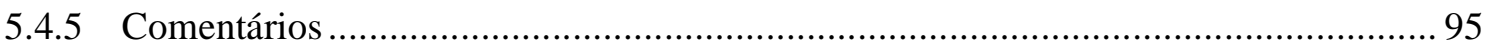

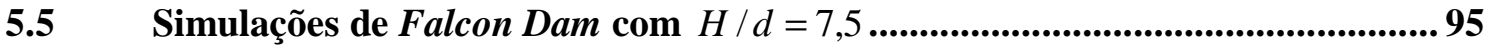

5.5.1 Perfil de Linha de Nível na Bacia Dissipadora com duas Válvulas em Operação ...... 95

5.5.2 Perfil de Linha de Nível na Bacia Dissipadora com uma Válvula em Operação ........ 98

5.5.3 Pressão no Fundo da Câmara Dissipadora ..................................................... 101

5.5.4 Análise e Cálculo de Eficiência de Dissipação de Energia ...................................... 102

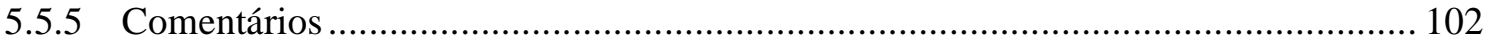

5.6 Definição dos Limites Operacionais da Câmara Dissipadora......................... 103

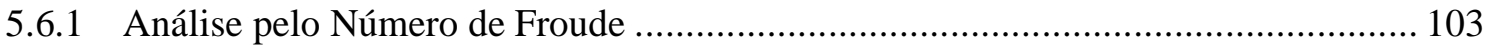

5.6.2 Análise de Perfil de Velocidades e Pressão no Fundo da Câmara Dissipadora ........ 109

5.6.3 Análise das Linhas de Corrente na Câmara Dissipadora....................................... 114

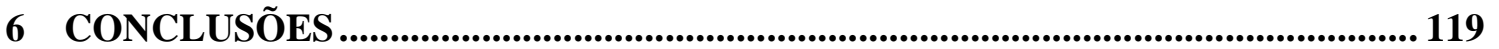




\section{INTRODUÇÃO}

Os sistemas dissipadores são construídos com o objetivo de permitir a vazão de água quando as turbinas da casa de força não estão operando, para controle de nível do reservatório, ou quando, na época de cheia, a vazão do rio deve ser descarregada de montante para jusante.

A questão de operação de um dispositivo dissipador depende basicamente das condições da válvula dispersora e das dimensões apropriadas da câmara dissipadora. Usualmente, ensaios de modelos em escala reduzida permitem prever o comportamento dos protótipos. Entretanto, muitos dos projetos de protótipo são adaptados às condições de operação não homólogas às de ensaio de modelo, dificultando a previsão do comportamento do protótipo.

Diante de análises qualitativas e quantitativas das dimensões da câmara dissipadora, oriundas de ensaios de modelo, as simulações numéricas podem ser calibradas para que possam ser utilizadas com o objetivo de prever o comportamento do protótipo com maior confiabilidade.

Os benefícios dos resultados das simulações numéricas em $C F D$ são a redução de tempo em horas de engenharia para estudar a viabilidade dos pontos de operação e a redução de número de ensaios de modelo físico, pois os resultados obtidos das simulações numéricas permitem eliminar os ensaios de modelo físico que trariam resultados negativos para um determinado ponto de operação, restando somente a execução dos ensaios onde foi prevista a operação bem sucedida durante as simulações numéricas. Desta forma, o banco de dados obtido através de cálculos numéricos proporciona uma rápida análise das adaptações necessárias que um projeto em particular exige, tornando mais seletiva a execução dos ensaios em modelo físico.

Devido à necessidade de calibração do modelo numérico, uma pesquisa bibliográfica foi feita tendo em mente encontrar a maior quantidade de dados disponíveis em modelo físico, não somente para a câmara de dissipação, mas também para a válvula dispersora e sua operação em conjunto com a câmara dissipadora. Nesta dissertação partiu-se de dados de operação de válvula dispersora tipo hollow-jet, que estão disponíveis na literatura, como será mostrado ao longo do texto. Montou-se assim um banco de dados para modelagem numérica usando $C F D$ e para exploração da faixa operativa da válvula em conjunto com a câmara dissipadora. 


\section{OBJETIVO}

Diante do exposto no resumo e introdução deste documento, a Dissertação de Mestrado tem como objetivo o estudo da faixa operativa da câmara de dissipação e das válvulas dispersoras através do uso de simulações numéricas em $C F D$, com uma proposta de determinar a dissipação de energia adequada no que se refere à distribuição de pressão e velocidade de escoamento na válvula e no fundo da câmara, à eficiência de dissipação de energia, ao comportamento do ressalto hidráulico e das linhas de corrente.

\section{REVISÃo BIBLIOGRÁFICA}

De modo a fundamentar a teoria que envolve o estudo de dissipação de energia em câmaras dissipadoras, é apresentada na sequência a revisão bibliográfica.

\subsection{Tipos de Válvulas Aplicadas em Câmaras Dissipadoras}

O tema desta dissertação trata das influências das dimensões da câmara dissipadora sucedidas por válvulas dispersoras. Assim, serão apresentados tipos de válvulas comumente utilizadas na dissipação de energia sob o ponto de vista hidráulico.

\subsubsection{Válvula de Cone Fixo (Howell-Bunger).}

Consiste em uma válvula para quedas baixas e médias, que dispersa a vazão através de um cone, sendo amplamente utilizada devido a sua simplicidade.

A figura 1 mostra a válvula Howell-Bunger em posição aberta e, seu fechamento se dá pelo contato da luva móvel e o cone fixo com ângulo de $45^{\circ}$, responsável pela dispersão da vazão. De acordo com a figura 1, quando a luva se desloca para a direita através dos atuadores hidráulicos ocorre seu fechamento, podendo ser total ou parcial. 


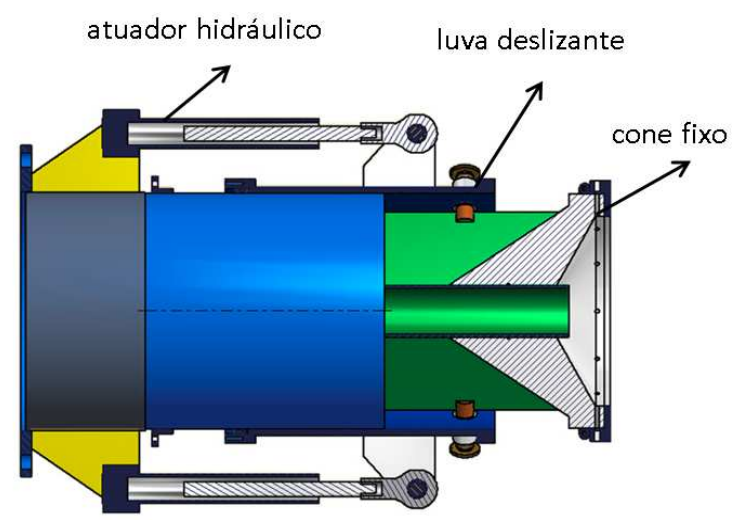

Figura 1. Válvula Howell-Bunger (adaptado de www.hookservice.eu (2015)).

De forma a se evitar que a vazão se espalhe demasiadamente e cause erosão nas estruturas ao redor, uma carcaça externa pode ser aplicada (hood), conforme mostra a figura 2. Esta também possui a função de controlar o empuxo axial causado pela vazão, sendo também muito utilizadas quando estas válvulas operam submersas, pois o confinamento do jato auxilia na redução de turbulências na câmara dissipadora.

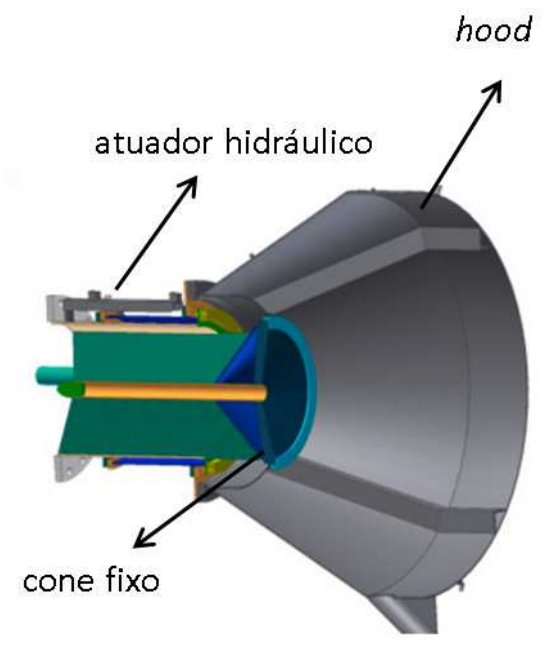

Figura 2. Válvula Howell-Bunger com Hood (adaptado de www.hookservice.eu (2015)).

Estas válvulas apresentam baixo custo relativo e podem ser operadas manualmente, eletromecanicamente ou por atuadores hidráulicos. Também permitem a passagem de sólidos 
em suspensão de tamanho relativamente grande e apresentam elevados coeficientes de descarga, ou seja, não necessitam de altos valores de queda líquida para altas vazões.

Por outro lado, como característica negativa, a vedação da luva deslizante pode vazar. Em adição a isso, pequenos sólidos podem ficar presos entre a luva e corpo da válvula, podendo causar emperramento ou danos a válvula.

\subsubsection{Válvula de Jato Oco (Hollow-Jet)}

Aplicada para quedas intermediárias e altas, esta válvula possui um cone interno, que se movimenta axialmente controlando a área de passagem de vazão. O jato é compacto apresentando menor aeração que o jato das válvulas Howell-Bunger. De forma a evitar excessiva turbulência na superfície da câmara de dissipação, estas válvulas costumam ser posicionadas a $30^{\circ} \mathrm{com}$ a horizontal, o que proporciona melhor penetração do jato proveniente da válvula dispersora na superfície de água da câmara.

A figura 3 mostra a válvula na posição aberta. Quando o cone se move para a esquerda, a válvula fecha, podendo operar em aberturas intermediárias.

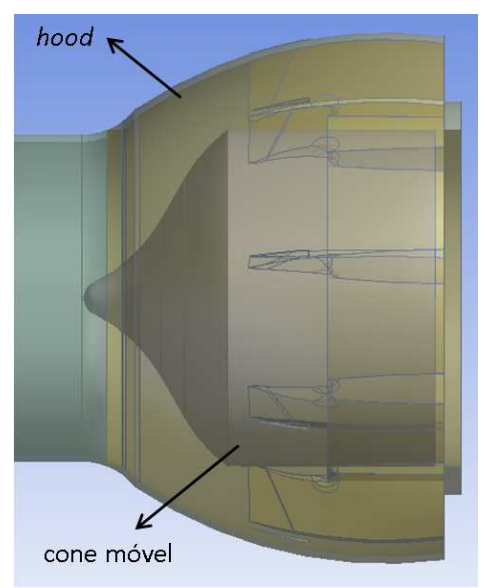

Figura 3. Válvula Hollow-Jet (adaptado de USBR Hydraulic Report Nº189, (1945)). 
Esta apresenta dissipação menos eficiente que a Howell-Bunger, necessitando assim de uma câmara dissipadora eficiente. Por outro lado, sua construção mecânica permite operação com quedas líquidas mais altas.

\subsubsection{Válvula Tipo Agulha (Needle Valve)}

De forma similar as válvulas de jato oco (hollow-jet), porém aplicada para quedas altas a válvula tipo agulha possui no lugar do cone, uma agulha interna que se movimenta axialmente, controlando a vazão.

$\mathrm{Na}$ figura 4, pode ser observado que o movimento da agulha para a direita resulta no fechamento da válvula enquanto que para a esquerda provoca sua abertura.

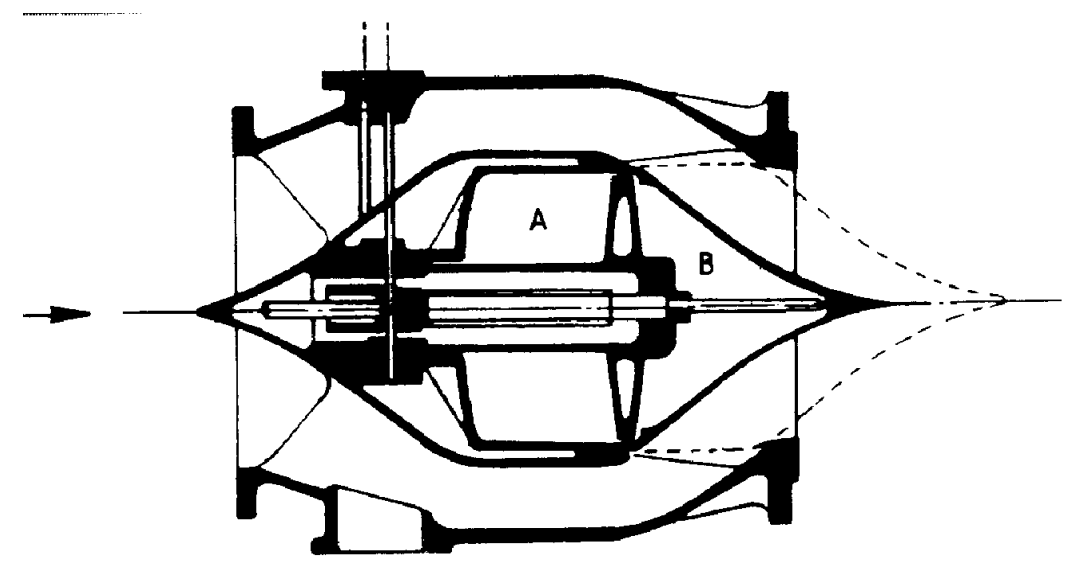

Figura 4. Válvula tipo Agulha (extraído de LEWIN, (1995)).

Seu acionamento pode ser hidráulico através de água pressurizada. Enquanto a câmara A é pressurizada a câmara B tem seu canal de drenagem aberto, o que implica no fechamento da válvula e vice-versa. 


\subsubsection{Válvula de Passo Anular (Plunger or Tube Valve)}

Aplicada para quedas intermediárias e altas, esta é considerada também como uma válvula redutora de pressão, as válvulas tipo Plunger possuem internamente um cilíndrico ou tubo perfurado (que pode apresentar diferentes padrões e tamanhos de perfuração), por onde a vazão encontra passagem. Estas válvulas também são chamadas de válvulas de tubo.

A parte superior da figura 5 mostra a válvula na posição aberta. Para fechamento completo da válvula o cilindro avança para a direita, onde uma parte não perfurada do mesmo começa a restringir a vazão por completo.

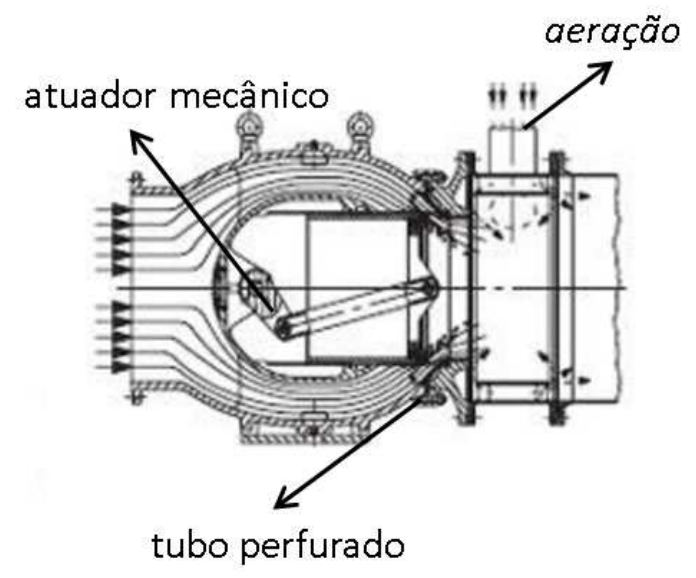

Figura 5. Válvula tipo Plunger (adaptado de www.unitracc.com, (2015))

De acordo com o USBR Hydraulic Report $N^{\circ} 240$ (1948), a diferença desta válvula para a válvula agulha é que a agulha é substituída por um tubo nas válvulas Plunger, minimizando o peso da válvula, empuxo axial, bem como possíveis áreas de cavitação atenuadas com a aeração à jusante, que ocorreriam na válvula agulha. Por outro lado, é comum que estas válvulas trabalhem com quedas líquidas menores que as agulhas.

Diferente das válvulas tipo agulha, as válvulas de tubo apresentam maiores instabilidades para operação em aberturas menores que $30 \%$. 
Diante dos pequenos furos que representam sua área de passagem de escoamento, sólidos podem ficar presos na válvula.

\subsubsection{Válvula tipo Luva (Sleeve valve)}

Consiste numa válvula dispersora aplicada para quedas intermediárias e altas, geralmente posicionada na vertical, que opera com uma luva que desliza verticalmente restringindo ou liberando os orifícios de passagem presentes no corpo.

Caracterizadas por sua simplicidade construtiva, são aplicadas quando a questão do espaço é limitada, pois a energia da vazão vinda de cada orifício é facilmente dissipada.

As válvulas tipo luva apresentam operação com baixo nível de ruído, pois a vazão além de ser submersa é dividida através dos diversos orifícios e, cada um destes é amortecido pela água que cerca a válvula.

A figura 6 mostra a configuração básica de uma válvula tipo luva, onde é possível ver os orifícios submersos por onde passa a vazão. Quando a luva mostrada na figura (peça amarela) se encontra sobre os orifícios, a válvula se encontra fechada.

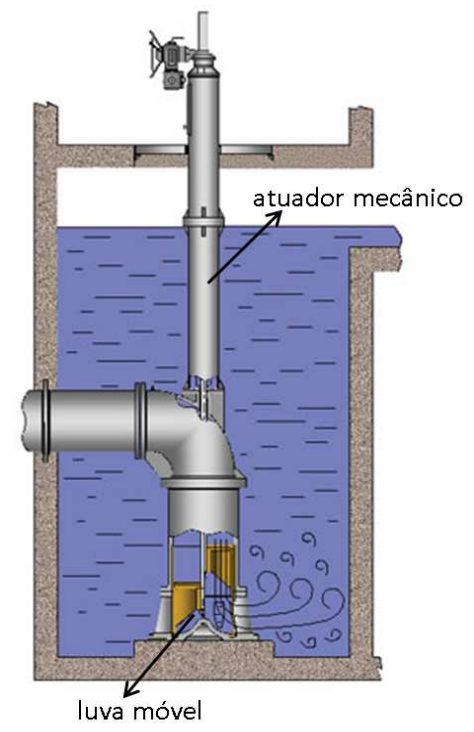

Figura 6. Válvula tipo luva (adaptado de www.enviropo.co.uk (2015)) 
De forma semelhante às válvulas de passo anular, estas válvulas apresentam baixa tolerância de passagem de sólidos em suspensão.

\subsection{Dimensionamento das Válvulas Hollow-Jet}

Devido à necessidade de calibração do modelo numérico, a escolha do tipo de válvula e sua respectiva câmara foi baseada na quantidade e detalhes de informações encontradas na literatura sobre ensaio de modelo como, informações de diagrama de pressão ao longo da válvula e câmara dissipadora bem como detalhes do dimensionamento da mesma. Sendo assim, para desenvolvimento do tema desta dissertação foi escolhida a válvula do tipo Hollow-Jet e sua câmara dissipadora.

De acordo com o USBR Engineering Monograph $N^{\circ} 25$ (1984), o dimensionamento das válvulas Hollow-Jet é feito utilizando a equação 1:

$Q=C_{d} A \sqrt{2 g H}$

O procedimento para calcular o diâmetro nominal da válvula é feito da seguinte forma: conhecendo a vazão necessária $(Q)$, o coeficiente de descarga $\left(C_{d}\right)$ é adotado para abertura máxima da válvula de $100 \%$ na figura 7 , enquanto a queda líquida $(H)$ é calculada considerando a queda estática $\left(H_{e s t}\right)$ menos as perdas de carga $\left(H_{p}\right)$ conforme mostrado nas equações 2 e 3 .

$H=H_{e s t}-H_{p}$

$H_{\text {est }}=H W L-C L_{\text {valve }}$

Como se pode notar a queda estática é calculada pelo nível de montante ( $H W L)$ menos o nível de elevação da linha de centro da válvula $\left(C L_{\text {valve }}\right)$. 
As perdas de carga podem ser calculadas pela equação de Darcy-Weisbach, que dependem do circuito hidráulico desde montante até a válvula dispersora.

Assim, com estas variáveis definidas, resta somente o cálculo da área da válvula e seu respectivo diâmetro.

A normalização do diâmetro deve ser feita sempre com um número um pouco maior que o diâmetro calculado de forma a atribuir certa margem de segurança para atender a vazão necessária, onde na prática isto resultará na válvula operando com abertura ligeiramente menor que $100 \%$.

Sendo a vazão necessária uma constante e considerando a normalização do diâmetro, eventuais adaptações no diâmetro do circuito hidráulico podem ser feitas e então suas perdas de carga recalculadas, que resultaria em uma nova queda líquida e diâmetro de válvula, entrando em um processo iterativo até sua convergência.

Como a área nesse momento já é conhecida calcula-se o coeficiente de descarga, verificando a nova abertura da válvula, que será menor que $100 \%$.

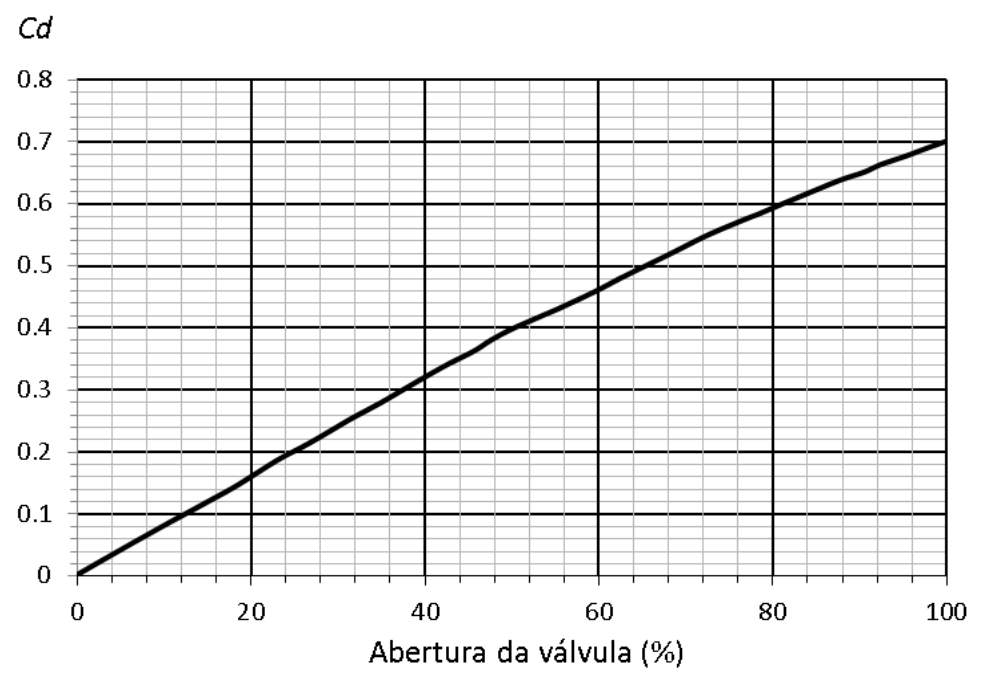

Figura 7. Coeficiente de descarga da válvula Hollow-Jet (adaptado de USBR Engineering Monograph $N^{o} 25$ (1984)) 
As dimensões em milímetros para diâmetro de entrada da válvula de $1000 \mathrm{~mm}$ são apresentadas na figura 8 .

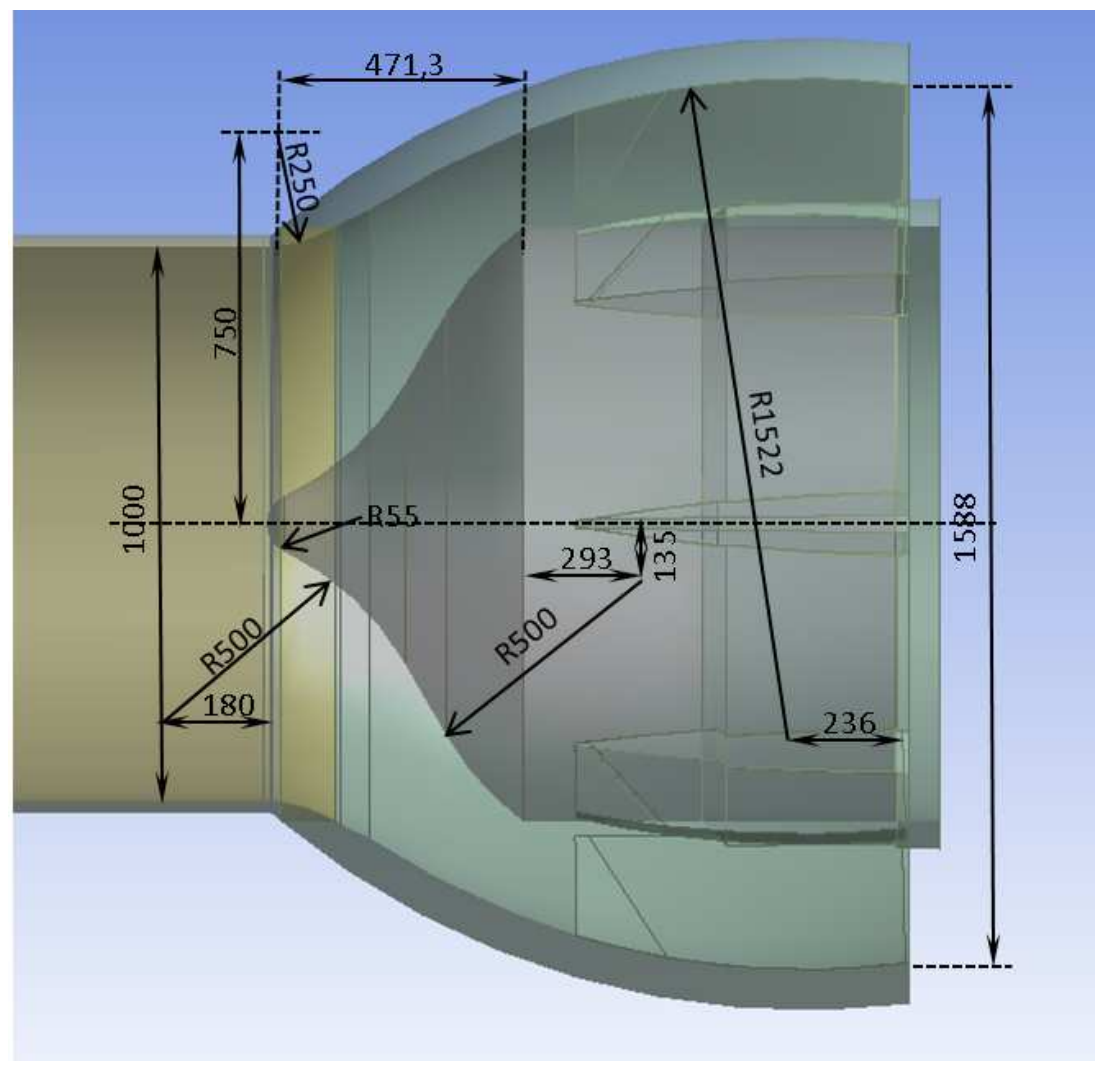

Figura 8. Dimensões em milímetros da válvula Hollow-Jet para as simulações numéricas (adaptado de USBR Engineering Monograph $N^{\circ} 25$ (1984))

A abertura em que a válvula operará influenciará nas dimensões da câmara dissipadora como será mostrado mais adiante.

Observando a cavitação, será mostrado mais adiante que devido à aeração natural e diagrama de pressão que ocorre dentro das válvulas, estas dificilmente apresentam cavitação, exceto quando há alguma irregularidade por falha na fabricação das peças que as compõem ou por condições de entrada de fluxo de água inadequadas. Assim, o projeto desta válvula é livre de cavitação (cavitation free), de acordo com USBR Engineering Monograph N²5 (1984). 


\subsection{Turbulência, Escoamento Multifásico, Cavitação e Semelhança.}

\subsubsection{Turbulência}

Os escoamentos turbulentos ocorrem na grande maioria dos fenômenos analisados na natureza e, por definição os escoamentos turbulentos são aqueles onde turbilhões do fluido se formam com o escoamento dos mesmos. Por outro lado, para o escoamento em regime laminar, o fluido se desloca suavemente em camadas adjacentes, não havendo mistura macroscópica.

A formação de turbilhões se dá por perturbações, sendo naturais ou forçadas, inseridas no meio, que geram instabilidades que se expandem naturalmente.

De acordo com ORTIZ (2010), pode-se então associar a estabilidade de um escoamento a um escoamento laminar e, a instabilidade de um escoamento como um escoamento de transição. Assim, esta seção mostrará os principais conceitos do escoamento em regime turbulento através do estudo de equações clássicas, onde se pretende fazer uma relação com o tema desta dissertação.

Da experiência de Reynolds, chega-se à conclusão que nos escoamentos laminares as perturbações são amortecidas pelas forças viscosas do fluido enquanto que nos escoamentos turbulentos as forças de inércia (velocidade) do escoamento sobrepujam as forças viscosas, possibilitando a formação de vórtices que se ampliam, o que se entende por escoamento instável.

É observado que entre o escoamento laminar e o turbulento existe uma transição. Esta se dá pela amplificação não linear dos vórtices até que se atinja o escoamento turbulento.

Quando um escoamento turbulento é analisado, nota-se que ao mesmo tempo que existe certa periodicidade dos movimentos do fluido, também ocorre sua imprevisibilidade. Assim, com 
base na periodicidade a estatística pode ser aplicada de forma a se determinar valores médios que são utilizados como parâmetros de análise de medições.

Os primeiros estudos sobre instabilidade e turbulência de escoamentos foram pesquisados por Osborne Reynolds no final do século XIX. Reynolds estudou o escoamento no interior dos tubos definindo os regimes de escoamento laminar e turbulento através de um parâmetro que definia a relação entre forças de inércia do escoamento e forças viscosas do fluido, ou seja, o número de Reynolds.

$$
\operatorname{Re}=\frac{V \cdot D_{H}}{v}
$$

$\mathrm{Na}$ equação acima as forças de inércia são representadas pela velocidade enquanto as forças de atração entre as moléculas de fluidos são representadas pela viscosidade dividida por uma dimensão de referência, que no caso é o diâmetro hidráulico do conduto.

$\mathrm{Na}$ época de seus estudos, ficou determinado que escoamentos laminares podem ocorrer para número de Reynolds até 3000. Entretanto, hoje é sabido que dependendo das instalações experimentais e das condições de amortecimento das perturbações externas, é possível obter escoamentos laminares para números de Reynolds ainda maiores.

Ainda assim, o número de Reynolds é um importante parâmetro considerando as condições particulares de cada aplicação de escoamento.

Ainda no século XIX Navier e posteriormente Stokes desenvolveram as equações que generalizam os movimentos, com a inclusão do conceito de viscosidade para fluidos newtonianos na equação de Euler.

As equações de Navier-Stokes conservação de Massa são equações básicas da hidrodinâmica apresentadas a seguir, que servem de base para o cálculo das simulações numéricas. 
As equações da continuidade e quantidade de movimento para a velocidade $\vec{V}(\mathrm{r}, \mathrm{t})$ mostra o campo de velocidade em função do tempo e espaço.

$$
\begin{aligned}
& \frac{\partial \rho}{\partial t}+\nabla \bullet(\rho \vec{V})=0 \\
& \rho \frac{\partial \vec{V}}{\partial t}+\rho(\vec{V} \cdot \nabla) \vec{V}=-\rho \vec{g}-\nabla p+\mu \nabla^{2} \vec{V}
\end{aligned}
$$

Considerando que o escoamento é incompressível, a variação de massa específica ao longo do tempo é igual zero, o que resulta em $\nabla \bullet \vec{V}=0$

Escrevendo estas equações na forma Cartesiana considerando o escoamento incompressível, tem-se (GAO, et al 2009):

$$
\begin{aligned}
& \rho \frac{\partial u_{i}}{\partial x_{i}}=0 \\
& \rho \frac{\partial u_{i}}{\partial x_{i}}+\rho u_{i} \frac{\partial u_{i}}{\partial x_{j}}=-\frac{\partial p}{\partial x_{i}}+\mu \frac{\partial^{2} u_{i}}{\partial x_{i} \partial x_{j}}+\frac{\partial}{\partial x_{j}}\left(\rho \overline{u_{i}^{\prime} u_{j}^{\prime}}\right)+\rho g_{i}
\end{aligned}
$$

Onde na equação (8) o lado esquerdo da equação representa as forças de aceleração do fluido enquanto o lado direito representa o balanço das forças do gradiente de pressão, forças viscosas do fluido e campo gravitacional.

Assim, a solução da equação de Navier-Stokes seria aplicá-las para cada ponto no espaço e tempo para compreender as turbulências. Entretanto isto seria inviável para altos números de Reynolds considerando os termos não lineares dessa equação.

Assim, o escoamento turbulento pode ser considerado como o estado natural de escoamento, onde o campo de velocidades flutua aleatoriamente no tempo e apresenta altos níveis de variações espaciais. Além disto, o campo de velocidades é imprevisível no sentido de que uma mudança nas condições iniciais produzirá mudança significativa no movimento subsequente, o que caracteriza o comportamento turbulento (ORTIZ, 2010). 


\subsubsection{Escoamento Multifásico}

Devido à intensa mistura de escoamento de água e ar na câmara dissipadora, o escoamento é tratado como multifásico.

Conforme explica BUDO (2013), há duas formas de se modelar o escoamento de água e ar que são montar equações para a mistura ou para cada componente separadamente.

A vantagem de se modelar as equações para a mistura está na simplicidade do modelo. Entretanto estas são aplicáveis somente para casos onde a concentração de ar é pequena.

Dado que a concentração de ar na câmara de carga é elevada, o segundo método é preferido, aplicando as equações de conservação de massa e quantidade de movimento para cada fase, tem-se, respectivamente (ANSYS CFX, 2010):

$$
\begin{aligned}
& \frac{\partial}{\partial t}\left(\alpha_{q} \rho_{q}\right)+\vec{\nabla} \cdot\left(\alpha_{q} \rho_{q} u_{q}\right)=\sum_{p=1}^{n} \dot{m}_{p q} \\
& \frac{\partial}{\partial t}\left(\alpha_{q} \rho_{q} u_{q}\right)+\vec{\nabla} \cdot\left(\alpha_{q} \rho_{q} u_{q} u_{q}\right)=\alpha_{q} \rho_{q} \vec{g}-\alpha_{q} \cdot \vec{\nabla} p+\vec{\nabla} \cdot \tau_{q}+\sum_{p=1}^{n}\left(R_{p q}+\dot{m}_{p q} u_{q}\right)+ \\
& +\alpha_{q} \rho_{q}\left(F_{q}+F_{l i f t, q}+F_{v m, q}\right)
\end{aligned}
$$

$\mathrm{Na}$ equação de conservação de quantidade de movimento o primeiro termo representa a aceleração local do fluido e o segundo representa a convecção, onde $\alpha_{q}$ é a fração da fase $q$ contida no volume de controle, $\rho_{q}$ é a massa específica da fase $q, u_{q}$ é a velocidade de escoamento da fase q, $g$ é o vetor de aceleração da gravidade, $p$ é a pressão estática, $\tau_{q}$ é o tensor de tensão de cisalhamento (viscoso e turbulento) para a fase $q$.

O termo $R_{p q}$ é o termo de força que considera a interação entre fases, $m_{p q} u_{q}$ que representam troca de massa. Os termos que representam forças externas, empuxo e forças de massas virtuais são $F_{q}, F_{l i f t, q}$ e $F_{v m, q}$, respectivamente. 
O termo $R_{p q}$ é escrito conforme mostra a equação 11 :

$$
R_{p q}=K_{p q}\left(u_{p}-u_{q}\right)
$$

Utilizando o modelo de tensão de Reynolds, a equação a ser utilizada na solução do escoamento multifásico é apresentada (ANSYS CFX, 2010):

$\frac{\partial}{\partial t}\left(\alpha^{q} \rho^{q} Y_{i}^{q}\right)+\vec{\nabla} \cdot\left(\alpha^{q} \rho^{q} u^{q} Y_{i}^{q}\right)=-\vec{\nabla} \cdot \alpha^{q} J_{i}^{q}+\alpha^{q} R_{i}^{q}+\alpha^{q} S_{i}^{q}+\sum_{p=1}^{n}\left(\dot{\left.m_{p^{i} q^{j}}-\dot{m}_{q^{i} p^{j}}\right)}\right.$

Onde $\frac{\partial}{\partial t}\left(\alpha^{q} \rho^{q} Y_{i}^{q}\right)$ representa a aceleração local do fluido, $\vec{\nabla} \cdot\left(\alpha^{q} \rho^{q} u^{q} Y_{i}^{q}\right)$ é a convecção, $\vec{\nabla} \cdot \alpha^{q} J_{i}^{q}$ é a difusão, $\alpha^{q} R_{i}^{q}$ é a dissipação homogênea, $\sum_{p=1}^{n}\left(\dot{m}_{p^{i} q^{j}}-\dot{m}_{q^{i} p^{j}}\right)$ é a dissipação heterogênea e $\alpha^{q} S_{i}^{q}$ é a produção de turbulência.

\subsubsection{Cavitação}

A cavitação é um fenômeno onde a pressão local em determinado ponto do escoamento diminui o suficiente até que esta atinja a pressão de vapor, formando bolhas no escoamento. As bombas de vapor ao ganharem energia de pressão em um determinado ponto do escoamento podem implodir, liberando grande quantidade de energia que, ao ocorrer próxima a uma superfície sólida provoca sua erosão.

A cavitação dificilmente ocorre nas válvulas Hollow-Jet porque estas trabalham desafogadas, ou seja, os efeitos da cavitação no ar são muito inferiores quando ocorre na água.

Por outro lado a cavitação pode ocorrer na câmara dissipadora, como será explicado na sequência. 
A diminuição da pressão geralmente é provocada por perdas de carga acompanhadas de turbulência onde, diante o princípio da conservação de energia, o aumento da velocidade resulta em queda de pressão.

Os danos devido à cavitação devem ser evitados, pois a médio prazo podem destruir completamente o equipamento, causando paradas forçadas para manutenção e consequente prejuízo financeiro.

Somado a isto, os danos da cavitação podem gerar acidentes dependendo da forma que uma câmara dissipadora é afetada, pois a cavitação pode gerar danos estruturais à câmara dissipadora.

A figura 9 mostra a ocorrência de cavitação em formas de bolhas de vapor logo após a mudança brusca de geometria, representada pela mancha escura logo acima do degrau.

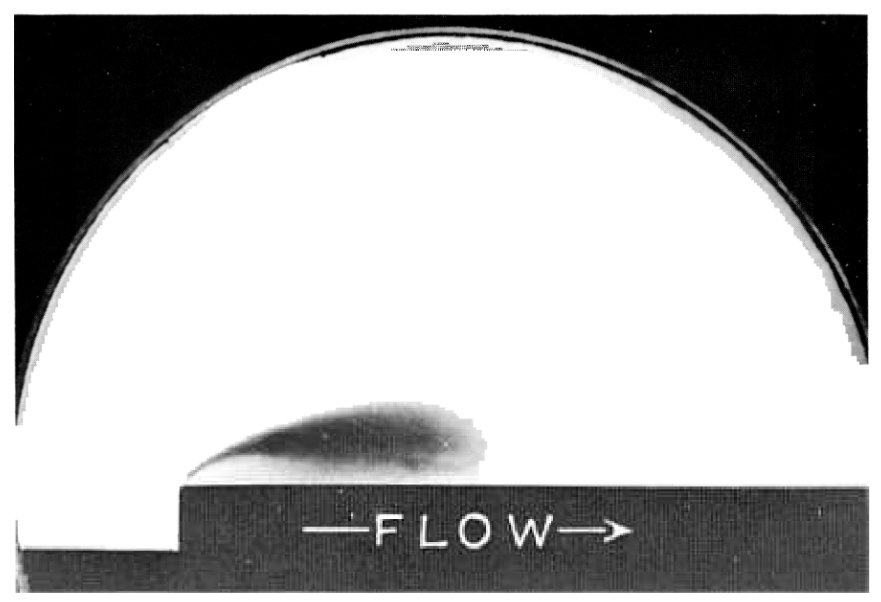

Figura 9. Cavitação a jusante de um degrau de $6 \mathrm{~mm}$ de altura (extraído de USBR Hydraulic Laboratory Technique, (1980)).

Segundo o manual USBR - Hydraulic Laboratory Technique (1980), a cavitação pode ser causada em situações como mudança de geometria acentuada não condizendo com a tendência de escoamento do fluido e/ou variações extremas de energia potencial. 
Geralmente a cavitação pode ser estudada com a medição da pressão nas regiões de interesse, onde ocorrem as tendências de cavitação.

De forma a evitar danos por cavitação é importante que não haja material de superfície susceptível a cavitação, ou do contrário, a implosão das bolhas de vapor próximas a qualquer parte do equipamento fará com que sua superfície seja erodida ao longo do tempo.

Devido a muitas incertezas referentes às diversas dimensões de uma câmara dissipadora, relacionados ao cenário propício à cavitação, projetar uma estrutura dissipadora totalmente isenta de cavitação raramente é possível sem o auxílio de simulações numéricas ou ensaios em modelo.

Uma forma de projetar uma estrutura dissipadora minimizando ao máximo as regiões de cavitação é estudar através do modelo numérico em $C F D$ o perfil de pressão ao longo de toda a câmara dissipadora, observando as regiões de possível cavitação, ou seja, aquelas com pressão estática próxima a pressão de vapor.

Durante o mapeamento de pressões no modelo, podem-se detectar pressões acima da pressão de vapor enquanto no seu protótipo, devido aos efeitos de escala, estas pressões podem chegar a valores próximos ou mesmo abaixo da pressão de vapor, resultando assim na cavitação.

Um parâmetro para análise de cavitação é o número de cavitação, expresso pela equação 13:

$$
\sigma=\frac{p_{x}-p_{\text {vapor }}}{\frac{V^{2}}{2 g}}
$$

Onde $p_{x}$ é a carga de pressão absoluta medida em metros em um determinado ponto, $p_{\text {vapor }}$ é a carga de pressão de vapor e $V$ é a velocidade em um ponto de referência.

O número de cavitação pode ser utilizado para prever o comportamento da cavitação no protótipo, pois considerando que a pressão de vapor é praticamente a mesma entre modelo físico e protótipo, o mesmo $\sigma$ é aplicado para ambos. Desta maneira, com a velocidade de 
referência do protótipo, tem-se a pressão prevista no mesmo onde se pode avaliar a ocorrência de cavitação.

\subsubsection{Semelhança de Froude entre Modelo e Protótipo.}

Para que seja possível fazer a relação entre modelo físico e protótipo, as relações de Froude, referenciadas nas dimensões entre modelo e protótipo, podem ser usadas conforme consta no USBR Hydraulic Report No276 (1950).

O número de Froude é definido como a relação de forças de inércia e força gravitacional.

$$
F r=\frac{\sqrt{2 g H}}{\sqrt{g y}}=\frac{V}{\sqrt{g y}}
$$

Partindo da semelhança entre modelo e protótipo $\left(F r_{m}=F r_{p}\right)$ e, considerando que o comprimento é o produto da velocidade e do tempo, as relações são apresentadas nas equações de 15 a 18 .

Pressão: $p_{m}=p_{p} \cdot \frac{l_{m}}{l_{p}}$

Velocidade de escoamento: $v_{m}=v_{p} \sqrt{\frac{l_{m}}{l_{p}}}$

Vazão volumétrica: $Q_{m}=Q_{p}\left(\frac{l_{m}}{l_{p}}\right)^{2,5}$

Tempo de ensaio (ou operação): $T_{m}=T_{p} \sqrt{\frac{l_{m}}{l_{p}}}$

Onde o índice $m$ se refere ao modelo e o índice $p$ se refere ao protótipo. 


\subsection{Dimensionamento Básico da Câmara Dissipadora para Válvulas Hollow-Jet com Base em Ensaio de Modelo Físico Reduzido}

De acordo com o USBR Engineering Monograph $N^{o} 25$ (1984), a câmara dissipadora costuma ser construída adjacente à casa de força de forma a se obter um projeto mais econômico e compacto.

Esta dissertação de mestrado analisa o desempenho da câmara de dissipação sob o ponto de vista hidráulico, ou seja, para que seja possível a construção do protótipo as questões estruturais como deformações, tensões, danos por cavitação e vibrações devem ser observadas.

Independente da vazão e queda líquida, as válvulas Hollow-Jet apresentam um jato de água anular de diâmetro praticamente regular ao longo do espaço, facilitando a dissipação de energia em câmaras menores. Assim, válvulas que apresentam jato de água que não seja oco não podem ser utilizadas nas câmaras dissipadoras que serão apresentadas.

A figura 10 mostra a vista esquemática da câmara dissipadora para operação de duas válvulas Hollow-Jet. Os detalhes e função de cada dimensão da câmara dissipadora serão explicados mais adiante. 


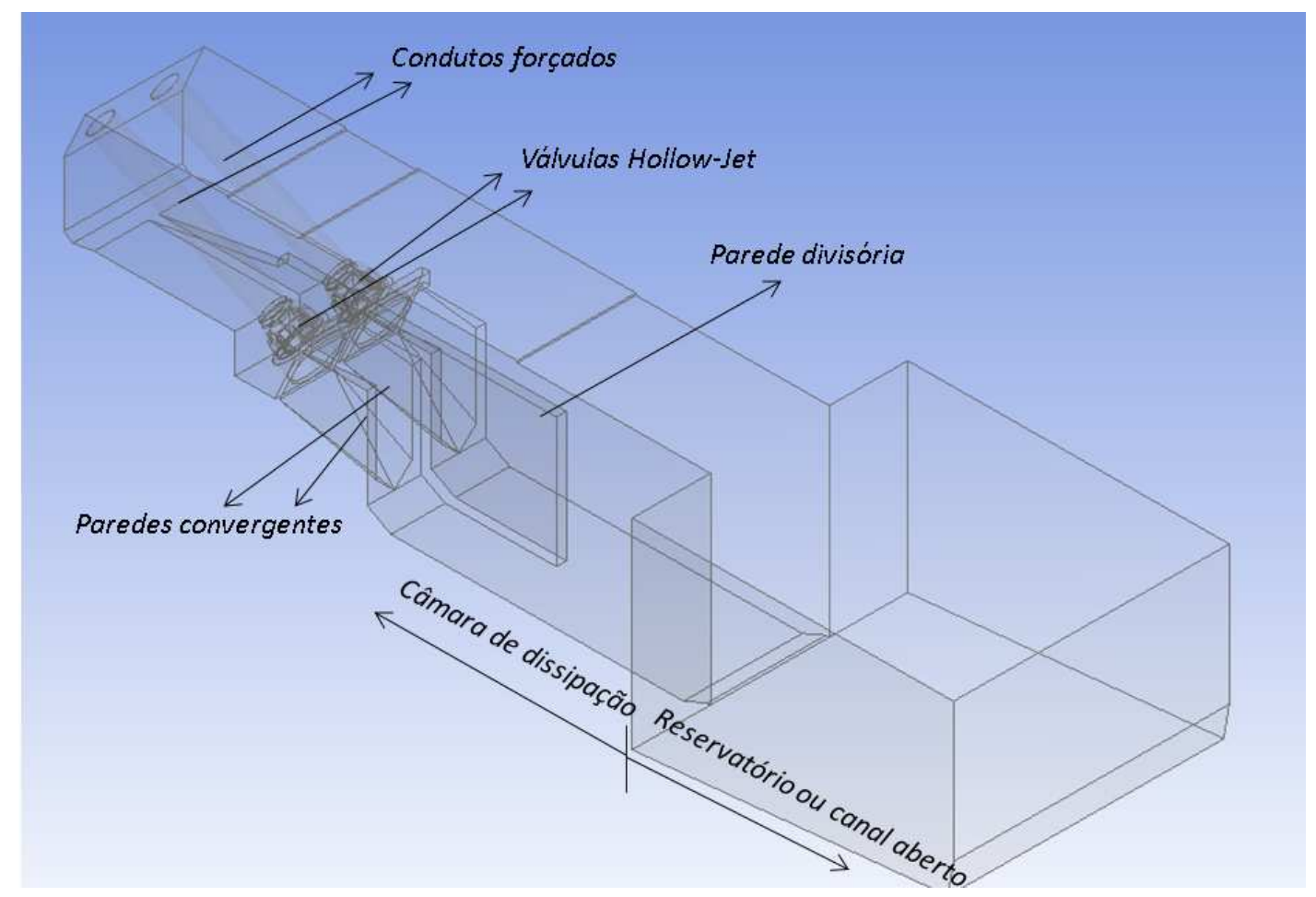

Figura 10. Vista esquemática de uma câmara dissipadora para válvulas Hollow-Jet

(adptado de USBR Engineering Monograph No25 (1984)).

Nos primeiros projetos de câmara dissipadora o posicionamento das válvulas foi estudado na posição horizontal, o que resultava em comprimentos muito longos da câmara porque o jato de água penetrava na superfície da água com maior dificuldade, necessitando de mais espaço. Posteriormente, conforme pode ser observado na figura 10, foi notado que se as válvulas fossem inclinadas para baixo com um determinado ângulo, a dissipação de energia seria mais eficiente fazendo com que a câmara dissipadora pudesse ser mais curta e econômica. Assim, o jato na posição horizontal não permitia que o mesmo penetrasse na água, fazendo com que ele espirrasse sobre a superfície de jusante, diminuindo a dissipação de energia. Por outro lado, se o jato penetrasse na superfície com ângulo muito agudo, o mesmo retornaria para cima causando muita agitação na superfície da água. 
Observando a figura 11, também pode ser notada a presença de paredes convergentes logo após a válvula. Estas tem a função de evitar que o jato se espalhe antes de penetrar na água a jusante. Além disto, as paredes convergentes fazem com que a espessura da "parede" do jato oco seja comprimida, se tornando mais fina, o que facilita a penetração do jato na superfície.

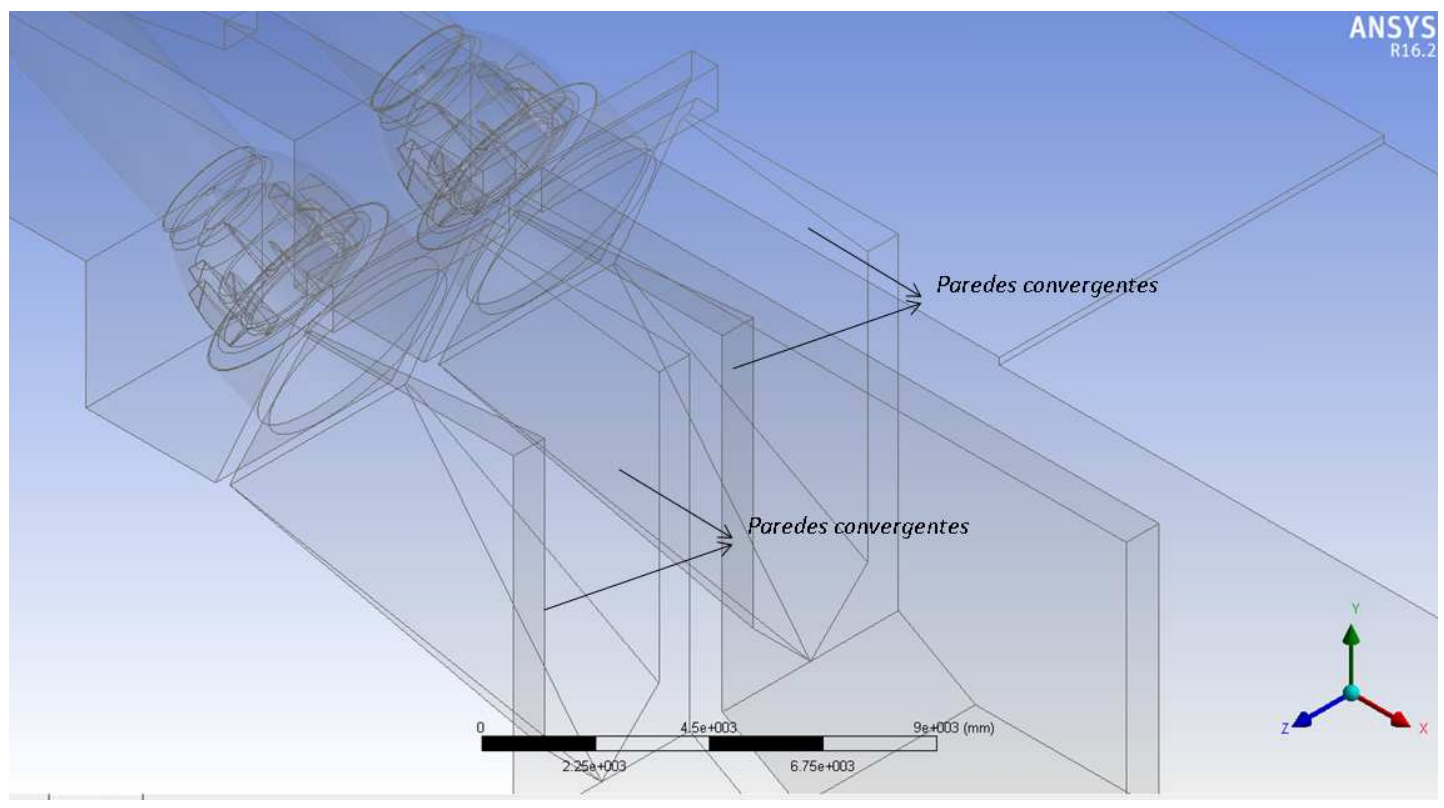

Figura 11. Vista esquemática das paredes convergentes (adptado de USBR Engineering Monograph $\left.N^{o} 25(1984)\right)$.

Dado que a penetração do jato na superfície da água é facilitada pelo aumento da velocidade, deve-se verificar o nível de pressão nas paredes convergentes e rampa durante o projeto, pois se a mesma for muito baixa pode-se induzir cavitação e erosão da superfície. Assim, quanto maior a vazão em relação ao diâmetro da válvula, maior é a necessidade de estender o comprimento das paredes convergentes, que pode chegar até ao fundo da câmara dissipadora. A altura das paredes convergentes segue a mesma linha de raciocínio, diminuindo ao longo do comprimento. 
Uma vez que o jato penetrou na água, este é submetido a uma rápida expansão quando chega ao fim das paredes convergentes. Esta expansão proporciona dissipação de energia abaixo da superfície, minimizando a agitação da mesma.

O interesse em minimizar a agitação da superfície é também minimizar as dimensões da câmara dissipadora, que precisaria ter espaço suficiente para absorver as grandes oscilações de nível da superfície.

Ainda assim, nota-se que caso seja aplicada mais de uma válvula na mesma câmara, é necessária uma parede divisória para evitar que a vazão de uma válvula influencie nas condições de dissipação da outra, minimizando a agitação da superfície da água durante o processo de dissipação.

A extensão da parede divisória é variável, mas, dificilmente é necessário que ela se estenda totalmente na câmara dissipadora. A questão é determinar seu comprimento ótimo para cada caso, pois sua extensão demasiada pode fazer com que a vazão não se espalhe depois de passar pelas paredes convergentes, o que pode aumentar as agitações na superfície. Assim, conclui-se que as dimensões da câmara dissipadora devem ser ideais, pois uma câmara grande demais não necessariamente significa dissipação de energia suficiente.

A soleira representa o comprimento horizontal da câmara dissipadora (entre as paredes convergentes e a rampa ao final da câmara) possui a função de proporcionar espaço para que a dissipação se estabilize após a expansão ao passar das paredes convergentes, onde a pressão pode chegar a valores em torno de $33 \%$ da queda líquida da válvula. As dimensões ideais de comprimento da soleira são obtidas através de ensaios de modelo, observando o comportamento das linhas de corrente no fundo que começam a subir sem a existência de uma rampa. A subida das linhas de corrente sem uma rampa demonstra que o processo de dissipação já ocorreu na câmara e que as linhas de corrente provocam baixa pressão na soleira, favorecendo a erosão da superfície de concreto por destacamento. 
Importante observar que se o comprimento da soleira for muito mais longo que o necessário, o solo do canal de fuga é carregado para dentro da câmara, pois a baixa pressão gerada na soleira possibilita a entrada de materiais sólidos do canal de fuga, no sentido de jusante para montante. Quando estes sólidos entram na câmara, estes assumem a trajetória turbulenta da corrente, acentuando a erosão por arraste do concreto da câmara.

Por outro lado, utilizando o raciocínio inverso, se a câmara for curta demais, a tendência é que haja forte erosão por arraste do solo do canal de fuga.

Para atenuar ou mesmo eliminar o problema de erosão por arraste de sólidos devido ao material do canal de fuga invadir a câmara dissipadora, recomenda-se utilizar o enrocamento no canal de fuga. Este deve conter diâmetros apropriados que sejam pesados o suficiente para que as correntes de escoamento não destaquem os blocos de enrocamento por diferenciais de pressão (uplift).

Ao final da câmara dissipadora tem-se uma rampa (end sill) que possui a função de isolar mais efetivamente o processo de dissipação do canal de fuga, que segue após o fim da câmara dissipadora. Suas dimensões ideais também foram obtidas através de ensaio de modelo, observando a dissipação mais eficiente de energia.

Da mesma forma, a altura das válvulas em relação ao nível de água bem como a profundidade e largura da câmara são ajustadas com base na dissipação mais eficiente de energia, onde a variação da largura da câmara é ajustada por último.

$\mathrm{Na}$ figura 12 é possível notar as equações iniciais necessárias para dimensionamento da câmara dissipadora. A determinação do diâmetro da válvula foi previamente apresentada bem como a vazão de projeto, queda líquida de projeto e coeficiente de descarga da válvula. 


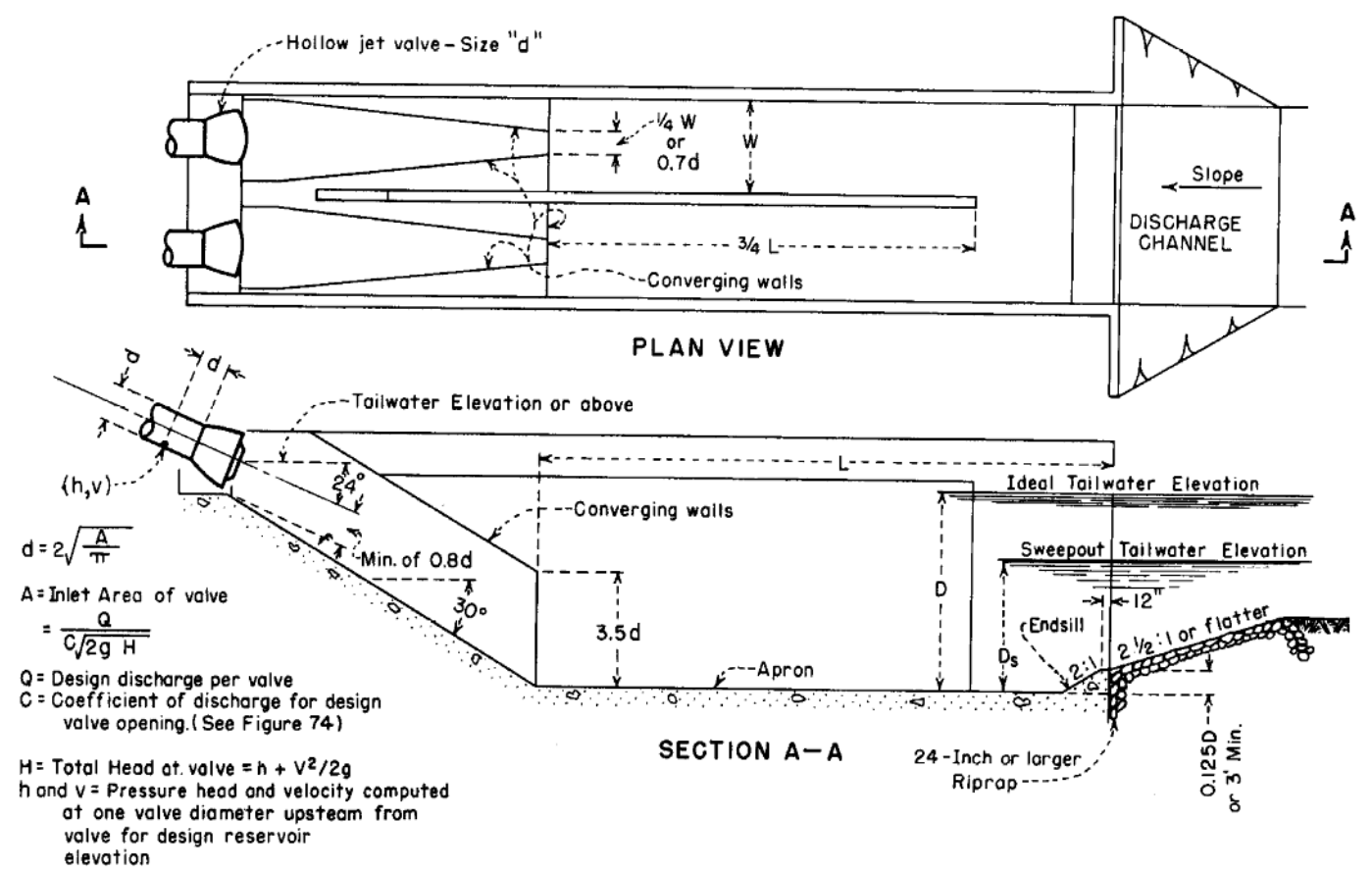

Figura 12. Dimensões gerais da câmara dissipadora para válvulas Hollow-Jet (extraído de USBR Engineering Monograph $N^{\circ} 25$ (1984))

Conforme será mostrado mais adiante a partir de resultados de ensaios de modelo, a largura da câmara dissipadora pode variar entre 2,5 a 3,0 vezes o diâmetro nominal da válvula. Caso a largura seja maior que o ideal, a câmara dissipadora se tornaria proporcionalmente curta demais para a largura aplicada, ou seja, seria algo similar com a inexistência de uma câmara dissipadora que conduz o fluido, onde se perde o propósito de projeto da mesma. Caso a largura seja menor que o ideal, resulta em comprimento necessário maior da câmara, o que significa que não haveria espaço suficiente para dissipação de energia ocorrer, se assemelhando a um canal de condução simples.

O nível de jusante ideal deve ser definido de forma a minimizar as oscilações na câmara dissipadora. De acordo com ensaios de modelo, se o nível d’água fica acima do ideal faz com que o jato da válvula possa se estender por um comprimento maior na soleira da câmara, o que aumenta as oscilações na superfície fazendo com que os turbilhões antes pequenos se 
tornem maiores e de menor rotação. Isto ocorre devido ao aumento da coluna de água logo no início da câmara dissipadora, que tende a empurrar o processo de dissipação de energia para a jusante, fora da câmara dissipadora.

Por outro lado se o nível fica abaixo do ideal, faz com que a função de dissipação da câmara se desloque para jusante além de fazer com que o jato espirre mais, pois o jato da válvula adentra a superfície tardiamente e, além disto, níveis mais baixos para uma dada vazão resultam em velocidades de escoamento maiores o que pode resultar em erosão por abrasão após a câmara, pois de acordo com a equação da energia, a pressão estática próxima às superfícies seria demasiadamente pequena.

Caso o nível de jusante seja diminuído ainda mais, chega-se ao ponto da câmara não funcionar mais como um dispositivo de dissipação (nível este chamado de sweepout depth). Assim, os projetos devem dispor de uma lei de manobra de abertura de válvula para evitar que o nível jusante atinja valores abaixo do admissível.

Ainda assim, para todas as condições descritas acima, deve-se considerar a operação em abertura parciais da válvula dispersora, o que é comum nas aplicações em protótipos.

Em resumo, o nível jusante é sempre posicionado na elevação da parte inferior da válvula conforme mostra a figura 12 e sendo conhecidos o comprimento e a largura do modelo físico do projeto básico e a vazão desejada, a profundidade da câmara é ajustada de forma a provocar menor agitação na superfície. Com isto, as dimensões da câmara são experimentadas através de ensaios de modelo físico, de forma a se atingir as dimensões ideais para a dissipação de energia.

Com as funções principais da câmara dissipadora representadas sob o ponto de vista hidráulico, será apresentada uma forma de dimensionamento da mesma considerando a câmara com uma ou duas válvulas. A diferença de dimensionamento entre a câmara de dissipação com uma ou duas válvulas está na parede divisória. 
Referente ao processo de dissipação de energia, as dimensões da câmara dissipadora estão relacionadas com as condições de vazão, queda líquida e diâmetro nominal da válvula.

O dimensionamento da câmara dissipadora, apresentado a seguir, é baseado em exemplos reais de ensaios de modelo, presentes no USBR Engineering Monograph $N^{\circ} 25$ (1984), que também servirá como banco de dados para a calibração das simulações numéricas.

A queda líquida da válvula pode ser calculada pela soma da pressão manométrica mais a energia cinética, localizados a uma diâmetro nominal da válvula a montante da entrada da mesma. Salienta-se que a referência para medição de pressão e cálculo da velocidade média é posicionada um diâmetro nominal antes da entrada da válvula.

A figura 13 mostra a profundidade de água ideal da câmara dissipadora (expressa pela letra “ $D$ ”) onde se tolera variação de mais ou menos $40 \%$ do diâmetro nominal da válvula.

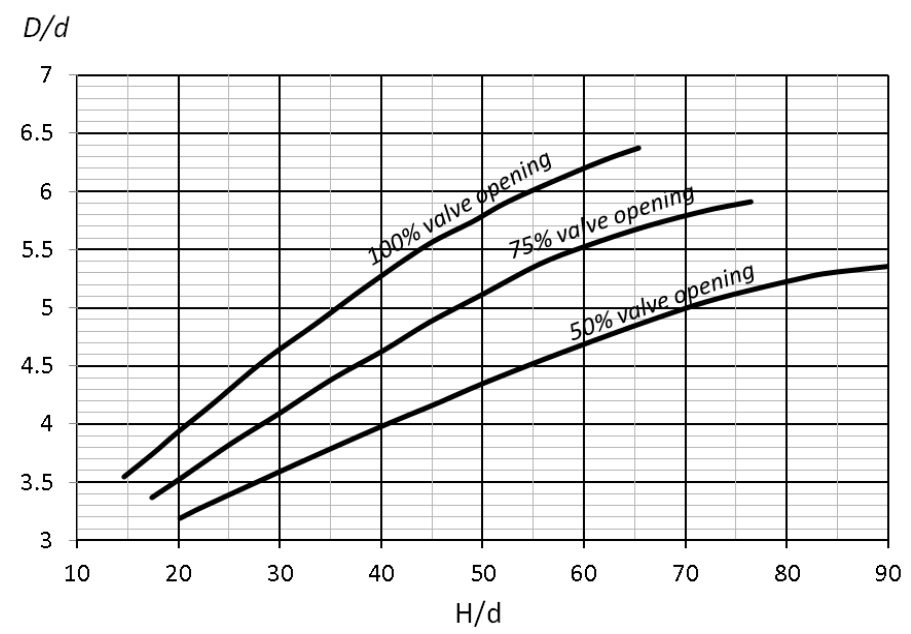

Figura 13. Definição da profundidade de água ideal em função da queda líquida, diâmetro e abertura da válvula (adaptado de USBR Engineering Monograph $N^{\circ} 25$ (1984))

A figura 14 mostra a profundidade mínima de água, expressa por $D s$, em que a câmara dissipadora ainda pode atuar como dispositivo dissipador, ou seja, abaixo desta a câmara deixa de exercer suas funções (nível chamado de sweepout depth). 


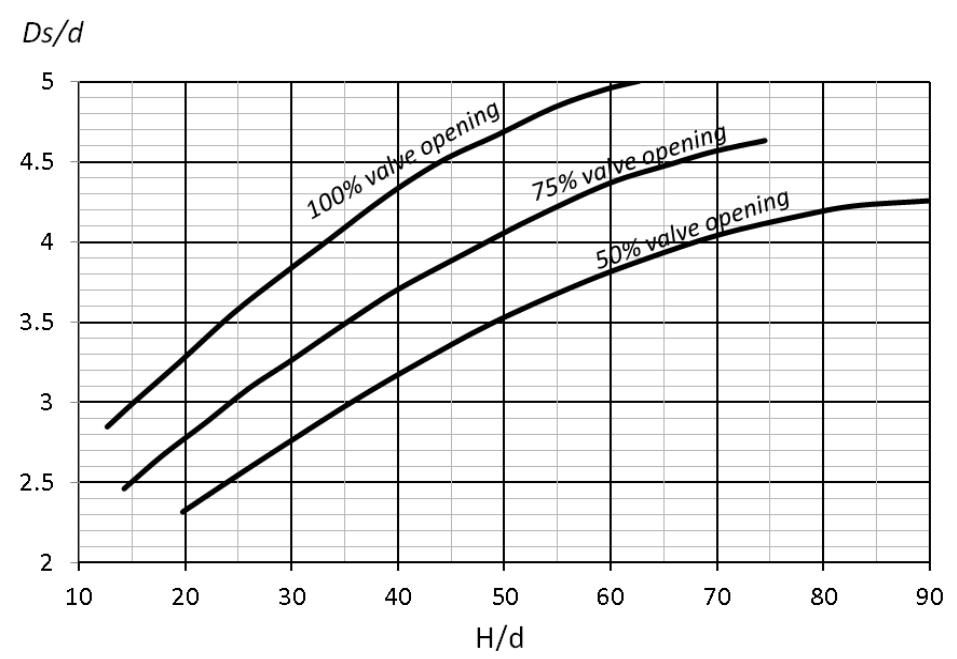

Figura 14. Definição da profundidade de água mínima em função da queda líquida, diâmetro e abertura da válvula (adaptado de USBR Engineering Monograph N²5 (1984))

A figura 15 mostra como se determina o comprimento da soleira da câmara dissipadora, expresso por $L$. Para isto deve-se entrar com a relação entre queda líquida e diâmetro nominal da válvula $(H / d)$ e, em função da abertura da válvula, a relação entre comprimento da soleira e diâmetro nominal da válvula $(L / d)$ é obtida.

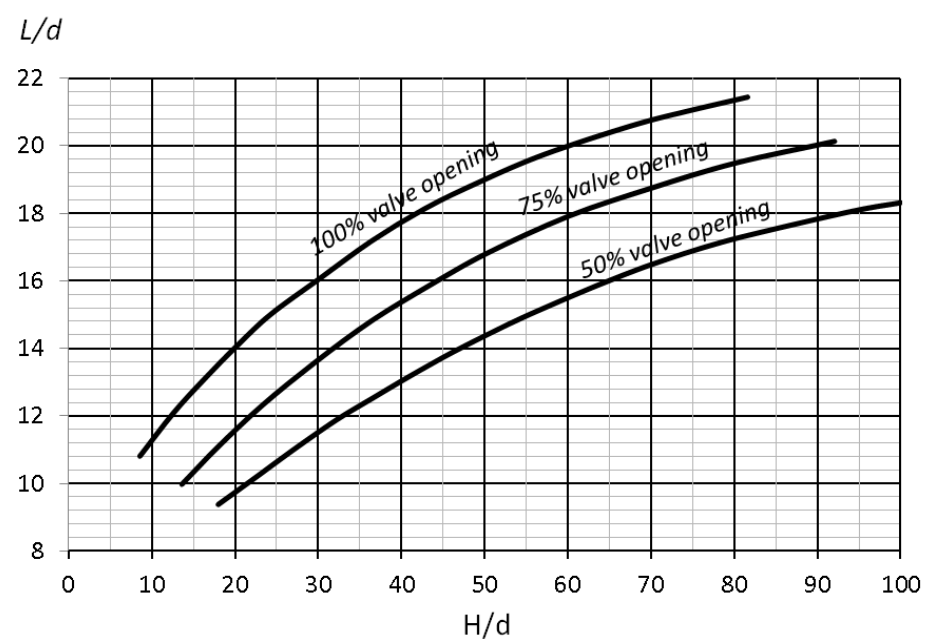

Figura 15. Definição do comprimento de soleira em função da queda líquida, diâmetro e abertura da válvula (adaptado de USBR Engineering Monograph No25 (1984)) 
De forma análoga a figura 15, a figura 16 mostra a obtenção da largura da câmara dissipadora expressa por $W$, em função da relação $H / d$.

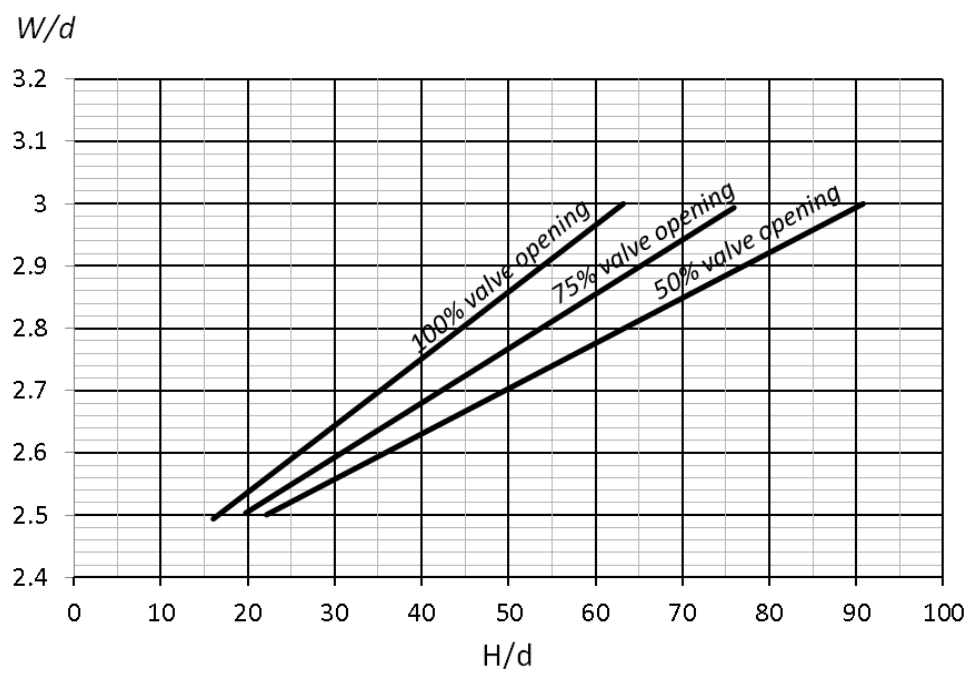

Figura 16. Definição da largura câmara em função queda líquida, diâmetro e abertura da válvula (adaptado de USBR Engineering Monograph No25 (1984))

Observa-se que não somente as vazões de projeto devem ser consideradas na determinação das medidas da câmara dissipadoras, mas também, as vazões parciais. Estas são caracterizadas por mudarem as condições de vórtices e seus posicionamentos ao longo da câmara. Desta maneira, a câmara dissipadora pode sofrer erosão por destacamento ou mesmo por arraste nas vazões parciais enquanto que o mesmo não ocorre na vazão de projeto. Estas situações serão consideradas nas simulações numéricas.

Caso a profundidade da câmara (no que se refere ao nível de jusante) seja a ideal, a largura da câmara pode ser 2,5 vezes o diâmetro nominal da válvula. Do contrário, a figura 16 deve ser utilizada, o que demonstra uma compensação entre nível de jusante e largura da câmara dissipadora, assim, os limites mínimos de nível de jusante e largura não devem ser utilizados em um mesmo projeto, o que evita que a área de passagem da câmara dissipadora seja reduzida de forma inadmissível. 
Deve-se então efetuar o dimensionamento da câmara dissipadora considerando toda a faixa operativa de projeto atuando com as válvulas e, sempre que possível ponderar a condição de operação com o tempo que a mesma atuará o que depende da disponibilidade de água. Esta ponderação ajuda a decidir quais dimensões finais da câmara devem ser construídas.

Durante os ensaios em modelo físico, foi determinado o comprimento das paredes divisórias como $75 \%$ do comprimento da soleira $L$ quando a operação de somente uma válvula é requisitada. Caso as duas válvulas forem operar conjuntamente na maior parte do tempo, seu comprimento pode ser reduzido a 50\%. Sua aplicação para câmaras dissipadoras com mais de uma válvula é fundamental, pois quando duas válvulas operam sem a parede divisória o volume de água oscila de um lado a lado da câmara, provocando instabilidades. Isto ocorre porque o período de onda provocado por cada válvula não é constante, resultando em movimento harmônico porque a onda provocada por uma válvula é excitada pela onda provocada pela outra válvula.

Quando apenas uma válvula opera (enquanto a outra está fechada) as instabilidades são piores porque a superfície agitada pela operação da válvula induz vazão na região da válvula que está fechada quando a superfície oscila para valores mais elevados que o nível de jusante normal, de forma semelhante ao explicado quando a largura da câmara é grande demais para a aplicação.

A válvula Hollow-Jet não deve operar submersa tendo em mente evitar a cavitação na mesma. Assim é recomendado que a mesma tenha sua elevação da linha de centro no mesmo nível de jusante ou, no pior caso que o topo da saída da válvula esteja na mesma elevação do nível de jusante.

De acordo com o manual da ELETROBRÁS (2003), a velocidade média em canais deverá ficar entre 4 e $6 \mathrm{~m} / \mathrm{s}$, considerando sua estrutura em concreto hidráulico. Desta maneira, a 
avaliação de erosão será baseada em respeitar estes limites, considerando também a formação de vórtices próximos às superfícies.

Tipicamente em protótipos, ao deixar a câmara dissipadora, a velocidade média de escoamento raramente excede $1,5 \mathrm{~m} / \mathrm{s}$.

\subsubsection{Análise de Cavitação e Eficiência de Dissipação de Energia}

A erosão pelos vórtices se dá pela grande variação de velocidade ou turbulência. Para os valores máximos de velocidade, tendo em mente a equação da energia de Bernoulli, as pressões são baixas, o que favorece a formação de cavitação. Assim, pode-se dizer que para evitar danos nas superfícies da câmara dissipadora, os vórtices devem estar longe das superfícies.

Devido a questões de instrumentação, é mais fácil e viável referenciar os estudos de erosão e cavitação através da medição de pressão nas paredes e, conforme descrito anteriormente, as pressões e velocidades devem ficar dentro de valores admissíveis para o concreto, comum em construção de câmaras dissipadoras.

De acordo com BUCK et al (2011), uma forma de avaliar o grau de dissipação é utilizar a equação 19.

$$
E_{d}=100 .\left(\frac{H-H_{f}}{H_{i}}\right)
$$

Onde $H$ é a queda líquida da válvula ou carga a montante da válvula e $H_{f}$ é a carga ao final da câmara dissipadora, de acordo com a equação de Bernoulli.

Calcula-se a velocidade média teórica do jato e então se faz uma relação com a velocidade de escoamento logo a jusante da câmara dissipadora, sendo que esta razão pode ser colocada em função do número de Froude, referenciado na saída do jato da válvula. 
Aplicando a equação de Bernoulli entre a entrada e saída da válvula, obtém-se:

$$
H_{\text {entrada }}=H_{\text {jato }}+H_{p} \rightarrow \frac{v_{\text {entrada }}^{2}}{2 g}+\frac{p_{\text {entrada }}}{\gamma}=\frac{v_{\text {saida }}^{2}}{2 g}+\frac{p_{\text {saida }}}{\gamma}+H_{p}
$$

Como a pressão na saída do jato é a pressão atmosférica, a equação se desenvolve:

$$
\frac{v_{\text {entrada }}^{2}}{2 g}+\frac{p_{\text {entrada }}}{\gamma}=\frac{v_{\text {saida }}^{2}}{2 g}+K_{S} \cdot \frac{v_{\text {entrada }}^{2}}{2 g}
$$

A velocidade do jato é obtida considerando a área de sua coroa. Assim, dividindo a vazão volumétrica pela área, tem-se a velocidade média do jato.

$$
v_{\text {jato }}=\frac{Q}{A_{\text {jato }}}
$$

Com a área do jato definida, a espessura do jato (b) é calculada pela equação 23:

$$
A_{\text {jato }}=\pi\left(R_{e}^{2}-R^{2}\right)
$$

Onde $R_{e}$ é o raio do corpo da válvula na saída do jato.

Conhecendo a área do jato e o raio do corpo da válvula, o raio interno de escoamento $R$ é calculado e então se define a espessura b:

$b=\left(R_{e}-R\right)$

Com isso, o número de Froude referenciado no jato, pode ser calculado.

$$
F r=\frac{\sqrt{2 g H}}{\sqrt{g b}}
$$

Para a equação de Froude mostrada acima, nota-se que números mais elevados correspondem a pequenas espessuras de jato, ou seja, a válvula opera em aberturas parciais e, números de Froude menores correspondem à válvula operando com maior abertura.

A velocidade na saída da câmara dissipadora pode ser determinada através da equação 26.

$$
\Sigma Q_{\text {válvula }}=Q_{\text {câmara }}=A_{\text {câmara }} \cdot v_{\text {câmara }} \Rightarrow v_{\text {câmara }}=\frac{Q_{\text {câmara }}}{A_{\text {câmara }}}
$$


Com relação à energia dissipada, o ideal é que esta seja maior possível para cada número de Froude em questão, pois isto indicará a eficácia de dissipação de energia da câmara.

O número de Froude será analisado ao longo da câmara de dissipação, avaliando a criticidade da faixa operativa, pois conforme mencionado anteriormente, deve-se tomar cuidado com a operação das válvulas em aberturas (ou vazões) parciais. Assim, será verificada a razão de velocidades e alturas de escoamento em função do número de Froude, considerando diferentes aberturas de válvula, ou seja, para aberturas parciais até a abertura total da válvula. Fica indicado que a menor velocidade na saída da câmara dissipadora em relação à velocidade do jato da válvula mostra menor chance de erosão por arraste de sólidos ou abrasão.

Outro fator que também pode causar erosão é a brusca variação de nível de jusante ao longo da câmara de dissipação devido aos ressaltos hidráulicos que podem ser causados durante o processo de dissipação de energia. Assim, outro parâmetro para se evitar erosão é minimizar estas variações de nível de jusante, que induzem destacamento de material.

\section{METODOLOGIA}

Diante do apresentado, a metodologia empregada toma como base a pesquisa bibliográfica de sistemas de dissipação de energia aplicados em usinas hidrelétricas com válvulas Hollow-Jet, o cálculo analítico decorrente da pesquisa bibliográfica e então as simulações numéricas desses sistemas de dissipação através do método dos volumes finitos.

Para que seja possível a calibração e estudo das dimensões e formas da câmara de dissipação através do método dos volumes finitos, utilizar-se-á uma referência de protótipo real (Falcon Dam) onde, serão comparadas as pressões atuantes no fundo da câmara dissipadora bem como o perfil de superfície de água ao longo da mesma, o que forma o cenário inicial das simulações numéricas. 
Após esta etapa, será explorada a faixa operativa desta câmara dissipadora, ou seja, serão simuladas outras razões de queda líquida e diâmetro nominal da válvula $(H / d)$ verificando o comportamento da câmara para condições diferentes das consideradas como ideais em seu projeto.

Desta forma, pretende-se obter soluções de dissipação proporcionando maior versatilidade da faixa operativa, frequentemente necessárias na adaptação de cada projeto ou mesmo devido a mudanças de vazões disponíveis que ocorrem durante os períodos de seca e cheia a cada ano.

\section{APLICAÇÃO DAS SIMULAÇÕES NUMÉRICAS E COMPARAÇÃO COM OS RESULTADOS DE ENSAIO DE MODELO E PROTÓTIPO}

\subsection{Introdução}

Mesmo que as simulações em CFD (Computational Fluid Dynamics) tenham como objetivo se aproximar ao máximo a realidade dos escoamentos em exemplos físicos, estes não substituem a necessidade de ensaio de modelos físicos. Conforme será mostrado a seguir, as simulações em $C F D$ se utilizam de aproximações e necessidade de calibração, oriundas de modelos físicos. Desta forma, ainda que as simulações em $C F D$ não substituam os ensaios em modelos físicos, estas servem para reduzir o número de possibilidades de ensaios destes modelos explorando diversas situações, resultado em menor número de ensaio em laboratório. Para discretização das equações de Navier-Stokes e seu modelo de turbulência aplicado, utiliza-se a técnica de volumes finitos, onde o software Ansys CFX será aplicado.

Os contornos sólidos das válvulas e câmara dissipadoras, feitos em um modelador 3D, são importados para o Ansys $C F X$ e então, a malha é aplicada nestes sólidos. 
Durante a fase de pré-processsamento da simulação numérica, primeiramente é necessário definir o volume de controle sobre o modelo geométrico onde se pretende analisar as características do escoamento. O volume de controle é a discretização do modelo geométrico em elementos de volume que formam uma malha, onde as faces de cada volume costumam ser identificadas pelas direções cardeais (VERSTEEG \& MALALASEKERA, 1995). A definição da malha é dividida em células cada uma com uma dimensão considerada. Assim, quanto maior o número de divisões destas células, melhor discretizada será a malha. Por outro lado, uma malha mais refinada exigirá maior capacidade computacional para efetuar os cálculos, resultando em maior tempo necessário para processar os cálculos. Desta maneira, deve-se discretizar a malha com critério baseado em mudanças das propriedades do escoamento, ou seja, onde ocorrerem muitas mudanças de pressão e/ou velocidade, a malha deve ser melhor subdividida para que os valores médios de cada célula representem valores coerentes com a realidade. Seguindo a mesma linha de raciocínio, para as regiões onde o escoamento varia pouco suas propriedades não há necessidade de maior refinamento da malha (SILVA, 2013).

Conforme será mostrado mais adiante, os resultados de modelos físicos e protótipos utilizados para esta dissertação não trazem detalhes sobre flutuações de pressão ou velocidade (turbulência) e, desta forma, a análise de mudanças mais bruscas das propriedades do escoamento ficam mais difíceis. Diante desta condição, a discretização da malha foi feita inicialmente considerando uma malha bastante refinada que, após os resultados da simulação serem compatíveis com os dados de ensaio de protótipo (linha de nível de água e diagrama de pressão), esta foi deixada menos discreta nas regiões com menor mudança de propriedades de escoamento, voltando-se a comparar com os resultados de ensaio de protótipo. Desta forma, o modelo de cálculo trouxe menor exigência computacional, tendendo a ser simulado mais rapidamente. 
Um recurso de solução para discretização da malha de acordo com a variação das propriedades de escoamento é a criação de blocos de malhas onde, nas regiões de maior interesse a malha será mais fina enquanto que nas regiões de menor interesse a malha será mais grossa (SILVA, 2013).

Com a malha aplicada ao modelo numérico, iniciou-se a aplicação das condições de fronteira de cálculo, ou seja, as condições de contorno entre a entrada e saída do modelo de cálculo.

As condições de entrada e saída devem ser definidas no modelo numérico de forma a limitar o espaço físico onde as equações discretizadas serão aplicadas. Para definiç̧ão das condições de contorno, utilizam-se alguns recursos de cálculo descritos na sequência, conforme aponta VERSTEEG \& MALALASEKERA (1995).

A simetria é um recurso utilizado em escoamentos que envolvam superfície livre porque considera a mesma condição de resultados entre os nós que fazem vizinhança direta com os nós da fronteira da malha de cálculo. Assim, este recurso possibilita prever as mesmas condições do fluido ao final da fronteira para as mesmas condições imediatamente fora da mesma.

A simetria pode ser aplicada somente onde não há condições de fronteira impostas como pressão e velocidade, caso contrário ocorrerá a não continuidade de resultados com as condições impostas gerando oscilações de pressão e pulsações de velocidade, induzidas para dentro do domínio de cálculo.

Ainda que a simetria seja um benefício expressivo ao que se refere a esforço computacional, cabe mencionar que esta se trata de uma aproximação conceitual para prever o traçado das linhas de corrente, porque os ressaltos hidráulicos na realidade nunca são totalmente simétricos. 
Segundo o manual do software ANSYS (2013), o modelo mais robusto de condição de contorno é aquele onde a vazão mássica é aplicada nas entradas (inlet) enquanto pressões efetivas devem ser aplicadas nas condições de saída de fluido (outflow) ou abertas (opening). Como exemplo das simulações que foram aplicadas nesta dissertação é possível citar as condições de escoamento na entrada da válvula, ou seja, pode-se inserir uma condição de vazão mássica imposta a montante da válvula de modo a evitar que seu circuito hidráulico, que vai desde o nível de montante até a entrada da válvula tenha que ser considerado. Ainda assim se deve tomar cuidado para a condição de vazão mássica imposta, pois se aplicadas em uma região de elevada variação de velocidade ou pressão na seção de escoamento, os resultados tendem a divergirem da realidade consideravelmente. Um exemplo disto seria aplicar pressão imposta logo após uma curva, onde o escoamento ainda não se desenvolveu completamente.

Tem-se também a condição de fronteira de saída de pressão também conhecido como outflow. Esta auxilia que o domínio computacional fique restrito às regiões onde haja interesse de obter resultados de simulação. Para esta dissertação a condição de outflow pode ser definida ao final do canal de fuga, ou seja, suficientemente afastada do final da câmara dissipadora, pois as condições de outflow são definidas onde o escoamento é aproximadamente unidirecional, conforme explica VERSTEEG \& MALALASEKERA (1995). Desta maneira, foi definida esta distância nas simulações numéricas utilizando o Ansys CFX.

Ainda assim, existem as fronteiras onde não se sabe se serão de entrada ou saída de escoamento. No Ansys $C F X$ estas são colocadas como fronteiras livres também chamadas de openings, onde se insere somente a pressão estática nessas fronteiras. Como exemplo nas simulações desta dissertação de mestrado tem-se as partes superiores da câmara de dissipação abertas à pressão atmosférica. 
Com as condições de pré-processamento definidas, segue a parte de processamento das equações de Navier-Stokes e de transporte, através do software Ansys CFX.

\subsection{Modelo de Turbulência}

Como o escoamento em câmaras dissipadoras e válvulas dispersoras é turbulento foram investigados os modelos de turbulência que se adequem às simulações desta dissertação, de forma a se obter resultados mais próximos com os de ensaio físico de modelo ou de protótipo. Diante de pesquisa sobre exemplos de simulações numéricas no $C F X$, o modelamento das equações de Navier-Stokes foi o Reynolds-Averaged Navier-Stokes (RANS) porque além de boa confiabilidade nos resultados este apresenta menor custo computacional do que o modelo Large Eddy Simulation (LES), principalmente para soluções de escoamentos com elevado número de Reynolds (GERDIN \& KEIJSER, 2014).

O método RANS, decompõe as variáveis do problema em equações de Navier-Stokes instantâneas entre componentes médias e de flutuações. Entretanto, as decomposições das equações instantâneas resultam em um termo adicional desconhecido, denominado tensão de Reynolds que representa o termo da turbulência. Para a solução deste problema pode-se aplicar isotropia para viscosidade turbulenta cujo modelo é denominado Eddy Viscosity Model ou aplicar o modelo de tensões de Reynolds, conhecido como Reynolds Stress Model (RSM). O modelo RSM utiliza equações extras para resolver as tensões de Reynolds e a taxa de dissipação, o que resulta em maior custo computacional. Desta forma costuma-se preferir o modelo de viscosidade turbulenta.

Para escoamentos turbulentos, a velocidade instantânea $\left(u_{i}\right)$ é composta pela velocidade

média $\left(\overline{u_{i}}\right)$ mais o valor de flutuação de velocidade $\left(u_{i}{ }^{\prime}\right)$, apresentada na equação 27. 
$u_{i} \equiv \bar{u}_{i}+u_{i}^{\prime}$

E considerando as componentes como uma média ao longo do tempo, têm-se as equações 28 e 29, denominadas Reynolds-Averaged Navier-Stokes (RANS).

$$
\begin{aligned}
& \frac{\partial \rho}{\partial t}+\frac{\partial}{\partial x_{i}}\left(\rho u_{i}\right)=0 \\
& \frac{\partial}{\partial t}\left(\rho u_{i}\right)+\frac{\partial}{\partial x_{j}}\left(\rho u_{i} u_{j}\right)=-\frac{\partial p}{\partial x_{i}}+\frac{\partial}{\partial x_{j}}\left[\mu\left(\frac{\partial u_{i}}{\partial x_{j}}+\frac{\partial u_{j}}{\partial x_{i}}-\frac{2}{3} \delta_{i j} \frac{\partial u_{l}}{\partial x_{l}}\right)\right]+\frac{\partial}{\partial x_{j}}\left(-\rho \overline{u_{i}^{\prime} u_{j}^{\prime}}\right)
\end{aligned}
$$

A tensão de Reynolds expressa pelo termo $\left(-\rho \overline{{\overline{u_{i}}}_{i} u_{j}^{\prime}}\right)$ deve ser modelada de forma que a equação 29 possa ser resolvida. Para isso utiliza-se a hipótese de Boussinesq através da equação 30, que assume que a tensão média turbulenta se assemelha a tensão média laminar, proporcional a uma viscosidade turbulenta (eddy visosity). Salienta-se que a viscosidade turbulenta se refere às condições de escoamento e não a propriedade do fluido.

$$
-\rho \overline{u_{i}^{\prime} u_{j}^{\prime}}=\mu\left(\frac{\partial u_{i}}{\partial x_{j}}+\frac{\partial u_{j}}{\partial x_{i}}\right)-\frac{2}{3}\left(\rho k+\mu_{t} \frac{\partial u_{l}}{\partial x_{l}}\right)
$$

A viscosidade turbulenta é definida pela equação 31 .

$$
\mu_{t}=\rho C_{\mu} \frac{k^{2}}{\varepsilon}
$$

Dentre os diversos modelos de turbulência RANS disponíveis no $C F X$, alguns exemplos que podem ser empregados para simulações numéricas que envolvam escoamento em superfície livre são: o modelo $k-\varepsilon$ Re-Normalization Group (RNG), o modelo $k-\varepsilon$ com lei de parede, o modelo $k-\omega$ e o modelo SST (Shear Stress Tensor).

Segundo o manual da software ANSYS (2013) o modelo $k-\varepsilon$ RNG é o modelo $k-\varepsilon$ simples mas com uso de um termo adicional que proporciona maior precisão nas regiões onde há variações bruscas de escoamento, sendo indicado para simulações de jatos. 
O modelo $k-\varepsilon$ RNG é um modelo semi-empírico que resolve as equações de energia cinética $(k)$ e a taxa de dissipação $(\varepsilon)$ separadamente. Este modelo é largamente aplicado assim como o $k-\varepsilon$ puro, devido ao baixo custo computacional associado à boa precisão nos resultados das simulações quando aplicados a escoamentos totalmente turbulentos (GERDIN \& KEIJSER, 2014).

Durantes as simulações presentes nesta dissertação, foram testados os modelos $k-\varepsilon$ RNG, o modelo $k-\varepsilon$, o modelo $k-\omega$ e o modelo SST. Os resultados de cada modelo de turbulência não demonstraram diferenças relevantes para o modelo aplicado. Assim, o modelo de turbulência escolhido foi o $k-\varepsilon$ RNG, indicado pelo manual do software ANSYS (2013).

As equações do modelo $k-\varepsilon$ RNG são apresentadas abaixo, (ANSYS, 2013):

$$
\begin{aligned}
& \frac{\partial}{\partial t}(\rho k)+\frac{\partial}{\partial x_{i}}\left(\rho k u_{i}\right)=\frac{\partial}{\partial x_{j}}\left[\left(\mu+\frac{\mu_{t}}{\sigma_{k}}\right) \frac{\partial k}{\partial x_{j}}\right]+P_{k}-\rho \varepsilon+P_{k b} \\
& \frac{\partial}{\partial t}(\rho \varepsilon)+\frac{\partial}{\partial x_{i}}\left(\rho \varepsilon u_{i}\right)=\frac{\partial}{\partial x_{j}}\left[\left(\mu+\frac{\mu_{t}}{\sigma_{\varepsilon}}\right) \frac{\partial \varepsilon}{\partial x_{j}}\right]+\frac{\varepsilon}{k}\left(C_{\varepsilon 1} P_{k}-C_{\varepsilon 2} \rho \varepsilon+C_{\varepsilon 1} P_{\varepsilon b}\right)
\end{aligned}
$$

Nas equações 32 e 33 as constantes são definidas como $\sigma_{k}=1,0 \sigma_{\varepsilon}=1,3$ enquanto as constantes $\mathrm{C}$ são definidas na forma $C_{1 \varepsilon}=1,42-f_{n}$ e $C_{2 \varepsilon}=1,68$, conforme o manual do software ANSYS (2013).

O termo $P_{k}$ apresentado na equação 34 representa a geração de turbulência cinética devido aos gradientes de velocidade média enquanto $P_{k b}$ e $P_{\varepsilon b}$ representam a influência do empuxo, apresentados nas equações 35 e 36.

$$
\begin{aligned}
& P_{k}=\mu_{t}\left(\frac{\partial u_{i}}{\partial x_{j}}+\frac{\partial u_{j}}{\partial x_{i}}\right) \frac{\partial u_{i}}{\partial x_{j}}-\frac{2}{3} \frac{\partial u_{k}}{\partial x_{k}}\left(3 \mu_{t} \frac{\partial u_{k}}{\partial x_{k}}+\rho k\right) \\
& P_{k b}=\frac{\mu_{t}}{\rho \sigma_{\rho}} \rho \beta g_{i} \frac{\partial T}{\partial x_{i}} \\
& P_{g b}=C_{3} \cdot \max \left(0, P_{k b}\right) \cdot \operatorname{sen} \phi
\end{aligned}
$$


Onde $g_{i}$ é a aceleração da gravidade, $\phi$ é o ângulo entre a gravidade e o escoamento, $\sigma_{\rho}=1$ é o número de Schmidt, $\mu_{t}$ é a viscosidade turbulenta e $C_{3}=1$.

O termo $C_{1 \varepsilon}$ representa é definido conforme o manual do software ANSYS (2013).

$C_{1 \varepsilon}=1,42-f_{n}=1,42-\frac{\eta\left(1-\frac{\eta}{4,38}\right)}{\left(1+\beta_{R N G} \eta^{3}\right)}$

Onde $\eta$ é expresso pela equação 38.

$\eta=\sqrt{\frac{P_{k}}{\rho C_{\mu R N G} \varepsilon}}$

O modelo Shear Stress Transport $k-\omega$ (SST) associa a vantagem de simulação de superfície livre do modelo $k-\varepsilon$ com as vantagens de análise de escoamentos próximos às paredes do modelo $k-\omega$. Ainda assim, este não trouxe diferença relevante nos resultados para as malhas simuladas.

Tendo as condições de pré-processamento definidas e o processamento executado com o modelo de turbulência adequado, segue a fase de pós-processamento de dados, onde as análises e interpretações de resultados serão feitas.

Dependendo dos resultados das análises na fase de pós-processamento confrontados com os resultados de ensaios físicos, novas definições de malha foram testadas, dando início a um método iterativo, que será utilizado na fase de calibração do modelo numérico explicado na sequência. 


\subsection{Calibração do Modelo Numérico}

Para que a calibração da simulação numérica fosse comprovada, foram observadas as condições de operação tanto da válvula como da câmara dissipadora, tomando como base de dados estudos feitos em modelo físico na válvula e em seu protótipo na câmara de dissipação, tanto para a válvula como para a câmara dissipadora.

De forma a assegurar que o jato proveniente da válvula incida sobre a câmara dissipadora corretamente, foram consideradas simulações numéricas para obter o diagrama de pressão em função da abertura da válvula, onde a figura 17 mostra o posicionamento dos transdutores de pressão realizados em um ensaio de modelo físico aplicados no cone e no corpo da válvula, já escalados para a condição do protótipo.

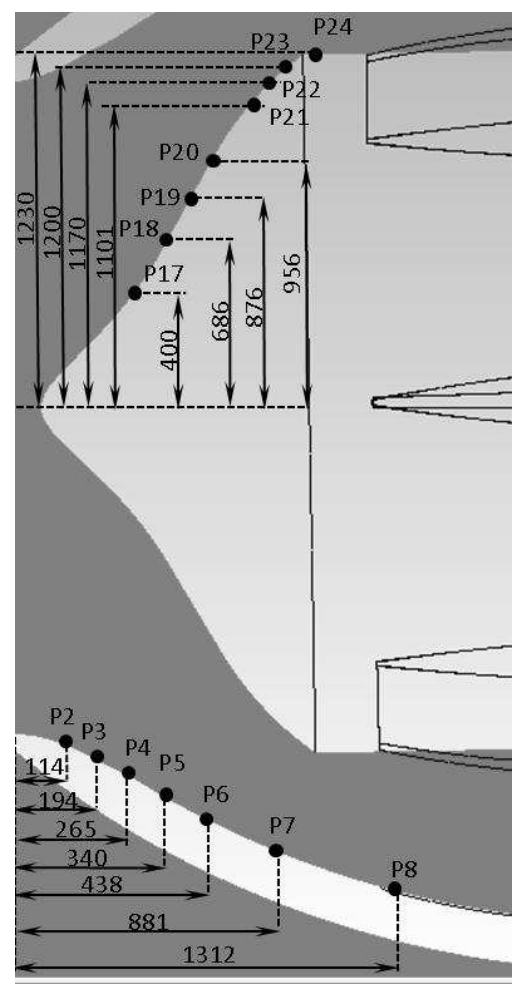

Figura 17. Posição dos piezômetros na cone e corpo da válvula (adaptado de USBR

Hydraulic Report $\left.N^{\circ} 189,(1945)\right)$ 
Com os transdutores instalados o diagrama de pressão ao longo da válvula pode ser definido, em forma de valores normalizados na forma de fator de pressão.

$$
F=\frac{p / \gamma}{H}
$$

Onde $p / \gamma$ é a carga de pressão manométrica medida do ponto em questão e $H$ é a queda líquida da válvula, expressa pela soma da pressão estática a montante da válvula mais sua energia cinética no mesmo ponto.

$$
H=\frac{p}{\gamma}+\frac{u^{2}}{2 g}
$$

A figura 18 mostra o diagrama de fator de pressão ao longo do cone da válvula em função da abertura da válvula realizado em modelo físico e, na ordenada da direita, pode-se notar o coeficiente de descarga da válvula, em função da abertura da mesma. 


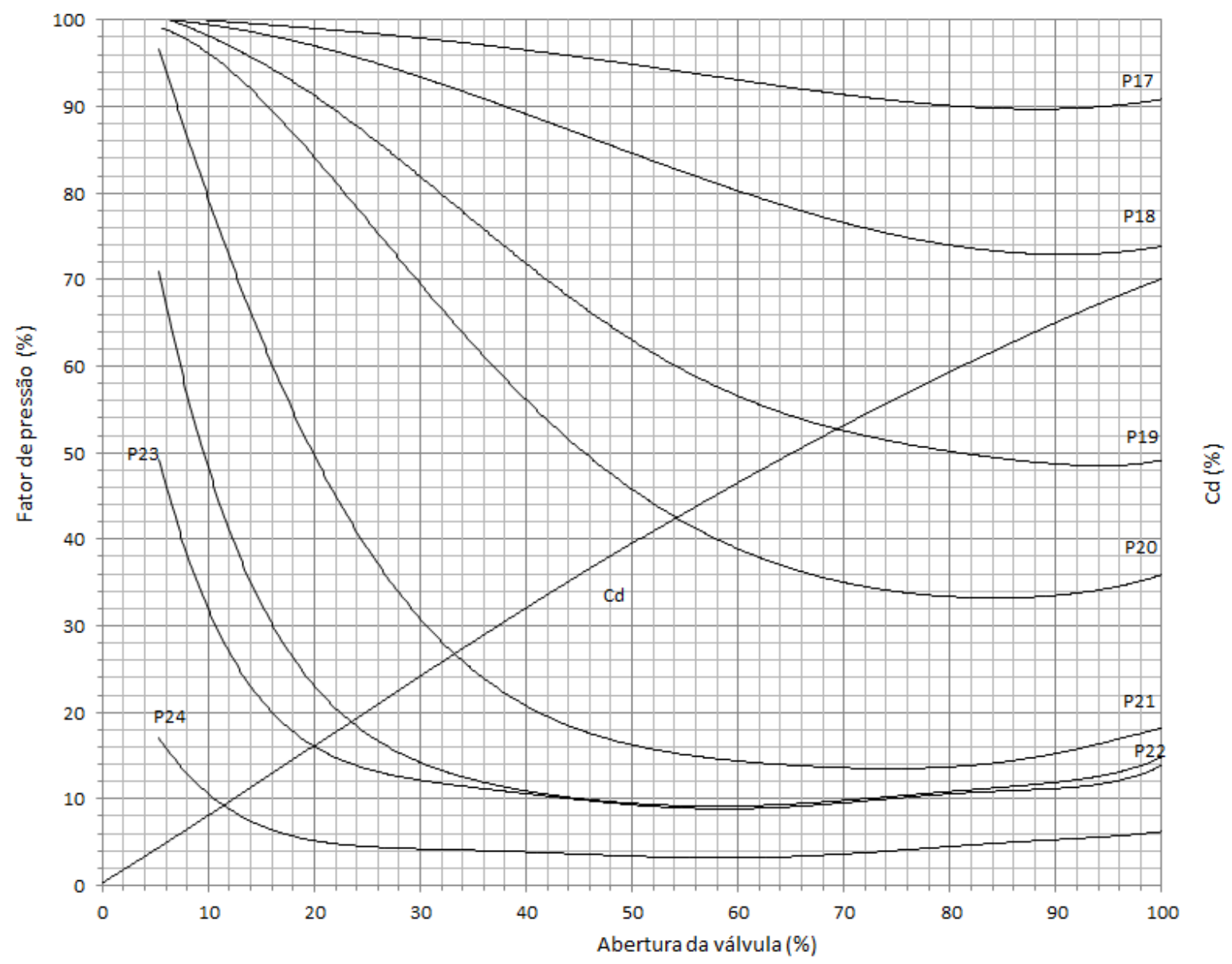

Figura 18. Diagrama de fator pressão no cone da válvula (adaptado de USBR Hydraulic

Report $\left.N^{o} 189,(1945)\right)$

Analogamente, a pressão no corpo da válvula também é monitorada com transdutores de pressão, conforme mostra a figura 19.

Como pode ser notado na figura 19, o diagrama de fator de pressão obtido de modelo físico de cada transdutor de pressão são apresentados na sequência, em função da abertura da válvula. 


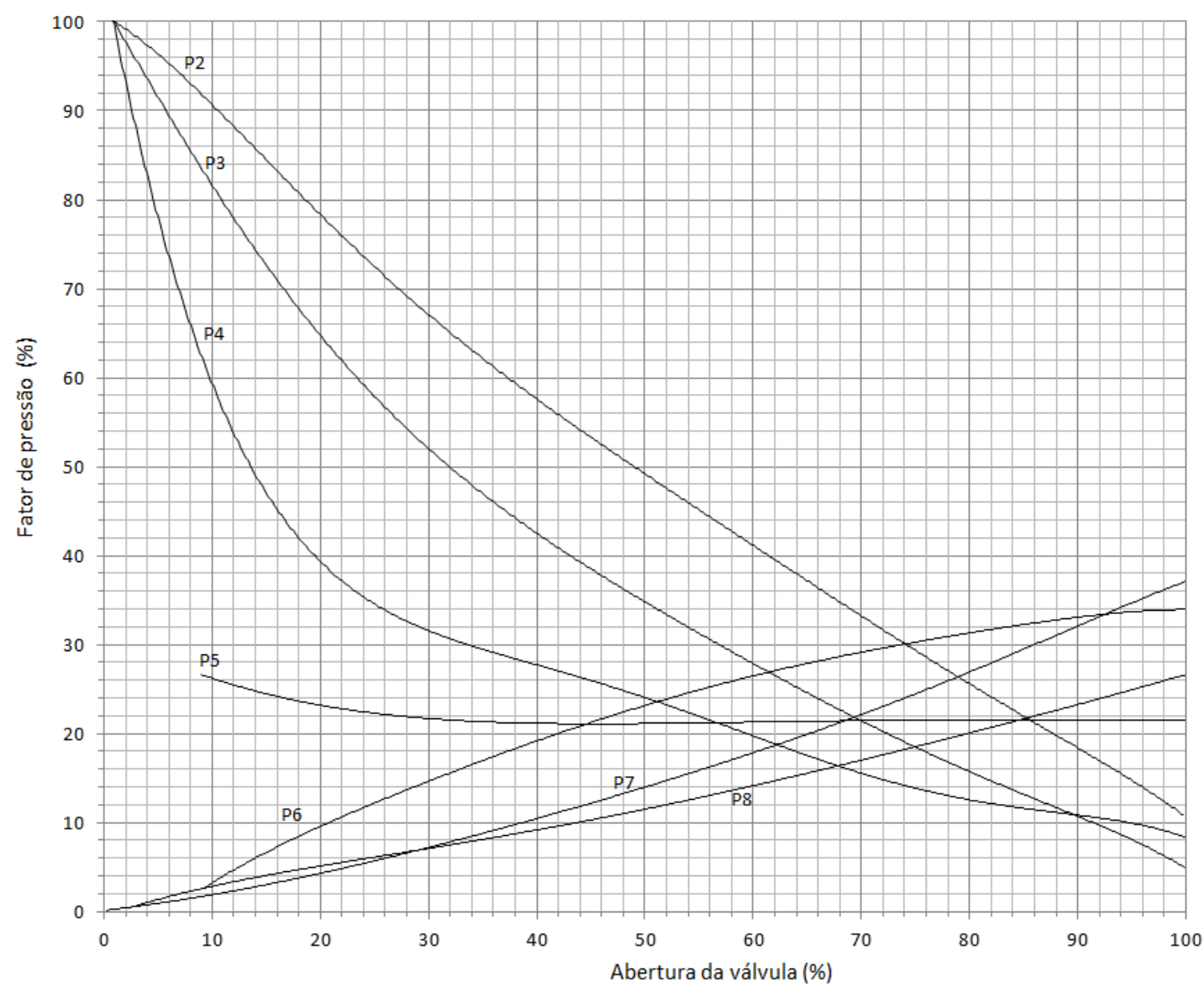

Figura 19. Diagrama de fator pressão no corpo da válvula (adaptado de USBR Hydraulic

Report $\left.N^{\circ} 189,(1945)\right)$

Sob o ponto de vista da câmara dissipadora, o formato do perfil hidráulico da superfície de água bem como as pressões estáticas no fundo da câmara, obtidos nas simulações numéricas, foram comparadas com os resultados de protótipo de Falcon Dam de acordo com o USBR Hydraulic Report $N^{o} 276$ (1950), que utiliza válvulas Hollow-jet de 90 polegadas $(2250 \mathrm{~mm})$. Suas dimensões principais em metros do protótipo são mostradas na figura 20: 

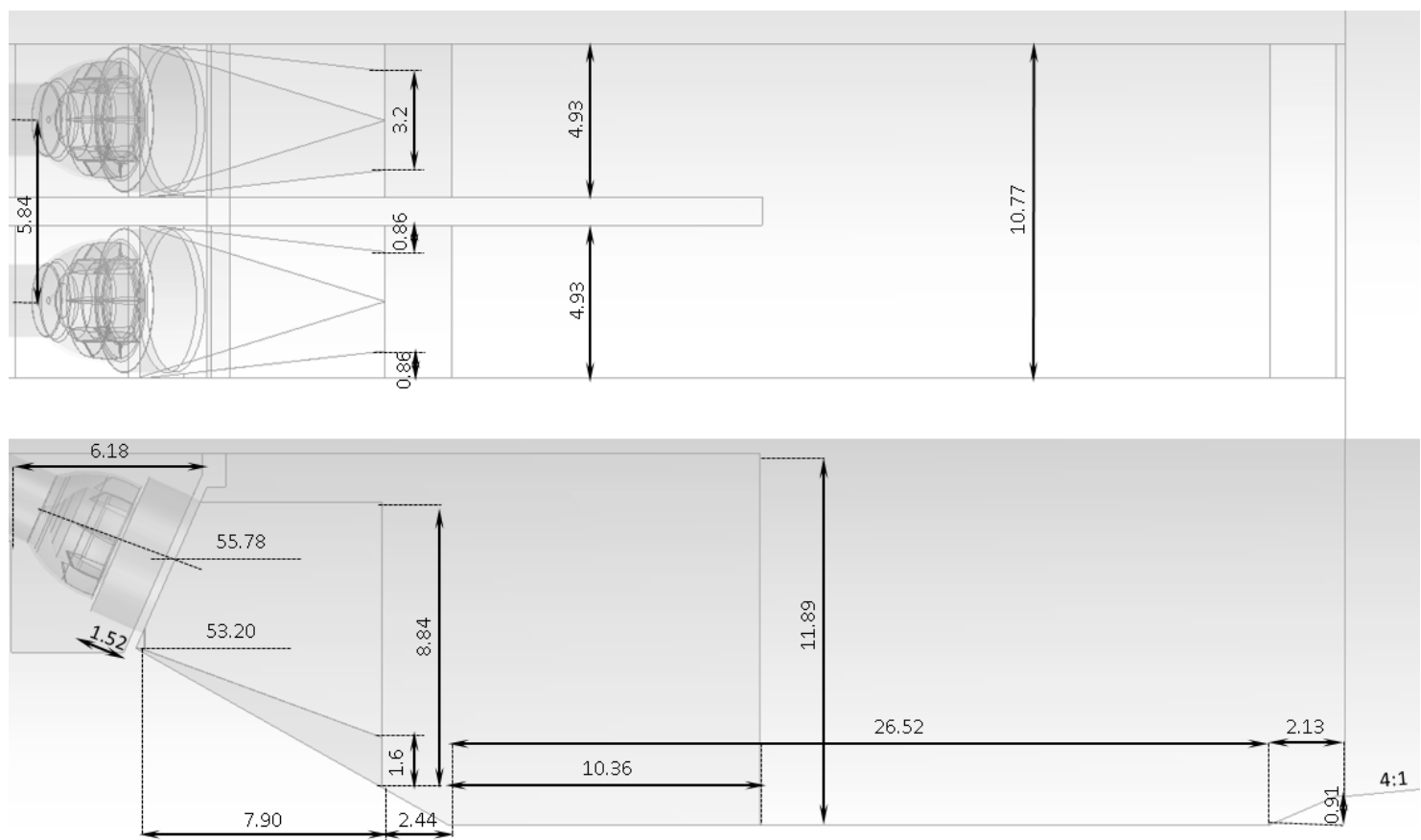

Figura 20. Dimensões da câmara dissipadora de Falcon Dam (adaptado de USBR Hydraulic Report No276, (1950))

Tendo-se os resultados das simulações numéricas da operação das válvulas calibrada e, as dimensões da câmara dissipadora, as simulações numéricas aplicadas à câmara dissipadora foram feitas tendo em mente obter o diagrama de pressão ao longo da câmara dissipadora, para que este seja comparado com os dados de ensaio de protótipo apresentados a seguir.

A figura 21 mostra a disposição em metros dos transdutores de pressão ao longo da câmara, efetuados no ensaio de protótipo. 


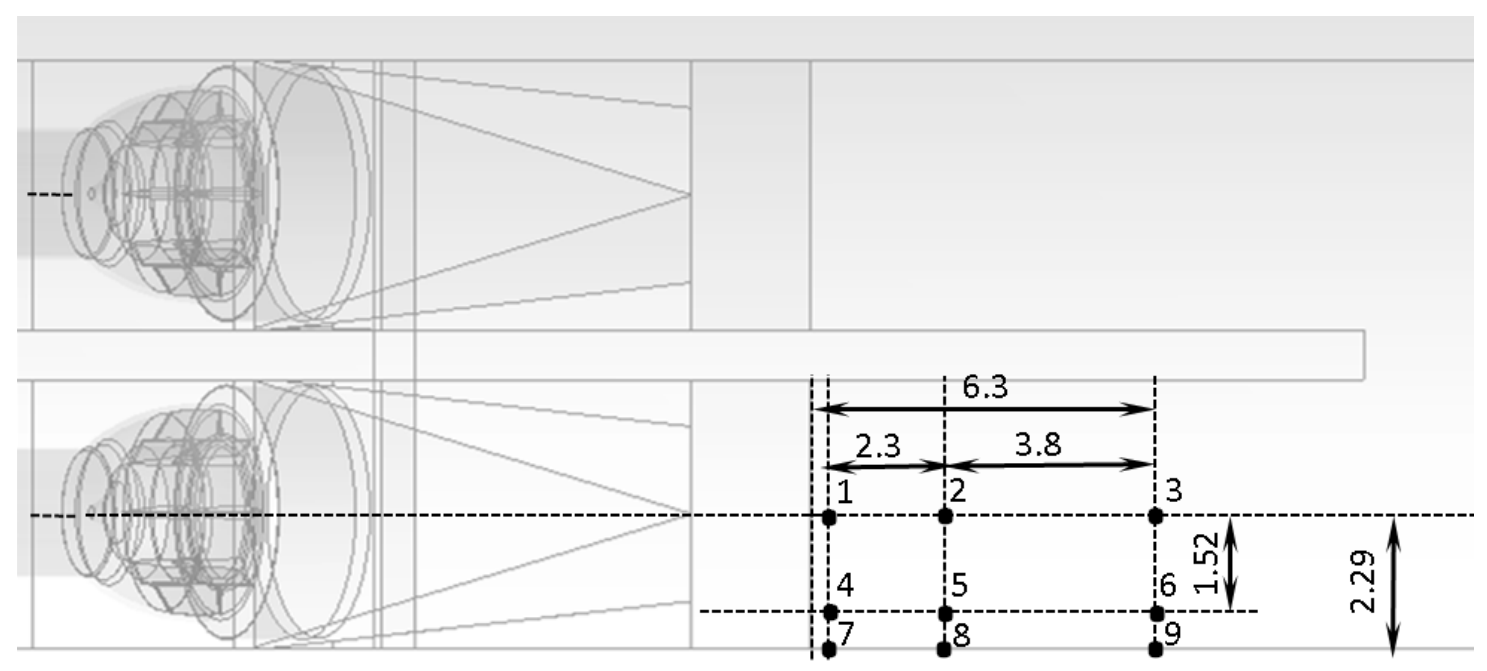

Figura 21. Posição dos piezômetros no fundo da câmara dissipadora (extraído de USBR Hydraulic Report No276, (1950))

O diagrama de carga de pressão mostrado na figura 22 foi obtido em ensaio de modelo físico e se aplica para as diferentes posições ao longo da largura da câmara.

A linha com traços curtos representa o diagrama de pressão para vazão de $4570 \mathrm{ft}^{3} / \mathrm{s}$ $\left(129,4 \mathrm{~m}^{3} / \mathrm{s}\right)$ e queda líquida de $81,9 \mathrm{ft}(25,0 \mathrm{~m})$ com as duas válvulas operando.

A linha com traço e ponto representa o diagrama de pressão para os mesmos piezômetros mostrados na figura 21, porém para vazão de $2400 \mathrm{ft} 3 / \mathrm{s}\left(68 \mathrm{~m}^{3} / \mathrm{s}\right)$ e $90,3 \mathrm{ft}(27,5 \mathrm{~m})$ de queda líquida, onde somente a válvula da esquerda opera.

Finalmente a linha em forma de traços longos representa o perfil de nível de água para vazão de $3210 \mathrm{ft}^{3} / \mathrm{s}\left(90,9 \mathrm{~m}^{3} / \mathrm{s}\right)$ e duas válvulas operando. 

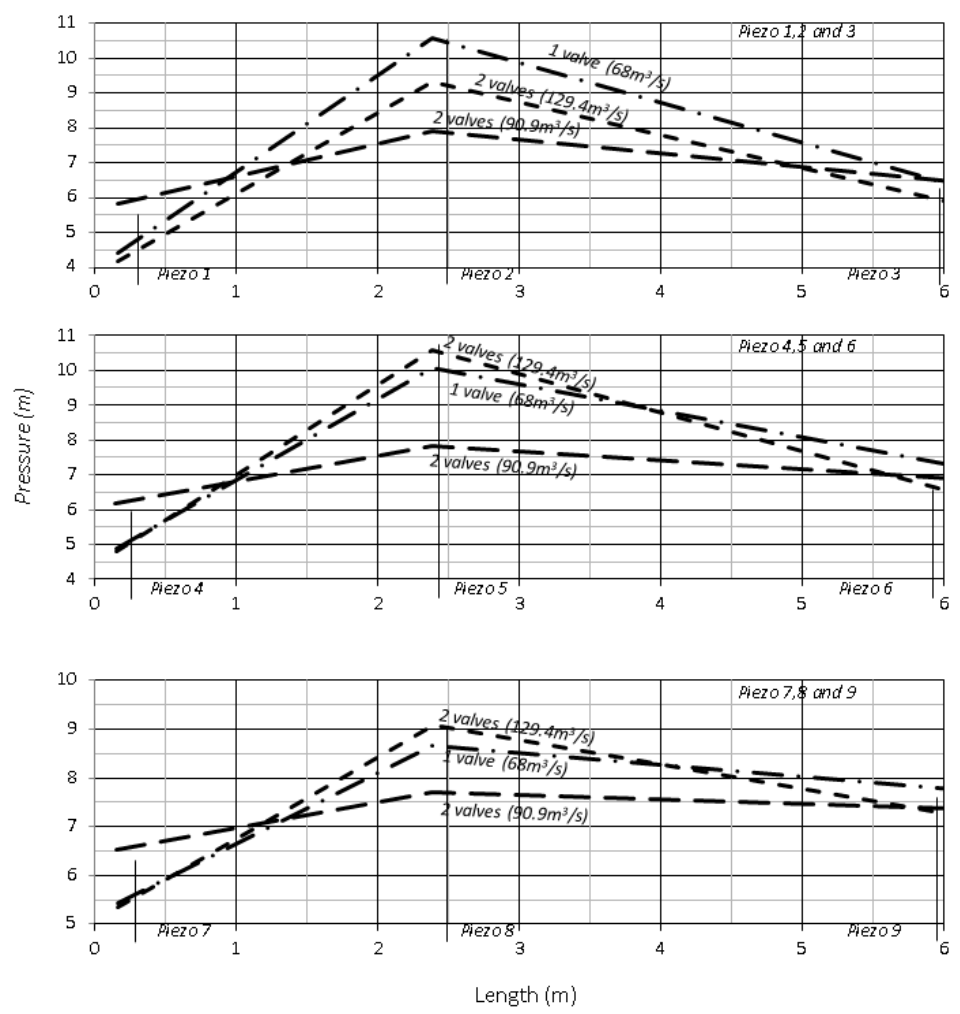

Figura 22. Perfil longitudinal de carga de pressão estática no fundo da câmara dissipadora (adaptado de USBR Hydraulic Report No276, (1950))

O perfil longitudinal de água mostrado na figura 23 se aplica para as diferentes posições ao longo da largura da câmara dissipadora.

Neste caso a traço-ponto representa o nível de água na linha de centro da câmara dissipadora, considerando vazão de 4570 ft³/s $\left(129,4 \mathrm{~m}^{3} / \mathrm{s}\right)$ e as duas válvulas operando.

A linha tracejada mostra o nível de água próximo à parede lateral da câmara dissipadora, porém, considerando vazão de $2400 \mathrm{ft} 3 / \mathrm{s}\left(68 \mathrm{~m}^{3} / \mathrm{s}\right)$ e somente a válvula da esquerda operando, observada de montante para a jusante.

A linha cheia representa o nível de água para a mesma localização descrita no parágrafo acima; com vazão de $4570 \mathrm{ft} 3 / \mathrm{s}(129,4$ m³/s) e as duas válvulas operando. 


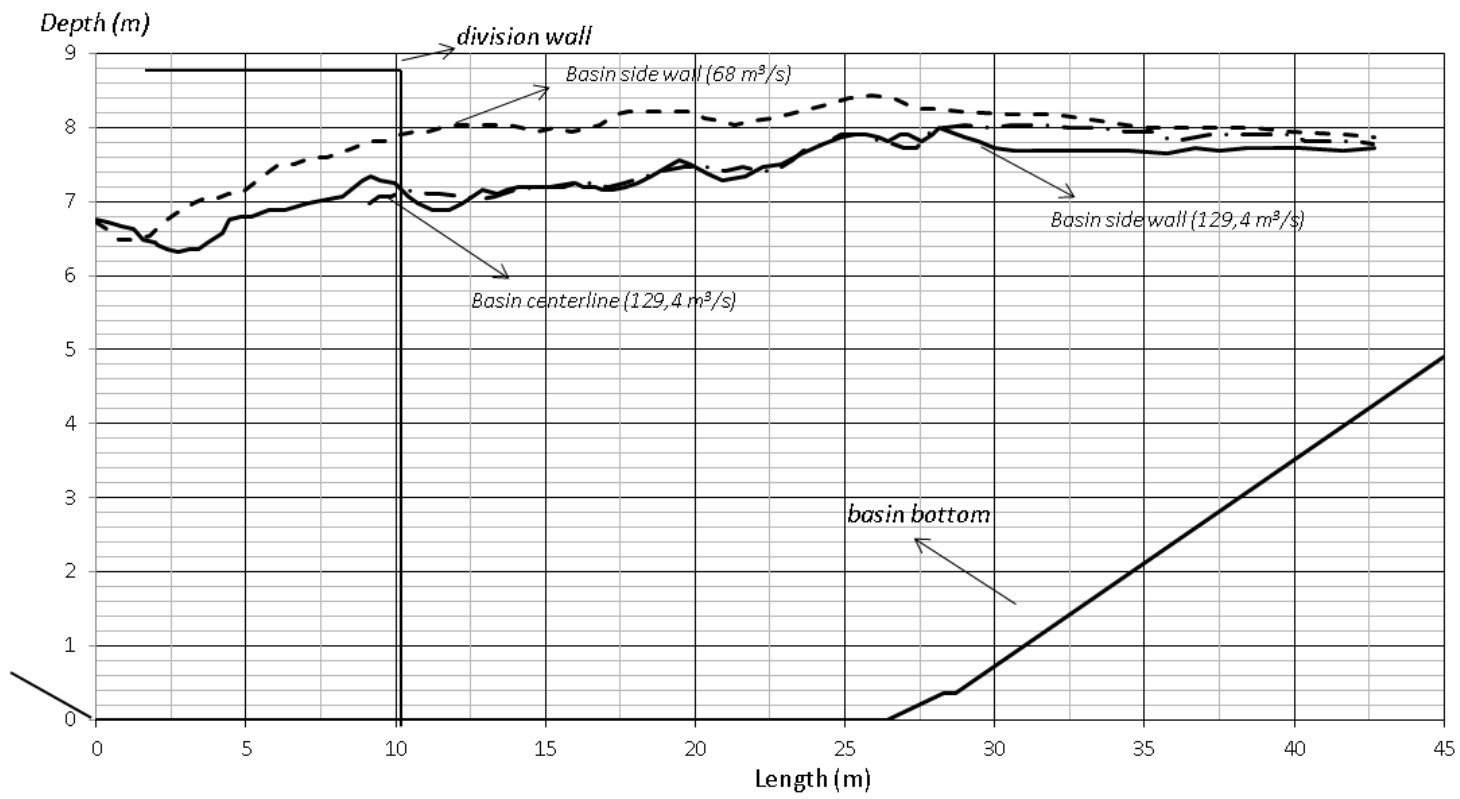

Figura 23. Perfil longitudinal de nível de água da câmara dissipadora (adaptado de USBR Hydraulic Report No276, (1950))

A figura 24 mostra o perfil de nível de água na seção transversal no final da parede divisória e no final da câmara dissipadora, visto de jusante para montante com apenas a válvula da esquerda operando. 


\section{$\operatorname{Depth}(m)$}

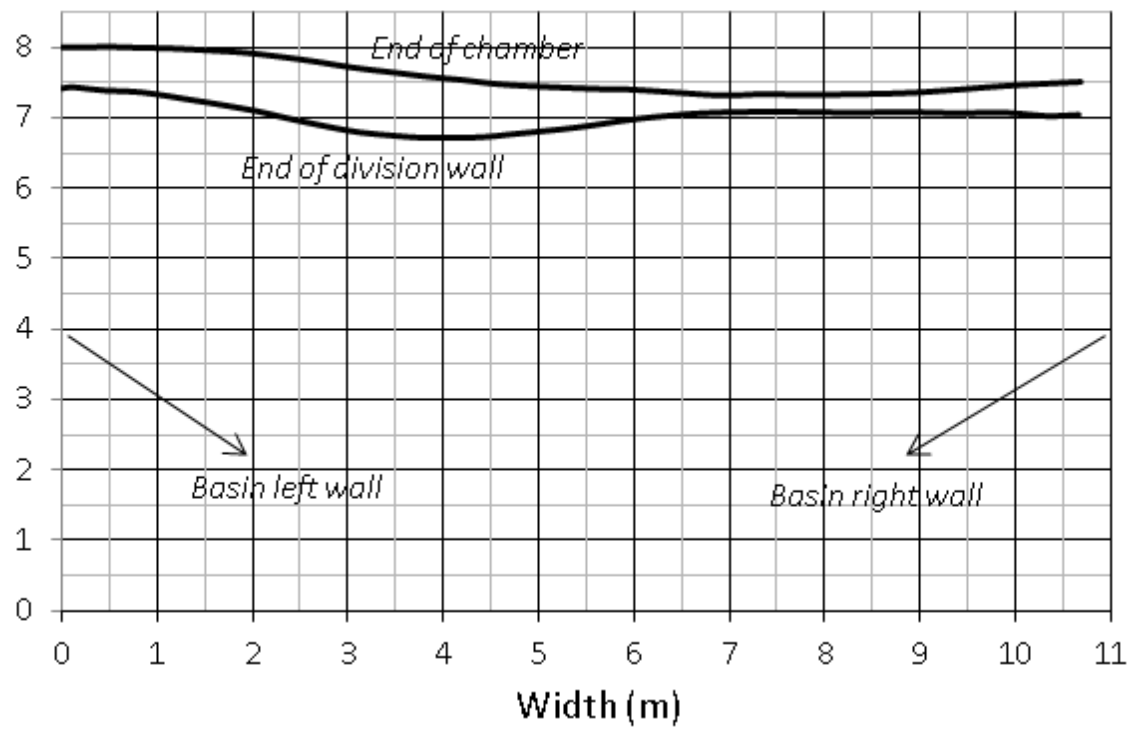

Figura 24. Perfil transversal de nível de água no fim da parede divisória e final da câmara dissipadora (extraído de USBR Hydraulic Report N²76, (1950))

Desta forma, foram estabelecidos os parâmetros que formam o banco de dados, que foi utilizado para a calibração das simulações numéricas.

Tratando da simulação do escoamento multifásico, o software $C F X$ possui duas aproximações para solução destes. A primeira aproximação é o modelo homogêneo, que considera o mesmo campo de velocidade para as duas fases, usualmente aplicado para pequenas frações de volume, ou seja, quando uma das fases é representa pouco volume em relação à outra. O outro modelo é o modelo heterogêneo, que considera campos de velocidades para cada uma das fases separadamente.

Diante das grandes frações de volume e suas variações no modelo a ser simulado, o modelo heterogêneo se demonstrou mais adequado, proporcionando capturar a formação do jato oco dentro da válvula, tendo como consequência pressões calculadas mais próximas do modelo físico. 


\subsection{Simulações Numéricas}

Após a reprodução das simulações referentes ao protótipo de Falcon Dam, condições de operação diferentes sob o ponto de vista de abertura de válvula e queda líquida serão simuladas, avaliando os efeitos do escoamento ao longo da câmara dissipadora, perfis de linha de água e linhas de corrente e eficiência de dissipação energética.

A tabela 1 mostra as dimensões principais da bacia dissipadora que serão utilizadas.

Tabela 1. Dimensões da câmara dissipadora de Falcon Dam $(H / d=10,94, D / d=3,3, L / d=$ 12,53 e W/d = 2,16 e Abertura das Válvulas em 100\%)

\begin{tabular}{|l|c|c|}
\hline & Dimensão & Unidade \\
\hline Diâmetro da Válvula (d) & 2286,0 & $\mathrm{~mm}$ \\
\hline Queda líquida (H) & 25,0 & $\mathrm{~m}$ \\
\hline Vazão de Projeto por Válvula (Q) & 64,7 & $\mathrm{~m}^{3} / \mathrm{s}$ \\
\hline Coeficiente de Descarga (Cd) & 0,70 & - \\
\hline Abertura da válvula (-) & 100,0 & $\%$ \\
\hline Profundidade da Água (D) & 7544 & $\mathrm{~mm}$ \\
\hline Comprimento (L) & 28651 & $\mathrm{~mm}$ \\
\hline Largura (W) & 4928 & $\mathrm{~mm}$ \\
\hline Altura do degrau & 914 & $\mathrm{~mm}$ \\
\hline Inclinação do degrau & $2: 1$ & \\
\hline Altura do vão das paredes convergentes & 8838 & $\mathrm{~mm}$ \\
\hline Largura do vão das paredes convergentes & 3200 & $\mathrm{~mm}$ \\
\hline Comprimento da Parede Divisória & 10363 & $\mathrm{~mm}$ \\
\hline Inclinação do canal de fuga & $4: 1$ & \\
\hline
\end{tabular}

As simulações numéricas trazem maior seletividade em termos do número de ensaios de modelo físico reduzido para diferentes pontos de operação do conjunto válvula e câmara, reduzindo assim o tempo aplicado a estes testes bem como os custos envolvidos.

Após chegar às dimensões ótimas da câmara dissipadora, os resultados das simulações numéricas ficarão disponíveis para comparação no futuro com ensaios em modelos reduzidos. 


\subsection{Configuração da Malha e Setup}

Devido à complexidade da geometria e a necessidade de medição de pressão em algumas superfícies utilizou-se malha estruturada em camada de prismas de modo a capturar os efeitos da camada limite e, malha não estruturada na forma de tetraedros no restante do domínio. O teste de sensibilidade nos resultados quanto ao número de volumes inseridos na malha é feito de modo que a diferença de resultados entre a última e atual simulação seja satisfatória, ou seja, quando os resultados forem próximos aos do banco de dados de modelo físico.

A figura 25 mostra a estratégia dos elementos estruturados em camadas de prismas e os não estruturados na forma de tetraedros, sendo aplicados os prismas nas superfícies e os tetraedros nas demais regiões.

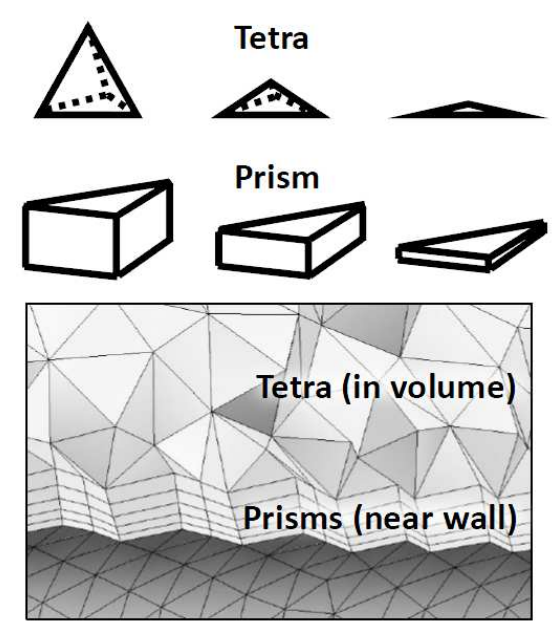

Figura 25. Exemplo de estratégia de aplicação de malha (extraído de ANSYS - Lecture 7, Mesh Quality and Advanced Topics (2014))

Ainda assim, vale mencionar que o refinamento da malha deve respeitar o limite de esforço computacional disponibilizado, o que por vezes pode resultar em algumas imprecisões nos resultados das simulações em função deste limite. 
Devido à geometria simétrica, este recurso foi utilizado de forma a reduzir o esforço computacional. A malha alcançada possui aproximadamente 5,5 milhões de elementos e como se pode notar na figura 26 , os tamanhos dos elementos foram separados convenientemente em cada região, de modo a capturar o diagrama de pressão dentro da válvula, a formação do jato oco e o perfil de linha de água na câmara dissipadora.

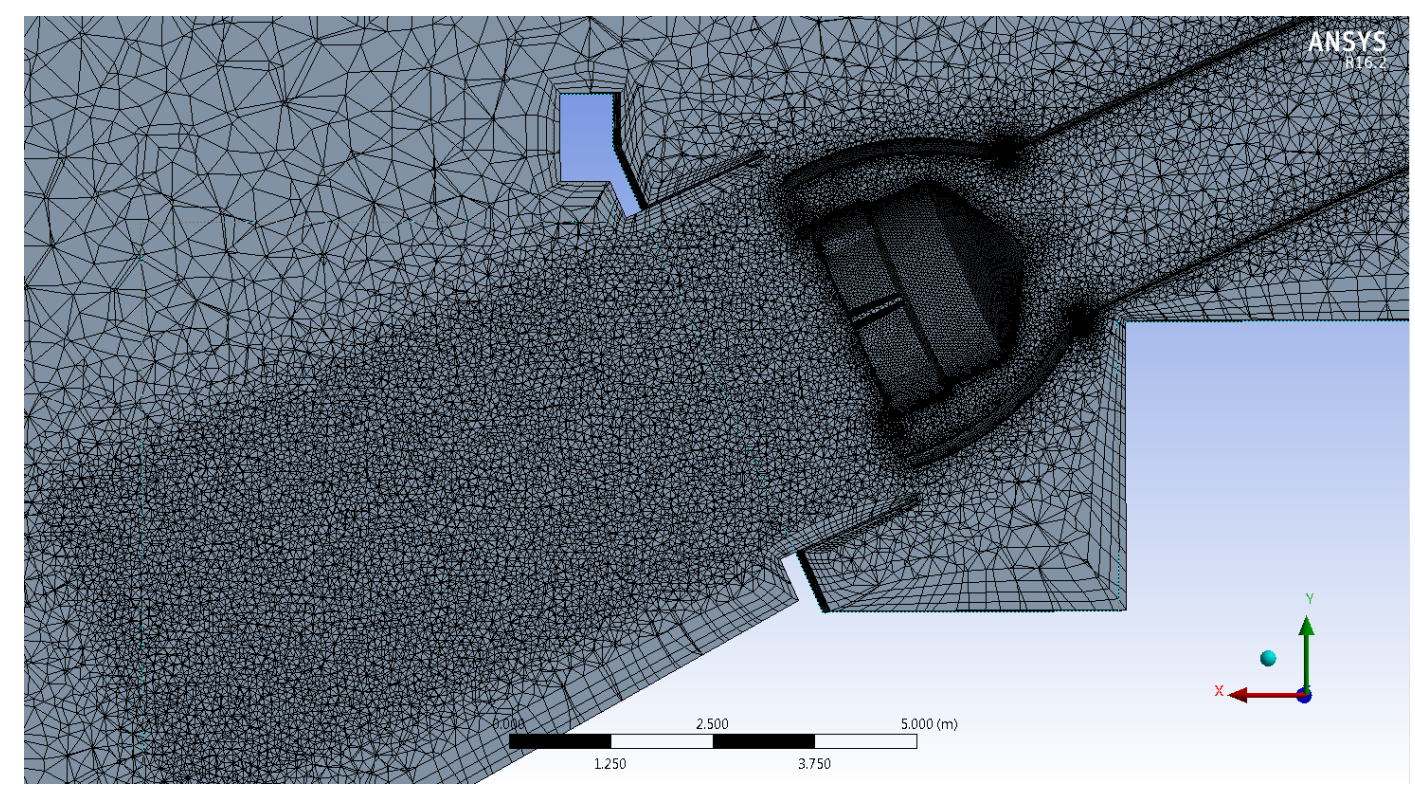

Figura 26. Malha aplicada em camadas de prisma nas superfícies seguida de tetraedros.

Vale mencionar que um bloco de malha mais refinado foi estrategicamente posicionado na saída da válvula, o que contribuiu para melhor captura da formação do jato oco incidindo na câmara de dissipação, trazendo não somente maior precisão geométrica na formação do jato, como também nas pressões ocorrentes no interior da válvula.

A tabela 2 mostra as características da malha utilizada para cada região do volume de controle. 
Tabela 2. Características Gerais da Malha

\begin{tabular}{|c|c|c|c|c|}
\cline { 2 - 5 } \multicolumn{1}{c|}{} & Válvula & $\begin{array}{c}\text { Conduto } \\
\text { forçado }\end{array}$ & $\begin{array}{c}\text { Região do } \\
\text { Jato Oco }\end{array}$ & $\begin{array}{c}\text { Câmara } \\
\text { dissipadora }\end{array}$ \\
\hline $\begin{array}{c}\text { Número de camadas de } \\
\text { prisma }\end{array}$ & 5 & 5 & - & 4 \\
\hline $\begin{array}{c}\text { Espessura total da } \\
\text { camada de prisma }\end{array}$ & $60 \mathrm{~mm}$ & $60 \mathrm{~mm}$ & - & $60 \mathrm{a} 600 \mathrm{~mm}$ \\
\hline $\begin{array}{c}\text { Comprimento e largura } \\
\text { dos elementos }\end{array}$ & $45 \mathrm{~mm}$ & $100 \mathrm{~mm}$ & $105 \mathrm{~mm}$ & $400 \mathrm{~mm}$ \\
\hline
\end{tabular}

Conforme mencionado anteriormente, no setup da simulação foi utilizado o modelo multifásico heterogêneo para possibilitar a captura do jato oco formado pela válvula, devido à campos de velocidades diferentes entre água e ar. As simulações começam na situação onde o volume de controle está preenchido totalmente com ar, sendo a água injetada através dos condutos.

De acordo com o explicado anteriormente, a aproximação por simetria foi aplicada para os casos onde as duas válvulas operam, indicada em setas vermelhas de forma a minimizar o esforço computacional.

Outro ponto relevante é que as simulações foram realizadas em regime estacionário (e não transiente) de forma a minimizar o esforço computacional. Assim, eventuais oscilações de pressão devem ser verificadas em ensaios com modelo físico.

A figura 27 mostra as aplicações das condições de entrada de escoamento, foi utilizada a vazão em massa de água através do conduto, indicada com a seta preta.

Nas condições livres para saída do volume de controle, foram utilizadas as condições de contorno chamadas aberturas (openings) indicadas em setas azuis, onde a pressão atmosférica é informada. 


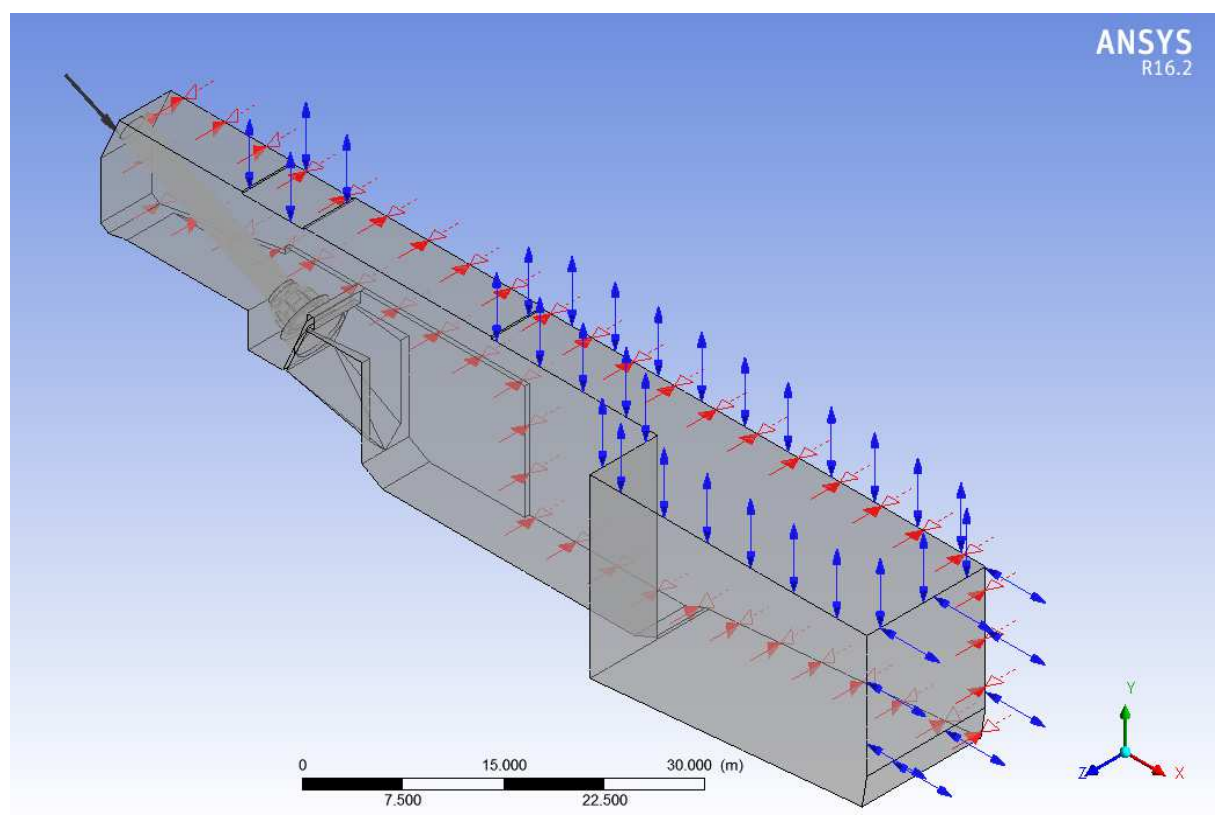

Figura 27. Condições de Contorno utilizadas durante o setup.

\section{RESULTADOS}

\subsection{Diagrama de Pressão na Válvula Dispersora}

Os diagramas de pressão no cone e corpo da válvula foram levantados de acordo com a localização dos piezômetros utilizados no ensaio de modelo, as pressões medidas são apresentadas na forma normalizada de acordo com a equação 39 e em função da abertura da válvula como segue.

Na tabela 3 pode-se notar de forma geral que os fatores de pressão calculados por $C F D$ são mais próximos aos valores de ensaio de modelo para os piezômetros de 17 a 20, ou seja, para os piezômetros localizados ao início do cone.

A partir do piezômetro 21, nota-se desvio maior do cálculo $C F D$ comparado aos dados de ensaio de modelo e este desvio se acentua até o piezômetro 24. 
O desvio de resultados decorre do forte decréscimo de pressão ocorrente nesta região do cone para aberturas menores que $63 \%$, o que sugere maior refinamento nesta região. Ainda assim, as válvulas não são projetadas para operar a maior parte do tempo em aberturas pequenas o que consequentemente faz com que o estudo da câmara de dissipação seja realizado para abertura entre $50 \%$ e $100 \%$. Portanto, as simulações procederam desta maneira.

Tabela 3. Fatores de Pressão para os Piezômetros do Cone da Válvula

\begin{tabular}{|c|c|c|c|c|c|c|c|c|c|c|c|c|c|c|c|c|}
\hline & \multicolumn{2}{|c|}{ Piezo 17} & \multicolumn{2}{|c|}{ Piezo 18} & \multicolumn{2}{|c|}{ Piezo 19} & \multicolumn{2}{|c|}{ Piezo 20} & \multicolumn{2}{|c|}{ Piezo 21} & \multicolumn{2}{|c|}{ Piezo 22} & \multicolumn{2}{|c|}{ Piezo 23} & \multicolumn{2}{|c|}{ Piezo 24} \\
\hline $\begin{array}{c}\text { Abertura } \\
\text { da } \\
\text { válvula } \\
(\%)\end{array}$ & $\begin{array}{c}\text { FP } \\
\text { CFD } \\
(\%)\end{array}$ & $\begin{array}{c}\text { FP } \\
\text { Modelo } \\
(\%)\end{array}$ & $\begin{array}{c}\text { FP } \\
\text { CFD } \\
(\%)\end{array}$ & $\begin{array}{c}\text { FP } \\
\text { Modelo } \\
(\%)\end{array}$ & $\begin{array}{l}\text { FP } \\
\text { CFD } \\
(\%)\end{array}$ & $\begin{array}{c}\text { FP } \\
\text { Modelo } \\
(\%)\end{array}$ & $\begin{array}{c}\text { FP } \\
\text { CFD } \\
(\%)\end{array}$ & $\begin{array}{c}\text { FP } \\
\text { Modelo } \\
(\%)\end{array}$ & $\begin{array}{l}\text { FP } \\
\text { CFD } \\
(\%)\end{array}$ & $\begin{array}{c}\text { FP } \\
\text { Modelo } \\
(\%)\end{array}$ & $\begin{array}{c}\text { FP } \\
\text { CFD } \\
(\%)\end{array}$ & $\begin{array}{c}\text { FP } \\
\text { Modelo } \\
(\%)\end{array}$ & $\begin{array}{l}\text { FP } \\
\text { CFD } \\
(\%)\end{array}$ & $\begin{array}{c}\text { FP } \\
\text { Modelo } \\
(\%)\end{array}$ & $\begin{array}{c}\text { FP } \\
\text { CFD } \\
(\%)\end{array}$ & $\begin{array}{c}\text { FP } \\
\text { Modelo } \\
(\%)\end{array}$ \\
\hline 10 & 100.3 & 100.0 & 99.8 & 99.4 & 99.0 & 98.1 & 97.7 & 96.3 & 92.2 & 80.3 & 90.4 & 46.4 & \begin{tabular}{|l|}
87.5 \\
\end{tabular} & 32.2 & -31.1 & 10.5 \\
\hline 25 & 98.0 & 98.5 & 95.5 & 95.3 & 90.5 & 86.7 & 86.7 & 76.8 & 63.0 & 38.9 & 58.9 & 17.4 & 53.7 & 13.4 & -34.5 & 4.5 \\
\hline 50 & 92.9 & 94.9 & 86.4 & 84.5 & 74.9 & 63.1 & 57.7 & 45.6 & 27.2 & 16.6 & 22.2 & 9.5 & 17.0 & 9.4 & -25.8 & 6.4 \\
\hline 63 & 91.0 & 92.4 & 83.2 & 79.0 & 61.6 & 55.1 & 45.0 & 37.4 & 24.6 & 14.0 & 22.2 & 9.5 & 19.5 & 9.3 & -1.7 & 3.3 \\
\hline 75 & 87.8 & 90.6 & 80.3 & 75.4 & 49.4 & 51.0 & 40.9 & 33.9 & 13.7 & 13.2 & 12.0 & 10.1 & 8.5 & 9.9 & -8.1 & 4.0 \\
\hline 80 & 87.9 & 90.2 & 74.9 & 74.0 & 69.6 & 50.0 & 48.1 & 33.5 & 22.7 & 13.7 & 21.3 & 12.0 & 15.7 & 10.1 & 5.2 & 4.4 \\
\hline 85 & 84.2 & 89.8 & 72.4 & 73.4 & $\begin{array}{l}48.7 \\
\end{array}$ & 49.2 & 37.1 & 33.2 & 9.1 & 14.4 & 7.3 & 11.2 & 7.6 & 10.8 & -32.5 & 4.9 \\
\hline 90 & 86.6 & 89.5 & 72.9 & 73.1 & 58.1 & 48.0 & 36.4 & 33.6 & 18.6 & 15.3 & 17.2 & 12.0 & \begin{tabular}{|l|}
14.9 \\
\end{tabular} & 11.5 & 1.6 & 5.4 \\
\hline 95 & 84.8 & 90.1 & 75.5 & 73.0 & 52.1 & 47.8 & 41.9 & 34.4 & 20.2 & 16.5 & 17.6 & 13.2 & 15.1 & 12.5 & 1.5 & 5.8 \\
\hline 100 & 84.8 & 91.0 & 69.9 & 72.5 & 54.9 & 47.5 & 38.2 & 35.8 & 20.4 & 18.4 & 18.6 & 14.6 & 16.5 & 13.6 & 4.9 & 6.2 \\
\hline
\end{tabular}

Vale salientar ainda que no piezômetro 24 , os fatores de pressão negativos podem provocar cavitação dependendo da queda líquida aplicada, ou seja, o fator de pressão negativo pode resultar em pressão próxima da pressão de vapor, baixa o suficiente para provocar cavitação.

Tabela 4. Diferenças de Fator de Pressão no Cone da Válvula entre o CFD e ensaio de modelo.

\begin{tabular}{|c|c|c|c|c|c|c|c|c|}
\cline { 2 - 10 } \multicolumn{1}{c|}{} & \multicolumn{7}{c|}{ Diferença de Fator de Pressão (\%) } \\
\hline $\begin{array}{c}\text { Abertura } \\
\text { da } \\
\text { válvula } \\
(\%)\end{array}$ & $\begin{array}{c}\text { Piezo } \\
17\end{array}$ & $\begin{array}{c}\text { Piezo } \\
18\end{array}$ & $\begin{array}{c}\text { Piezo } \\
19\end{array}$ & $\begin{array}{c}\text { Piezo } \\
20\end{array}$ & $\begin{array}{c}\text { Piezo } \\
21\end{array}$ & $\begin{array}{c}\text { Piezo } \\
22\end{array}$ & $\begin{array}{c}\text { Piezo } \\
23\end{array}$ & $\begin{array}{c}\text { Piezo } \\
24\end{array}$ \\
\hline 10 & 0.3 & 0.4 & 0.9 & 1.4 & 11.9 & 44.0 & 55.3 & -41.6 \\
\hline 25 & -0.5 & 0.2 & 3.8 & 9.9 & 24.1 & 41.5 & 40.3 & -39.0 \\
\hline 50 & -2.0 & 1.9 & 11.8 & 12.1 & 10.6 & 12.7 & 7.6 & -32.2 \\
\hline 63 & -1.4 & 4.2 & 6.5 & 7.6 & 10.6 & 12.7 & 10.2 & -5.0 \\
\hline 75 & -2.8 & 4.9 & -1.6 & 7.0 & 0.5 & 1.9 & -1.4 & -12.1 \\
\hline 80 & -2.3 & 0.9 & 19.6 & 14.6 & 9.0 & 9.3 & 5.6 & 0.8 \\
\hline 85 & -5.6 & -1.0 & -0.5 & 3.9 & -5.3 & -3.9 & -3.2 & -37.4 \\
\hline 90 & -2.9 & -0.2 & 10.1 & 2.8 & 3.3 & 5.2 & 3.4 & -3.8 \\
\hline 95 & -5.3 & 2.5 & 4.3 & 7.5 & 3.7 & 4.4 & 2.6 & -4.3 \\
\hline 100 & -6.2 & -2.6 & 7.4 & 2.4 & 2.0 & 4.0 & 2.9 & -1.3 \\
\hline
\end{tabular}


A tabela 4 mostra que nos piezômetros de 17 a 20 as diferenças entre o valor calculado e obtido de modelo físico sejam menores, pode-se notar no piezômetro 17, que a diferença de resultados aumenta com o aumento da abertura da válvula, sendo que esta tendência vai se invertendo para os piezômetros seguintes.

Como se pode notar para o piezômetro 17 a diferença entre o valor calculado e o obtido por ensaio de modelo físico apresenta uma tendência constante a medida que a válvula apresenta valores maiores de abertura.

Da mesma forma, são apresentados na tabela 5 os valores de fatores de pressão para os piezômetros localizados no corpo da válvula.

Tabela 5. Fatores de Pressão para os Piezômetros do Corpo da Válvula

\begin{tabular}{|c|c|c|c|c|c|c|c|c|c|c|c|c|c|c|}
\cline { 2 - 16 } \multicolumn{1}{c|}{} & \multicolumn{2}{|c|}{ Piezo 2 } & \multicolumn{2}{c|}{ Piezo 3 } & \multicolumn{2}{c|}{ Piezo 4 } & \multicolumn{2}{c|}{ Piezo 5 } & \multicolumn{2}{c|}{ Piezo 6 } & \multicolumn{2}{c|}{ Piezo 7 } & \multicolumn{2}{c|}{ Piezo 8 } \\
\hline $\begin{array}{c}\text { Abertura } \\
\text { da } \\
\text { válvula } \\
(\%)\end{array}$ & $\begin{array}{c}\text { FP } \\
\text { CFD } \\
(\%)\end{array}$ & $\begin{array}{c}\text { Modelo } \\
(\%)\end{array}$ & $\begin{array}{c}\text { FP } \\
\text { CFD } \\
(\%)\end{array}$ & $\begin{array}{c}\text { FP } \\
\text { Modelo } \\
(\%)\end{array}$ & $\begin{array}{c}\text { FP } \\
\text { CFD } \\
(\%)\end{array}$ & $\begin{array}{c}\text { FP } \\
\text { Modelo } \\
(\%)\end{array}$ & $\begin{array}{c}\text { FP } \\
\text { CFD } \\
(\%)\end{array}$ & $\begin{array}{c}\text { FP } \\
\text { Modelo } \\
(\%)\end{array}$ & $\begin{array}{c}\text { FP } \\
\text { CFD } \\
(\%)\end{array}$ & $\begin{array}{c}\text { FP } \\
\text { Modelo } \\
(\%)\end{array}$ & $\begin{array}{c}\text { FP } \\
\text { CFD } \\
(\%)\end{array}$ & $\begin{array}{c}\text { FP } \\
\text { Modelo } \\
(\%)\end{array}$ & $\begin{array}{c}\text { FP } \\
\text { CFD } \\
(\%)\end{array}$ & $\begin{array}{c}\text { FP } \\
\text { Modelo } \\
(\%)\end{array}$ \\
\hline 10 & 83.8 & 90.4 & 63.3 & 81.8 & 29.0 & 58.7 & 1.1 & 26.2 & 4.8 & 3.2 & 9.5 & 2.0 & 9.5 & 2.6 \\
\hline 25 & 64.6 & 72.4 & 41.1 & 57.4 & 26.6 & 35.4 & 13.3 & 22.3 & 9.9 & 12.1 & 11.0 & 5.9 & 11.8 & 6.1 \\
\hline 50 & 39.9 & 49.4 & 23.9 & 39.8 & 21.6 & 23.7 & 13.5 & 21.1 & 1.3 & 23.0 & 15.3 & 14.0 & 17.1 & 11.5 \\
\hline 63 & 30.0 & 38.7 & 31.1 & 25.7 & 29.6 & 17.9 & 30.8 & 21.4 & 21.0 & 27.3 & 19.0 & 19.0 & -3.1 & 15.0 \\
\hline 75 & 18.0 & 29.5 & 13.9 & 18.7 & 17.7 & 14.4 & 26.1 & 21.5 & 17.3 & 30.2 & 21.0 & 24.6 & 21.0 & 24.6 \\
\hline 80 & 19.8 & 25.7 & 18.6 & 15.9 & 23.1 & 13.0 & 32.1 & 21.5 & 24.8 & 31.5 & 25.0 & 27.0 & 19.4 & 20.1 \\
\hline 85 & 4.9 & 22.0 & 4.5 & 13.2 & 11.6 & 11.2 & 22.1 & 21.5 & 15.3 & 32.2 & 22.1 & 29.5 & 20.9 & 21.7 \\
\hline 90 & 11.4 & 18.3 & 10.6 & 10.7 & 21.3 & 10.4 & 29.9 & 21.6 & 25.2 & 33.0 & 28.8 & 32.1 & 21.5 & 23.4 \\
\hline 95 & 6.8 & 14.6 & 7.9 & 7.9 & 17.5 & 9.6 & 29.7 & 21.6 & 25.8 & 33.7 & 30.7 & 34.6 & 24.1 & 25.0 \\
\hline 100 & 4.5 & 11.0 & 5.3 & 5.2 & 13.3 & 8.8 & 27.0 & 21.6 & 29.7 & 33.9 & 33.5 & 37.2 & 25.3 & 26.6 \\
\hline
\end{tabular}

Em geral se nota que as diferenças entre valores calculados por $C F D$ e modelo físico no corpo da válvula são menores que as diferenças encontradas no cone.

A tabela 6 mostra as diferenças encontradas entre o modelo $C F D$ e o ensaio real onde se pode notar que as diferenças tendem a diminuir para aberturas maiores, ou seja, as diferenças diminuem para as condições de abertura de válvula onde o gradiente de pressão é menos acentuado. 
Tabela 6. Diferenças de Fator de Pressão no Corpo da Válvula entre o CFD e ensaio de modelo.

\begin{tabular}{|c|c|c|c|c|c|c|c|}
\cline { 2 - 9 } \multicolumn{1}{c|}{} & \multicolumn{7}{c|}{ Diferença $\%$} \\
\hline $\begin{array}{c}\text { Abertura } \\
\text { da } \\
\text { válvula } \\
(\%)\end{array}$ & $\begin{array}{c}\text { Piezo } \\
2\end{array}$ & $\begin{array}{c}\text { Piezo } \\
3\end{array}$ & $\begin{array}{c}\text { Piezo } \\
4\end{array}$ & $\begin{array}{c}\text { Piezo } \\
5\end{array}$ & $\begin{array}{c}\text { Piezo } \\
6\end{array}$ & $\begin{array}{c}\text { Piezo } \\
7\end{array}$ & $\begin{array}{c}\text { Piezo } \\
8\end{array}$ \\
\hline 10 & -6.6 & -18.5 & -29.7 & -25.1 & 1.6 & 7.5 & 6.9 \\
\hline 25 & -7.8 & -16.3 & -8.8 & -9.0 & -2.2 & 5.1 & 5.7 \\
\hline 50 & -9.5 & -15.9 & -2.1 & -7.6 & -21.7 & 1.3 & 5.6 \\
\hline 63 & -8.7 & 5.4 & 11.7 & 9.4 & -6.3 & 0.0 & -18.1 \\
\hline 75 & -11.5 & -4.8 & 3.3 & 4.6 & -12.9 & -3.6 & -3.6 \\
\hline 80 & -5.9 & 2.7 & 10.1 & 10.6 & -6.7 & -2.0 & -0.7 \\
\hline 85 & -17.1 & -8.7 & 0.4 & 0.6 & -16.9 & -7.4 & -0.8 \\
\hline 90 & -6.9 & -0.1 & 10.9 & 8.3 & -7.8 & -3.3 & -1.9 \\
\hline 95 & -7.8 & 0.0 & 7.9 & 8.1 & -7.9 & -3.9 & -0.9 \\
\hline 100 & -6.5 & 0.1 & 4.5 & 5.4 & -4.2 & -3.7 & -1.3 \\
\hline
\end{tabular}

A figura 28 mostra a distribuição de pressão ao longo da válvula para abertura de $100 \%$, resumindo os dados mostrados nas tabelas acima e as descrições sobre o gradiente de pressão.

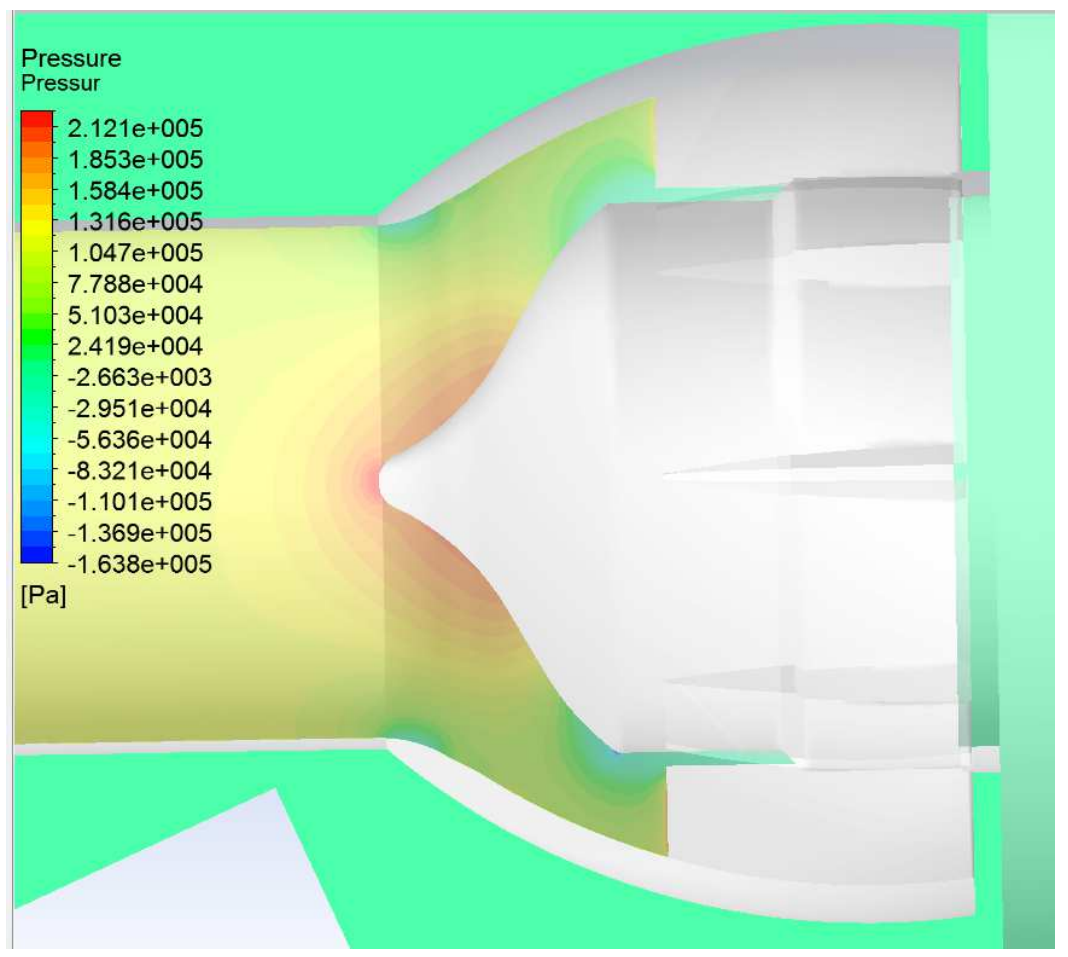

Figura 28. Distribuição de pressão ao longo da válvula para abertura de 100\%, obtido por $C F D$ 
A figura 29 mostra a formação do jato oco dentro da válvula, também para abertura de $100 \%$.

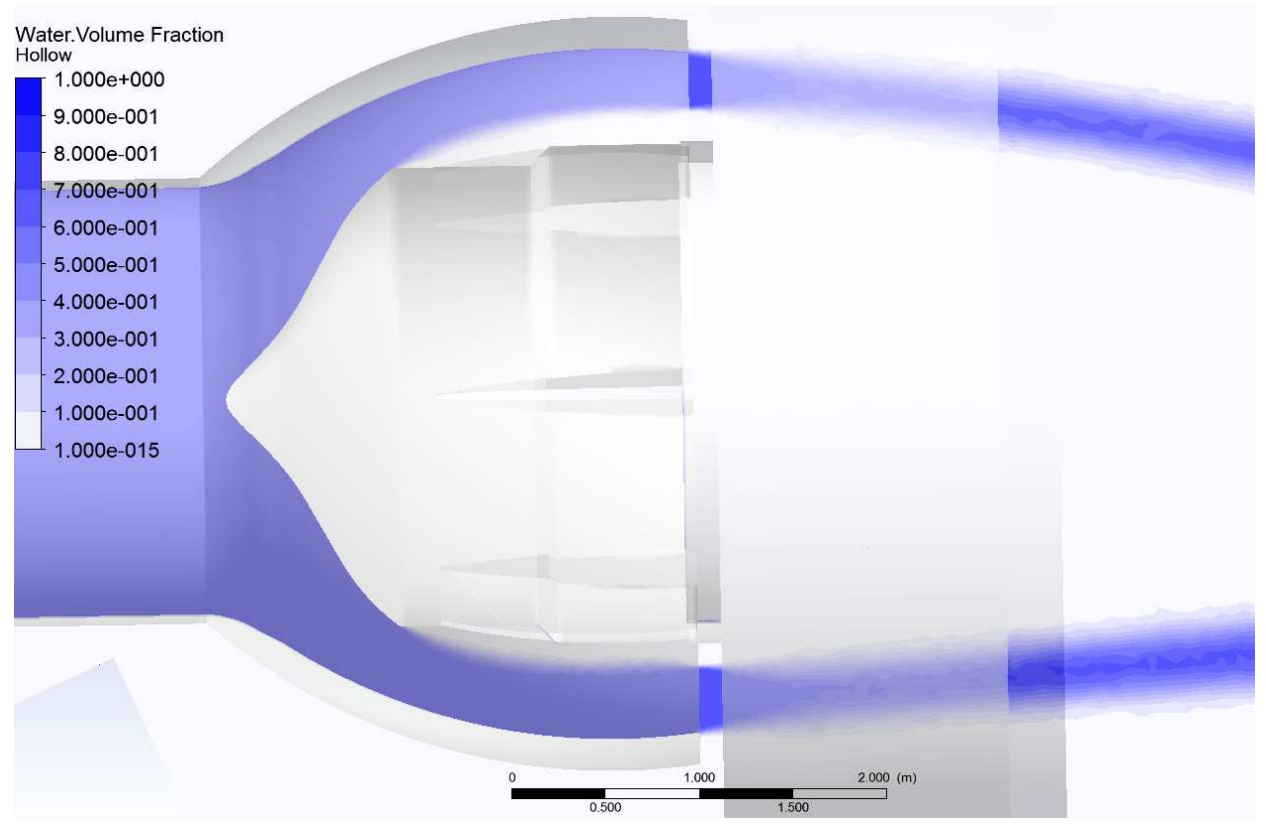

Figura 29. Fração de Volume ao longo da válvula para abertura de 100\%, obtido por CFD

Durante as simulações foi comprovada a formação do jato oco para qualquer abertura de válvula bem como qualquer queda líquida aplicada, ou seja, os resultados das simulações se mostraram adequados aos ensaios de modelo físico, onde o formato do jato praticamente não se altera com relação a mudanças de queda líquida.

Assim, pode-se dizer a alteração no formato do jato corre em sua espessura, que varia em função da abertura da válvula sem depender da queda líquida e vazão.

As figuras 30 e 31 mostram respectivamente a distribuição de pressão e a fração de volume para abertura de $50 \%$. 


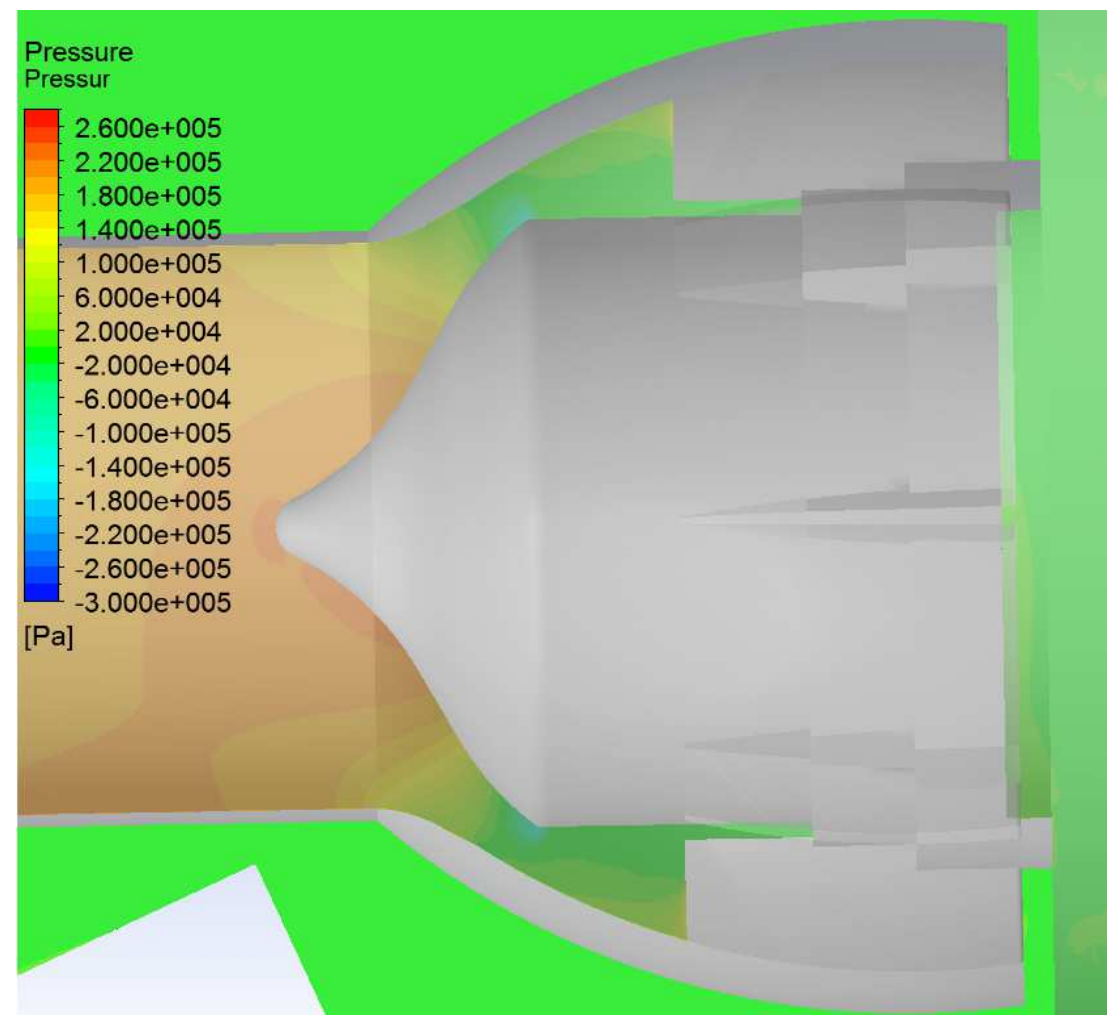

Figura 30. Distribuição de pressão ao longo da válvula para abertura de 50\%, obtido por $C F D$

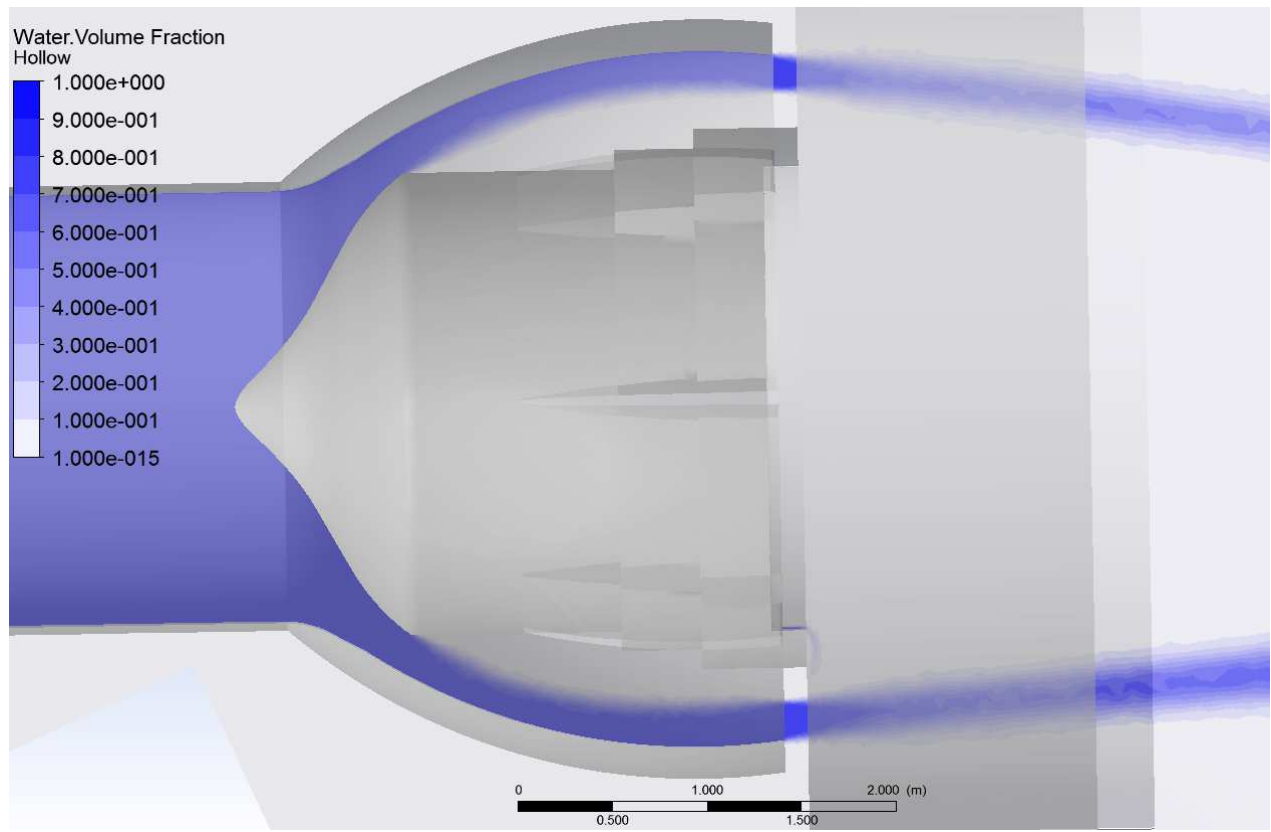

Figura 31. Fração de Volume ao longo da válvula para abertura de 50\%, obtido por CFD 
Os valores de coeficiente de descarga da válvula foram obtidos com auxílio das equações 39 e 1. Assim, conhecendo a vazão e a partir da medição da pressão a montante da válvula, a queda líquida é obtida somando a energia cinética à carga de pressão a montante da válvula. Os resultados do fator de descarga obtido através da equação 1, são apresentados na tabela 7 e figura 32 .

Tabela 7. Coeficientes de Descarga da Válvula Hollow-Jet

\begin{tabular}{|c|c|c|c|}
\hline Abertura da válvula (\%) & Cd CFD $(\%)$ & Cd modelo (\%) & Diferença (\%) \\
\hline 10 & 8.6 & 8.2 & 0.4 \\
\hline 25 & 20.3 & 20.2 & 0.1 \\
\hline 50 & 39.7 & 39.6 & 0.2 \\
\hline 63 & 46.4 & 49.0 & -2.6 \\
\hline 75 & 56.1 & 57.1 & -1.0 \\
\hline 80 & 58.0 & 60.3 & -2.4 \\
\hline 85 & 65.4 & 63.4 & 1.9 \\
\hline 90 & 65.7 & 66.4 & -0.7 \\
\hline 95 & 67.9 & 69.5 & -1.6 \\
\hline 100 & 70.9 & 70.0 & 0.9 \\
\hline
\end{tabular}



Abertura da válvula (\%)

Figura 32. Coeficiente de descarga da válvula Hollow-Jet obtido por CFD

A figura 33 mostra o diagrama de pressão no cone e coeficiente de descarga, seguido da figura 34 que mostra diagrama de pressão no corpo da válvula, obtidos por $C F D$. 


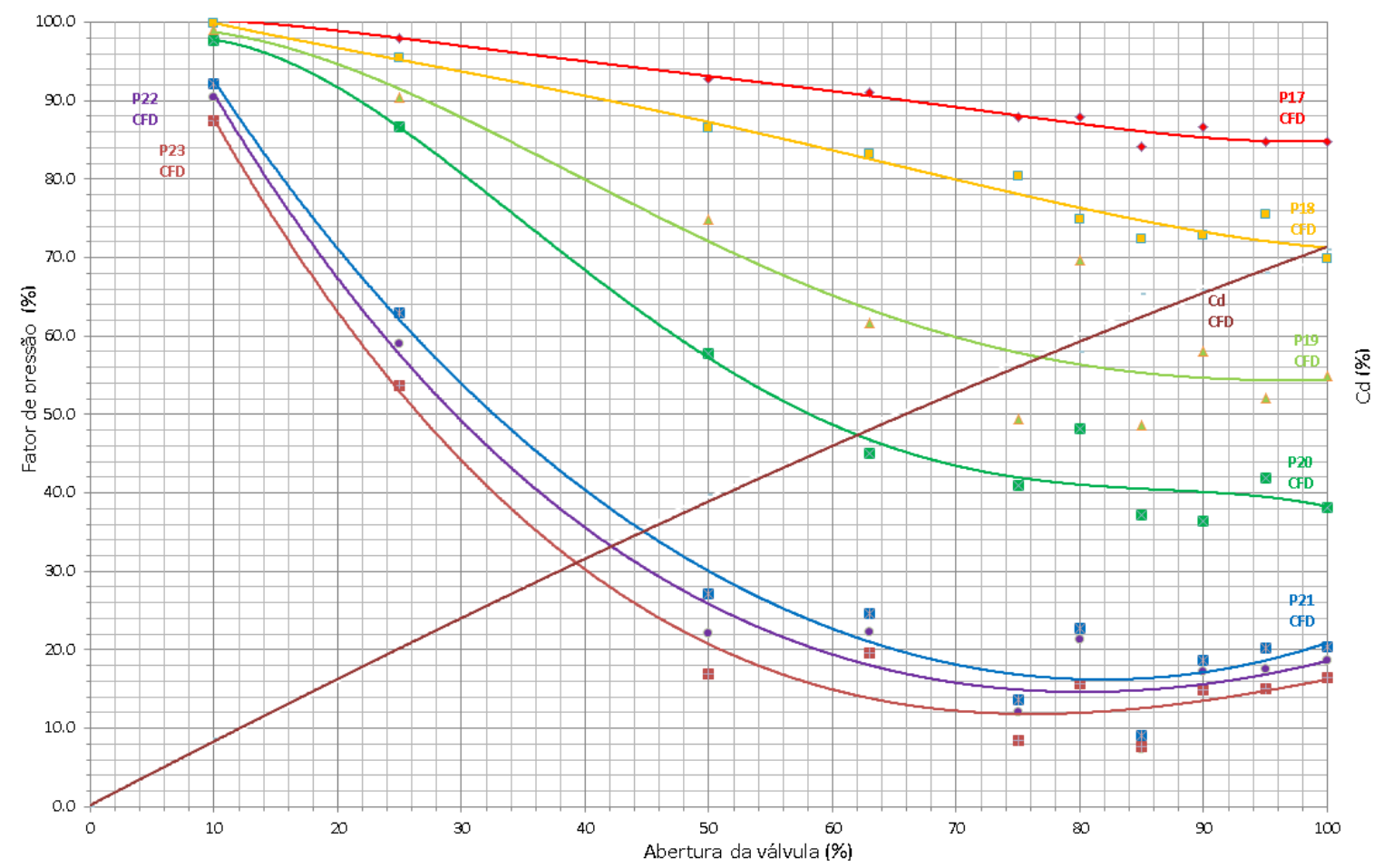

Figura 33. Diagrama de fator pressão no cone da válvula obtido por CFD.

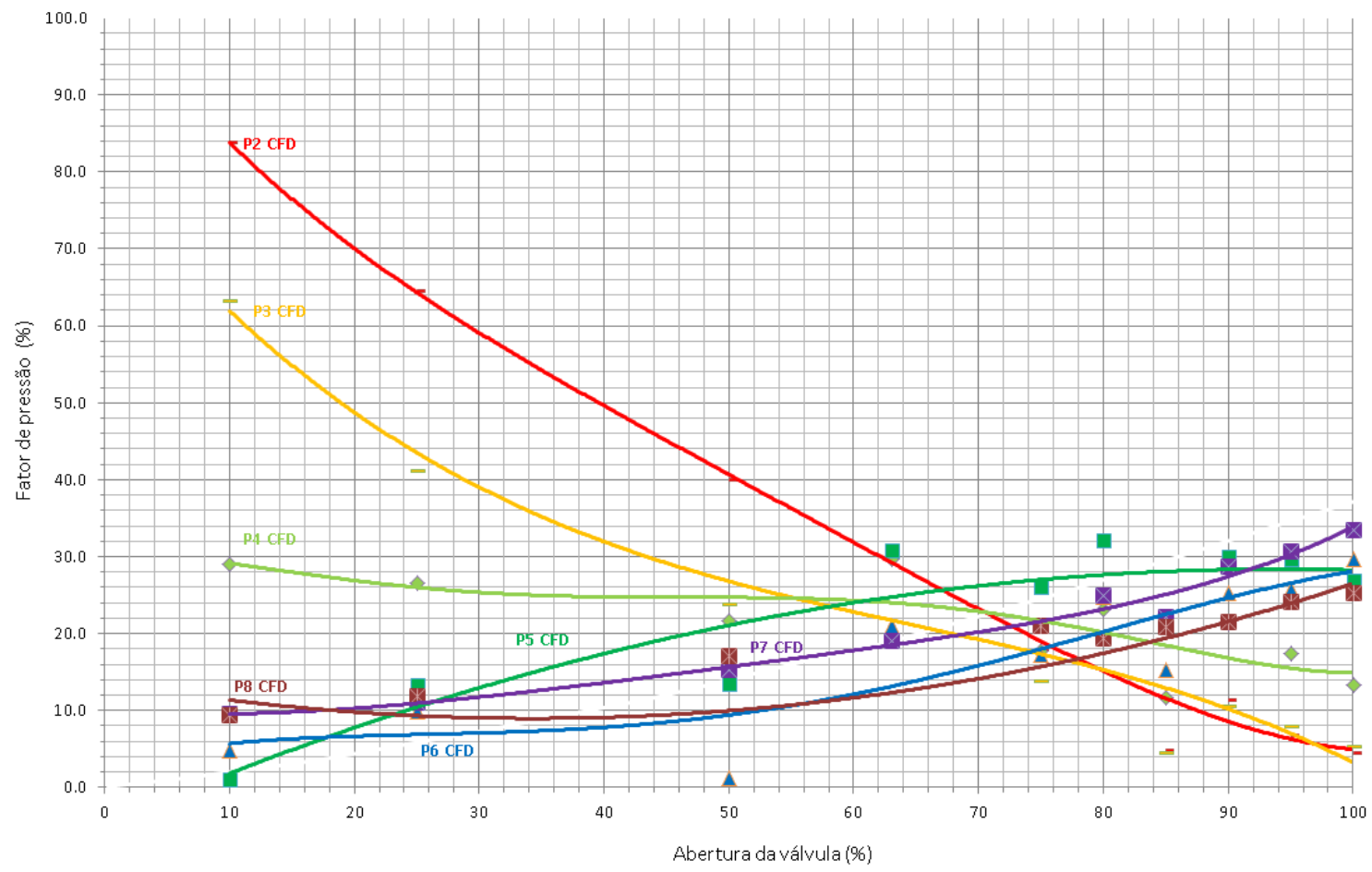

Figura 34. Diagrama de fator pressão no corpo da válvula obtido por CFD. 
Em geral as diferenças dos resultados de cálculo através do $C F D$ e dos ensaios em modelo são consideradas admissíveis já que os valores de fator de descarga e queda líquida da válvula, obtidos por $C F D$ praticamente não apresentaram desvios em relação aos resultados de modelo físico.

\subsection{Simulações das Condições de Protótipo de Falcon Dam $(H / d=11,2)$}

Dado que as simulações da válvula foram apresentadas, agora é possível estudar a dissipação de energia na câmara de dissipação de energia, onde serão apresentadas as linhas de perfil de água junto à análise de dissipação de energia.

\subsubsection{Perfil de Linha de Nível na Bacia Dissipadora com duas Válvulas em Operação}

De forma a comparar o perfil de superfície de água, as simulações foram executadas considerando as válvulas operando a $100 \%$ de abertura e vazão de 64,76 m³/s cada uma.

Tendo em mente estudar a faixa operativa da câmara dissipadora, a simulação considerando $50 \%$ de abertura da válvula com $36,3 \mathrm{~m}^{3} / \mathrm{s}$ cada uma, também foi executada na sequência.

A relação $H / d=11,2$ resulta na queda líquida de 25,6 m. 


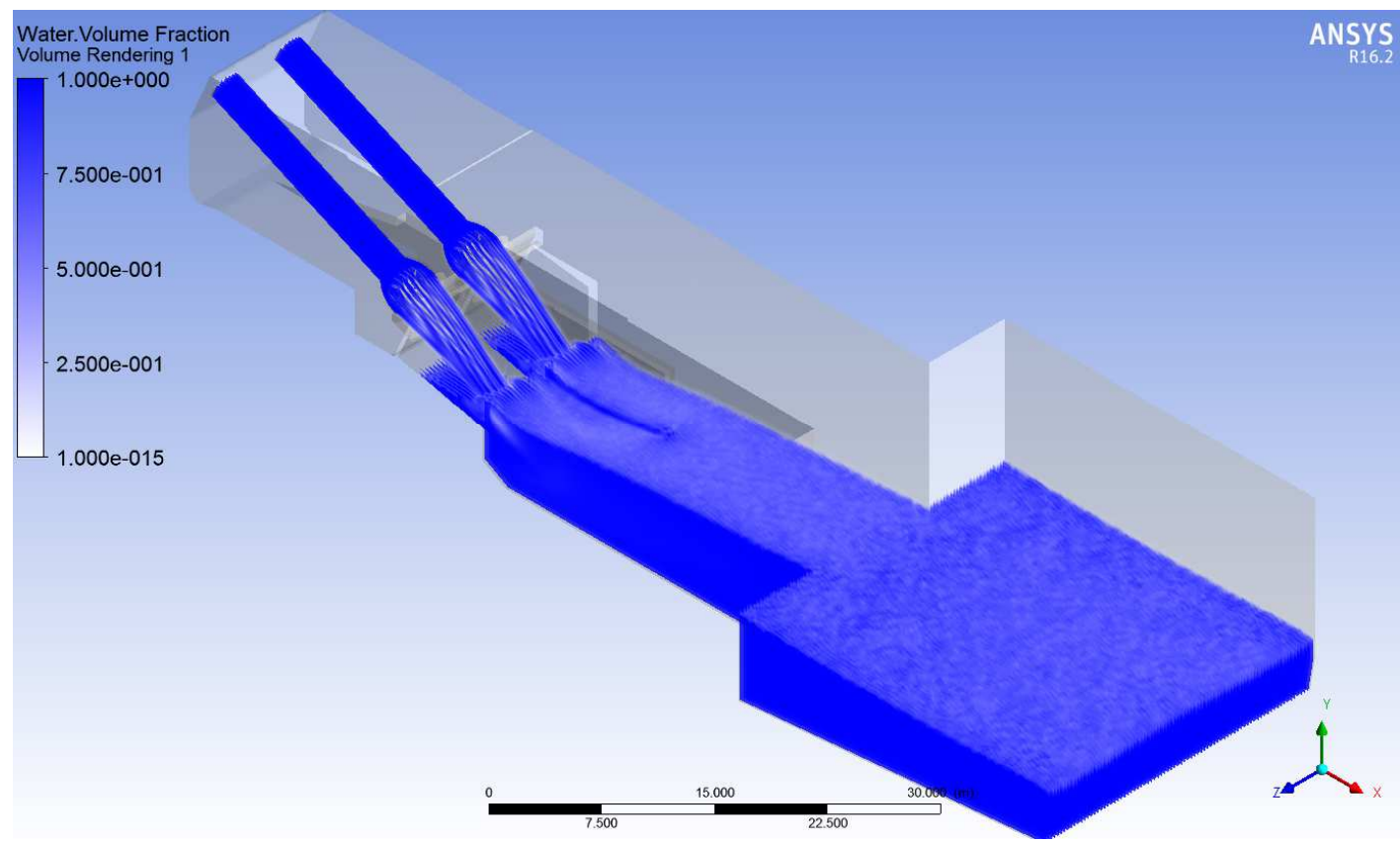

Figura 35. Vista isométrica: fração de volume da câmara, 2 válvulas a 64,76 $\mathrm{m}^{3} / \mathrm{s}$ cada

Os perfis registrados no protótipo estão localizados no eixo de simetria da câmara e na parede lateral da câmara, onde os ressaltos hidráulicos são mostrados nas figuras 36 e 37 os resultados obtidos por $C F D$.

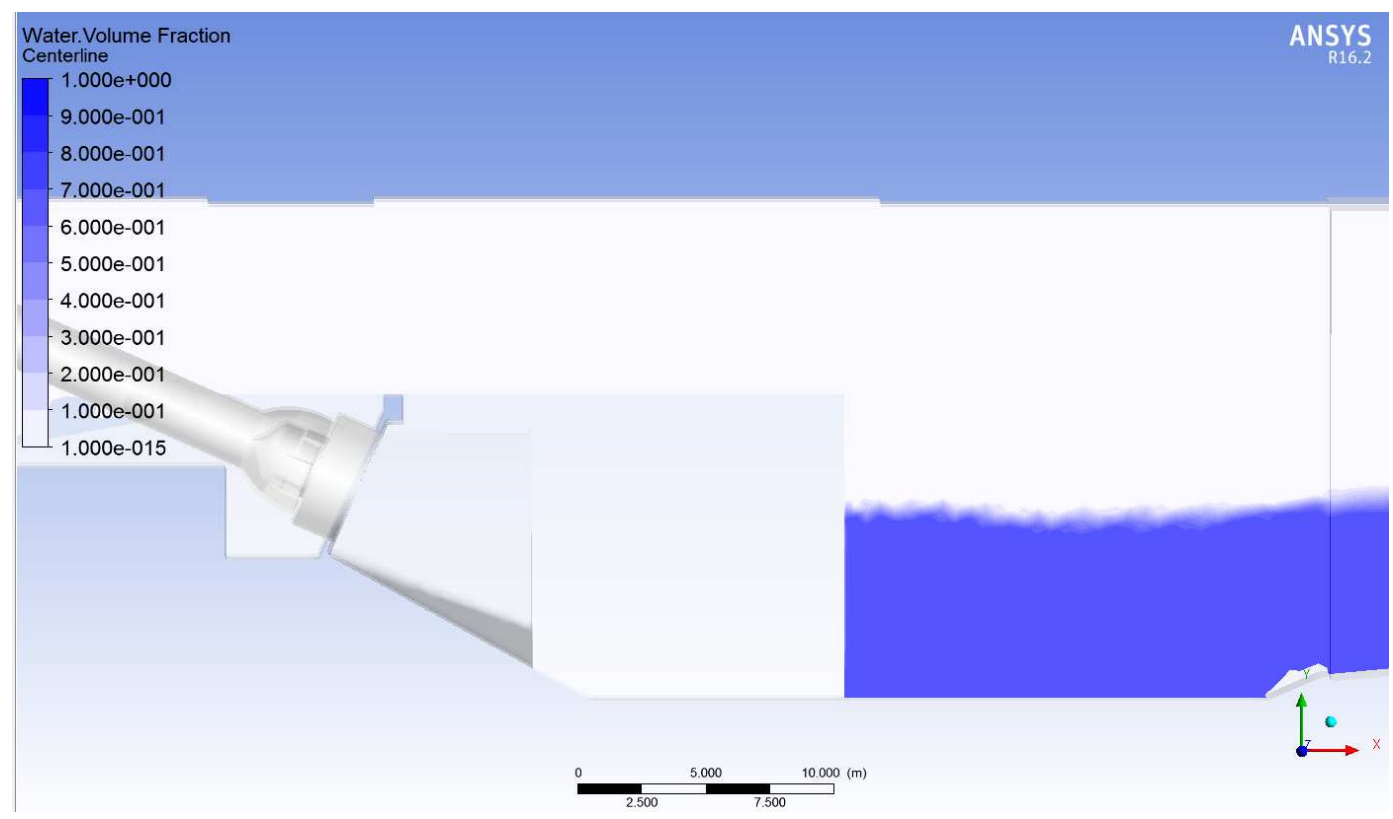

Figura 36. Perfil de linha d'água no eixo de simetria, 2 válvulas a $64,76 \mathrm{~m}^{3} / \mathrm{s}$ cada 


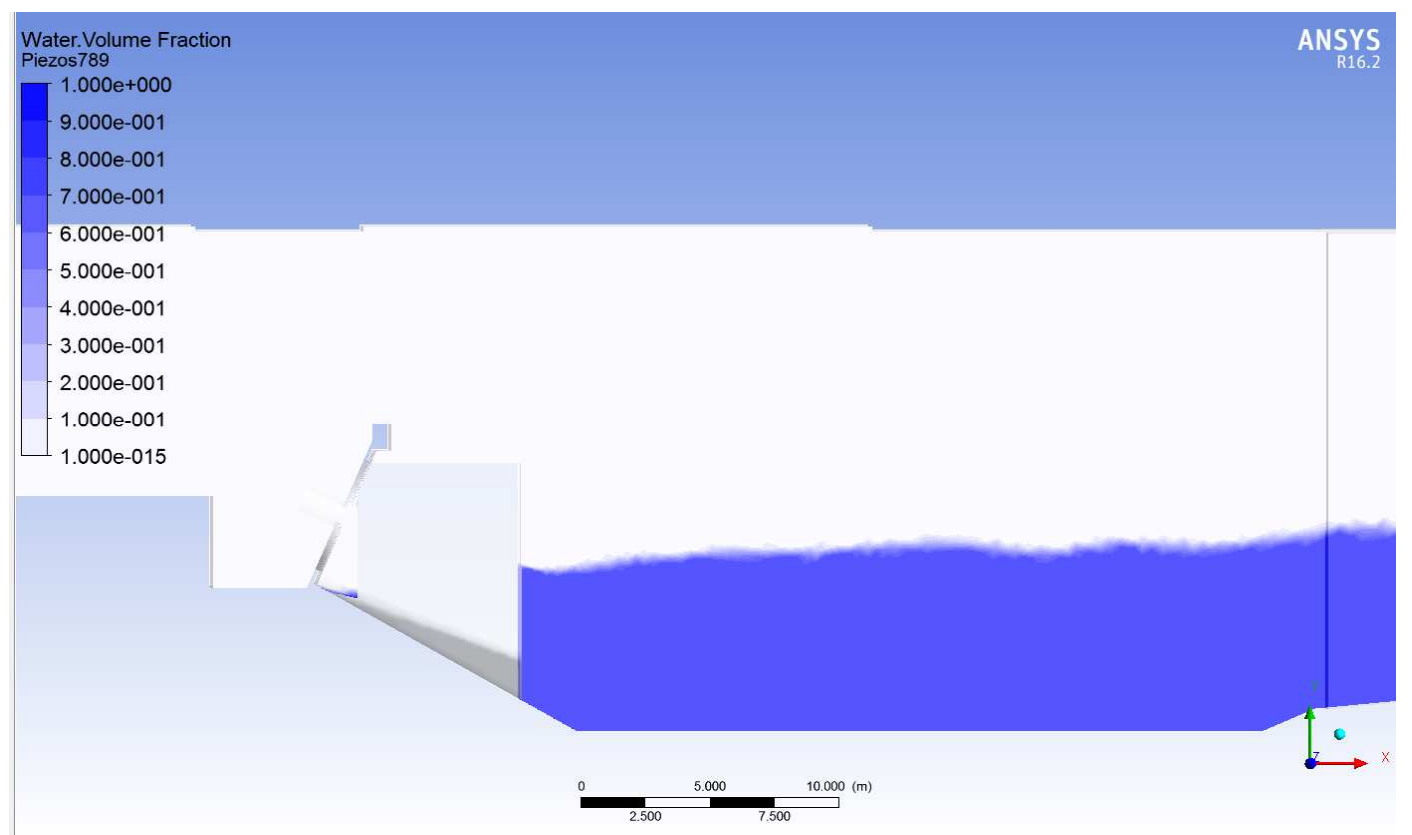

Figura 37. Perfil de linha d'água na parede lateral, 2 válvulas a $64,76 \mathrm{~m}^{3} / \mathrm{s}$ cada

A comparação entre o ressalto hidráulico medido no protótipo e o calculado por $C F D$ é mostrada nas figuras 38 e 39.

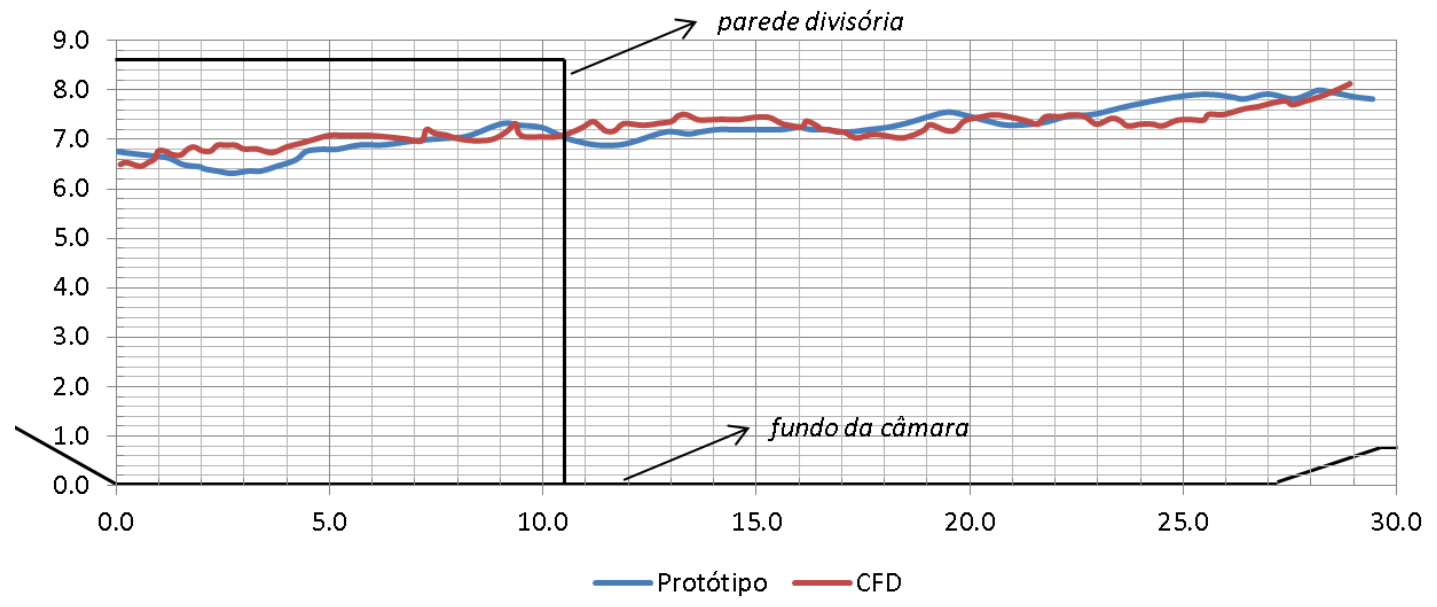

Figura 38. Comparação de perfil de linha d'água na parede lateral, 2 válvulas a $64,76 \mathrm{~m}^{3} / \mathrm{s}$ 


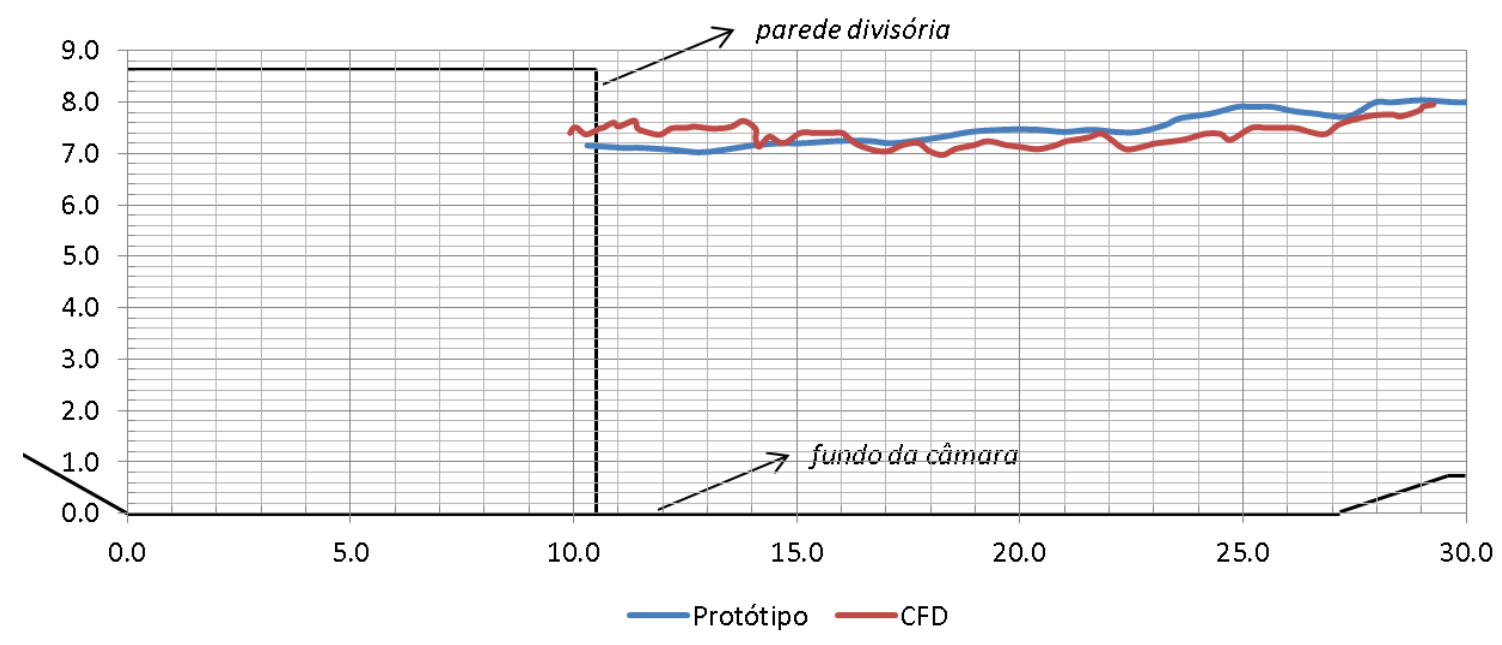

Figura 39. Comparação de perfil de linha d'água no eixo de simetria, 2 válvulas a $64,76 \mathrm{~m}^{3} / \mathrm{s}$

De acordo com as figuras 38 e 39, os níveis de água foram levantados mostrando pouca diferença quando comparado com os valores de protótipo.

Conforme já descrito anteriormente, de forma a investigar a faixa operativa da câmara dissipadora, as figuras 40 e 41 seguem da mesma maneira como os resultados apresentados nas figuras 38 e 39, mas para abertura de válvula de $50 \%$.

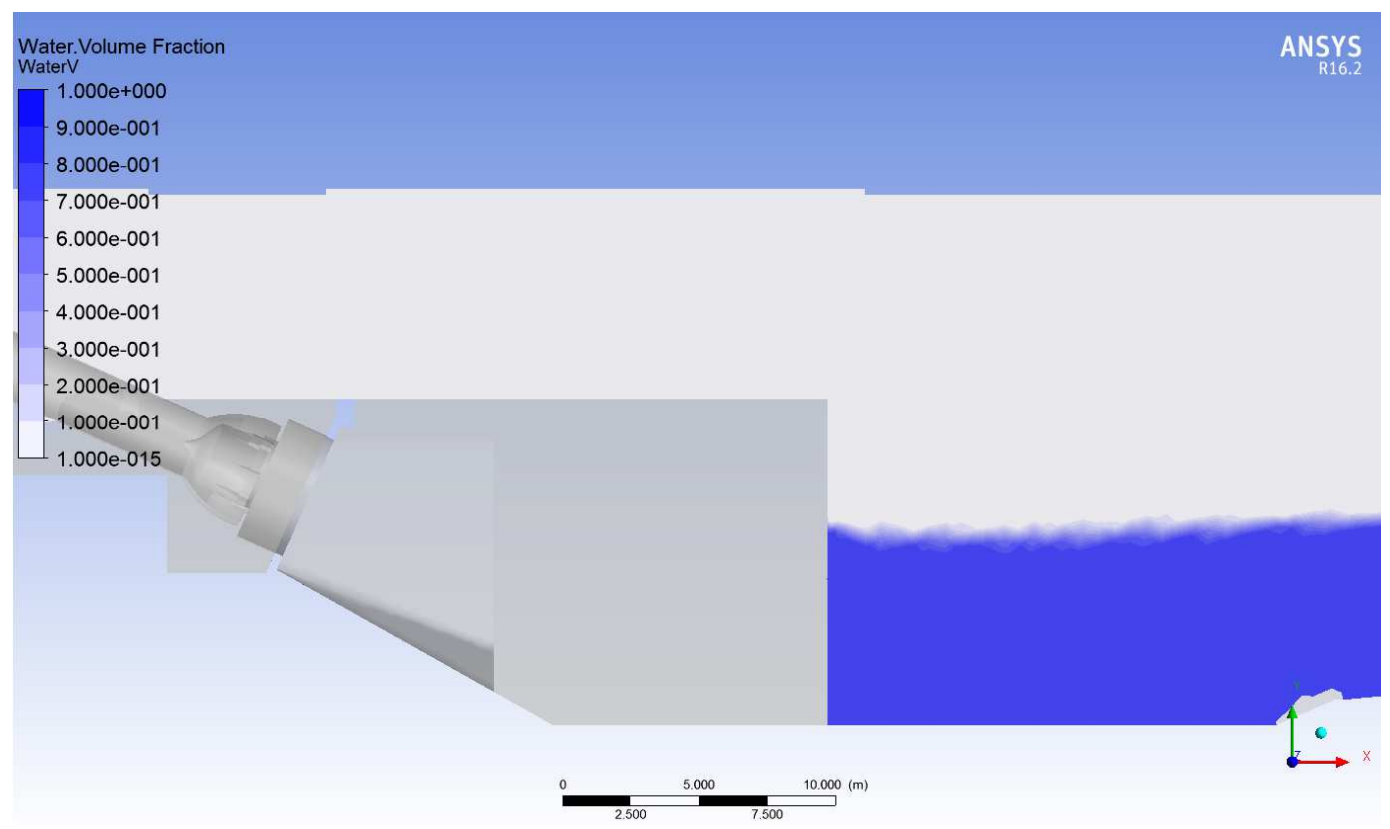

Figura 40. Perfil de linha d'água na parede lateral, 2 válvulas a 36,30 $\mathrm{m}^{3} / \mathrm{s}$ cada 


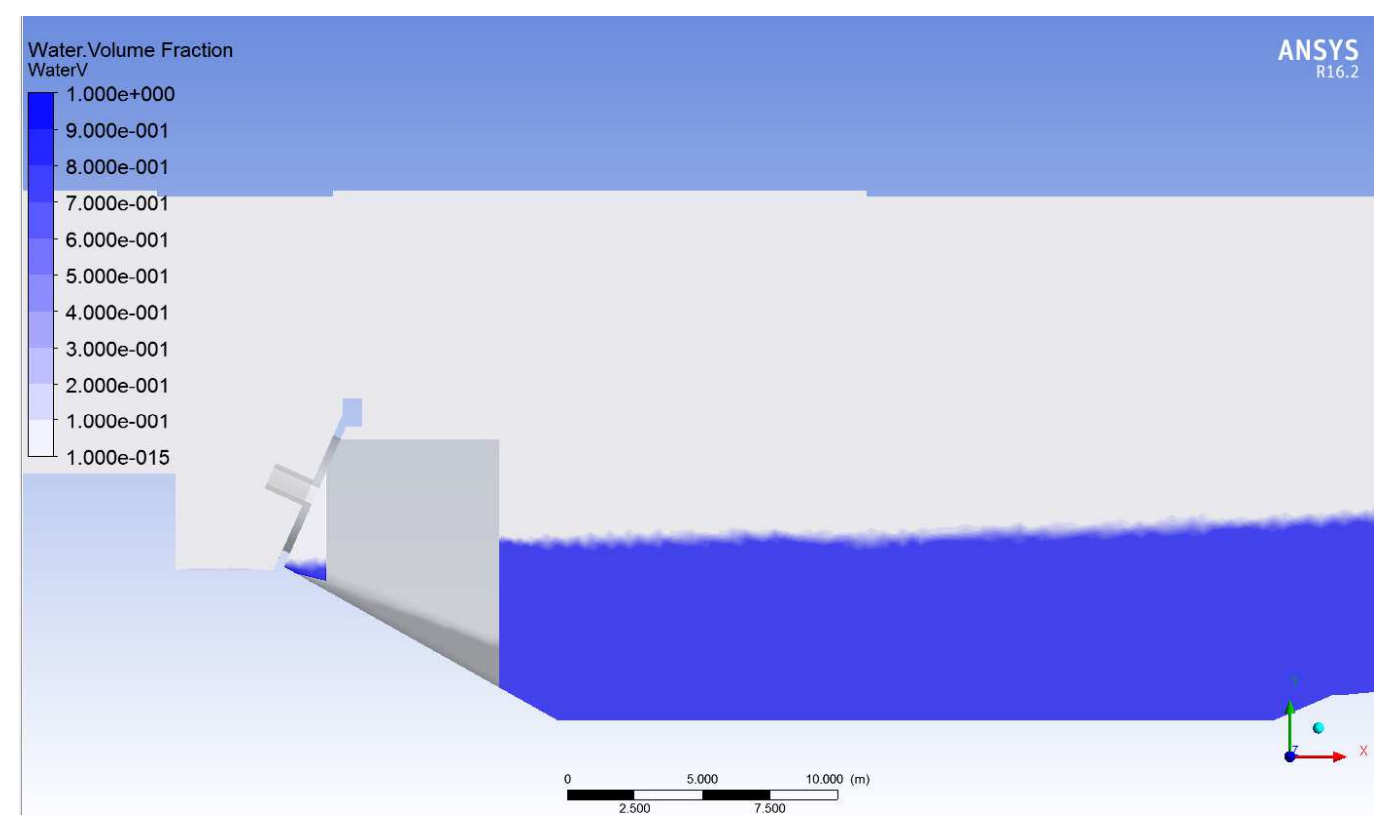

Figura 41. Perfil de linha d'água no eixo de simetria, 2 válvulas a 36,30 $\mathrm{m}^{3} / \mathrm{s}$ cada

Os gráficos acima mostram maior uniformidade do perfil da linha de água para vazão de $36,30 \mathrm{~m} 3 / \mathrm{s}$, onde esta tendência será observada nas simulações seguintes.

\subsubsection{Perfil de Linha de Nível na Bacia Dissipadora com uma Válvula em Operação}

A operação da câmara dissipadora com apenas uma válvula leva a assimetrias de ressalto hidráulico quando o escoamento é observado de jusante para montante e vice-versa.

De acordo com os dados de operação de protótipo, esta simulação foi analisada com uma válvula operando a $100 \%$ da abertura com $68 \mathrm{~m} 3 / \mathrm{s}$ enquanto a segunda válvula não opera. A relação $H / d=11,2$ resulta na queda líquida de $25,6 \mathrm{~m}$. 


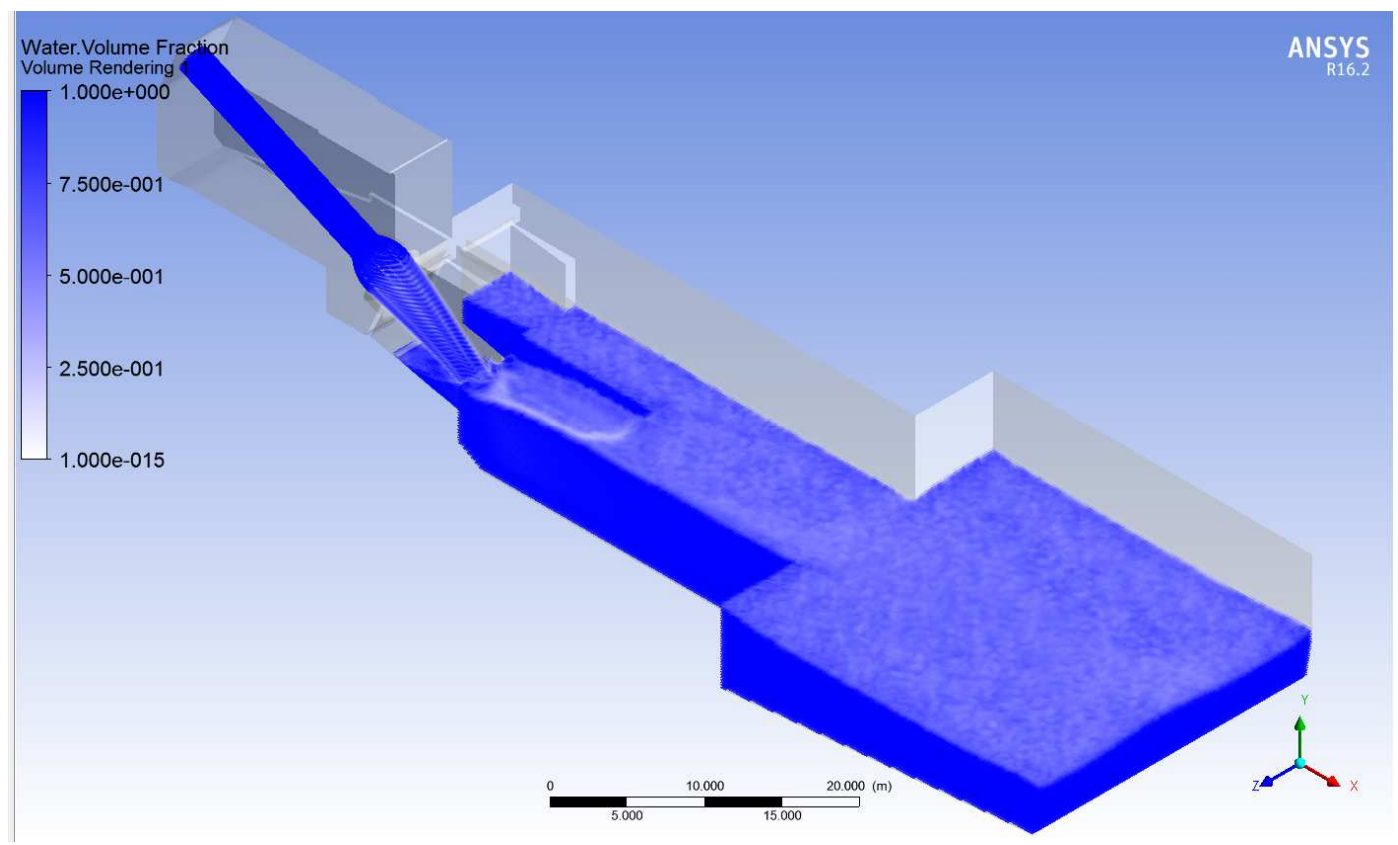

Figura 42. Vista isométrica: fração de volume da câmara, 1 válvula a 68,0 $\mathrm{m}^{3} / \mathrm{s}$

As figuras 43 e 44 mostram os resultados das simulações em $C F D$.

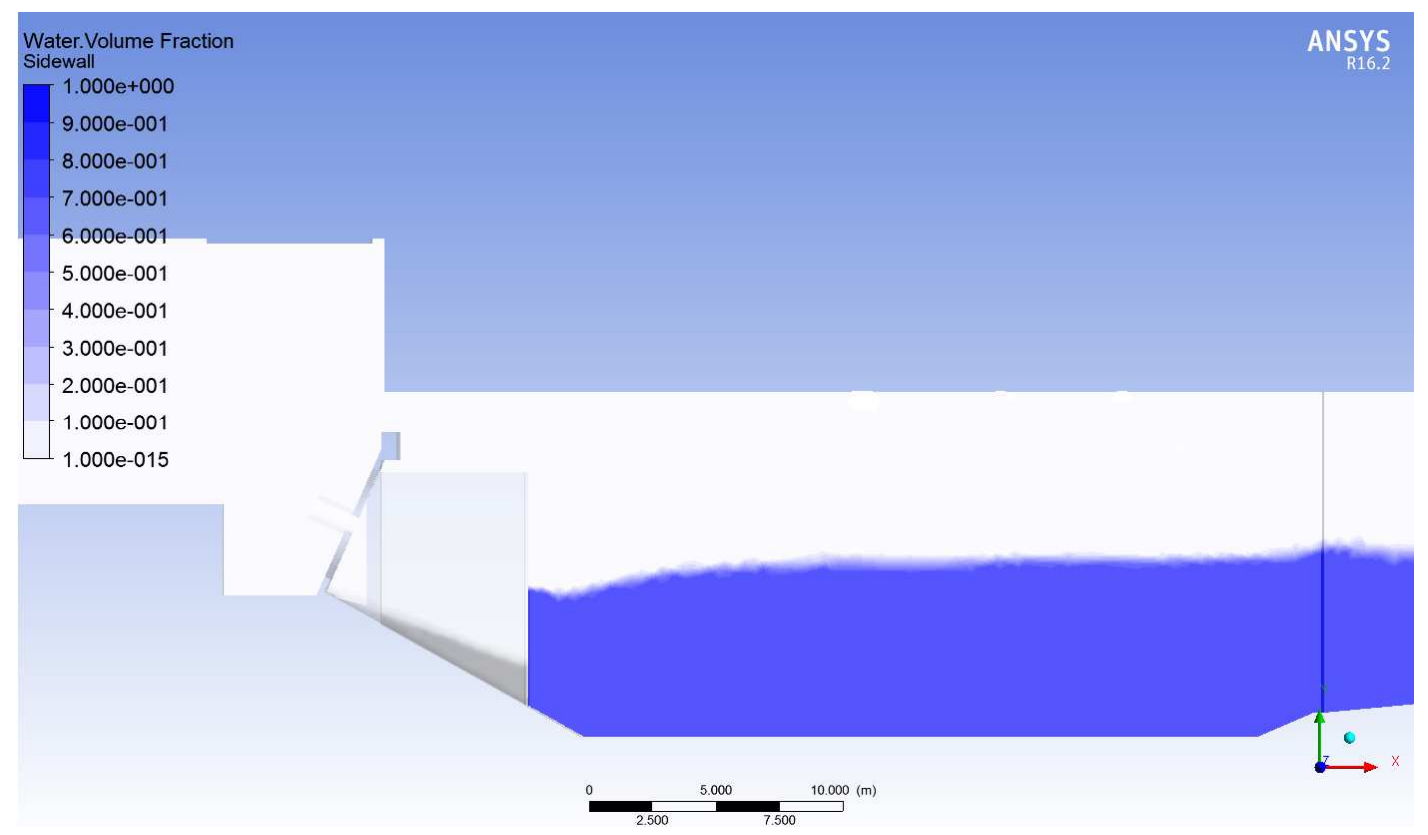

Figura 43. Perfil de linha d'água na parede lateral, 1 válvula a $68,00 \mathrm{~m} 3 / \mathrm{s}$ 
A figura 44 mostra o perfil de linha de água no final da câmara dissipadora, visto de jusante para montante. Neste gráfico pode-se notar a assimetria de fração de volume devido à operação de somente uma válvula.

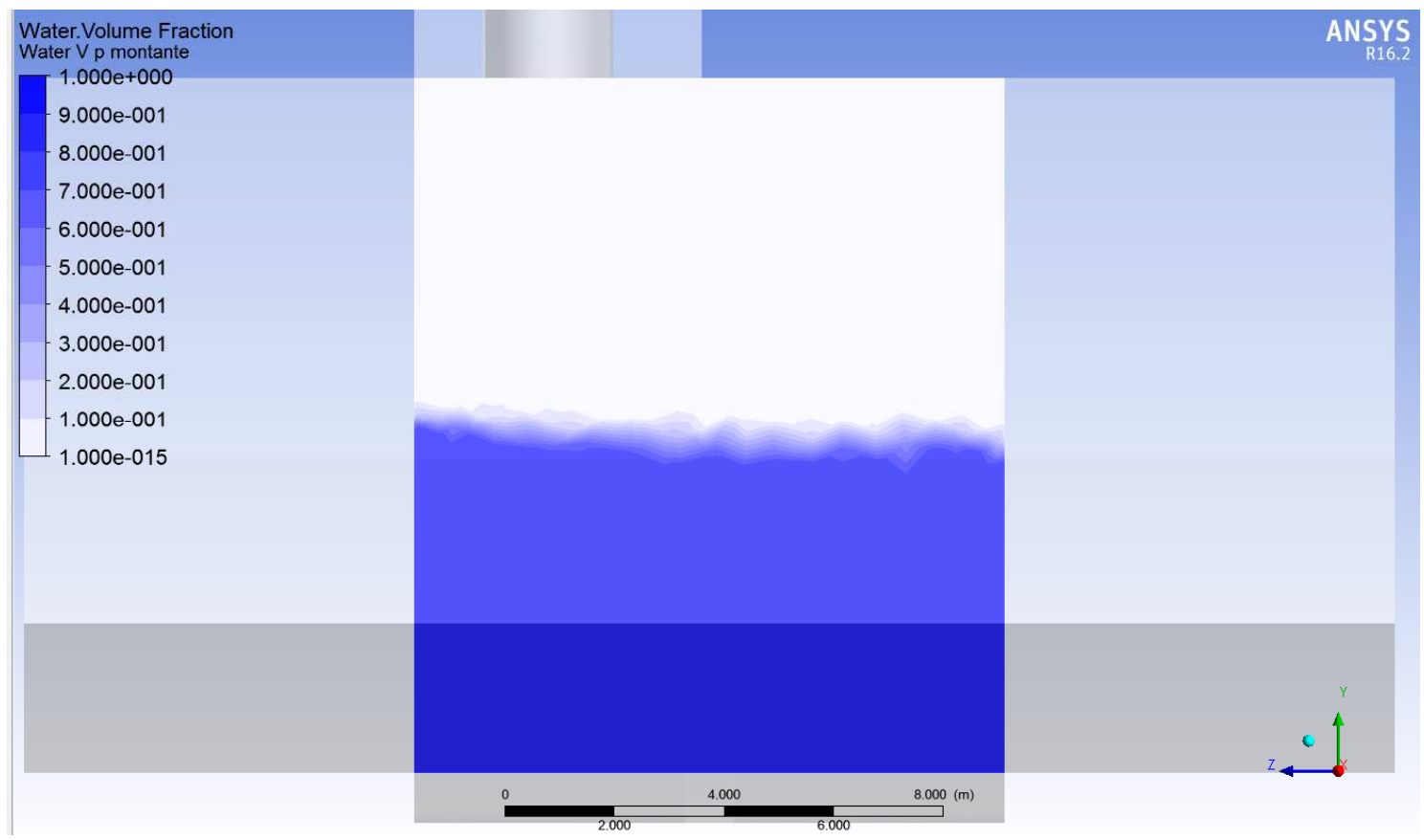

Figura 44. Perfil de linha d'água no final da câmara dissipadora, 1 válvula a 68,00 m³

Na sequência, a figura 45 mostra o perfil de linha de água no final da parede divisória, visto de jusante para montante.

Ainda que o nível de água seja mais alto na região da válvula que está operando, nota-se um pequeno decréscimo de nível de água na região da linha de centro da válvula, provocado pelo fluxo de água da válvula que empurra o nível da superfície de água. 


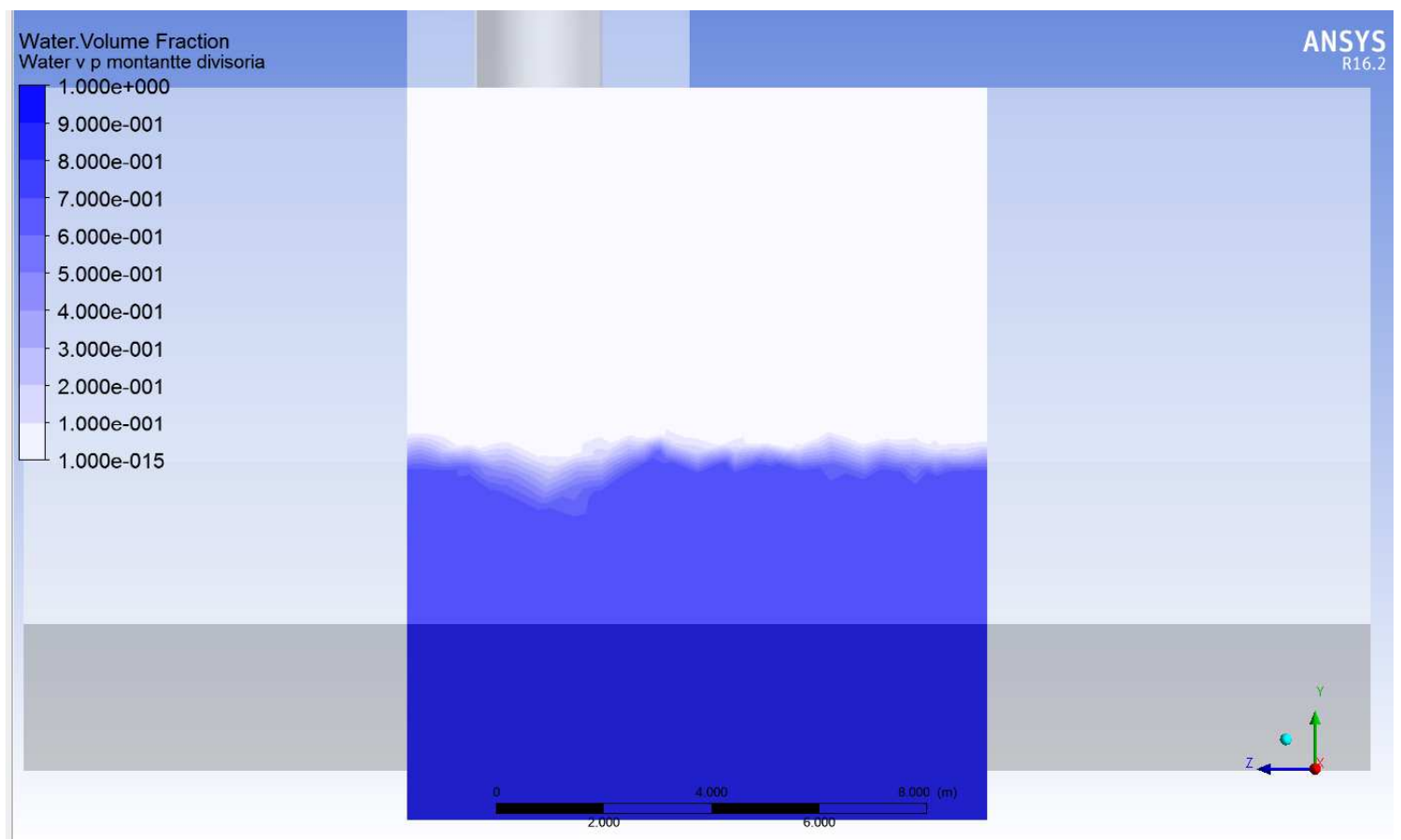

Figura 45. Perfil de linha d'água no final da parede divisória, 1 válvula a $68,00 \mathrm{~m} / \mathrm{s}$

A comparação entre os valores medidos no protótipo e os calculados por $C F D$ dos últimos três gráficos é mostrada nos gráficos 46,47 e 48 .

A figura 46 mostra a diferença encontrada de formato do perfil de água longitudinal ao longo da câmara dissipadora.

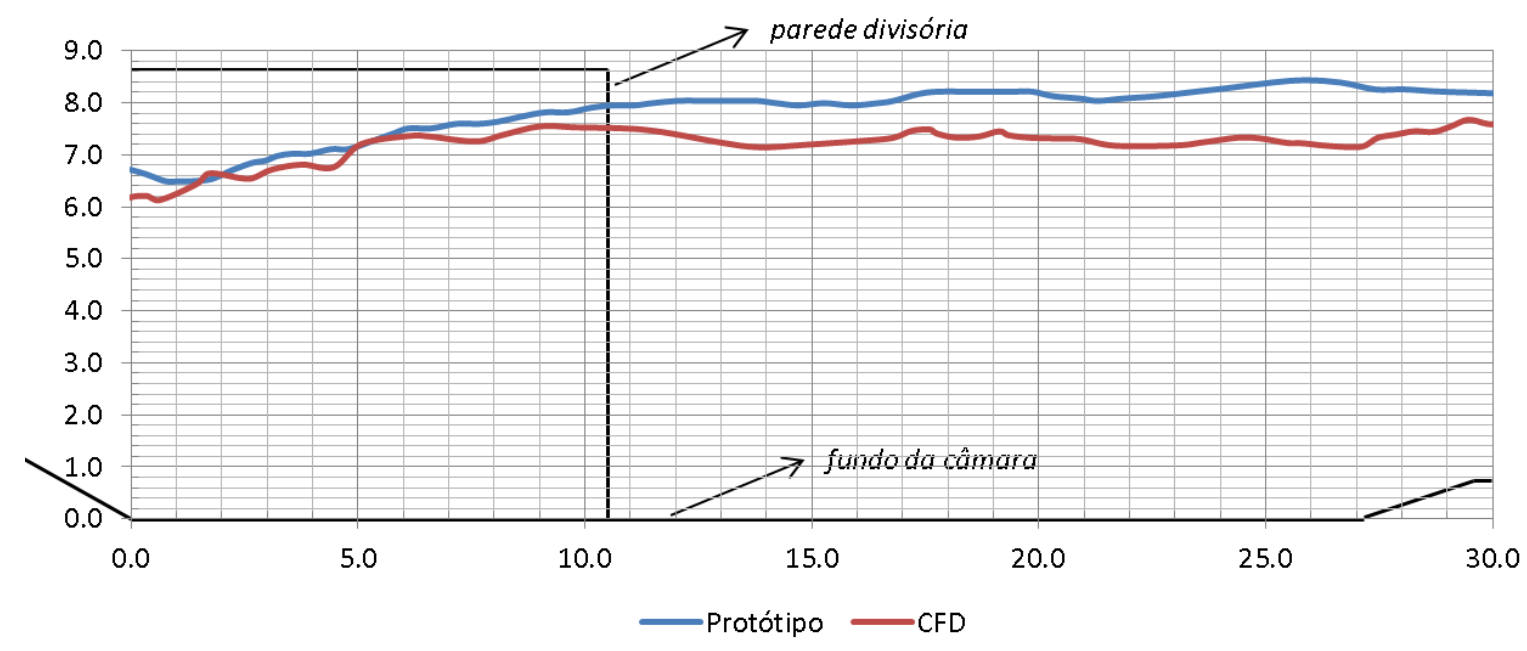

Figura 46. Comparação de perfil de linha d'água na parede lateral, 1 válvula a 68,0 $\mathrm{m}^{3} / \mathrm{s}$ 
Nas figuras 47 e 48 é possível notar a comparação entre os ressaltos hidráulicos de protótipo e $C F D$ no final da bacia dissipadora e final da parede divisória, vistos de jusante para montante.

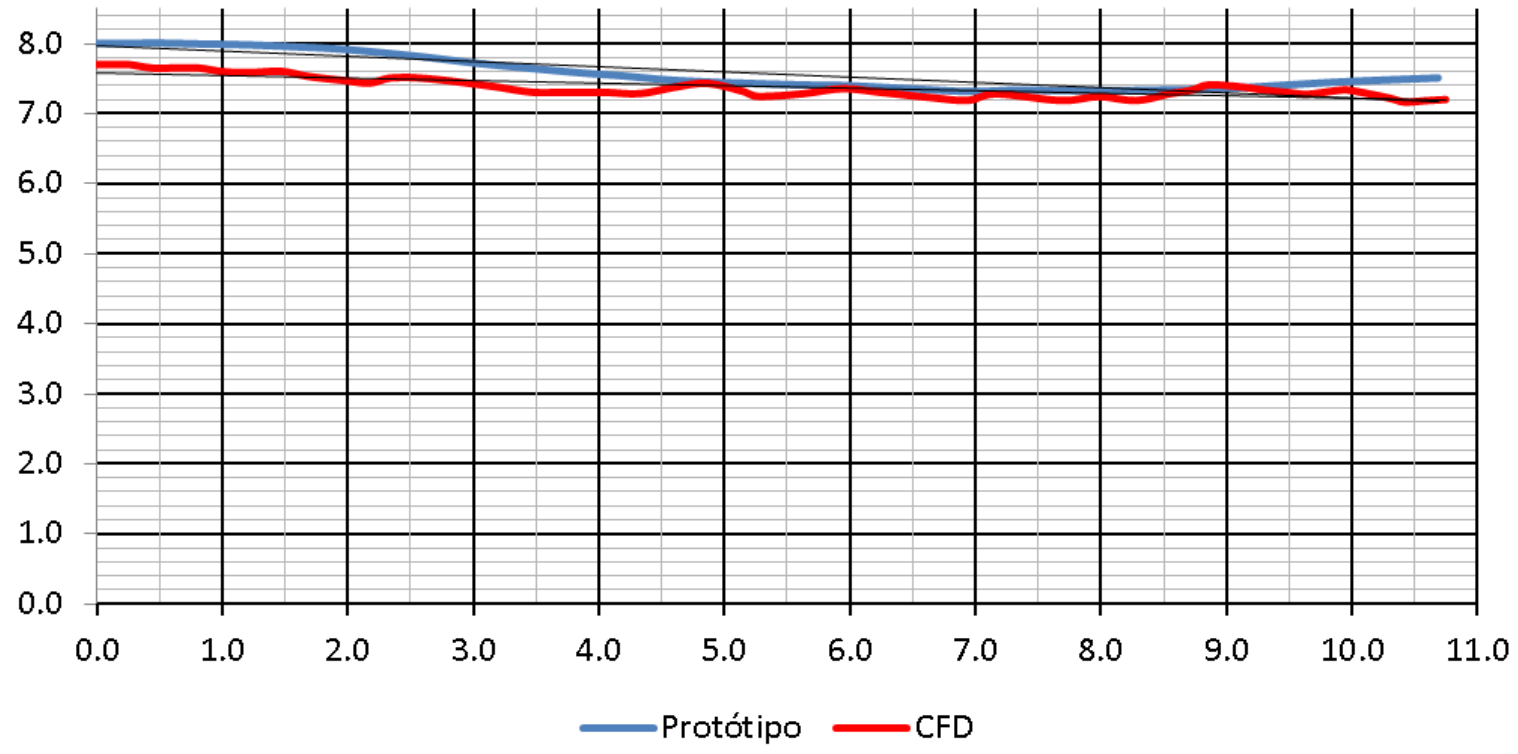

Figura 47. Comparação de perfil de linha d'água no final da câmara dissipadora, 1 válvula a $68,00 \mathrm{~m}^{3} / \mathrm{s}$

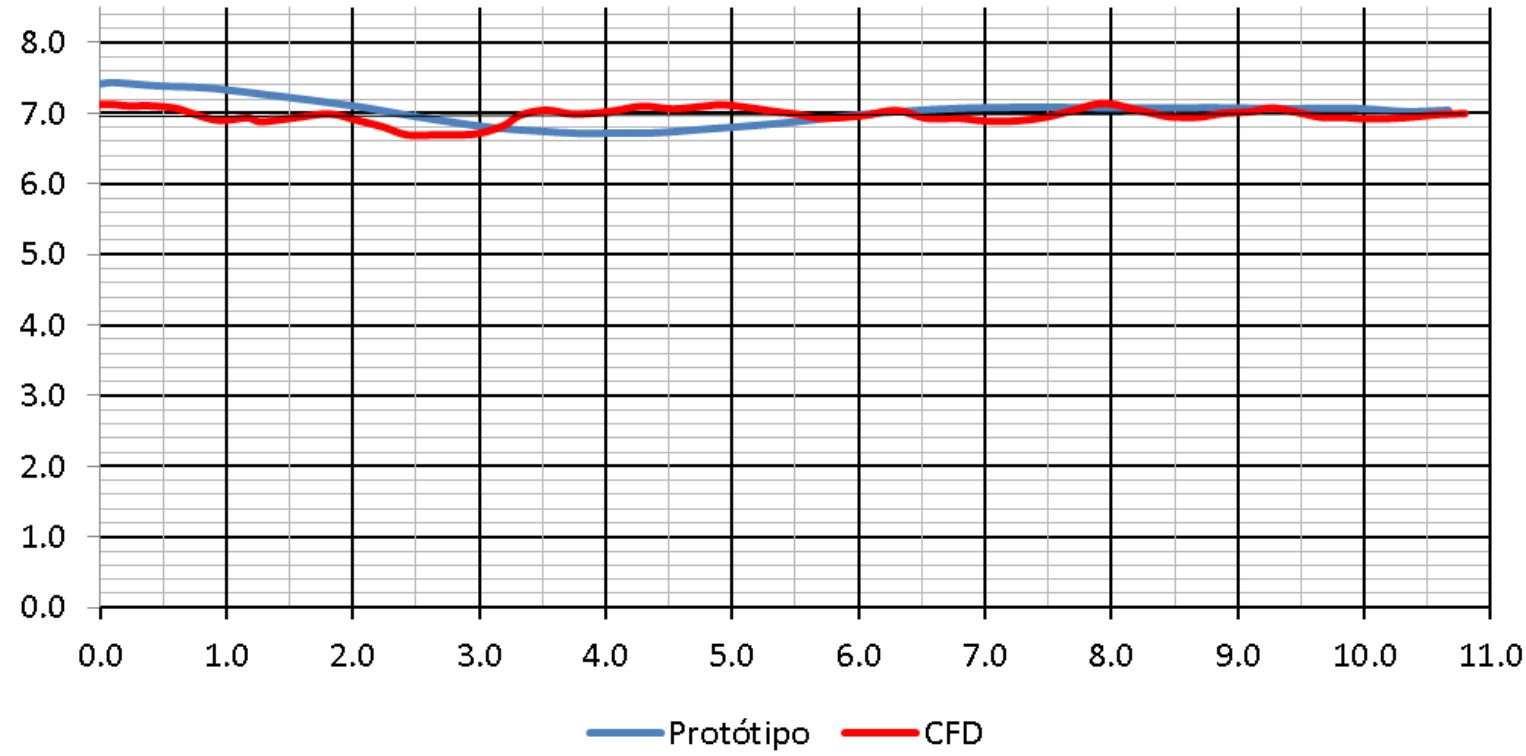

Figura 48. Comparação de perfil de linha d'água no final da parede divisória, 1 válvula a $68,00 \mathrm{~m}^{3} / \mathrm{s}$ 


\subsubsection{Pressão no Fundo da Câmara Dissipadora}

Conforme mostrado nas figuras 21 e 22 a pressão no fundo da câmara de dissipação é medida na região atingida pelo jato proveniente da válvula dispersora.

Nas figuras de 49 a 57, são mostrados os resultados em CFD para as linhas de piezômetros 1, 2 e 3, seguidas pela linha de piezômetros 4,5 e 6 e finalmente a linha 7, 8 e 9, considerando a operação de duas válvulas a 64,76 m³/s cada, seguidas da operação de duas válvulas a 45,45 $\mathrm{m}^{3} / \mathrm{s}$ cada e, finalmente, somente uma válvula operando a $68 \mathrm{~m}^{3} / \mathrm{s}$.

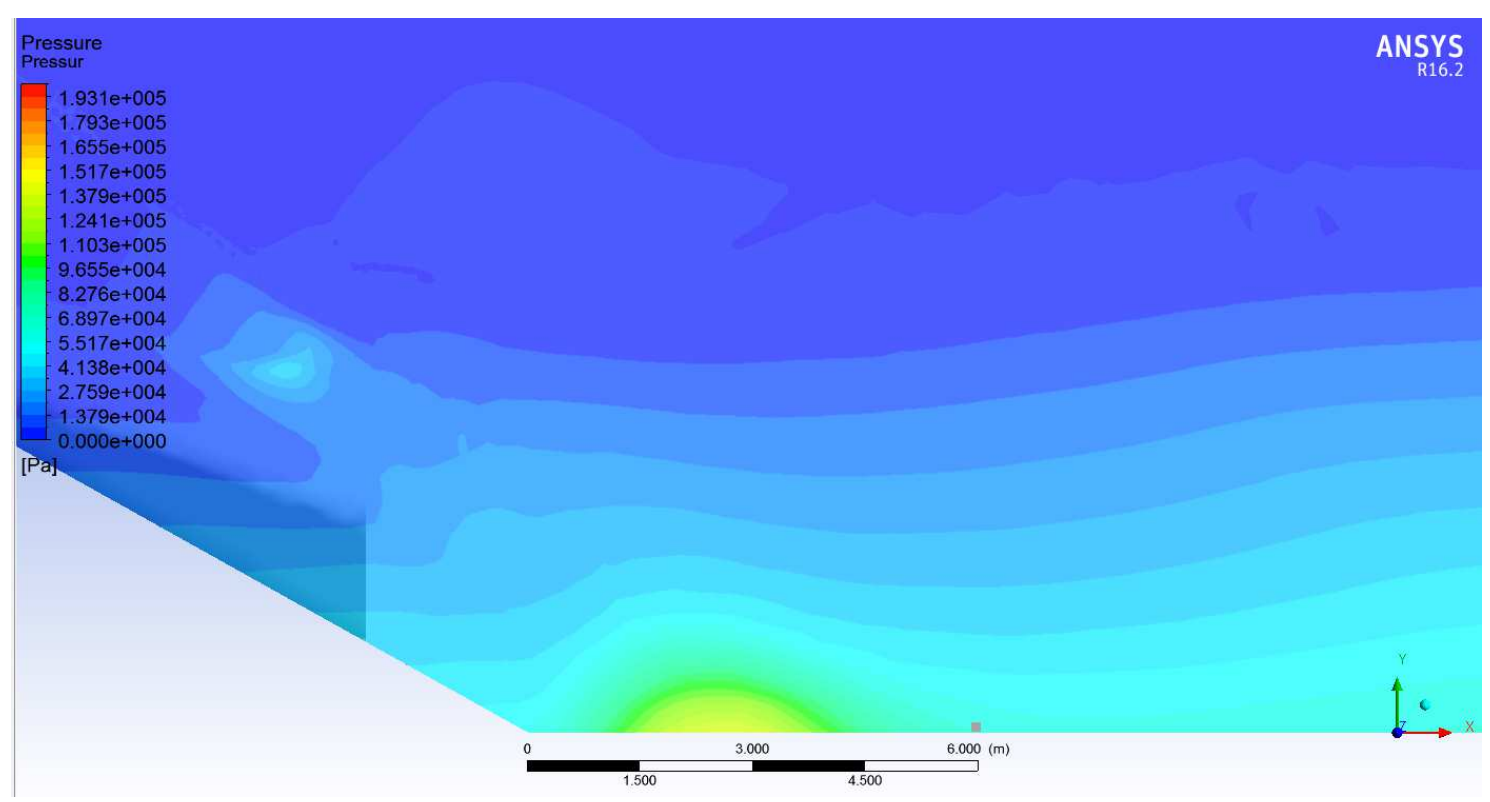

Figura 49. Pressão no fundo da câmara para linha dos piezômetros 1, 2 e 3, para 2 válvulas

$$
\text { a } 64,76 \mathrm{~m}^{3} / \mathrm{s}
$$




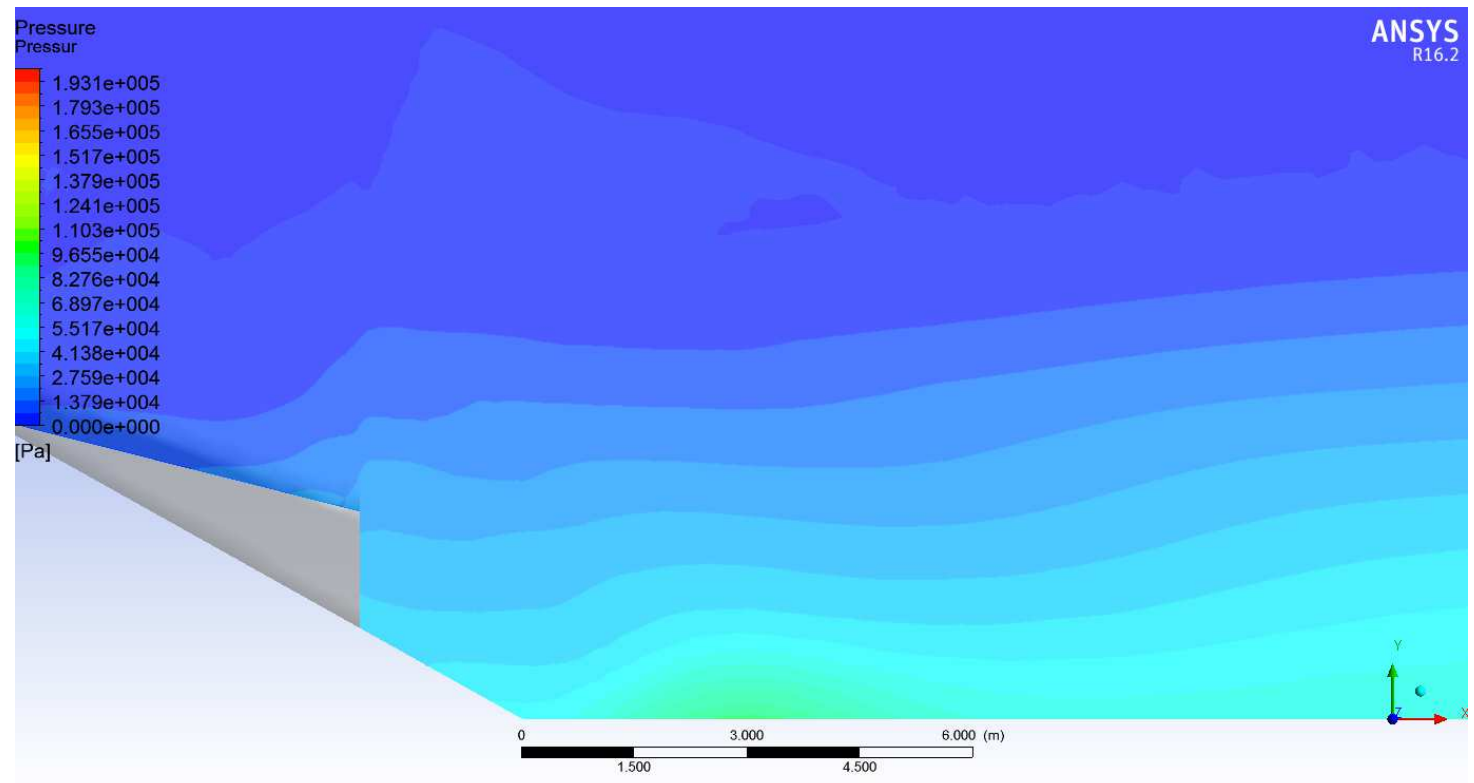

Figura 50. Pressão no fundo da câmara para linha dos piezômetros 4, 5 e 6, para 2 válvulas a $64,76 \mathrm{~m}^{3} / \mathrm{s}$

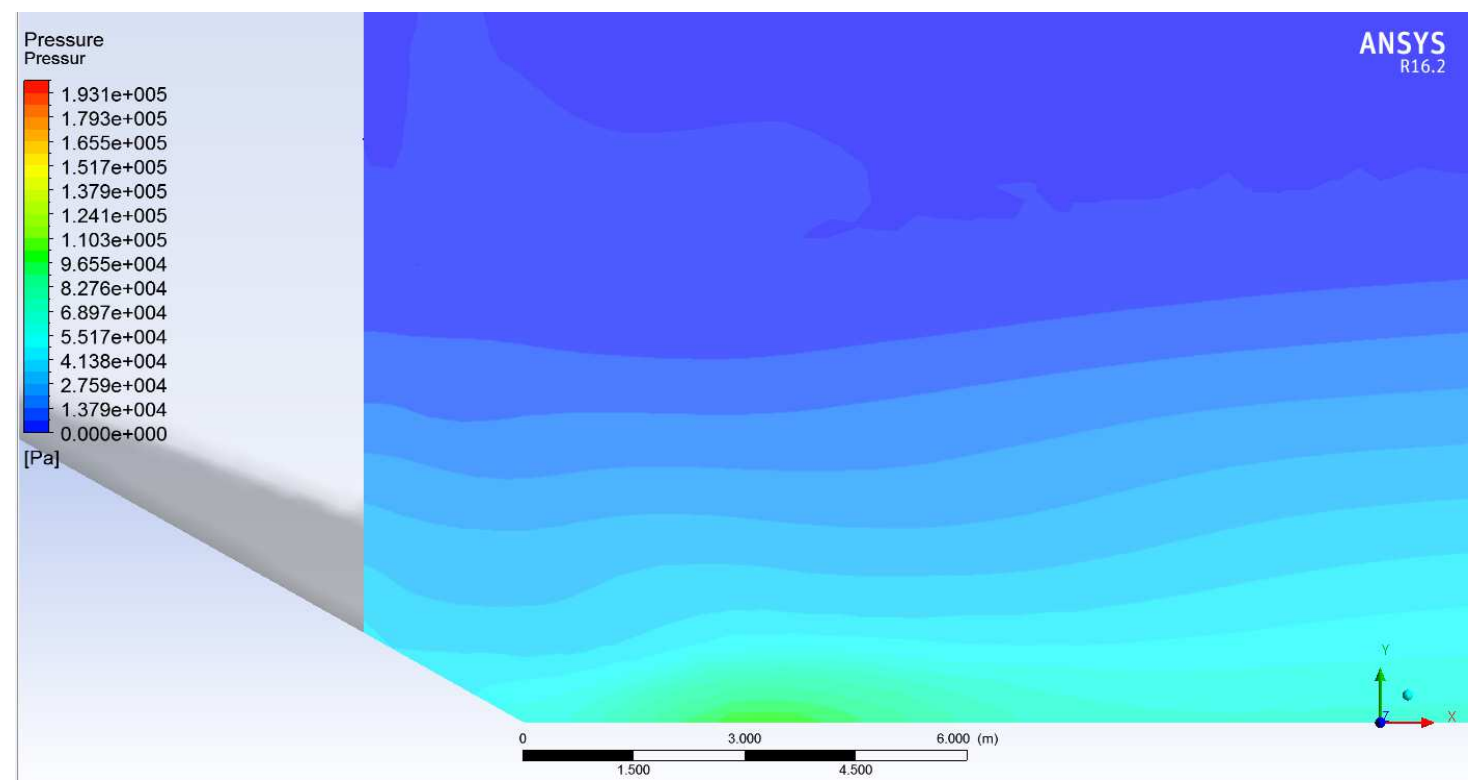

Figura 51. Pressão no fundo da câmara para linha dos piezômetros 7, 8 e 9, para 2 válvulas a $64,76 \mathrm{~m}^{3} / \mathrm{s}$ 


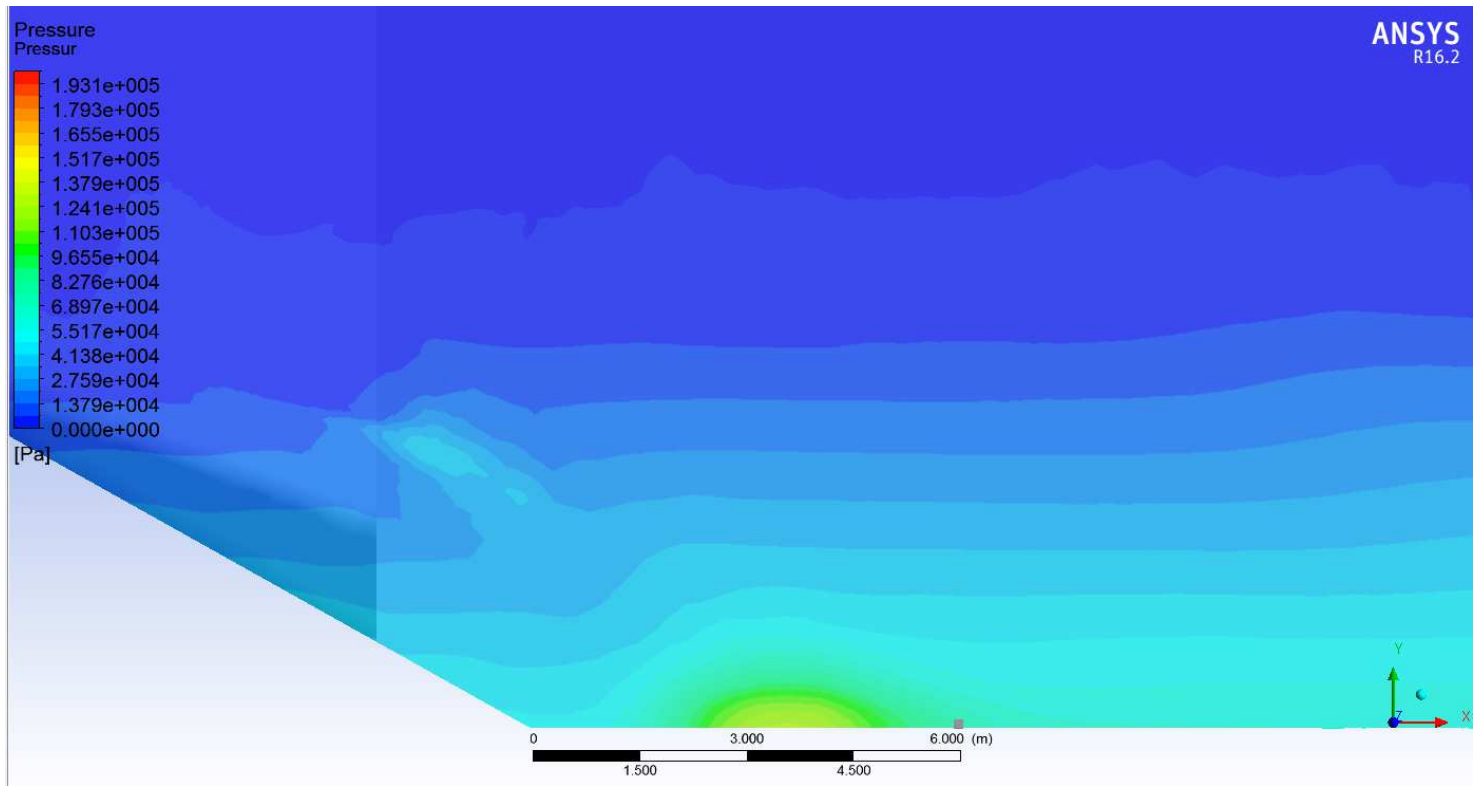

Figura 52. Pressão no fundo da câmara para linha dos piezômetros 1, 2 e 3, para 2 válvulas a $45,45 \mathrm{~m}^{3} / \mathrm{s}$

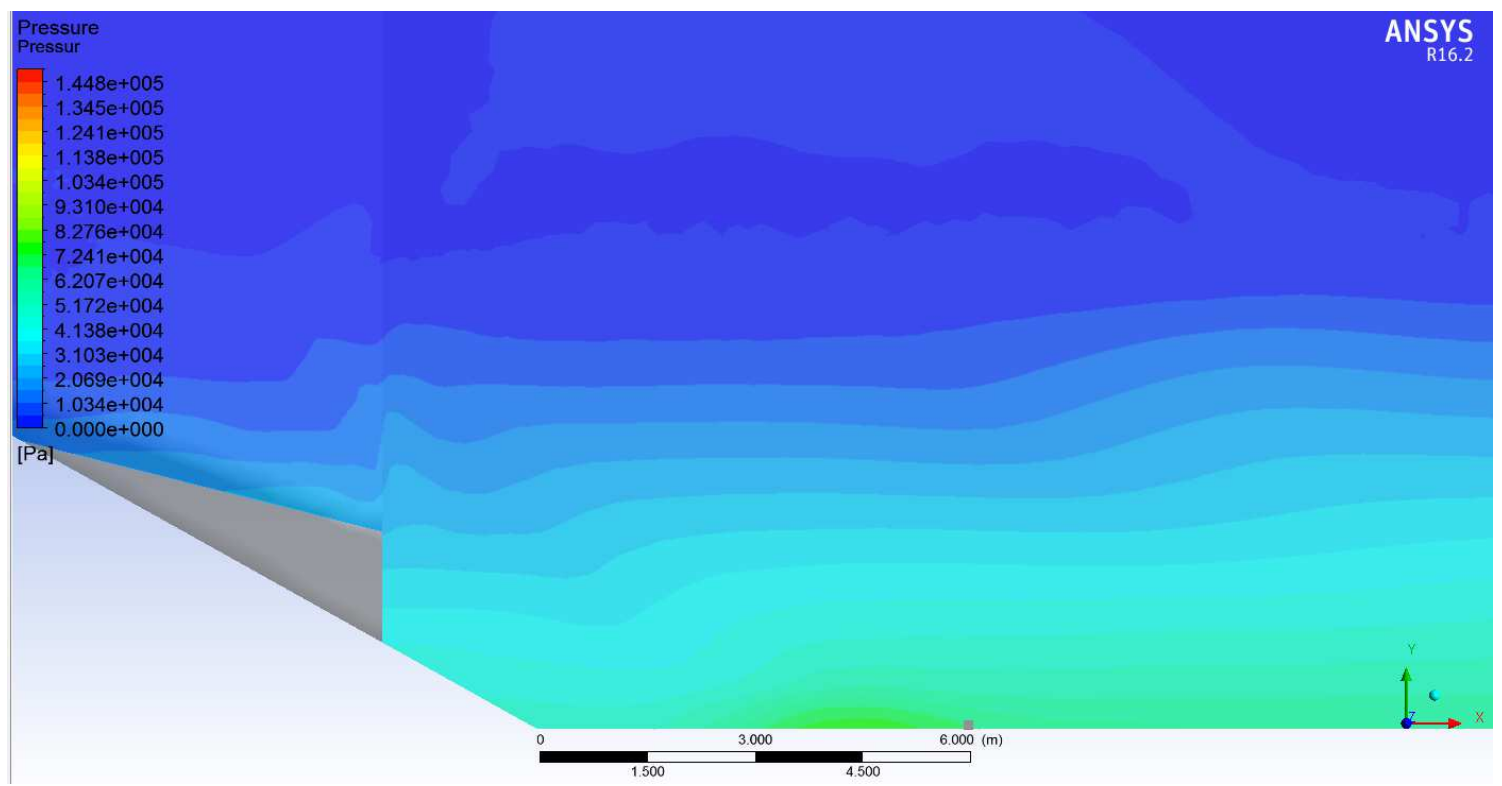

Figura 53. Pressão no fundo da câmara para linha dos piezômetros 4, 5 e 6, para 2 válvulas a $45,45 \mathrm{~m}^{3} / \mathrm{s}$ 


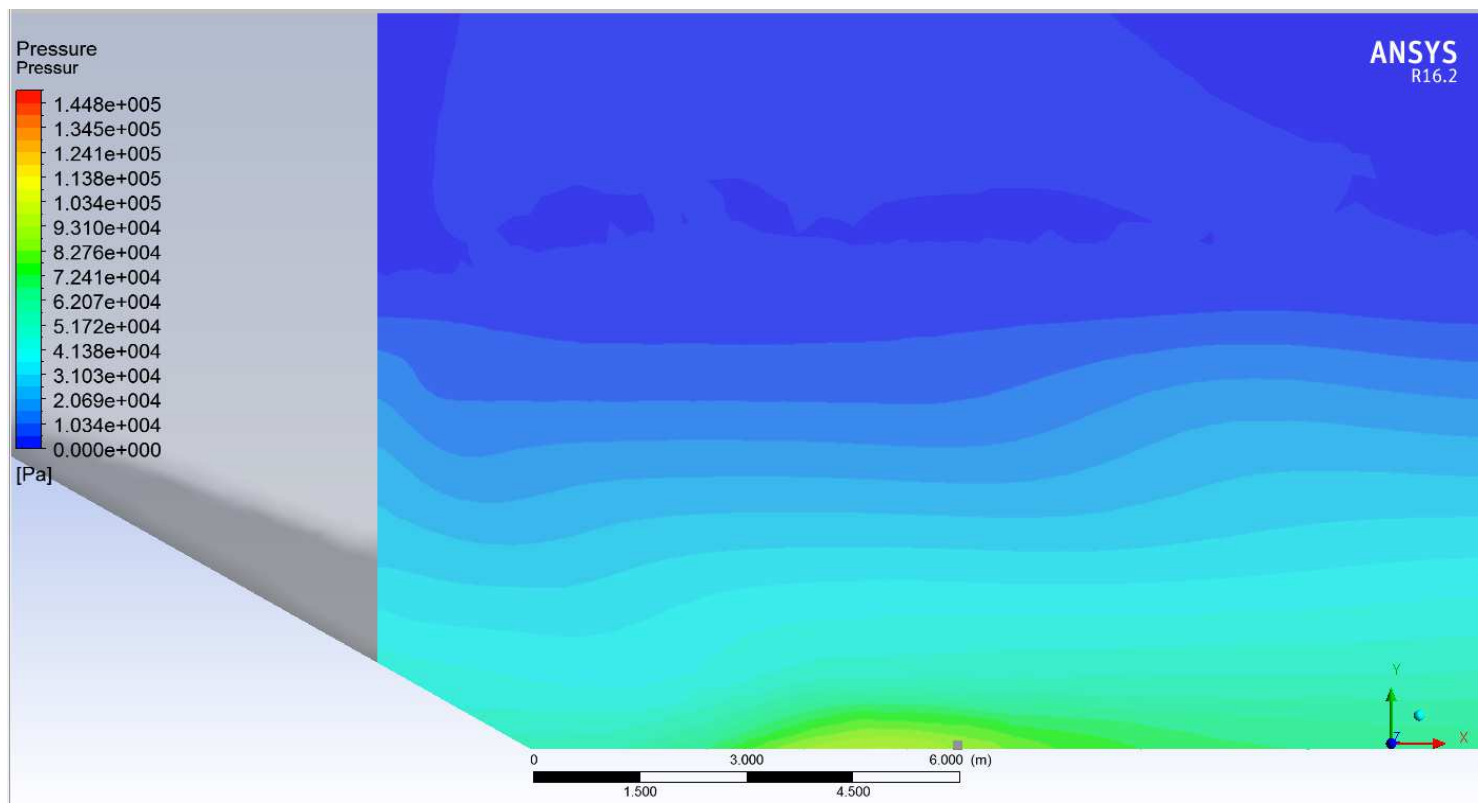

Figura 54. Pressão no fundo da câmara para linha dos piezômetros 7, 8 e 9, para 2 válvulas a $45,45 \mathrm{~m}^{3} / \mathrm{s}$

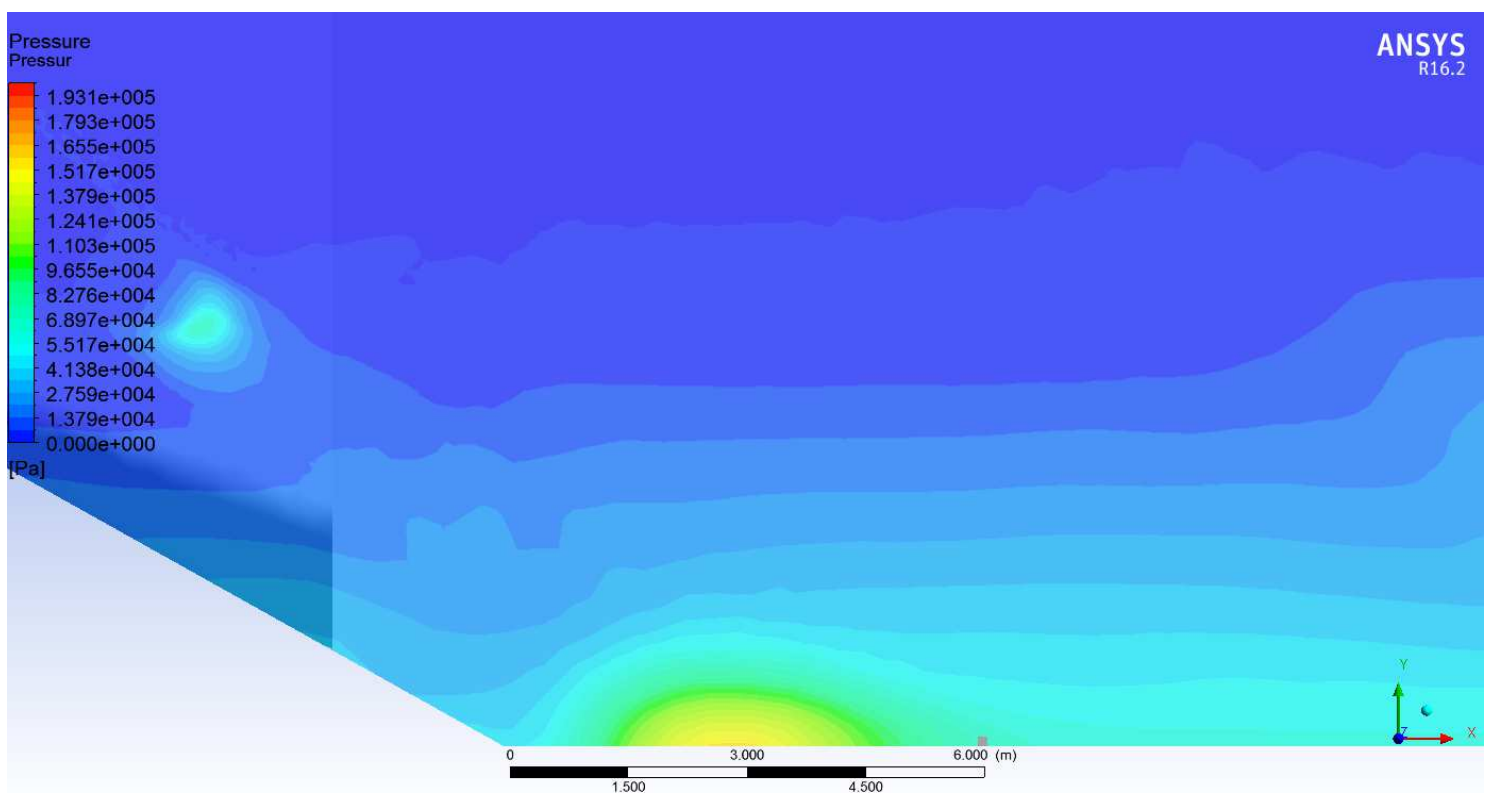

Figura 55. Pressão no fundo da câmara para linha dos piezômetros 1, 2 e 3, para 1 válvula a $68 \mathrm{~m}^{3} / \mathrm{s}$ 


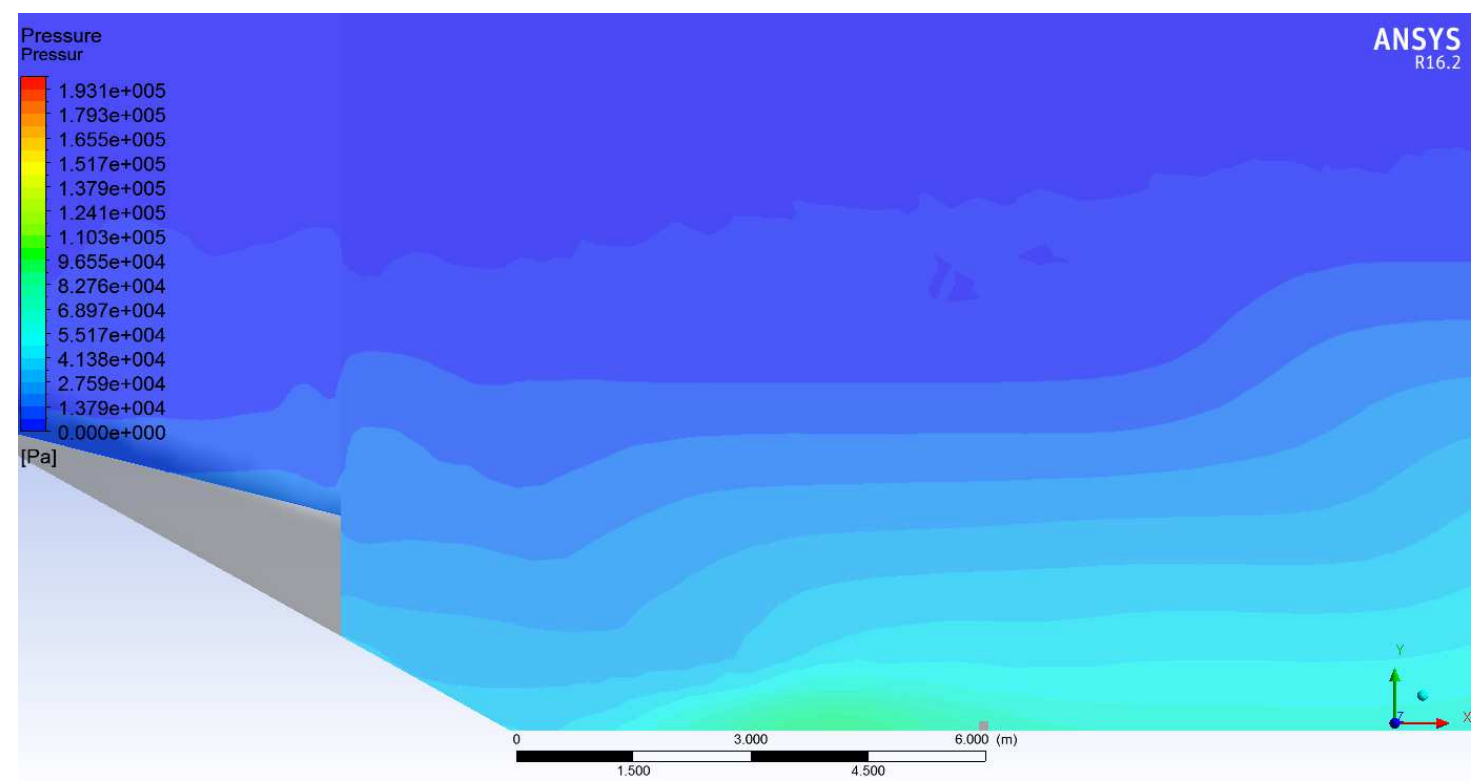

Figura 56. Pressão no fundo da câmara para linha dos piezômetros 4, 5 e 6, para 1 válvula a $68 \mathrm{~m}^{3} / \mathrm{s}$

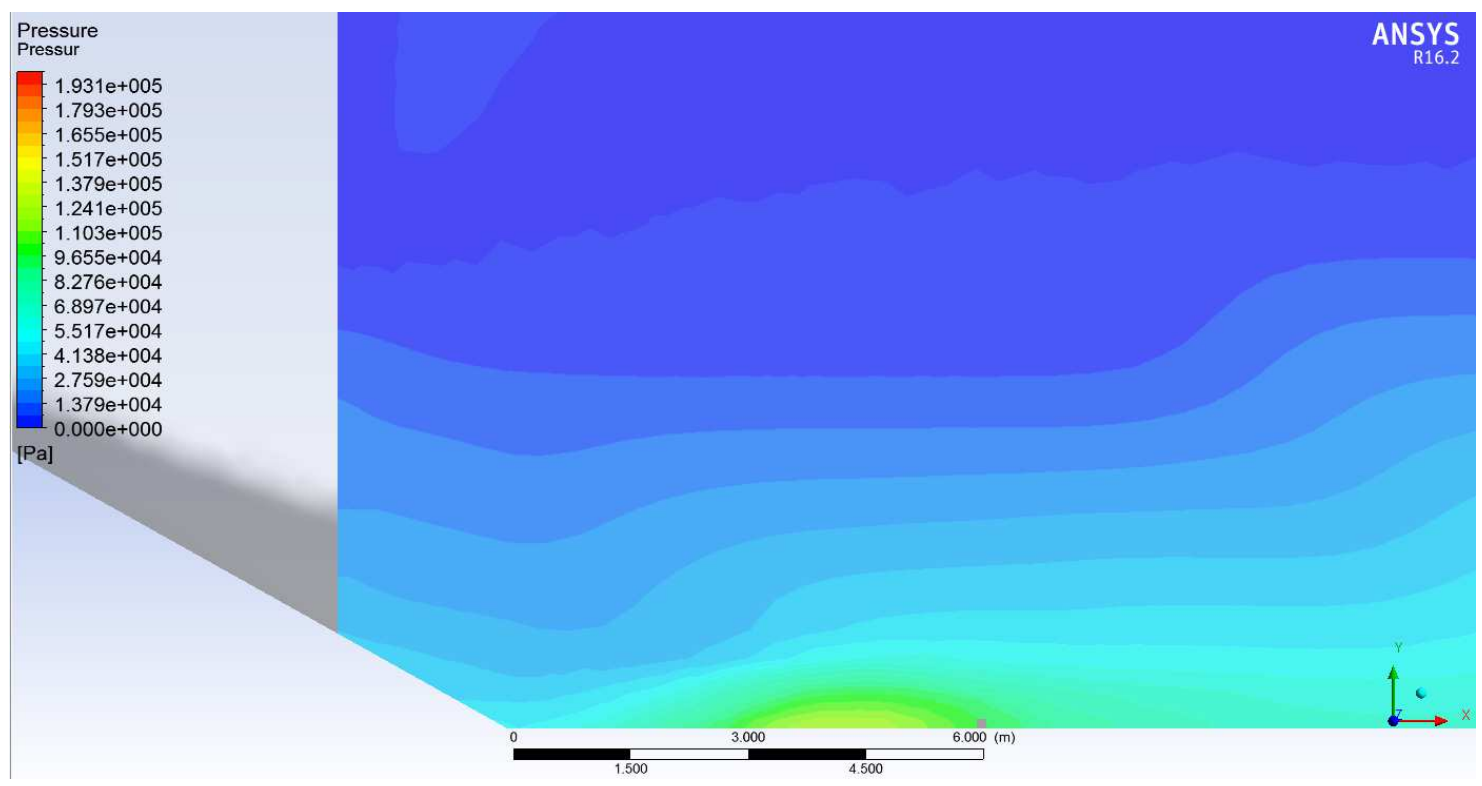

Figura 57. Pressão no fundo da câmara para linha dos piezômetros 7, 8 e 9, para 1 válvula a $68 \mathrm{~m}^{3} / \mathrm{s}$ 
Apesar de algumas diferenças de valores de carga de pressão encontrados por $C F D$, todos os perfis de pressão seguem um padrão para os piezômetros de 1 a 9 , que possuem suas localizações mostradas na figura 21 .

A comparação dos resultados obtidos por $C F D$ e os ensaios realizados em protótipo, são mostrados na tabela 8 .

Tabela 8. Cargas de pressão para os piezômetros de 1 a 9, obtidos por CFD para $H / d=11,2$

\begin{tabular}{|c|c|c|c|c|c|c|c|c|c|}
\hline & \multicolumn{3}{|c|}{2 válvulas a $64.76 \mathrm{~m}^{3} / \mathrm{s}$} & \multicolumn{3}{|c|}{2 válvulas a $45.45 \mathrm{~m}^{3} / \mathrm{s}$} & \multicolumn{3}{|c|}{1 válvula a 68 m/s } \\
\hline & $\begin{array}{c}\text { Protótipo } \\
\text { (mca) }\end{array}$ & $\begin{array}{l}\text { CFD } \\
\text { (mca) }\end{array}$ & $\begin{array}{c}\text { Diferença } \\
\text { (mca) }\end{array}$ & $\begin{array}{c}\text { Protótipo } \\
\text { (mca) }\end{array}$ & $\begin{array}{l}\begin{array}{c}\text { CFD } \\
\text { (mca) }\end{array} \\
\end{array}$ & $\begin{array}{c}\text { Diferença } \\
\text { (mca) }\end{array}$ & $\begin{array}{c}\text { Protótipo } \\
\text { (mca) }\end{array}$ & $\begin{array}{l}\begin{array}{c}\text { CFD } \\
\text { (mca) }\end{array} \\
\end{array}$ & $\begin{array}{c}\text { Diferença } \\
\text { (mca) }\end{array}$ \\
\hline Piezo 1 & 4.16 & 6.01 & 1.85 & 5.83 & 5.18 & -0.65 & 4.42 & 4.81 & 0.39 \\
\hline Piezo 2 & 9.30 & 13.77 & 4.47 & 7.90 & 10.08 & 2.19 & 10.57 & 15.19 & 4.61 \\
\hline Piezo 3 & 5.84 & 6.25 & 0.40 & 6.46 & 7.61 & 1.15 & 6.32 & 6.97 & 0.65 \\
\hline Piezo 4 & 4.81 & 5.27 & 0.46 & 6.17 & 5.19 & -0.98 & 4.90 & 4.23 & -0.67 \\
\hline Piezo 5 & 10.58 & 8.90 & -1.68 & 7.85 & 5.86 & -1.99 & 10.06 & 9.20 & -0.86 \\
\hline Piezo 6 & 6.47 & 6.24 & -0.23 & 6.88 & 6.87 & -0.01 & 7.26 & 7.00 & -0.26 \\
\hline Piezo 7 & 5.36 & 5.99 & 0.63 & 6.53 & 5.50 & -1.03 & 5.43 & 4.92 & -0.51 \\
\hline Piezo 8 & 9.08 & 9.49 & 0.41 & 7.70 & 6.73 & -0.97 & 8.66 & 9.18 & 0.51 \\
\hline Piezo 9 & 7.22 & 7.57 & 0.35 & 7.36 & 8.86 & 1.50 & 7.77 & 8.97 & 1.20 \\
\hline
\end{tabular}

Em geral, os resultados obtidos por $C F D$ apresentam valores mais altos que os obtidos em protótipo, o que caracteriza uma previsão mais crítica dos esforços atuantes no fundo da câmara dissipadora. Desta forma, ainda que haja diferenças consideráveis para o piezômetro 2, os valores encontrados por $C F D$ podem ser considerados adequados no que se refere a determinação de parâmetros de projeto da câmara dissipadora.

\subsubsection{Análise e Cálculo de Eficiência de Dissipação de Energia}

A tabela 9 mostra o resumo de dissipação de energia entre a entrada da válvula e o final da câmara de dissipação.

Os parâmetros utilizados na análise de dissipação de energia contemplam o número de válvulas em operação, as aberturas das válvulas com suas respectivas vazões, a espessura do 
jato e sua velocidade, a velocidade média da água na seção de saída da válvula, a velocidade final na saída da câmara de dissipação, a perda de carga da válvula, a perda de carga da câmara de dissipação e suas contribuições de dissipação em relação ao total de energia.

Tabela 9. Análise de Dissipação de Energia, obtido por CFD para $H / d=11,2$

\begin{tabular}{|c|c|c|c|c|c|c|c|c|c|c|c|c|c|}
\hline $\begin{array}{c}\text { Número } \\
\text { de } \\
\text { válvulas }\end{array}$ & $\begin{array}{c}\text { Abertura } \\
(\%)\end{array}$ & $\begin{array}{c}\mathrm{Q} \\
\text { válvula } \\
(\mathrm{m} / \mathrm{s})\end{array}$ & $\mathrm{H} / \mathrm{d}$ & $\begin{array}{c}\mathrm{b} \\
(\mathrm{m})\end{array}$ & $\begin{array}{c}\mathrm{v} \text { jato } \\
(\mathrm{m} / \mathrm{s})\end{array}$ & $\begin{array}{c}\text { v saída } \\
\text { válvula } \\
(\mathrm{m} / \mathrm{s})\end{array}$ & $\begin{array}{c}\text { v final } \\
\text { câmara } \\
(\mathrm{m} / \mathrm{s})\end{array}$ & $\begin{array}{c}\text { Hp } \\
\text { válvula } \\
(\mathrm{m})\end{array}$ & $\begin{array}{c}\text { Hp } \\
\text { câmara } \\
(\mathrm{m})\end{array}$ & $\begin{array}{c}\text { Hp } \\
\text { total } \\
(\mathrm{m})\end{array}$ & $\begin{array}{c}\text { Hp } \\
\text { válvula } \\
\text { /H }(\%)\end{array}$ & $\begin{array}{c}\text { Hp } \\
\text { câmara } \\
\text { /H }(\%)\end{array}$ \\
\hline 2 & 100 & 64.8 & 11.0 & 0.29 & 21.66 & 13.56 & 1.66 & 15.9 & 9.2 & 25.1 & 62.8 & 36.6 & 99.4 \\
\hline 2 & 95 & 62.3 & 11.1 & 0.28 & 21.87 & 15.20 & 1.60 & 13.7 & 11.7 & 25.4 & 53.7 & 45.7 & 99.4 \\
\hline 2 & 90 & 59.7 & 10.9 & 0.26 & 21.64 & 15.47 & 1.54 & 12.8 & 12.1 & 24.9 & 51.2 & 48.4 & 99.6 \\
\hline 2 & 85 & 57.1 & 10.1 & 0.27 & 19.64 & 14.22 & 1.48 & 12.8 & 10.2 & 23.0 & 55.4 & 44.1 & 99.5 \\
\hline 2 & 80 & 54.3 & 11.6 & 0.23 & 22.20 & 15.40 & 1.37 & 14.5 & 12.0 & 26.5 & 54.5 & 45.2 & 99.7 \\
\hline 2 & 75 & 51.5 & 11.2 & 0.23 & 21.64 & 14.72 & 1.33 & 14.4 & 11.0 & 25.4 & 56.6 & 43.0 & 99.6 \\
\hline 2 & 63 & 45.45 & 12.7 & 0.19 & 23.01 & 13.87 & 1.10 & 19.3 & 9.8 & 29.0 & 66.3 & 33.5 & 99.8 \\
\hline 2 & 50 & 36.25 & 11.0 & 0.17 & 21.04 & 11.63 & 0.97 & 18.3 & 6.9 & 25.2 & 72.6 & 27.2 & 99.8 \\
\hline 2 & 25 & 18.9 & 11.5 & 0.08 & 20.63 & 11.17 & 0.57 & 19.9 & 6.3 & 26.3 & 75.8 & 24.2 & $\sim 100.0$ \\
\hline 2 & 10 & 7.51 & 10.2 & 0.04 & 18.20 & 9.90 & 0.33 & 18.4 & 5.0 & 23.4 & 78.6 & 21.4 & $\sim 100.0$ \\
\hline 1 & 100 & 64.8 & 10.6 & 0.30 & 21.13 & 14.30 & 0.94 & 13.76 & 10.39 & 24.15 & 56.9 & 42.94 & 99.8 \\
\hline 1 & 50 & 36.25 & 10.9 & 0.17 & 21.17 & 12.38 & 0.53 & 17.20 & 7.81 & 25.01 & 68.7 & 31.19 & 99.9 \\
\hline
\end{tabular}

Pode-se observar que as relações entre perda de carga na câmara dissipadora e a perda total entre a entrada da válvula e câmara dissipadora são praticamente mantidas quando comparamos uma ou duas válvulas operando à mesma abertura. Como consequência, a eficiência de dissipação de energia se apresenta praticamente constante, em torno de $99 \%$.

A razão dos diversos pontos aplicados às duas válvulas em operação vem do aproveitamento das simulações utilizadas para levantamento das características da válvula, apresentadas anteriormente. 


\subsubsection{Comentários}

Os resultados de operação da válvula e comportamento dos níveis de água obtidos através das simulações em $C F D$ se demonstraram coerentes quando comparados aos valores reais. Considera-se então o modelo de cálculo calibrado e com isso, novas análises de eficiência de dissipação de energia podem ser feitas para outras condições de operação da câmara dissipadora.

De forma análoga ao executado em Falcon Dam, as próximas simulações considerarão as aberturas de válvulas em $100 \%$ e 50\%, experimentado diferentes quedas líquidas, ou seja, diferentes razões $H / d$. Assim, considerando as aberturas acima indicadas, a maior queda líquida resulta em maior vazão volumétrica e vice-versa.

Em resumo, a análise de faixa operativa que sucederá contempla não somente variação de queda líquida, mas também a variação de vazão volumétrica.

\subsection{Simulações de Falcon Dam com $H / d=20$}

\subsubsection{Perfil de Linha de Nível na Bacia Dissipadora com duas Válvulas em Operação}

O perfil de água foi traçado considerando as válvulas operando a $100 \%$ de abertura e vazão de $86,85 \mathrm{~m}^{3} / \mathrm{s}$ cada uma e, também a $50 \%$ de abertura com $48,50 \mathrm{~m}^{3} / \mathrm{s}$ cada uma.

A relação $H / d=20$ resulta na queda líquida de 45,80 m. 


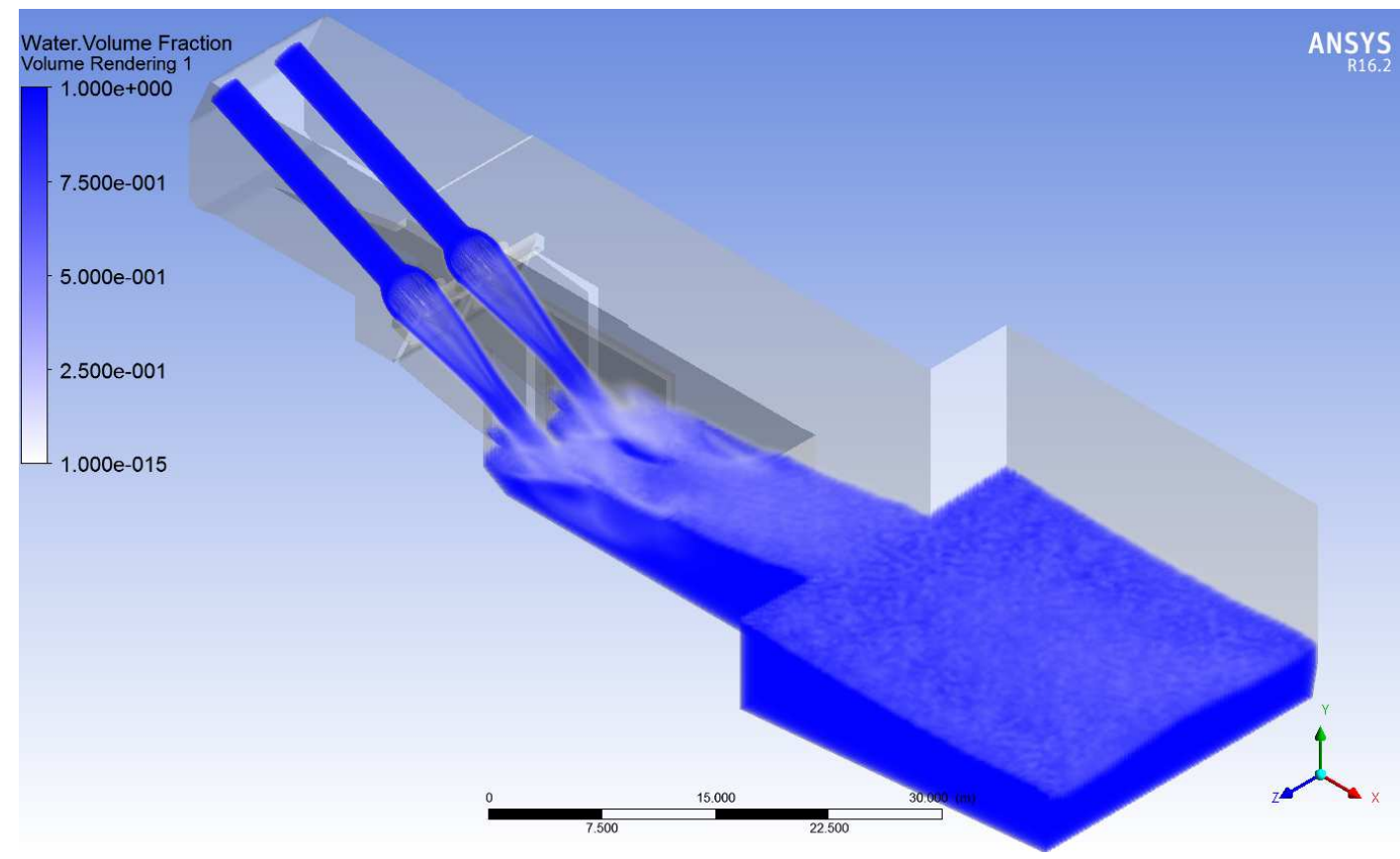

Figura 58. Vista isométrica: fração de volume da câmara, 2 válvulas a 86,85 $\mathrm{m}^{3} / \mathrm{s}$ cada

Em consequência da grande relação $H / d$, pode-se observar nas figuras de 59 a 62 que a vazão de $86,85 \mathrm{~m}^{3} / \mathrm{s}$ por válvula empurra a água para fora da câmara dissipadora, formando um ressalto hidráulico acentuado.

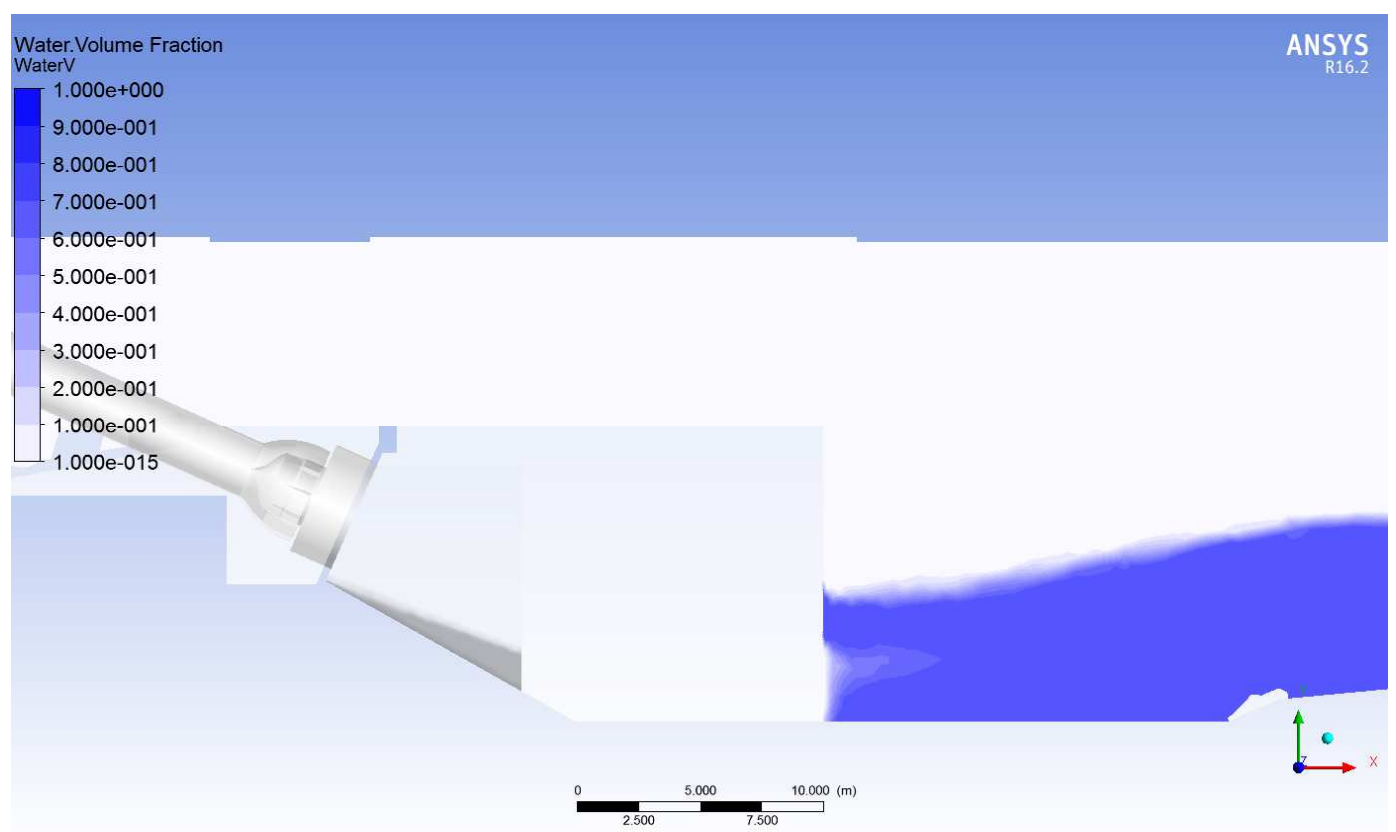

Figura 59. Perfil de linha d'água no eixo de simetria, 2 válvulas a $86,85 \mathrm{~m}^{3} / \mathrm{s}$ cada 


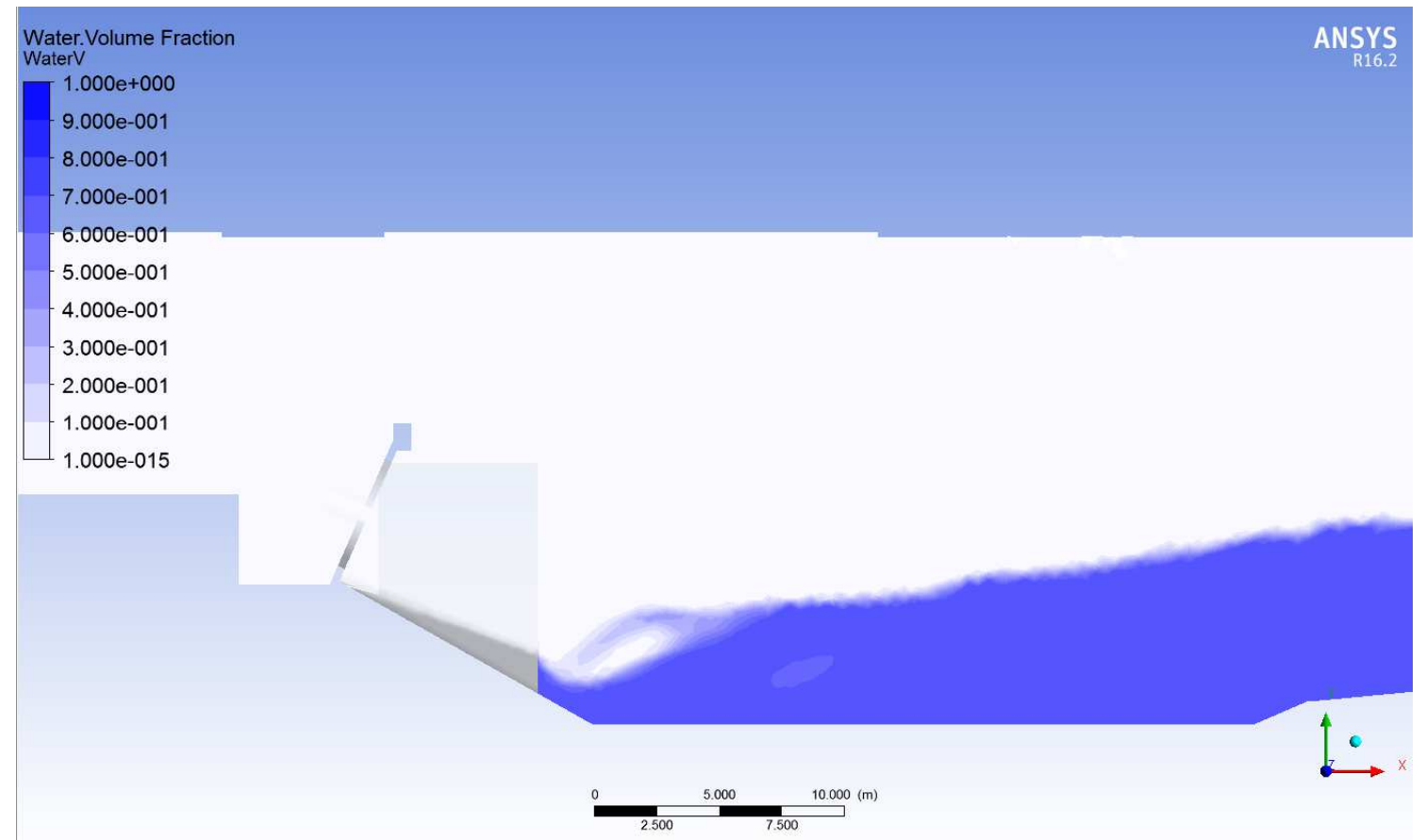

Figura 60. Perfil de linha d'água na parede lateral, 2 válvulas a 86,85 m³ cada

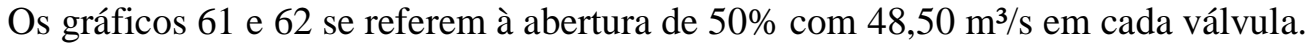

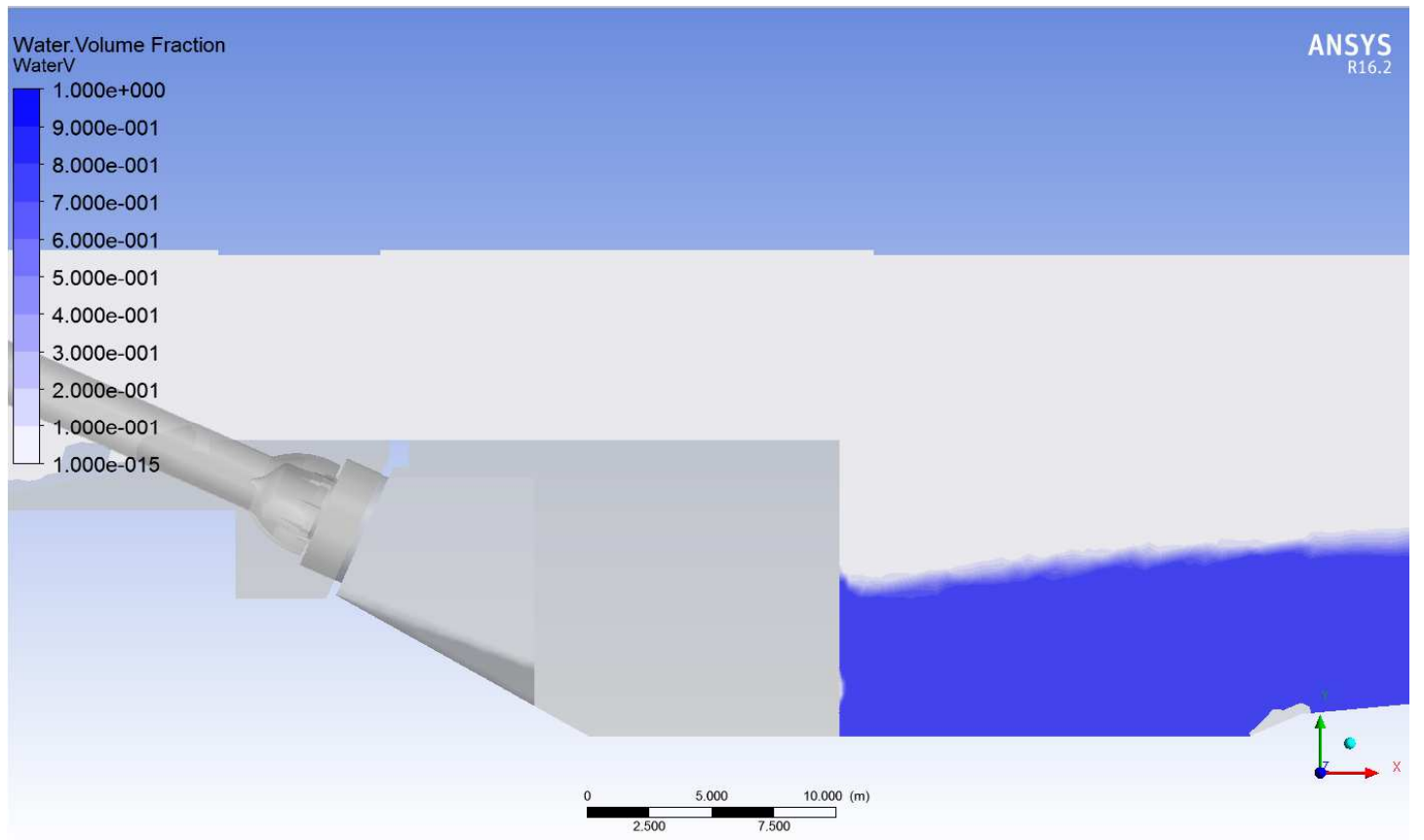

Figura 61. Perfil de linha d'água no eixo de simetria, 2 válvulas a 48,50 $\mathrm{m}^{3} / \mathrm{s}$ cada 


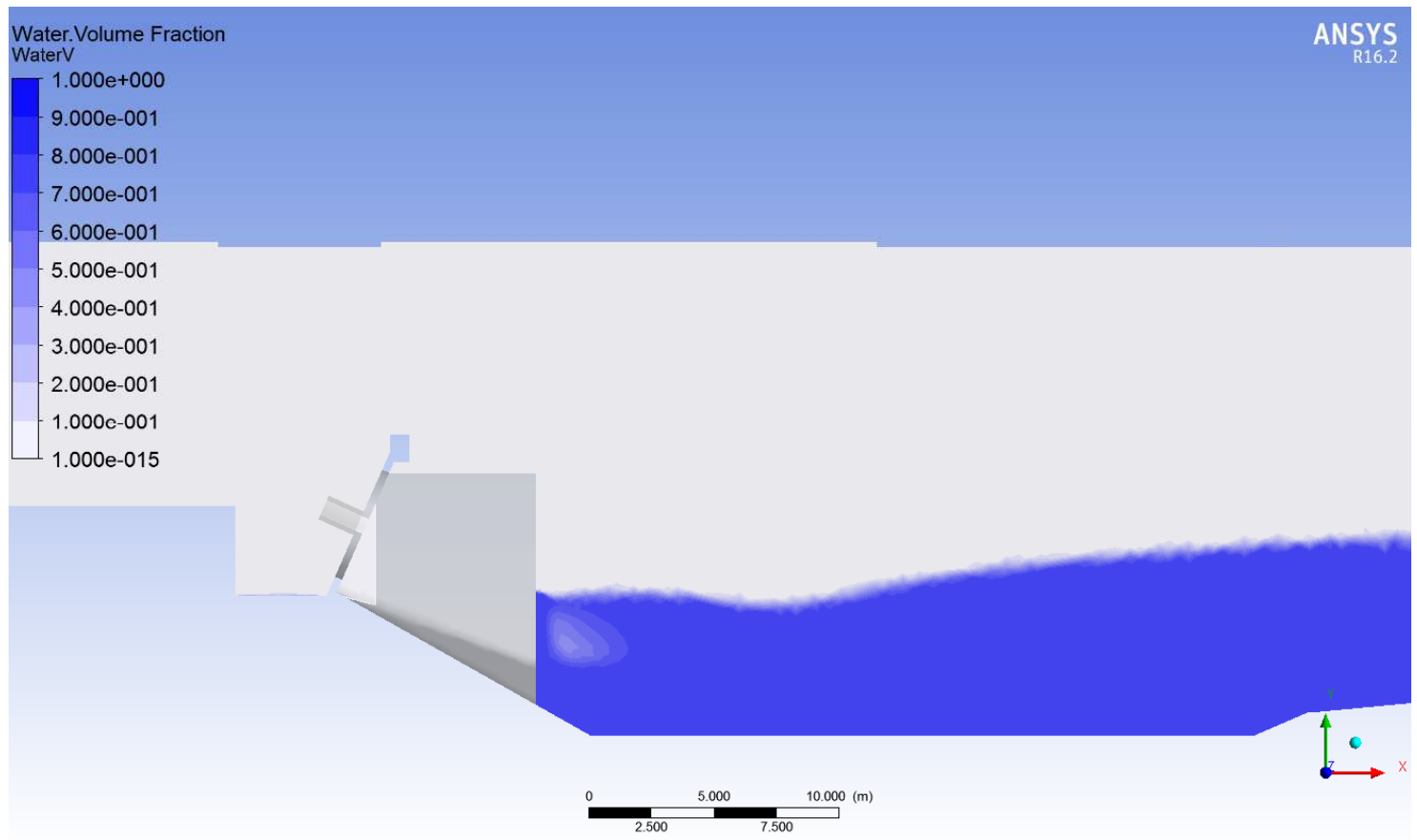

Figura 62. Perfil de linha d'água na parede lateral, 2 válvulas a 48,50 $\mathrm{m}^{3} / \mathrm{s}$ cada

\subsubsection{Perfil de Linha de Nível na Bacia Dissipadora com uma Válvula em Operação}

Conforme já explicado, a operação da câmara dissipadora com apenas uma válvula resulta em assimetria de nível de água quando o escoamento é observado de jusante para montante e vice-versa.

Esta simulação foi analisada com uma válvula operando a $100 \%$ da abertura com $86,85 \mathrm{~m} 3 / \mathrm{s}$ enquanto a segunda válvula não opera.

Lembrando que a relação $H / d=20$ resulta na queda líquida de $45,80 \mathrm{~m}$. 


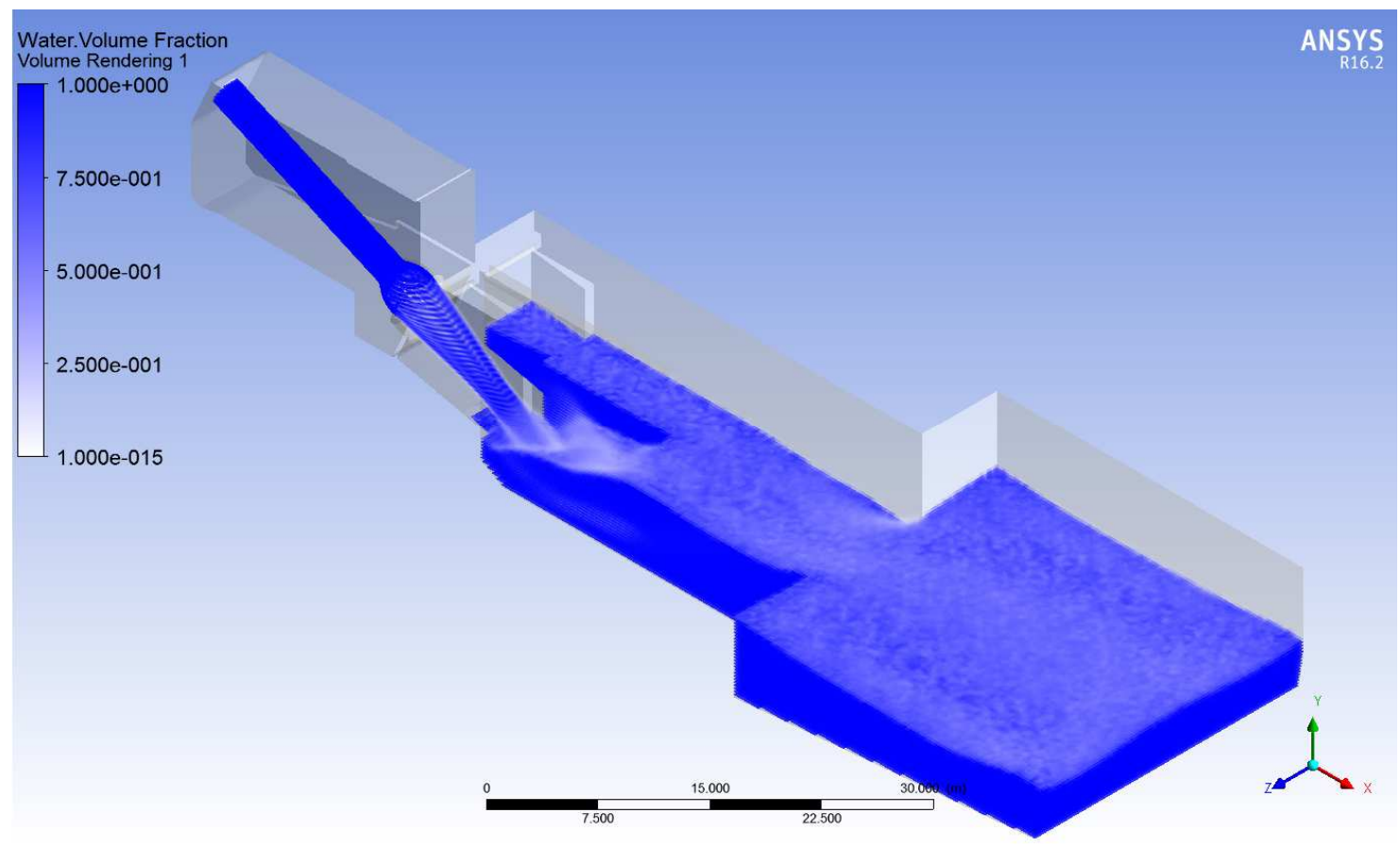

Figura 63. Vista isométrica: fração de volume da câmara, 1 válvula a $86,85 \mathrm{~m}^{3} / \mathrm{s}$

As figuras 64, 65 e 66 mostram os resultados das simulações em $C F D$ para os mesmos planos onde o protótipo foi estudado, onde pode ser observado o ressalto hidráulico assimétrico.

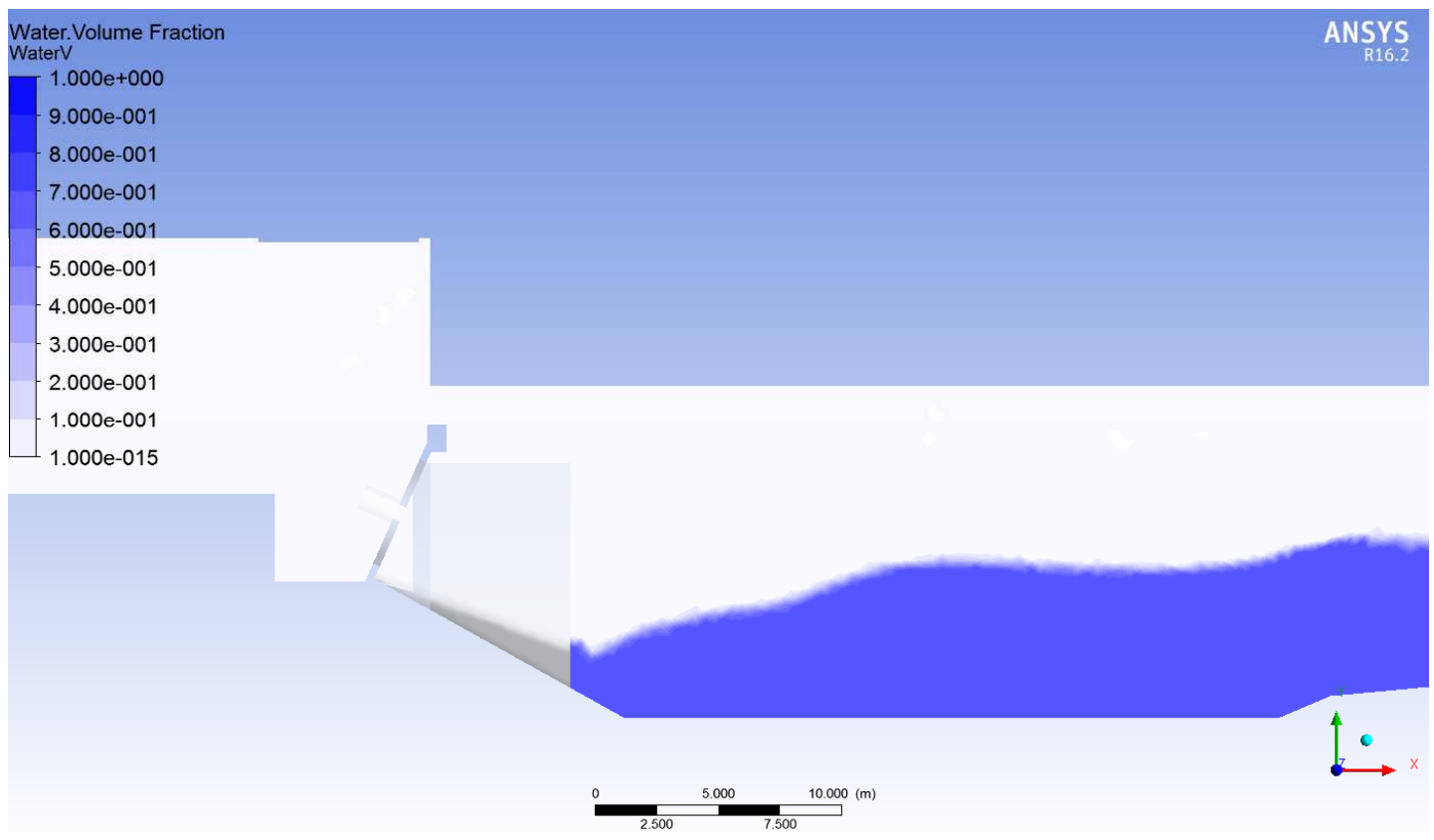

Figura 64. Perfil de linha d'água na parede lateral, 1 válvula a $86,85 \mathrm{~m}^{3} / \mathrm{s}$ 
A figura 65 mostra o perfil de linha de água no final da câmara dissipadora, visto de jusante para montante, onde se nota a assimetria devido à operação de somente uma válvula.

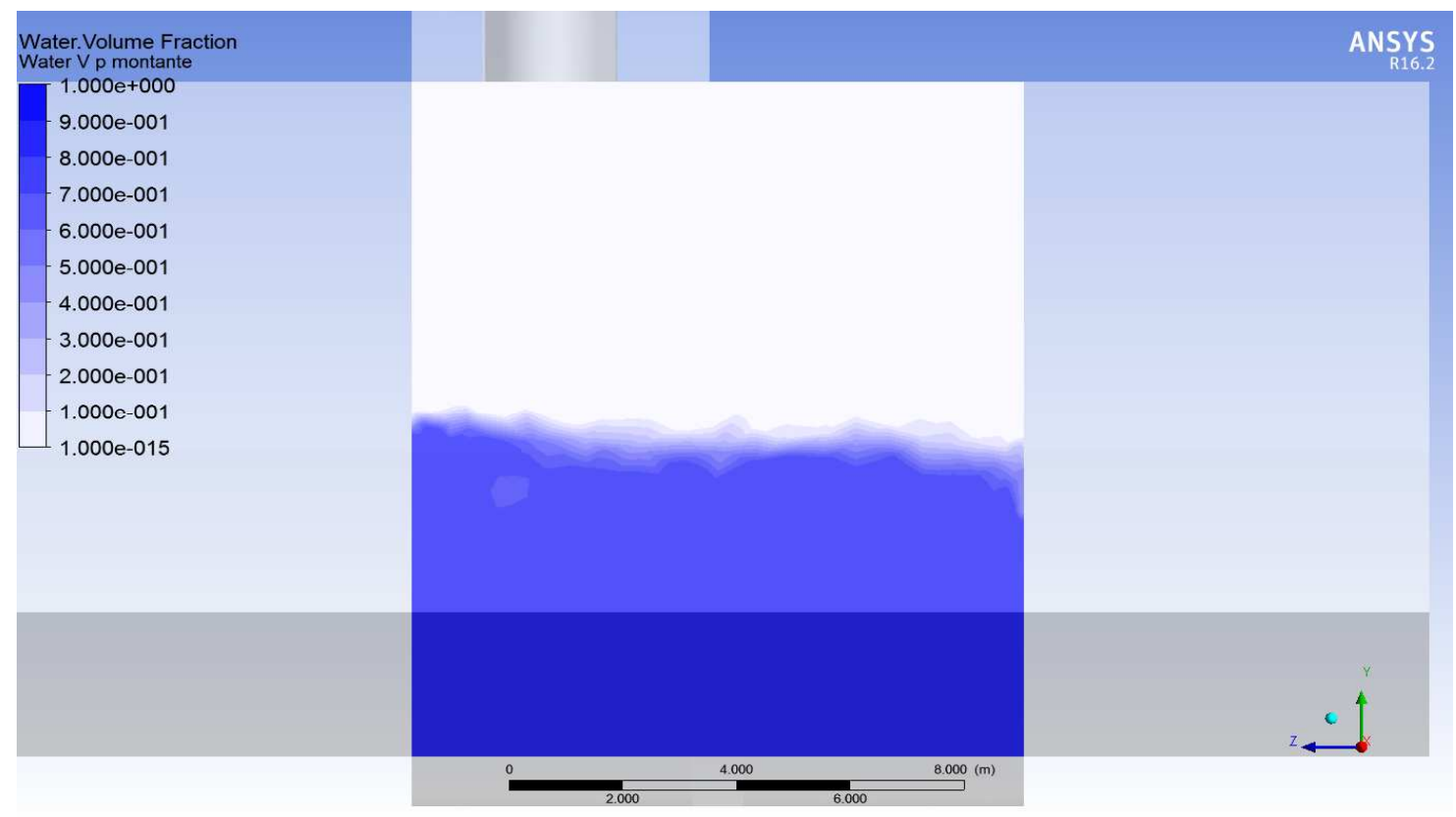

Figura 65. Perfil de linha d'água no final da câmara dissipadora, 1 válvula a $86,85 \mathrm{~m}^{3} / \mathrm{s}$

Na sequência, a figura 66 mostra o perfil de linha de água no final da parede divisória, visto de jusante para montante.

Nota-se um decréscimo bastante acentuado de nível de água na região da linha de centro da válvula, provocado pelo fluxo de água da válvula que empurra o nível a superfície de água. A vazão consideravelmente superior a qual a câmara foi projetada resulta em dificuldade de absorção do jato, indicada pela irregularidade na fração de volume vista na figura 66. 


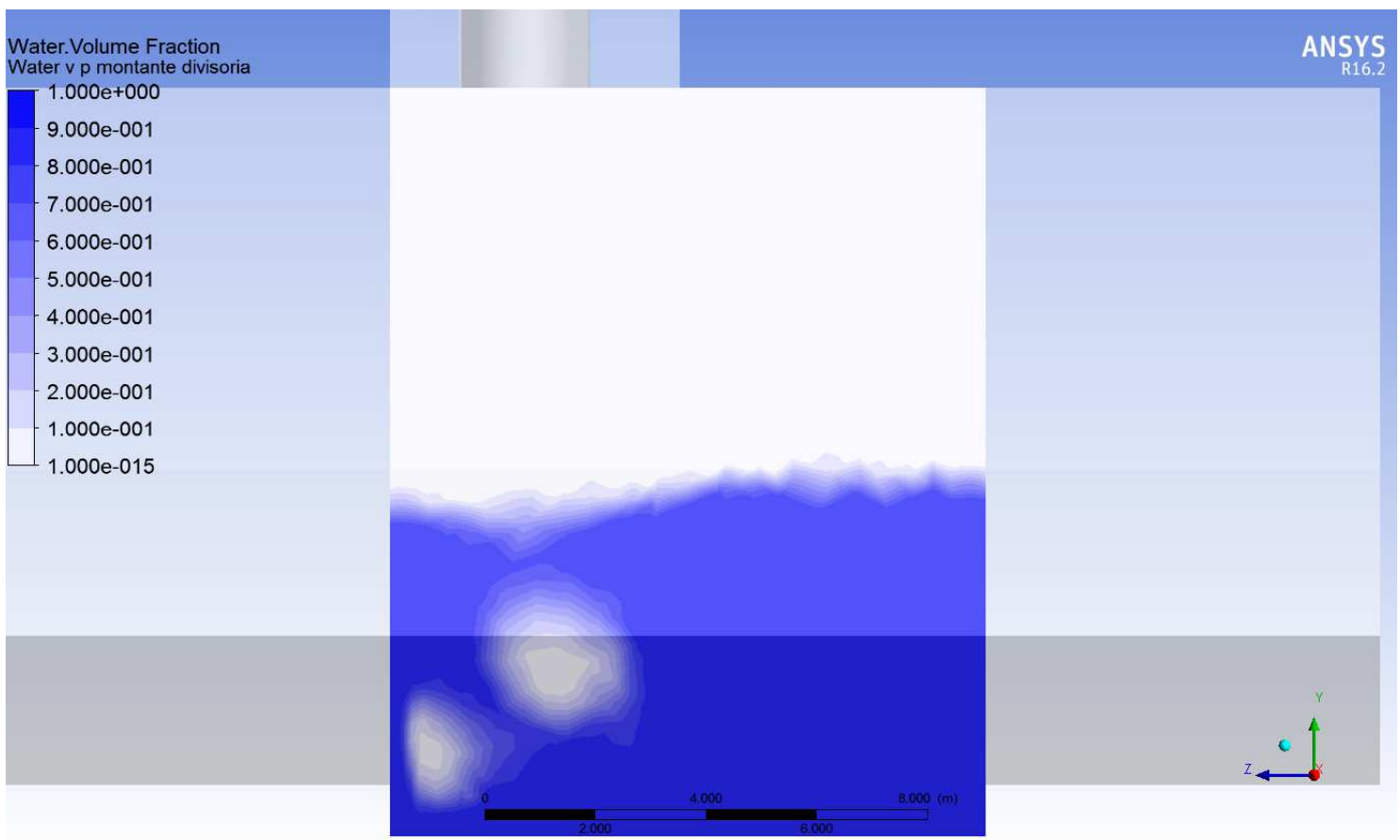

Figura 66. Perfil de linha d'água no final da parede divisória, 1 válvula a $86,85 \mathrm{~m}^{3} / \mathrm{s}$

\subsubsection{Pressão no Fundo da Câmara Dissipadora}

As pressões na região dos piezômetros de 1 a 9 são mostradas na tabela 10 .

Tabela 10. Cargas de pressão para os piezômetros de 1 a 9, obtidos por CFD para $H / d=20$

\begin{tabular}{|c|c|c|c|}
\cline { 2 - 4 } \multicolumn{1}{c|}{} & $\begin{array}{c}\text { 2 válvulas a } \\
86.65 \mathrm{~m}^{3} / \mathrm{s}\end{array}$ & $\begin{array}{c}2 \text { válvulas a } \\
48.5 \mathrm{~m}^{3} / \mathrm{s}\end{array}$ & $\begin{array}{c}1 \text { válvula a } \\
86.65 \mathrm{~m}^{3} / \mathrm{s}\end{array}$ \\
\cline { 2 - 4 } \multicolumn{1}{c|}{} & $\mathrm{CFD}(\mathrm{m})$ & $\mathrm{CFD}(\mathrm{m})$ & $\mathrm{CFD}(\mathrm{m})$ \\
\hline Piezo 1 & 2.06 & 4.43 & 2.64 \\
\hline Piezo 2 & 8.44 & 6.41 & 9.51 \\
\hline Piezo 3 & 10.52 & 8.23 & 11.16 \\
\hline Piezo 4 & 2.12 & 4.39 & 2.83 \\
\hline Piezo 5 & 2.86 & 4.83 & 3.43 \\
\hline Piezo 6 & 4.87 & 6.31 & 5.31 \\
\hline Piezo 7 & 2.17 & 4.41 & 3.05 \\
\hline Piezo 8 & 3.24 & 5.15 & 4.37 \\
\hline Piezo 9 & 10.39 & 8.04 & 9.79 \\
\hline
\end{tabular}


Diferente dos valores de pressão obtidos para a relação $H / d=11,2$, observa-se que os maiores valores de pressão foram encontrados nos piezômetros 3 e 9. Isto ocorre porque a mudança da relação $H / d$ resulta em diferença na vazão e consequentemente em diferença na velocidade do jato que, por sua vez, muda a região de incidência e de maior pressão no fundo da câmara.

Além disso, as mudanças de perfil na superfície de água mudam a carga estática sobre o fundo da câmara, o que também contribui para a mudança da região de pressão máxima.

\subsubsection{Análise e Cálculo de Eficiência de Dissipação de Energia}

Utilizando os mesmos parâmetros aplicados à relação $H / d=11,2$, a tabela 11 mostra o resumo de dissipação de energia entre a entrada da válvula e o final da câmara de dissipação.

Tabela 11. Análise de Dissipação de Energia, obtido por CFD para $H / d=20$

\begin{tabular}{|c|c|c|c|c|c|c|c|c|c|c|c|c|c|}
\hline $\begin{array}{c}\text { Número de } \\
\text { válvulas }\end{array}$ & $\begin{array}{c}\text { Abertura } \\
(\%)\end{array}$ & $\begin{array}{c}\mathrm{Q} \\
\text { válvula } \\
(\mathrm{m} / \mathrm{s})\end{array}$ & $\mathrm{H} / \mathrm{d}$ & $\begin{array}{c}\mathrm{b} \\
(\mathrm{m})\end{array}$ & $\begin{array}{c}\text { v jato } \\
(\mathrm{m} / \mathrm{s})\end{array}$ & $\begin{array}{c}\text { v saída } \\
\text { válvula } \\
(\mathrm{m} / \mathrm{s})\end{array}$ & $\begin{array}{c}\text { v final } \\
\text { câmara } \\
(\mathrm{m} / \mathrm{s})\end{array}$ & $\begin{array}{c}\mathrm{Hp} \\
\text { válvula } \\
(\mathrm{m})\end{array}$ & $\begin{array}{c}\mathrm{Hp} \\
\text { câmara } \\
(\mathrm{m})\end{array}$ & $\begin{array}{c}\text { Hp } \\
\text { total } \\
(\mathrm{m})\end{array}$ & $\begin{array}{c}\mathrm{Hp} \\
\text { válvula } \\
/ \mathrm{H}(\%)\end{array}$ & $\begin{array}{c}\mathrm{Hp} \\
\text { câmara } \\
/ \mathrm{H}(\%)\end{array}$ & $\mathrm{Ed}(\%)$ \\
\hline 2 & 100 & 86.65 & 19.4 & 0.29 & 28.74 & 18.03 & 2.20 & 27.8 & 16.3 & 44.1 & 62.6 & 36.8 & 99.4 \\
\hline 2 & 50 & 48.50 & 19.2 & 0.17 & 27.80 & 13.00 & 1.27 & 35.3 & 8.5 & 43.8 & 80.4 & 19.4 & 99.8 \\
\hline 1 & 100 & 86.65 & 18.4 & 0.30 & 27.90 & 17.23 & 1.34 & 26.8 & 15.1 & 41.9 & 63.9 & 35.9 & 99.8 \\
\hline 1 & 50 & 48.50 & 18.7 & 0.16 & 27.56 & 12.67 & 0.50 & 34.5 & 8.2 & 42.7 & 80.8 & 19.2 & $\sim 100.0$ \\
\hline
\end{tabular}

Analogamente à análise feita para relação $H / d=11,2$, as relações entre perda de carga na câmara dissipadora e a perda total entre a entrada da válvula e câmara dissipadora são praticamente mantidas, quando comparamos uma ou duas válvulas operando à mesma abertura. 


\subsubsection{Comentários}

A alta relação $H / d=20$ contrasta com a relação a qual a câmara foi projetada, ou seja, $H / d=11,2$. A extensão demasiada da faixa operativa e resultou na expulsão da água para fora da câmara e irregularidades na fração de volume.

Em resumo, não há espaço suficiente para o jato penetrar na superfície sem causar grandes perturbações na câmara dissipadora.

\subsection{Simulações de Falcon Dam com $H / d=15$}

\subsubsection{Perfil de Linha de Nível na Bacia Dissipadora com duas Válvulas em Operação}

O perfil de água foi traçado considerando as válvulas operando a 100\% de abertura e vazão de $74,95 \mathrm{~m}^{3} / \mathrm{s}$ cada uma e, também a $50 \%$ de abertura com $41,95 \mathrm{~m} 3 / \mathrm{s}$ cada uma.

A relação $H / d=15$ resulta na queda líquida de $34,30 \mathrm{~m}$.

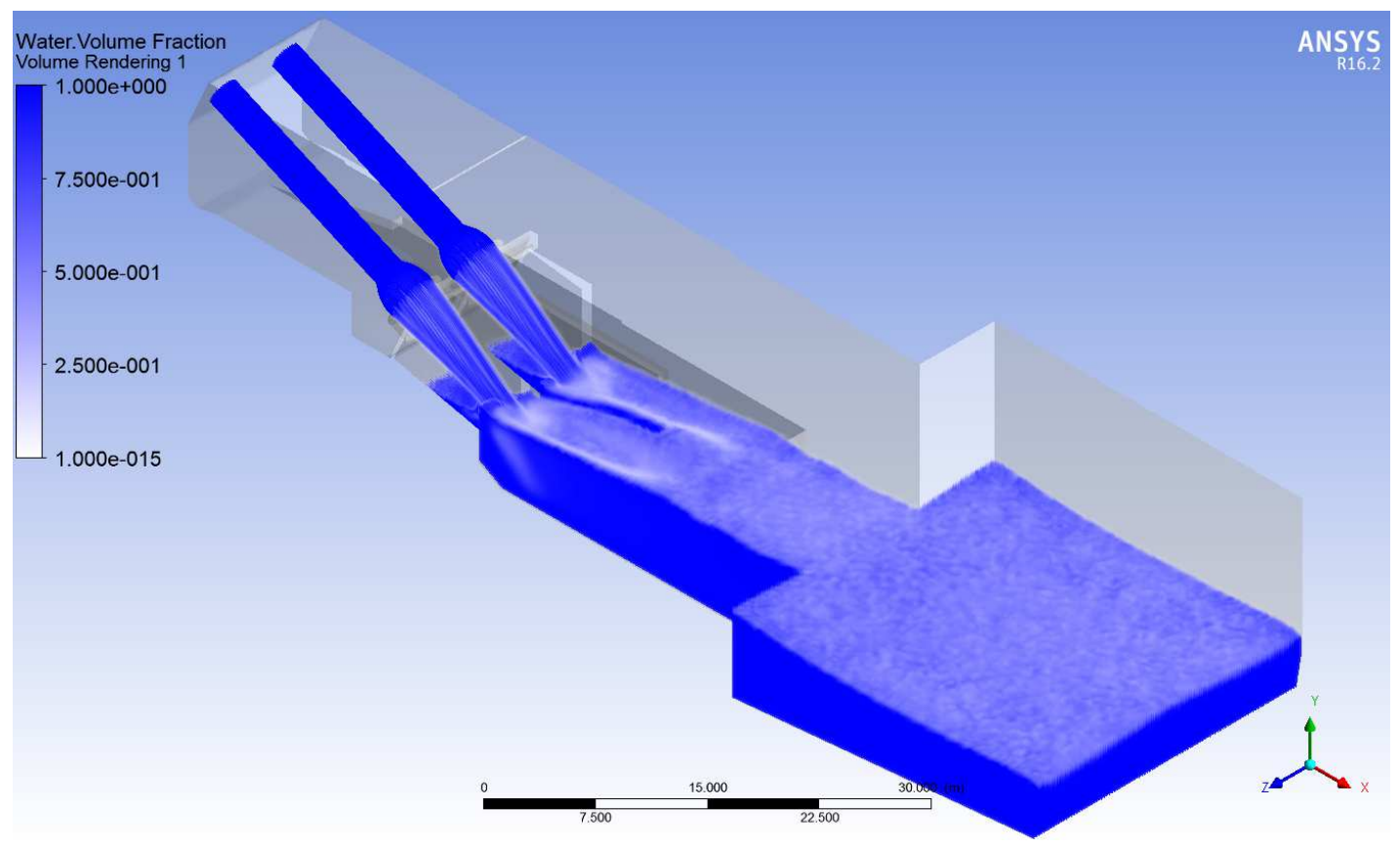

Figura 67. Vista isométrica: fração de volume da câmara, 2 válvulas a 74,95 m³/s cada 
Ainda que a relação $H / d$ aplicada esteja acima do seu valor de projeto, pode-se observar nas figuras 68 e 69 que a elevada vazão de $74,95 \mathrm{~m}^{3} / \mathrm{s}$ ainda resulta em perfis de linha de água similares às de projeto.

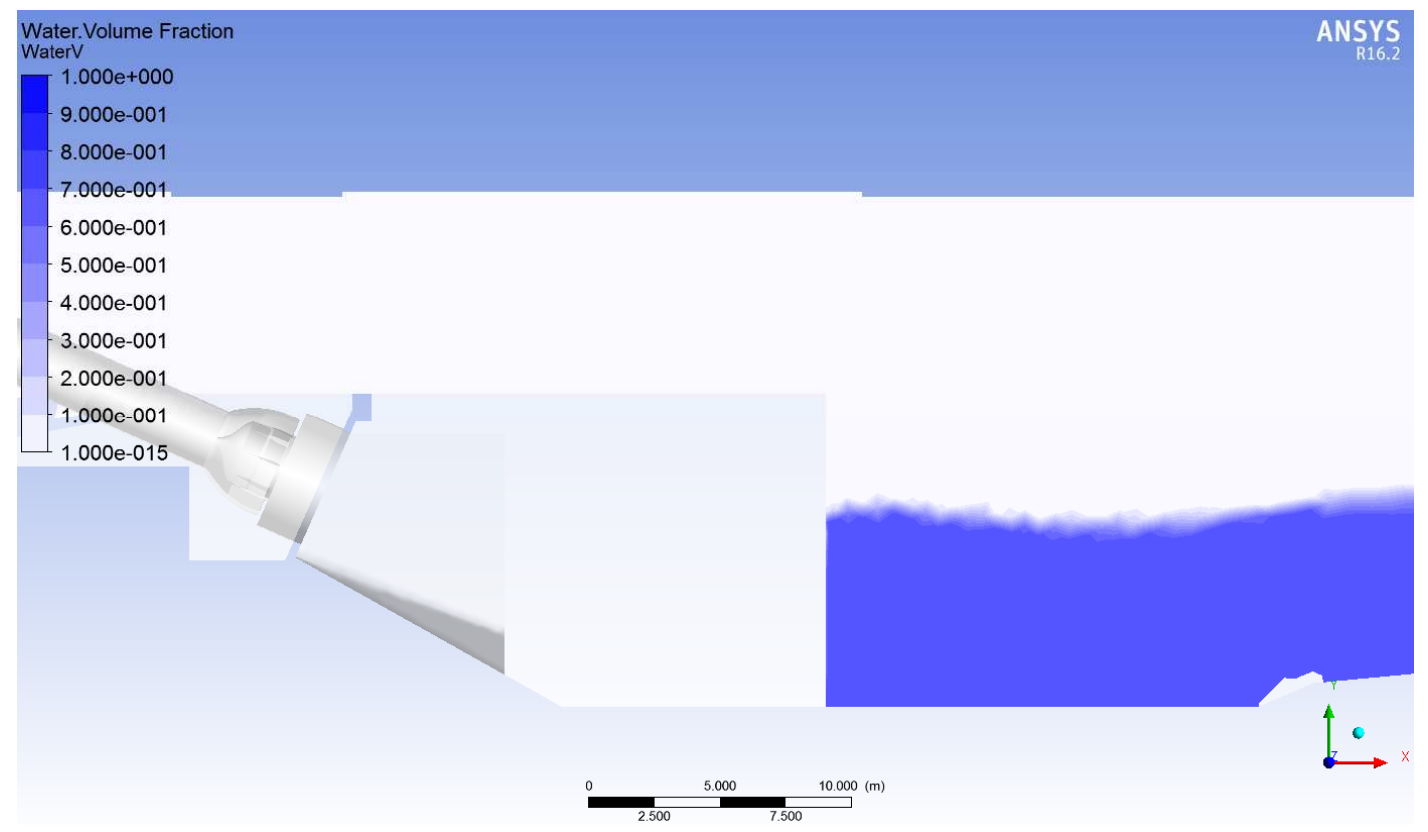

Figura 68. Perfil de linha d'água no eixo de simetria, 2 válvulas a 74,95 m³ cada

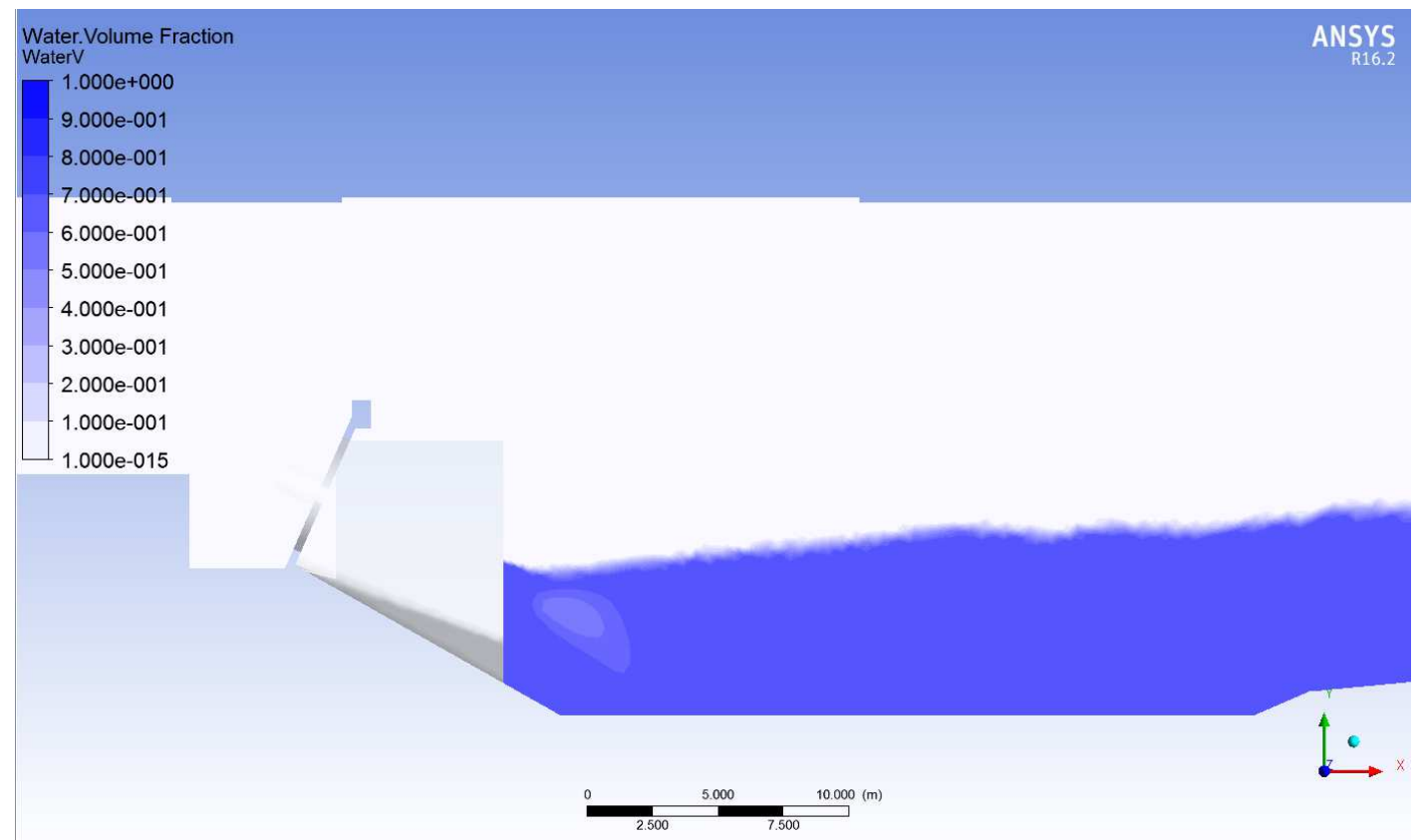

Figura 69. Perfil de linha d'água na parede lateral, 2 válvulas a 74,95 m³/s cada 
As figuras 70 e 71 são aplicadas aos mesmos planos mostrados acima, mas com abertura de $50 \%$ e vazão de $41,95 \mathrm{~m}^{3} / \mathrm{s}$ em cada válvula.

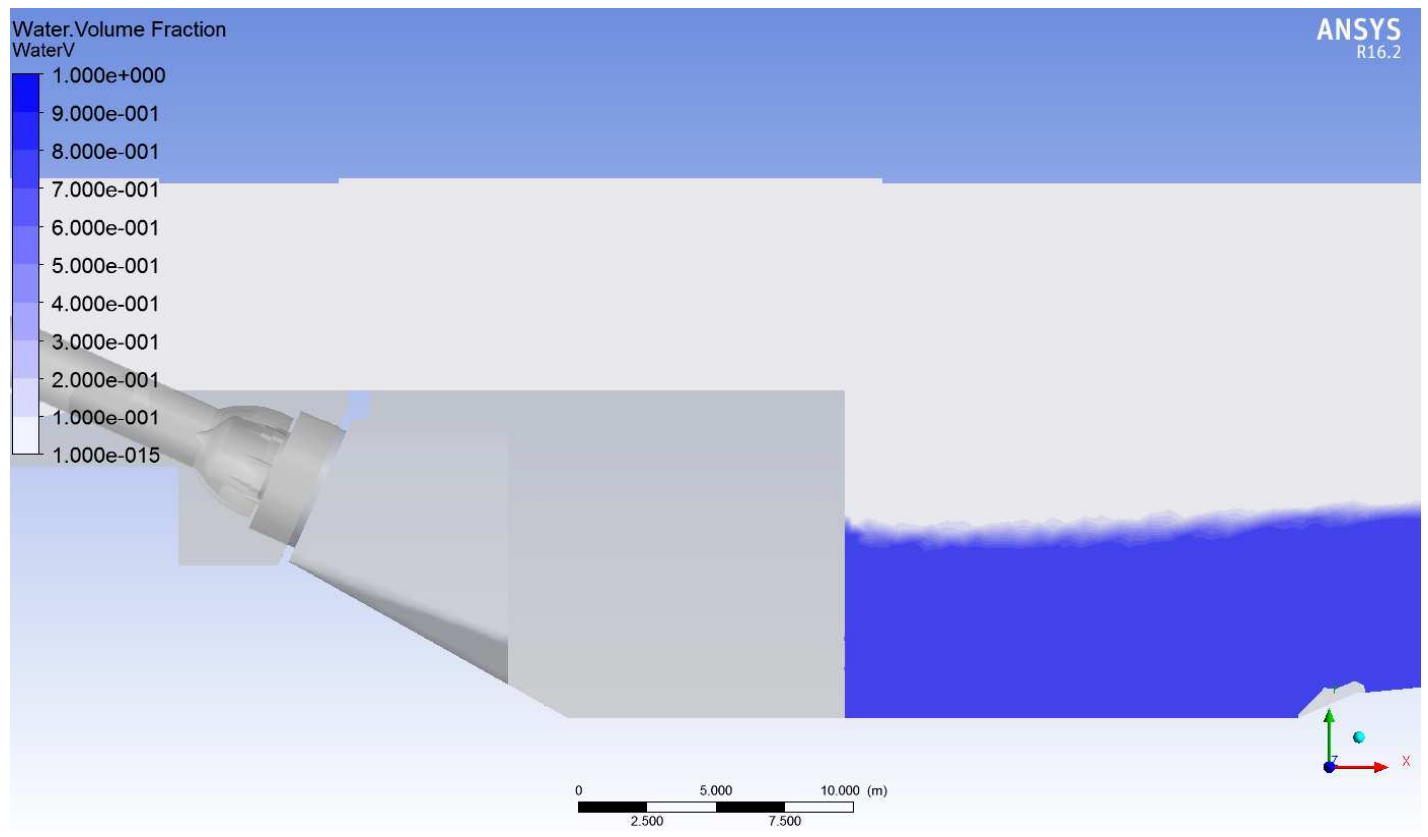

Figura 70. Perfil de linha d'água no eixo de simetria, 2 válvulas a 41,95 $\mathrm{m}^{3} / \mathrm{s}$ cada

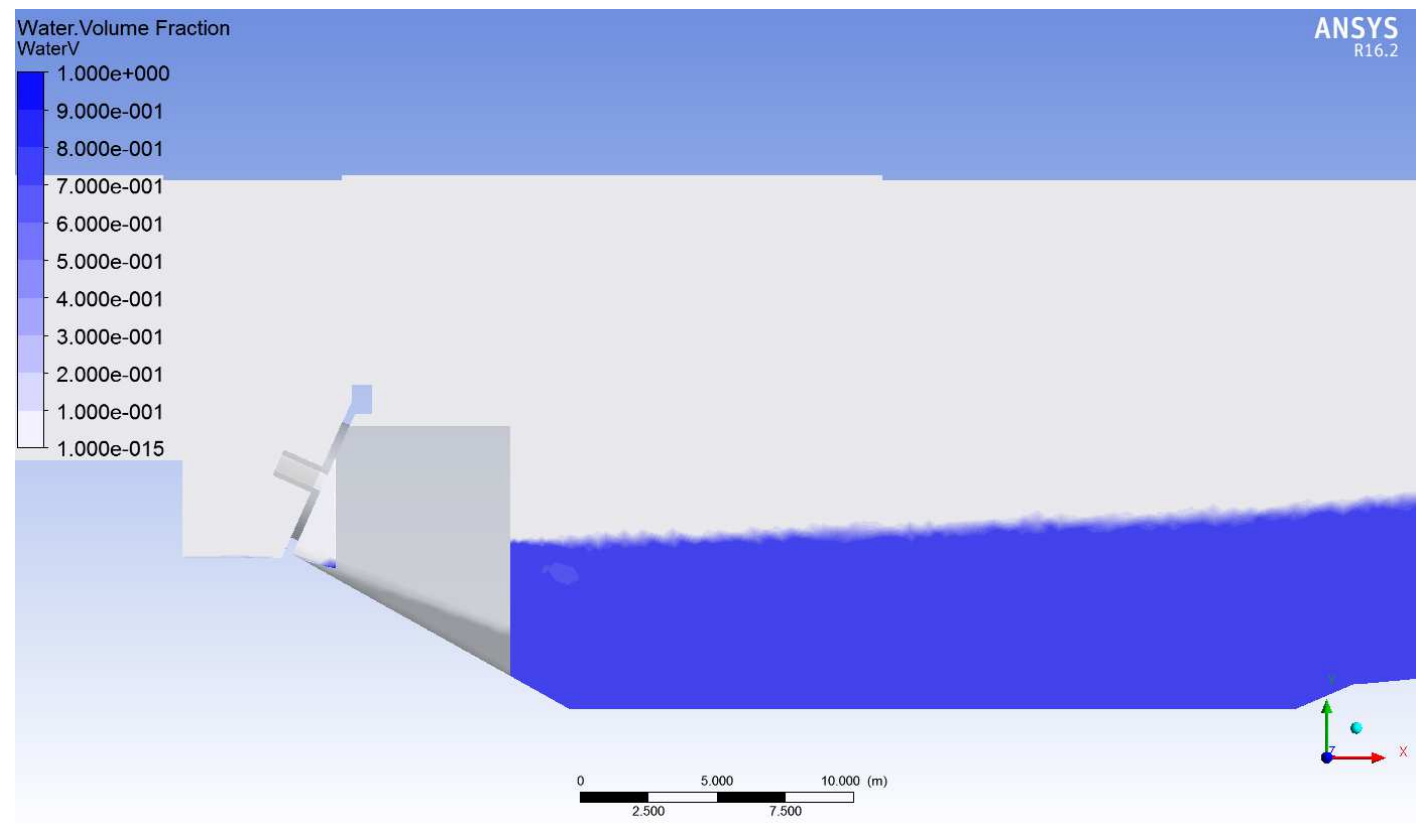

Figura 71. Perfil de linha d'água na parede lateral, 2 válvulas a 41,95 m³/s cada 


\subsubsection{Perfil de Linha de Nível na Bacia Dissipadora com uma Válvula em Operação}

Conforme já explicado, a operação da câmara dissipadora com apenas uma válvula leva a assimetrias de nível de água quando o escoamento é observado de jusante para montante e vice-versa.

Esta simulação foi analisada com uma válvula operando a $100 \%$ da abertura com $74,95 \mathrm{~m}^{3} / \mathrm{s}$ enquanto a segunda válvula não opera.

Lembrando que a relação $H / d=15$ resulta na queda líquida de $34,30 \mathrm{~m}$.

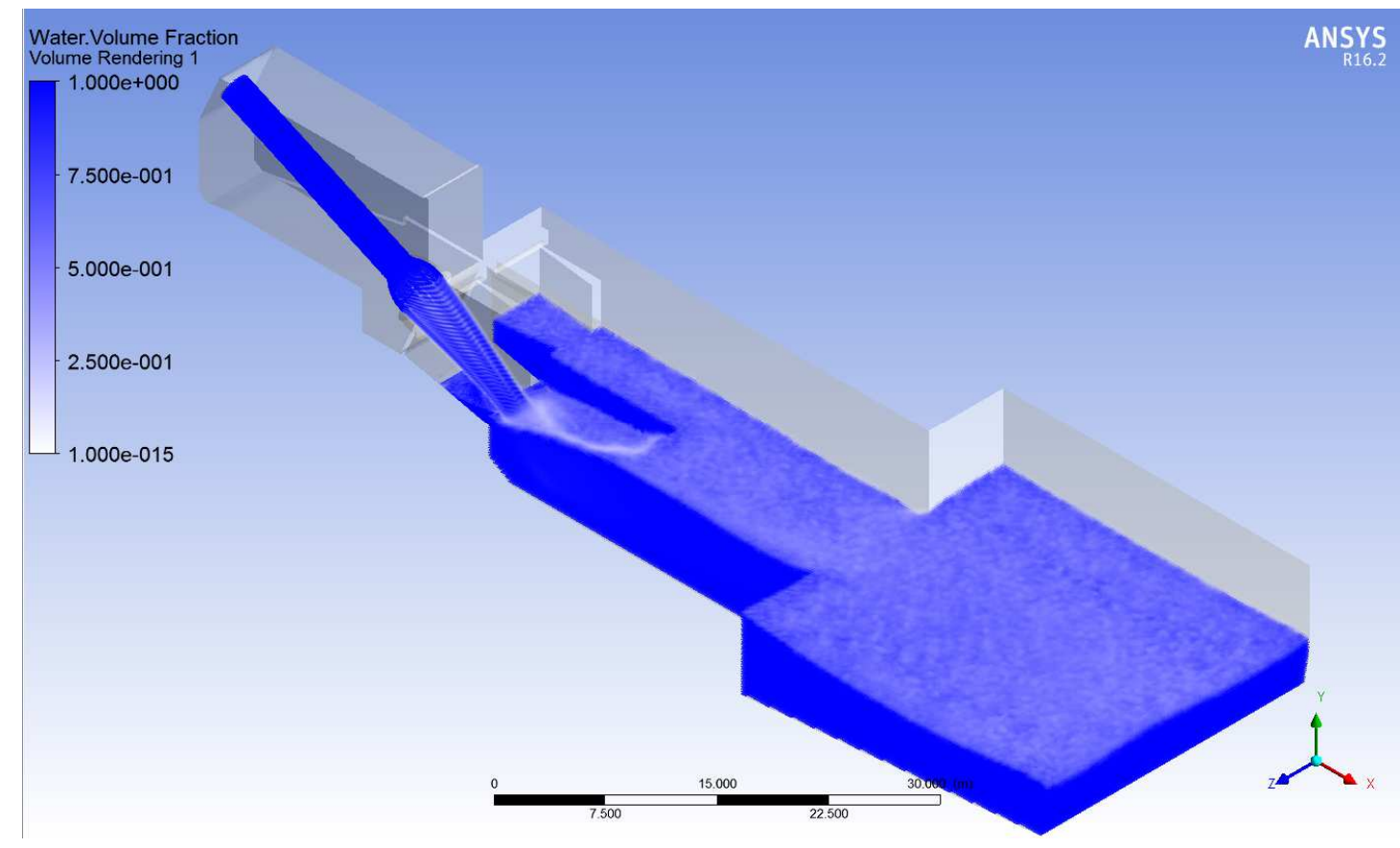

Figura 72. Vista isométrica: fração de volume da câmara, 1 válvula a 74,95 $\mathrm{m}^{3} / \mathrm{s}$

As figuras 73 e 74 mostram os resultados das simulações em $C F D$ para os mesmos planos onde o protótipo foi estudado. 


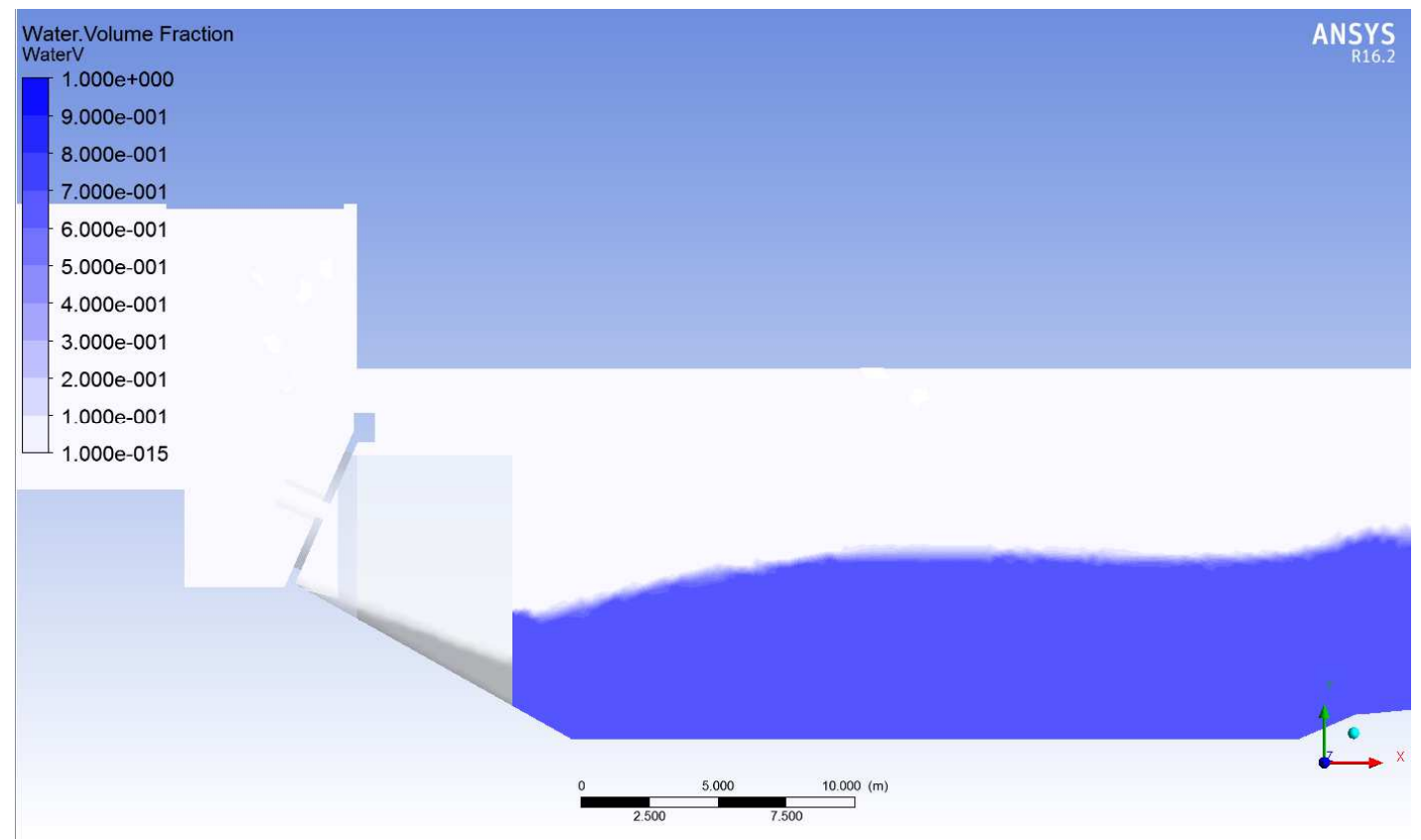

Figura 73. Perfil de linha d'água na parede lateral, 1 válvula a 74,95 m³/s

A figura 74 mostra o perfil de linha de água no final da câmara dissipadora, visto de jusante para montante. Neste gráfico pode-se notar a assimetria do ressalto hidráulico devido à operação de somente uma válvula.

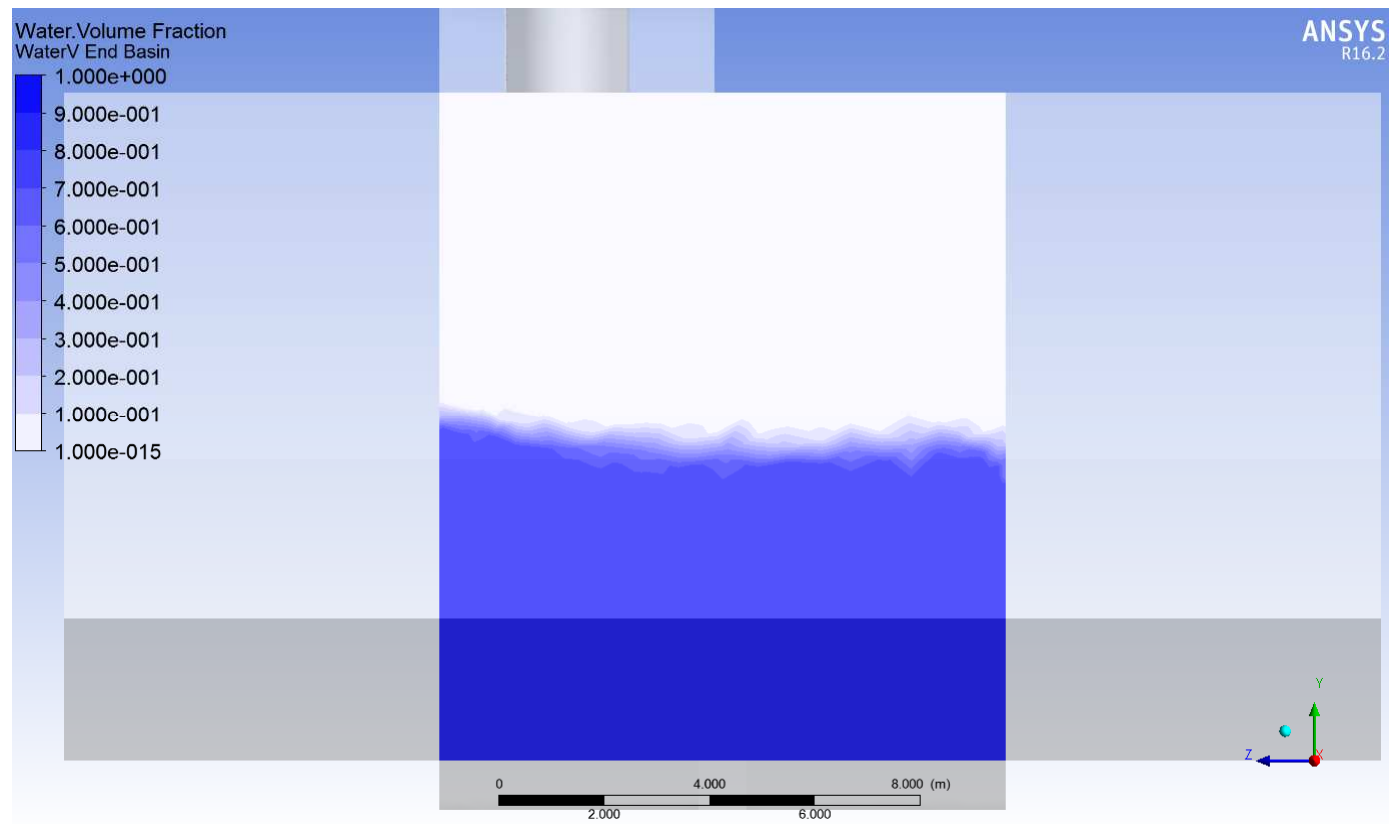

Figura 74. Perfil de linha d'água no final da câmara dissipadora, 1 válvula a 74,95 m³/s 
Na sequência, o gráfico 75 mostra o perfil de linha de água no final da parede divisória, visto de jusante para a montante.

Nota-se um decréscimo acentuado de nível de água na região da linha de centro da válvula, provocado pelo fluxo de água da válvula que empurra o nível a superfície de água.

Ainda que a vazão aplicada seja superior a qual a câmara foi projetada, não se nota dificuldade da câmara em absorver o jato, indicada pela regularidade na fração de volume vista na figura 75 .

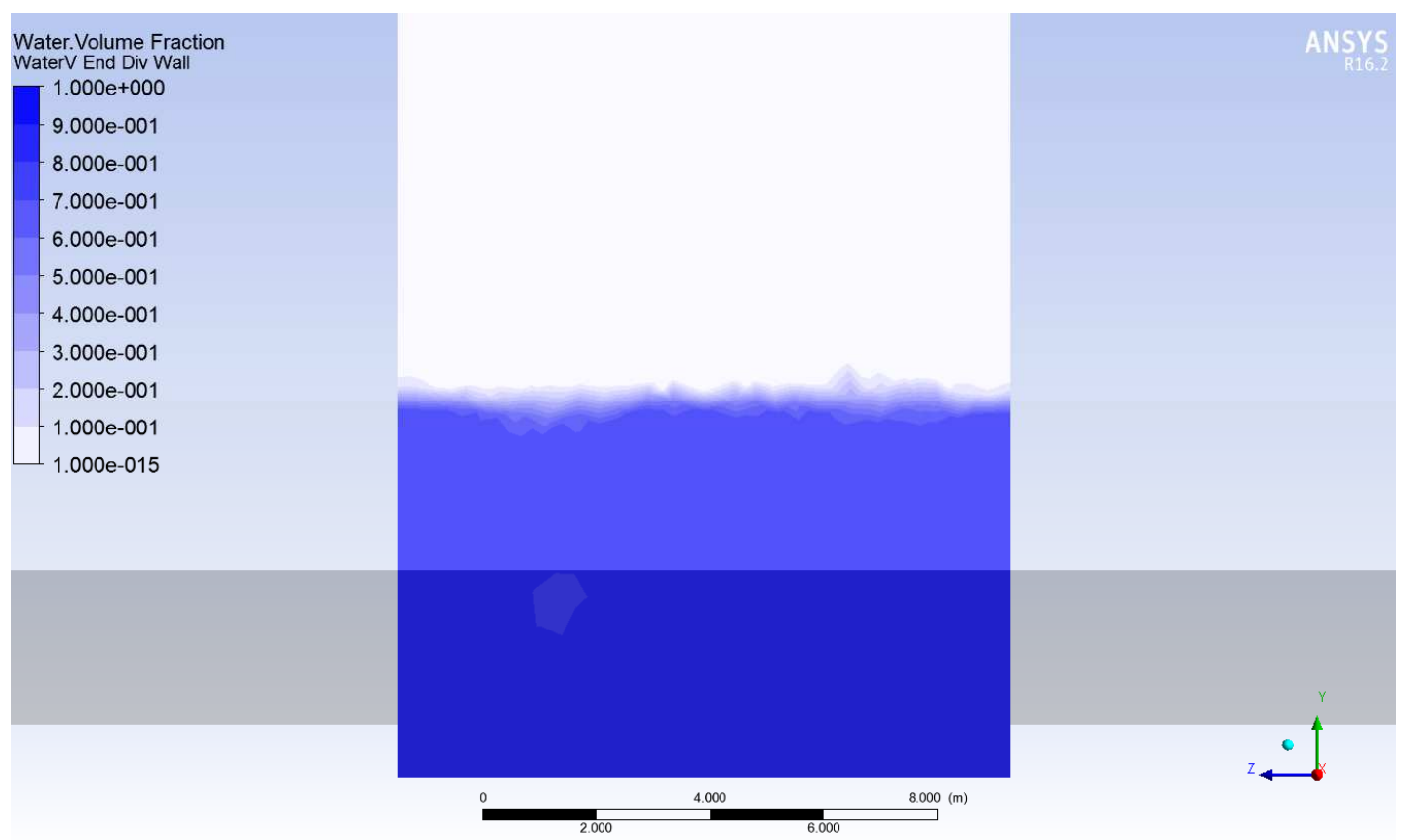

Figura 75. Perfil de linha d'água no final da parede divisória, 1 válvula a 74,95 m³/s

\subsubsection{Pressão no Fundo da Câmara Dissipadora}

As pressões na região dos piezômetros de 1 a 9 são mostradas na tabela 12 . 
Tabela 12. Cargas de pressão para os piezômetros de 1 a 9, obtidos por CFD para $H / d=15$

\begin{tabular}{|c|c|c|c|}
\cline { 2 - 4 } \multicolumn{1}{c|}{} & $\begin{array}{c}2 \text { válvulas a } \\
74.95 \mathrm{~m}^{3} / \mathrm{s}\end{array}$ & $\begin{array}{c}2 \text { válvulas a } \\
41.95 \mathrm{~m}^{3} / \mathrm{s}\end{array}$ & $\begin{array}{c}\text { 1 válvula a } \\
74.95 \mathrm{~m}^{3} / \mathrm{s}\end{array}$ \\
\cline { 2 - 4 } & $\mathrm{CFD}(\mathrm{m})$ & $\mathrm{CFD}(\mathrm{m})$ & $\mathrm{CFD}(\mathrm{m})$ \\
\hline Piezo 1 & 3.87 & 5.41 & 3.45 \\
\hline Piezo 2 & 13.55 & 8.48 & 13.52 \\
\hline Piezo 3 & 8.93 & 7.67 & 8.50 \\
\hline Piezo 4 & 3.67 & 4.98 & 3.43 \\
\hline Piezo 5 & 4.29 & 5.58 & 5.81 \\
\hline Piezo 6 & 6.64 & 6.90 & 7.81 \\
\hline Piezo 7 & 4.30 & 5.30 & 3.97 \\
\hline Piezo 8 & 6.72 & 6.35 & 7.31 \\
\hline Piezo 9 & 10.77 & 9.22 & 11.50 \\
\hline
\end{tabular}

Novamente, diferente dos valores máximos de pressão obtidos para as relações $H / d=11,2$ e $H / d=20$, observa-se que os maiores valores de pressão foram encontrados no piezômetro 2 e 9, o que indica mais uma vez que a relação $H / d$ e perfil da linha de água mudam a região de máxima pressão no fundo da câmara.

\subsubsection{Análise e Cálculo de Eficiência de Dissipação de Energia}

Utilizando os mesmos parâmetros aplicados à relação $H / d=11,2$, a tabela 13 mostra o resumo de dissipação de energia entre a entrada da válvula e o final da câmara de dissipação.

Tabela 13. Análise de Dissipação de Energia, obtido por CFD para $H$ / d =15

\begin{tabular}{|c|c|c|c|c|c|c|c|c|c|c|c|c|c|}
\hline $\begin{array}{c}\text { Número de } \\
\text { válvulas }\end{array}$ & $\begin{array}{c}\text { Abertura } \\
(\%)\end{array}$ & $\begin{array}{c}\mathrm{Q} \\
\text { válvula } \\
\left(\mathrm{m}^{3} / \mathrm{s}\right)\end{array}$ & $\mathrm{H} / \mathrm{d}$ & $\begin{array}{c}\mathrm{b} \\
(\mathrm{m})\end{array}$ & $\begin{array}{c}\text { v jato } \\
(\mathrm{m} / \mathrm{s})\end{array}$ & $\begin{array}{c}\text { v saída } \\
\text { válvula } \\
(\mathrm{m} / \mathrm{s})\end{array}$ & $\begin{array}{c}\text { v final } \\
\text { câmara } \\
(\mathrm{m} / \mathrm{s})\end{array}$ & $\begin{array}{c}\mathrm{Hp} \\
\text { válvula } \\
(\mathrm{m})\end{array}$ & $\begin{array}{c}\mathrm{Hp} \\
\text { câmara } \\
(\mathrm{m})\end{array}$ & $\begin{array}{c}\mathrm{Hp} \\
\text { total } \\
(\mathrm{m})\end{array}$ & $\begin{array}{c}\mathrm{Hp} \\
\text { válvula } \\
/ \mathrm{H}(\%)\end{array}$ & $\begin{array}{c}\mathrm{Hp} \\
\text { câmara } \\
/ \mathrm{H}(\%)\end{array}$ & $\begin{array}{c}\text { Ed } \\
(\%)\end{array}$ \\
\hline 2 & 100 & 74.95 & 14.8 & 0.29 & 25.01 & 16.50 & 2.23 & 19.8 & 13.6 & 33.5 & 58.8 & 40.4 & 99.2 \\
\hline 2 & 50 & 41.95 & 14.7 & 0.17 & 24.20 & 12.80 & 1.03 & 25.2 & 8.3 & 33.5 & 75.1 & 24.7 & 99.8 \\
\hline 1 & 100 & 74.95 & 14.0 & 0.30 & 23.30 & 14.79 & 1.10 & 20.7 & 11.1 & 31.8 & 65.0 & 34.8 & 99.8 \\
\hline 1 & 50 & 41.95 & 14.6 & 0.16 & 24.00 & 12.37 & 0.63 & 25.5 & 7.8 & 33.2 & 76.5 & 23.4 & 99.9 \\
\hline
\end{tabular}


Analogamente à análise feita para relação $H / d=11,2$, as relações entre perda de carga na câmara dissipadora e a perda total entre a entrada da válvula e câmara dissipadora são praticamente mantidas quando comparamos uma ou duas válvulas operando à mesma abertura.

\subsubsection{Comentários}

A relação $H / d=15$ não contrasta tanto com a relação a qual a câmara foi projetada, ou seja, $H / d=11,2$. Assim, baseado na regularidade de fração de volume, pode-se dizer que há indícios de que a faixa operativa possa ser estendida para $H / d=15$.

\subsection{Simulações de Falcon Dam com $H / d=7,5$}

\subsubsection{Perfil de Linha de Nível na Bacia Dissipadora com duas Válvulas em Operação}

O perfil de água foi traçado considerando as válvulas operando a $100 \%$ de abertura e vazão de $53,0 \mathrm{~m}^{3} / \mathrm{s}$ cada uma e, também a $50 \%$ de abertura com $29,67 \mathrm{~m}^{3} / \mathrm{s}$ cada uma.

A relação $H / d=7,5$ resulta na queda líquida de $17,10 \mathrm{~m}$. 


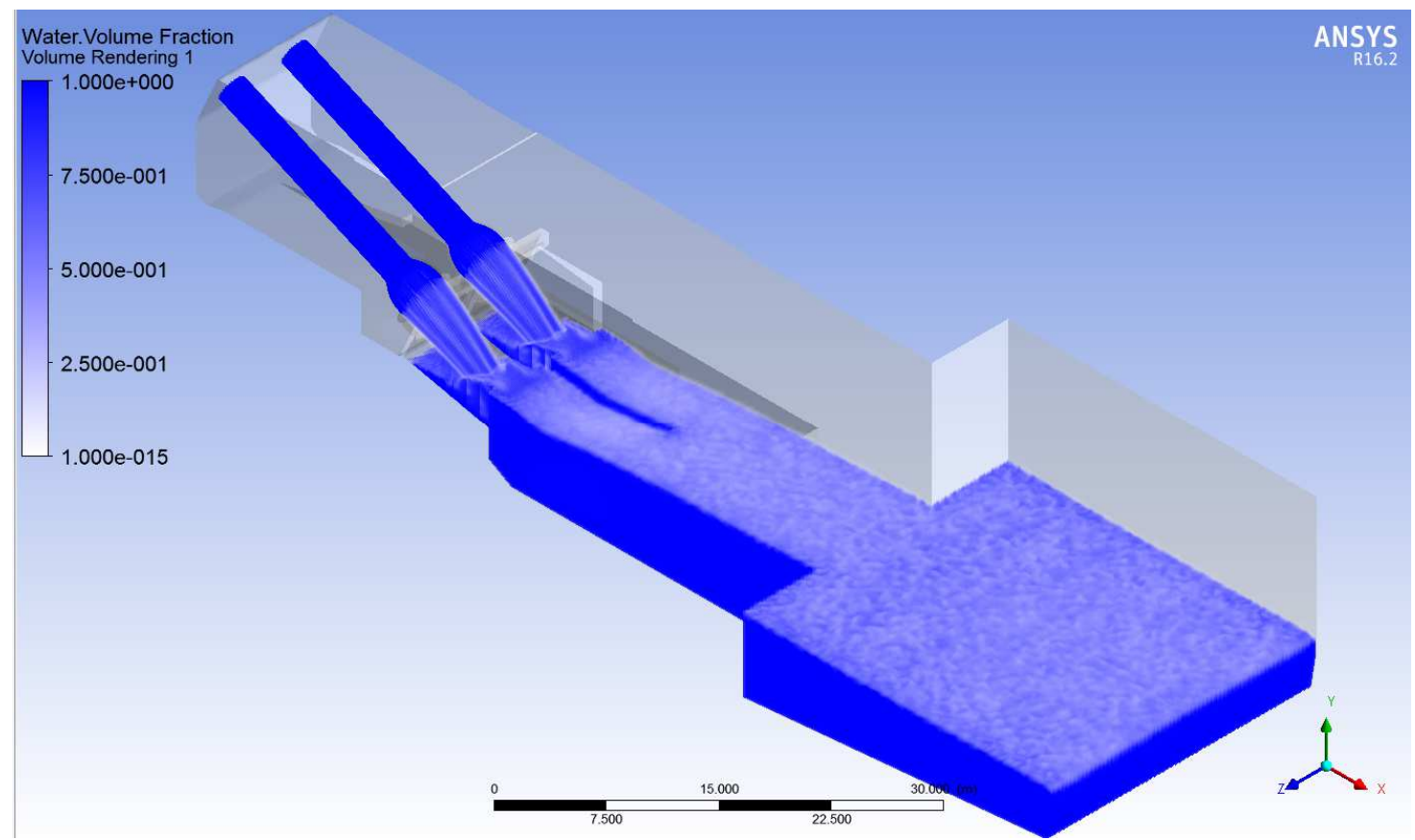

Figura 76. Vista isométrica: fração de volume da câmara, 2 válvulas a 53,0 $\mathrm{m}^{3} / \mathrm{s}$ cada

A relação $H / d$ aplicada está abaixo do seu valor de projeto, onde se pode observar nas figuras 77 e 78 que a vazão de 53,0 m³/s resulta em ressalto hidráulico mais suave que o de projeto.

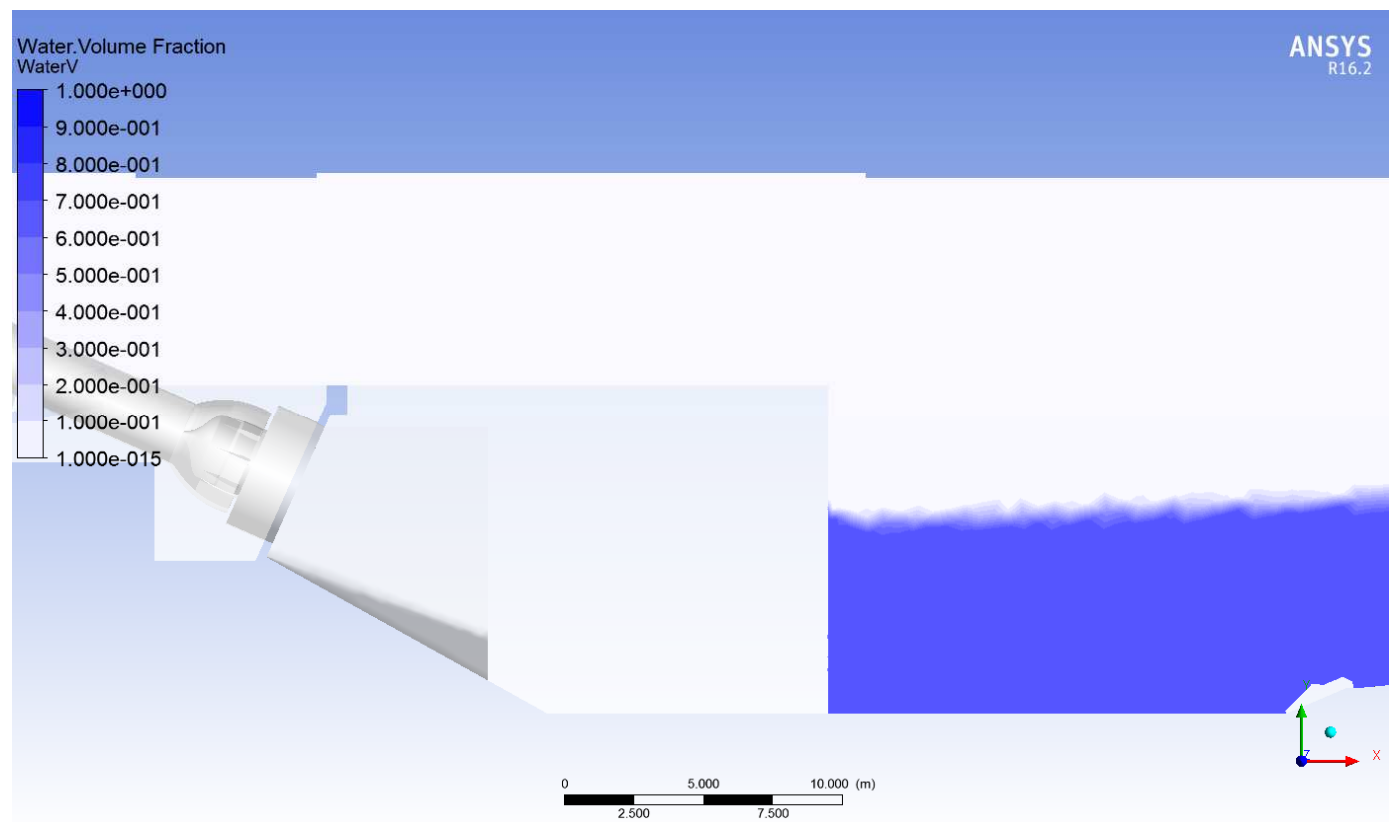

Figura 77. Perfil de linha d'água no eixo de simetria, 2 válvulas a 53,0 $\mathrm{m}^{3} / \mathrm{s}$ cada 


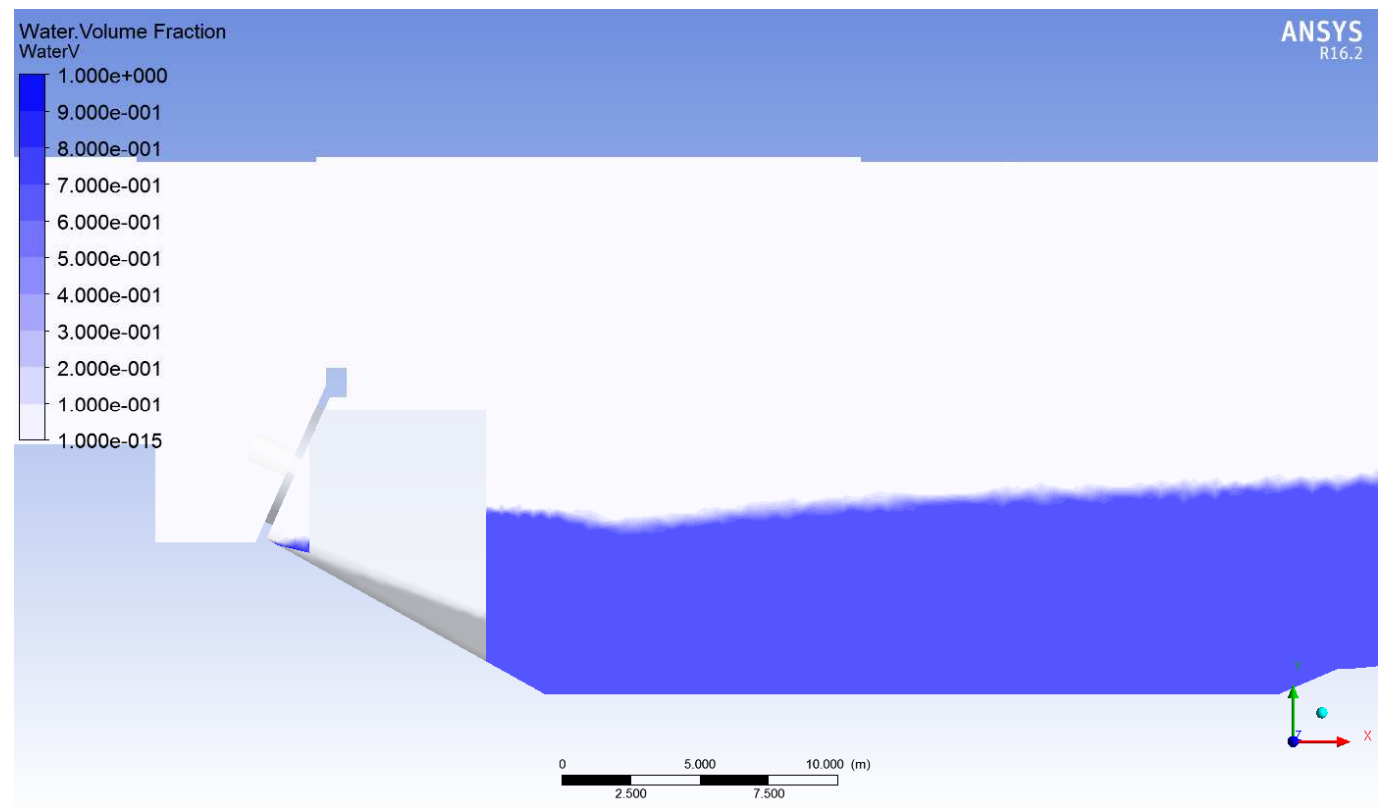

Figura 78. Perfil de linha d'água na parede lateral, 2 válvulas a 53,0 m³/s cada

As figuras 79 e 80 mostram os perfis de níveis de água considerando 50\% de abertura e vazão de $29,67 \mathrm{~m}^{3} / \mathrm{s}$ em cada válvula.

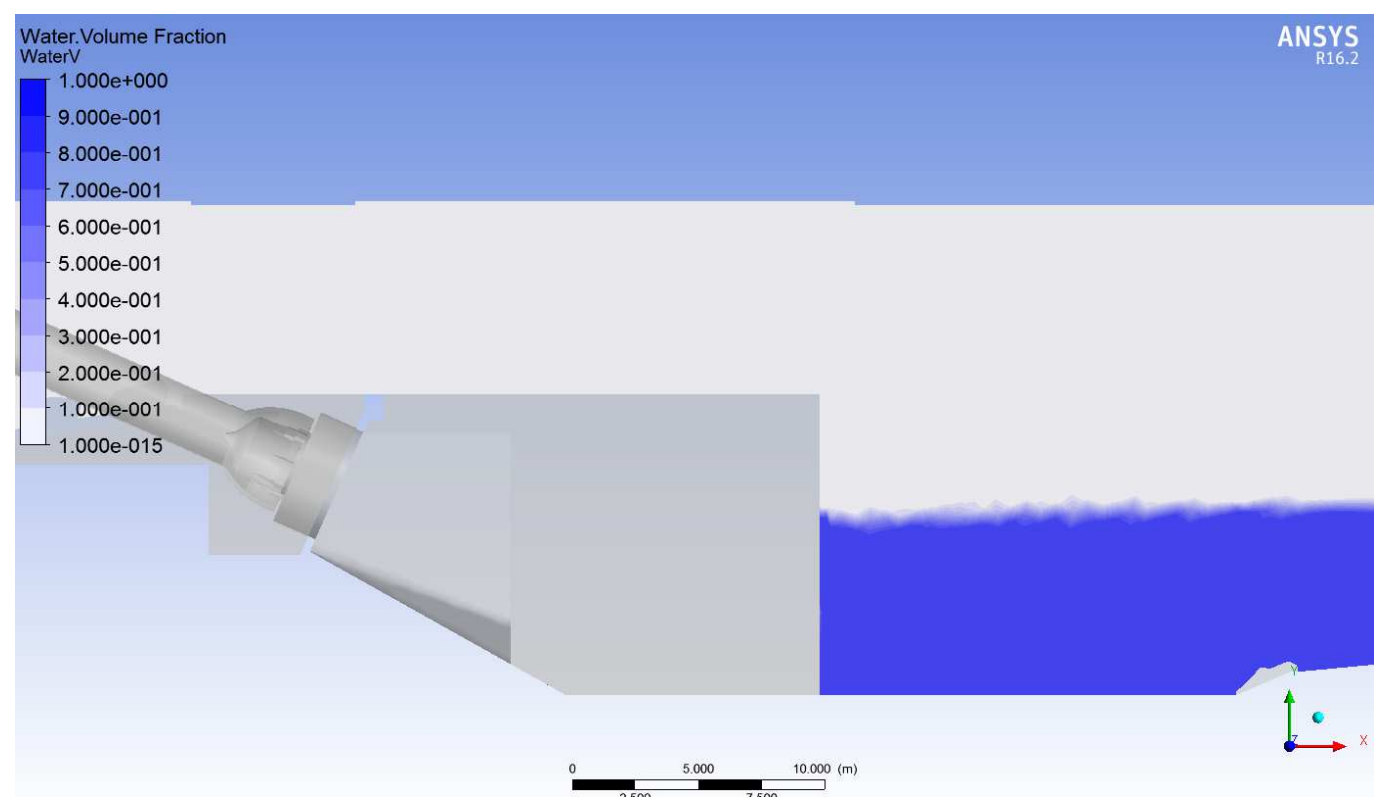

Figura 79. Perfil de linha d'água no eixo de simetria, 2 válvulas a 29,67 $\mathrm{m}^{3} / \mathrm{s}$ cada 


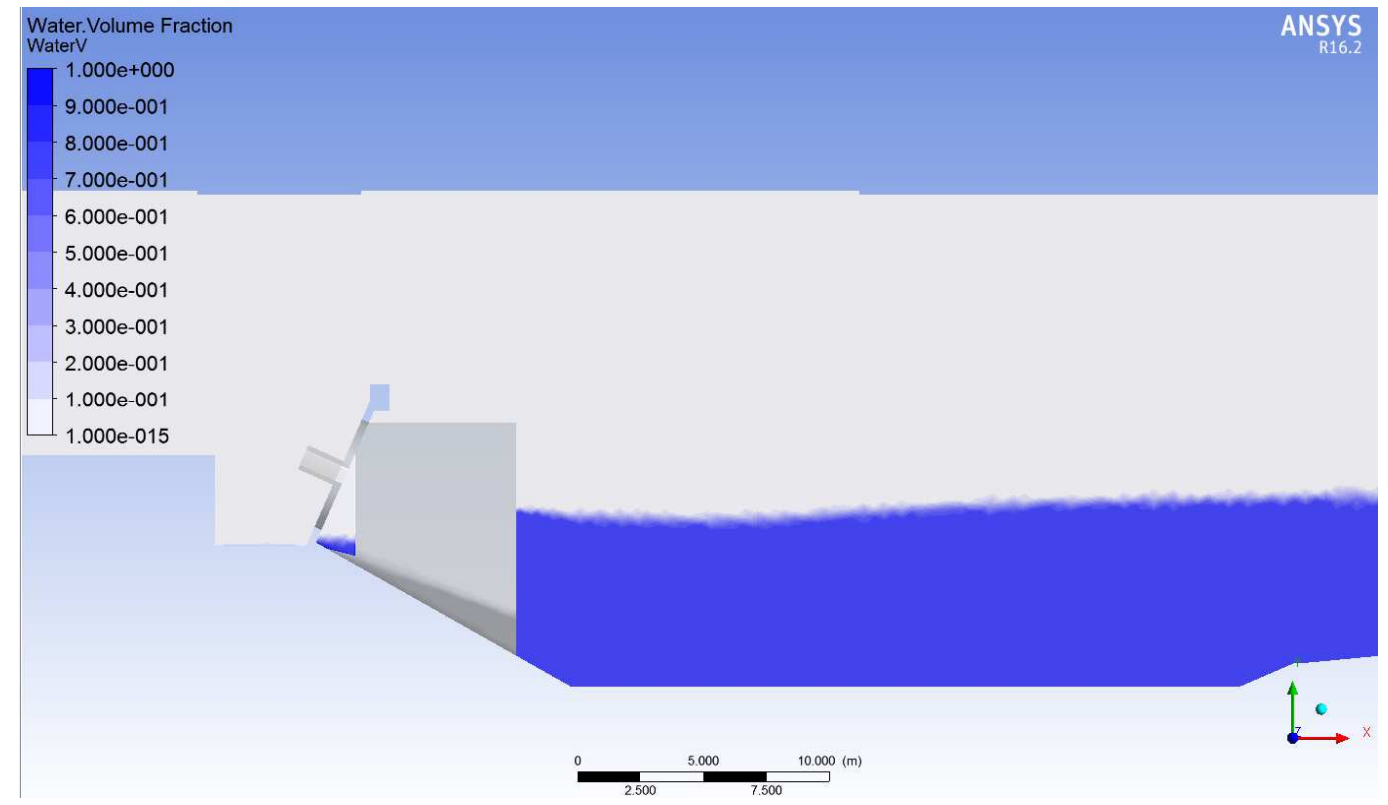

Figura 80. Perfil de linha d'água na parede lateral, 2 válvulas a 29,67 $\mathrm{m}^{3} / \mathrm{s}$ cada

Conforme esperado, as variações de nível de água são mais amenas quando a câmara dissipadora opera com $50 \%$ de abertura e $29,67 \mathrm{~m} 3 / \mathrm{s}$ em cada válvula.

\subsubsection{Perfil de Linha de Nível na Bacia Dissipadora com uma Válvula em Operação}

Conforme já explicado, a operação da câmara dissipadora com apenas uma válvula leva a assimetrias de nível de água quando o escoamento é observado de jusante para montante e vice-versa.

Esta simulação foi analisada com uma válvula operando a $100 \%$ da abertura com $53,0 \mathrm{~m} / \mathrm{s}$ enquanto a segunda válvula não opera.

Lembrando que a relação $H / d=7,5$ resulta na queda líquida de $17,10 \mathrm{~m}$. 


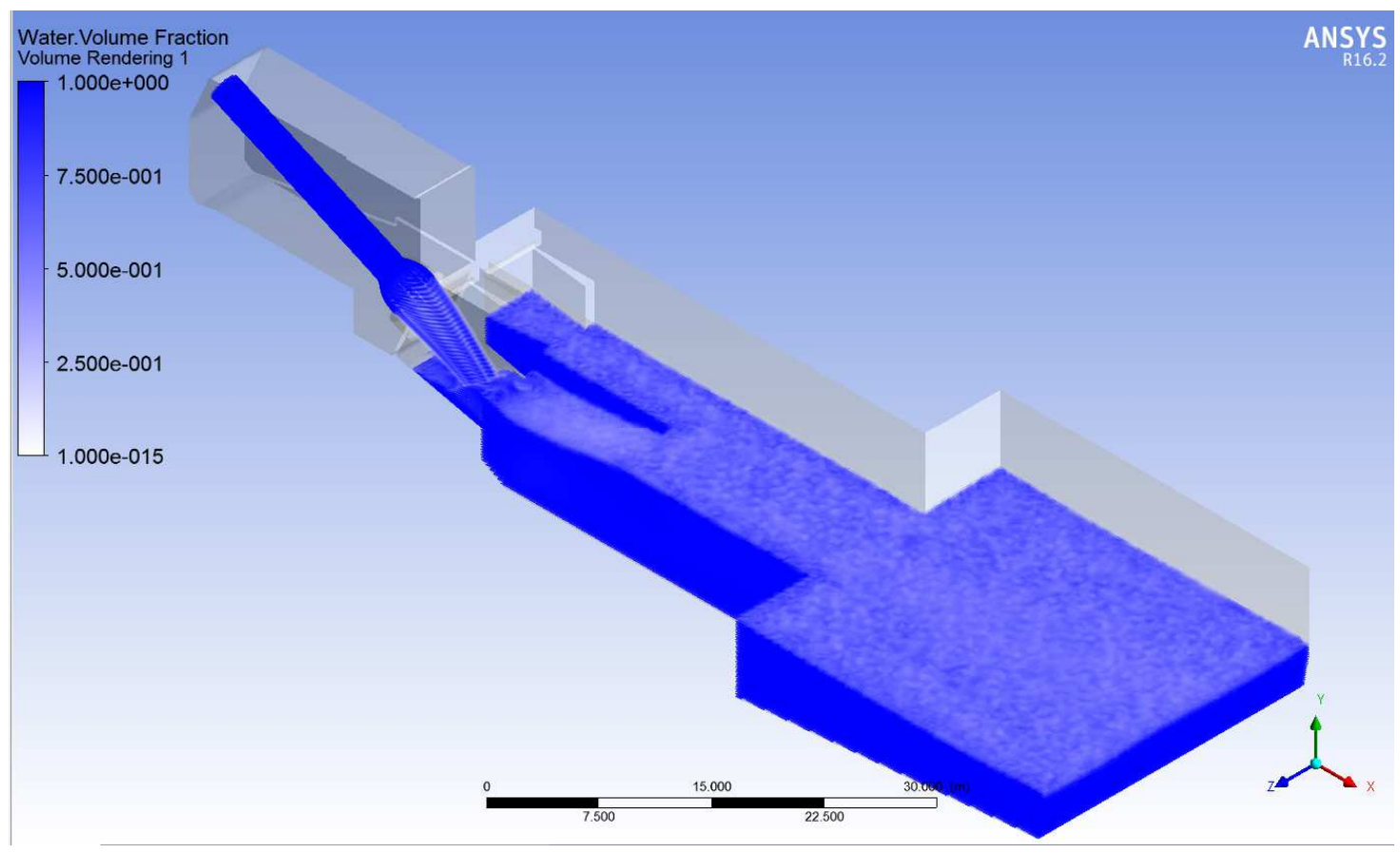

Figura 81. Vista isométrica: fração de volume da câmara, 1 válvula a 53,0 $\mathrm{m}^{3} / \mathrm{s}$

Os gráficos 82, 83 e 84 mostram os resultados das simulações em $C F D$ para os mesmos planos onde o protótipo foi estudado.

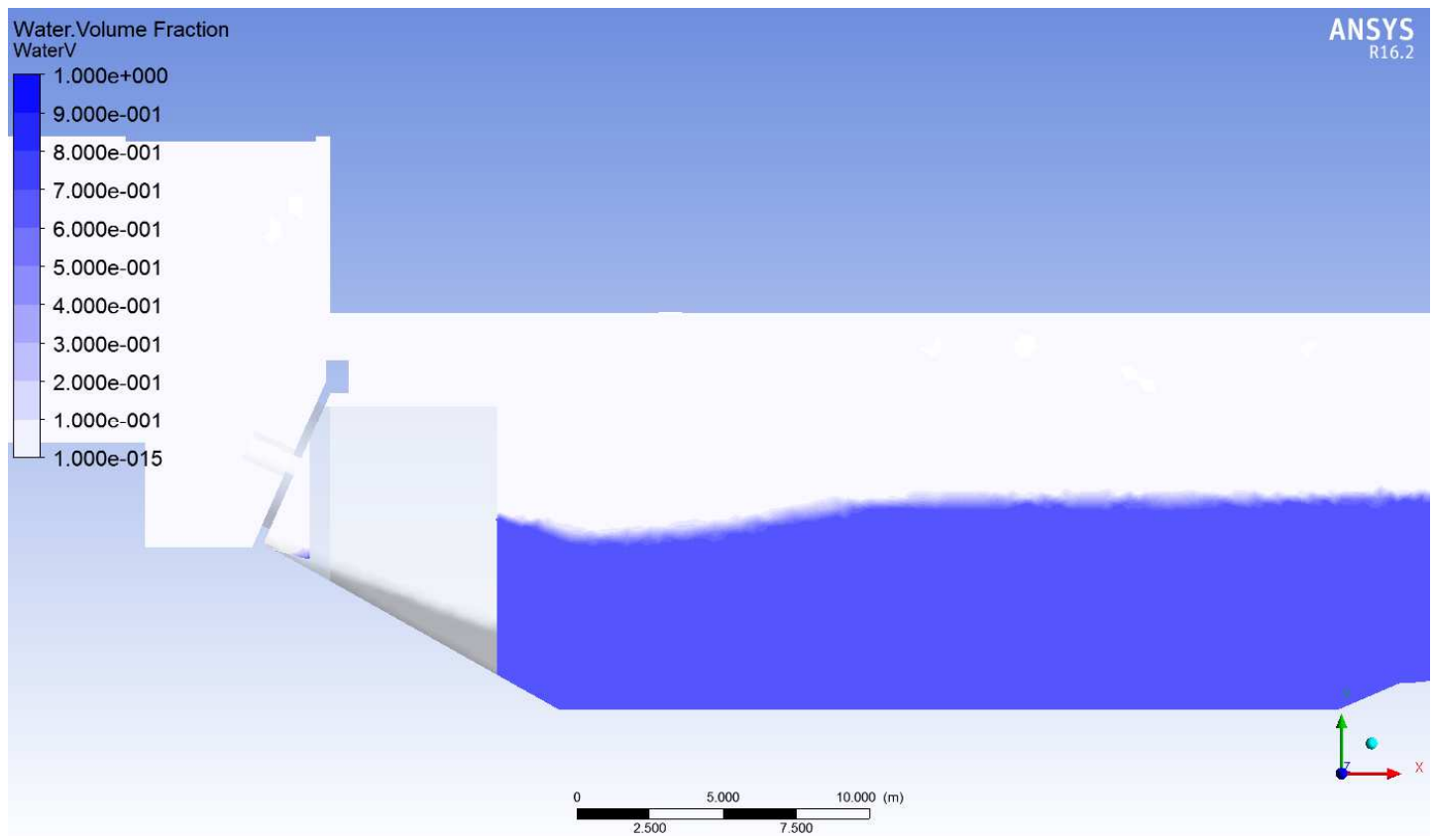

Figura 82. Perfil de linha d'água na parede lateral, 1 válvula a 53,0 m³ 
O gráfico 83 mostra o perfil de linha de água no final da câmara dissipadora, visto de jusante para montante. Neste gráfico pode-se notar pouca assimetria do ressalto hidráulico devido à operação de somente uma válvula.

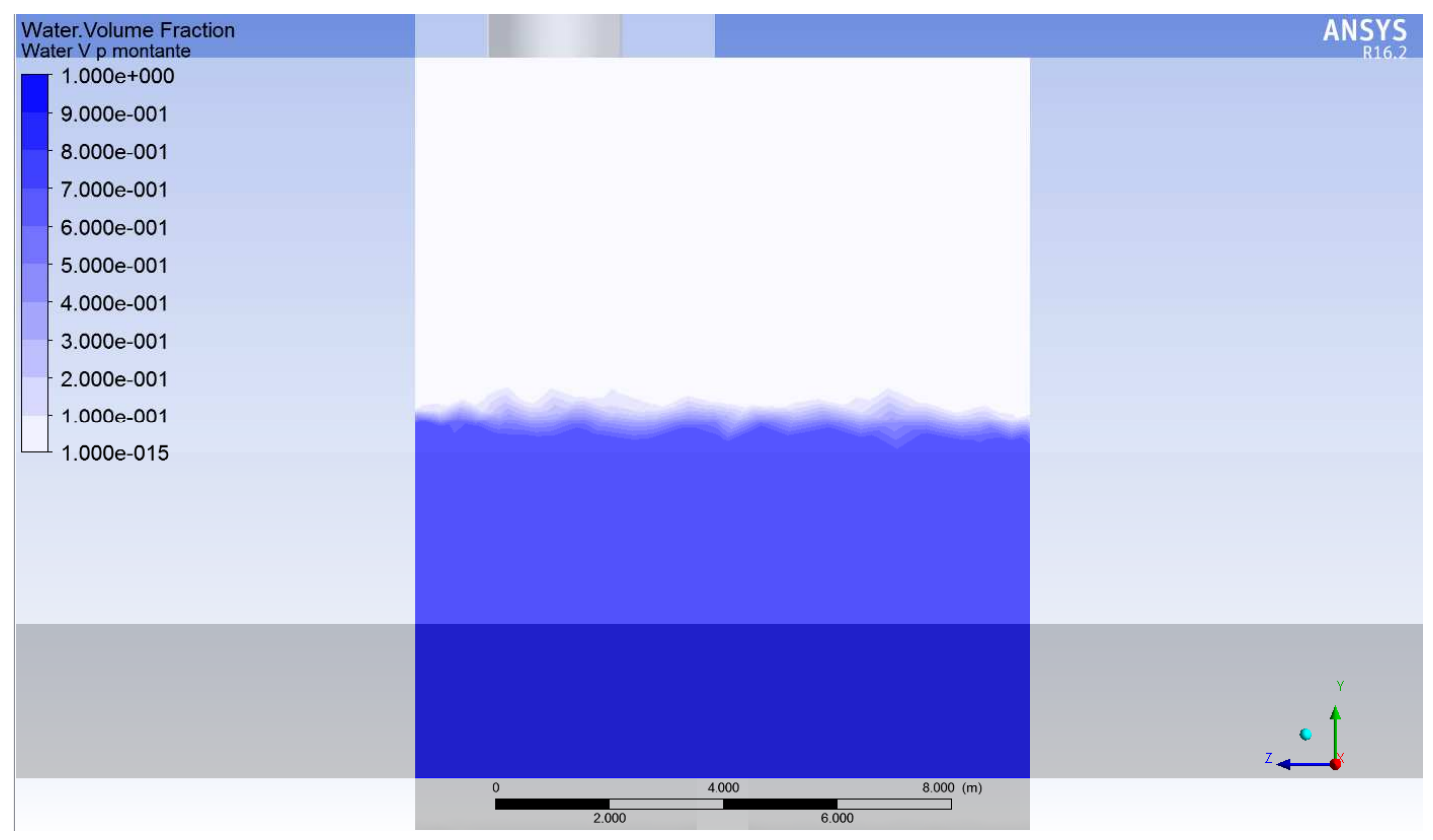

Figura 83. Perfil de linha d'água no final da câmara dissipadora, 1 válvula a 53,0 $\mathrm{m}^{3} / \mathrm{s}$

Na sequência, a figura 84 mostra o perfil do ressalto hidráulico no final da parede divisória, visto de jusante para montante.

Praticamente não se nota decréscimo de nível de água na região da linha de centro da válvula, que seria provocado pelo fluxo de água da válvula empurrando o nível a superfície de água. Neste caso não se nota dificuldade da câmara em absorver o jato, indicada pela regularidade na fração de volume vista na figura 84 . 


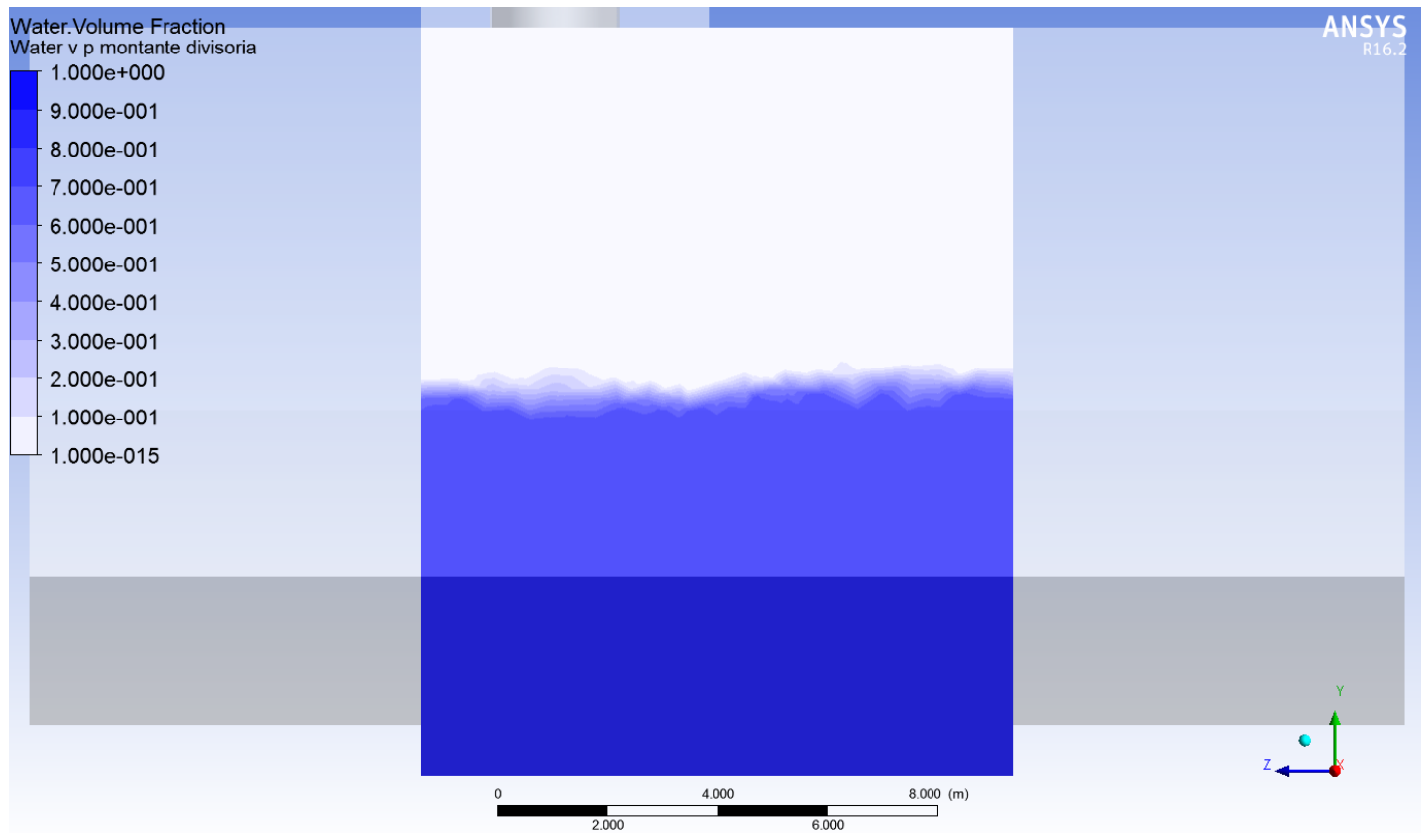

Figura 84. Perfil de linha d'água no final da parede divisória, 1 válvula a 53,0 m³/s

\subsubsection{Pressão no Fundo da Câmara Dissipadora}

As pressões na região dos piezômetros de 1 a 9 são mostradas na tabela 14 .

Tabela 14. Cargas de pressão para os piezômetros de 1 a 9, obtidos por CFD para $H / d=7,5$

\begin{tabular}{|c|c|c|c|}
\cline { 2 - 4 } \multicolumn{1}{c|}{} & $\begin{array}{c}\text { 2 válvulas a } \\
53.0 \mathrm{~m}^{3} / \mathrm{s}\end{array}$ & $\begin{array}{c}\text { 2 válvulas a } \\
29.67 \mathrm{~m}^{3} / \mathrm{s}\end{array}$ & $\begin{array}{c}\text { 1 válvula a } \\
53.0 \mathrm{~m}^{3} / \mathrm{s}\end{array}$ \\
\cline { 2 - 4 } \multicolumn{1}{c|}{} & $\mathrm{CFD}(\mathrm{m})$ & $\mathrm{CFD}(\mathrm{m})$ & $\mathrm{CFD}(\mathrm{m})$ \\
\hline Piezo 1 & 8.15 & 8.13 & 9.10 \\
\hline Piezo 2 & 10.85 & 8.34 & 10.12 \\
\hline Piezo 3 & 6.30 & 6.41 & 5.97 \\
\hline Piezo 4 & 7.11 & 7.23 & 7.31 \\
\hline Piezo 5 & 8.30 & 7.13 & 7.48 \\
\hline Piezo 6 & 6.27 & 6.35 & 5.96 \\
\hline Piezo 7 & 7.44 & 7.32 & 7.51 \\
\hline Piezo 8 & 8.72 & 7.41 & 8.55 \\
\hline Piezo 9 & 6.87 & 6.62 & 6.58 \\
\hline
\end{tabular}

Para a relação $H / d=7,5$ os valores máximos de pressão ocorrem no piezômetro 2 , ou seja, da mesma forma que ocorre para a relação $H / d=11,2$. Isto indica que a mudança não muito 
grande de vazão bem como a pequena mudança na formação do perfil da superfície de água entre estes dois casos, trouxeram aproximadamente a mesma região de carga cinética do jato e carga estática.

\subsubsection{Análise e Cálculo de Eficiência de Dissipação de Energia}

Utilizando os mesmos parâmetros aplicados à relação $H / d=11,2$, a tabela 15 mostra o resumo de dissipação de energia entre a entrada da válvula e o final da câmara de dissipação.

Tabela 15. Análise de Dissipação de Energia, obtido por CFD para $H$ / d =7,5

\begin{tabular}{|c|c|c|c|c|c|c|c|c|c|c|c|c|c|}
\hline $\begin{array}{c}\text { Número de } \\
\text { válvulas }\end{array}$ & $\begin{array}{c}\text { Abertura } \\
(\%)\end{array}$ & $\begin{array}{c}\mathrm{Q} \\
\text { válvula } \\
\left(\mathrm{m}^{3} / \mathrm{s}\right)\end{array}$ & $\mathrm{H} / \mathrm{d}$ & $\begin{array}{c}\mathrm{b} \\
(\mathrm{m})\end{array}$ & $\begin{array}{c}\text { v jato } \\
(\mathrm{m} / \mathrm{s})\end{array}$ & $\begin{array}{c}\text { v saída } \\
\text { válvula } \\
(\mathrm{m} / \mathrm{s})\end{array}$ & $\begin{array}{c}\text { v final } \\
\text { câmara } \\
(\mathrm{m} / \mathrm{s})\end{array}$ & $\begin{array}{c}\text { Hp } \\
\text { válvula } \\
(\mathrm{m})\end{array}$ & $\begin{array}{c}\mathrm{Hp} \\
\text { câmara } \\
(\mathrm{m})\end{array}$ & $\begin{array}{c}\text { Hp } \\
\text { total } \\
(\mathrm{m})\end{array}$ & $\begin{array}{c}\text { Hp } \\
\text { válvula } \\
\text { /H }(\%)\end{array}$ & $\begin{array}{c}\mathrm{Hp} \\
\text { câmara } \\
/ \mathrm{H}(\%)\end{array}$ & $\mathrm{Ed}(\%)$ \\
\hline 2 & 100 & 53.00 & 7.5 & 0.30 & 17.10 & 11.18 & 1.32 & 10.8 & 6.3 & 17.1 & 62.9 & 36.6 & 99.5 \\
\hline 2 & 50 & 29.66 & 7.5 & 0.17 & 16.57 & 9.62 & 0.84 & 12.4 & 4.7 & 17.1 & 72.4 & 27.4 & 99.8 \\
\hline 1 & 100 & 53.00 & 7.1 & 0.29 & 16.56 & 11.10 & 0.72 & 9.9 & 6.3 & 16.2 & 61.2 & 38.6 & 99.8 \\
\hline 1 & 50 & 29.66 & 7.4 & 0.16 & 16.60 & 9.22 & 0.43 & 12.6 & 4.3 & 16.9 & 74.4 & 25.6 & $\sim 100.0$ \\
\hline
\end{tabular}

Igualmente a todas outras simulações, as relações entre perda de carga na câmara dissipadora e a perda total entre a entrada da válvula e câmara dissipadora são praticamente mantidas quando comparamos uma ou duas válvulas operando à mesma abertura.

\subsubsection{Comentários}

A relação $H / d=7,5$ não contrasta tanto com a relação a qual a câmara foi projetada, ou seja, $H / d=11,2$. Assim, baseado na regularidade de fração de volume, pode-se dizer que há indícios de que a faixa operativa possa ser estendida para $H / d=7,5$. 


\subsection{Definição dos Limites Operacionais da Câmara Dissipadora}

Diante de todos os pontos operacionais apresentados, nota-se que a proporção de dissipação de energia da câmara dissipadora e da energia total é mantida praticamente constante para as mesmas aberturas de válvula, independente do número de válvulas em operação, relação $H$ / $d$ e vazão aplicada.

Entretanto, foram observadas diferenças significativas no perfil de superfície de água para cada abertura e relação $H / d$ aplicada, o que fornece indícios sobre limites de operação da câmara dissipadora, especialmente no que tange as relações $H / d$, vazões e recirculação de água.

Assim, o cálculo de eficiência de dissipação de energia apresentado considera somente velocidades médias na câmara de dissipação, sem considerar eventuais turbilhões e recirculações dentro da mesma, que impactariam na energia em uma dada seção. Assim, é necessária a definição de parâmetros para estabelecer limites de operação da câmara, que serão propostas a seguir.

\subsubsection{Análise pelo Número de Froude}

Em termos gerais, o número de Froude em estruturas de concreto não costuma exceder valores entre 5 e 6 , sendo comum ficar abaixo de 4, conforme recomenda o manual URBAN DRAINAGE AND FLOOD CONTROL DISTRICT (2016).

Outro parâmetro para estabelecer o limite de operação de uma estrutura de concreto é a velocidade média na seção de escoamento que usualmente não ultrapassa $6,0 \mathrm{~m} / \mathrm{s}$, conforme recomenda o manual da ELETROBRÁS (2003). 
Para todas as relações $H / d$ simuladas, serão analisadas aquelas com abertura de válvula de $100 \%$, que resulta em maior velocidade e maior número de Froude.

O cálculo do número de Froude que será apresentado mais adiante foi executado para todas as relações $H / d$ simuladas anteriormente, nas seções indicadas nas figuras de 85 a 88 :

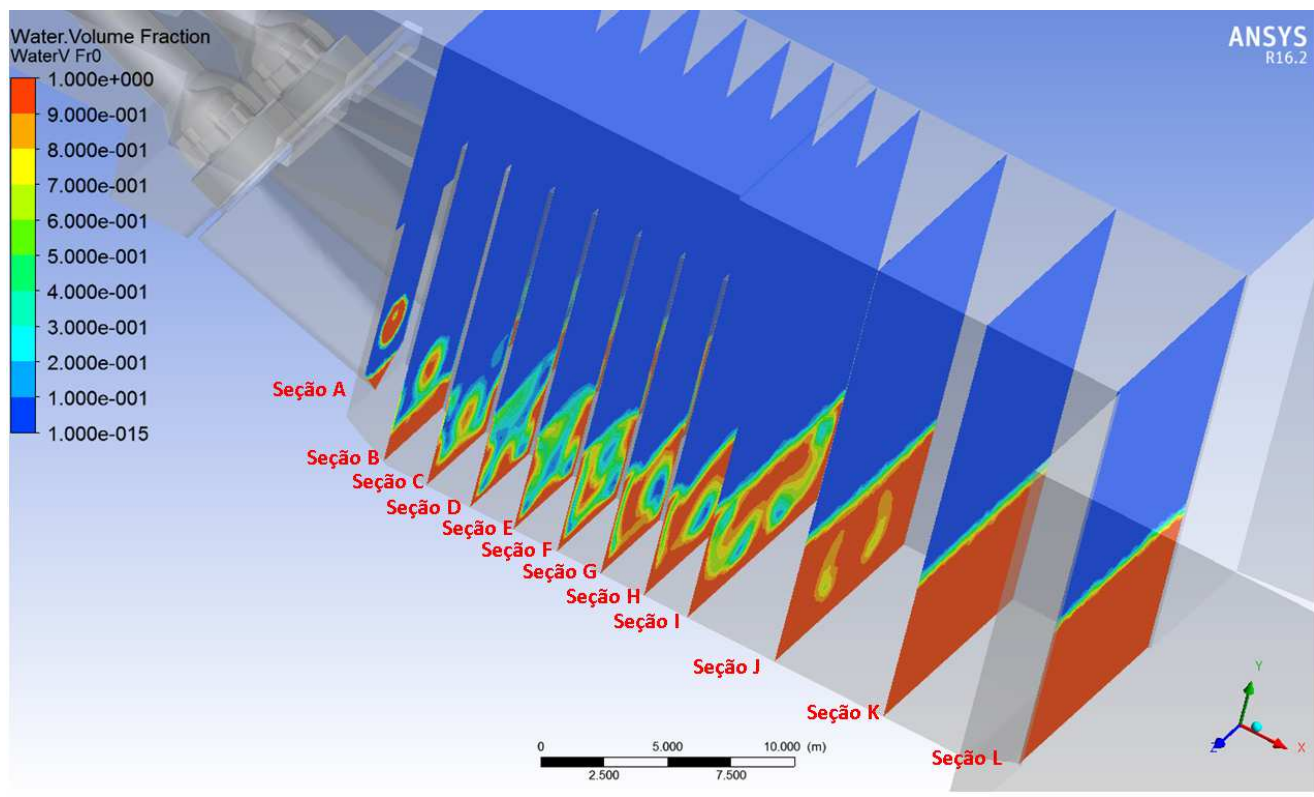

Figura 85. Fração de volume nas seções analisadas pelo número de Froude, $H / d=20$

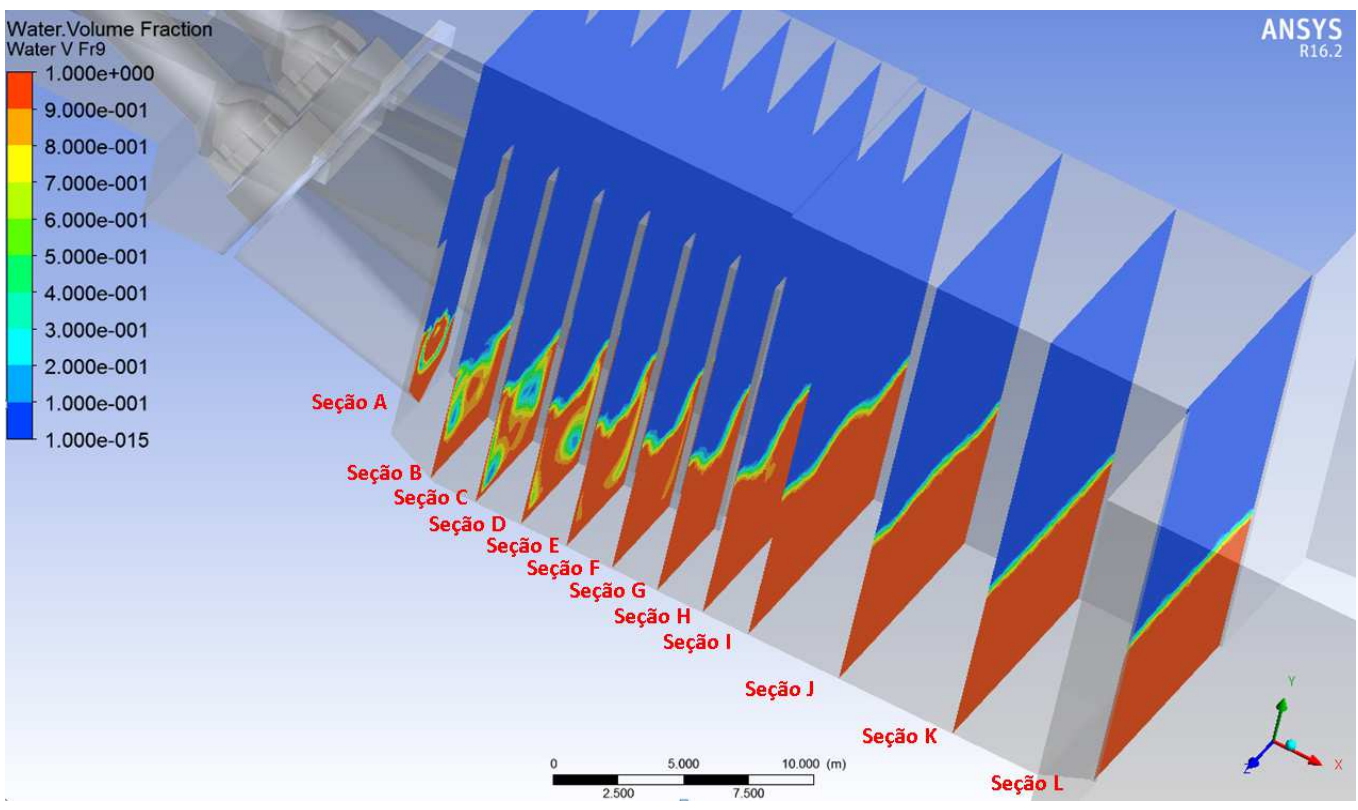

Figura 86. Fração de volume nas seções analisadas pelo número de Froude, $H$ / d =15 


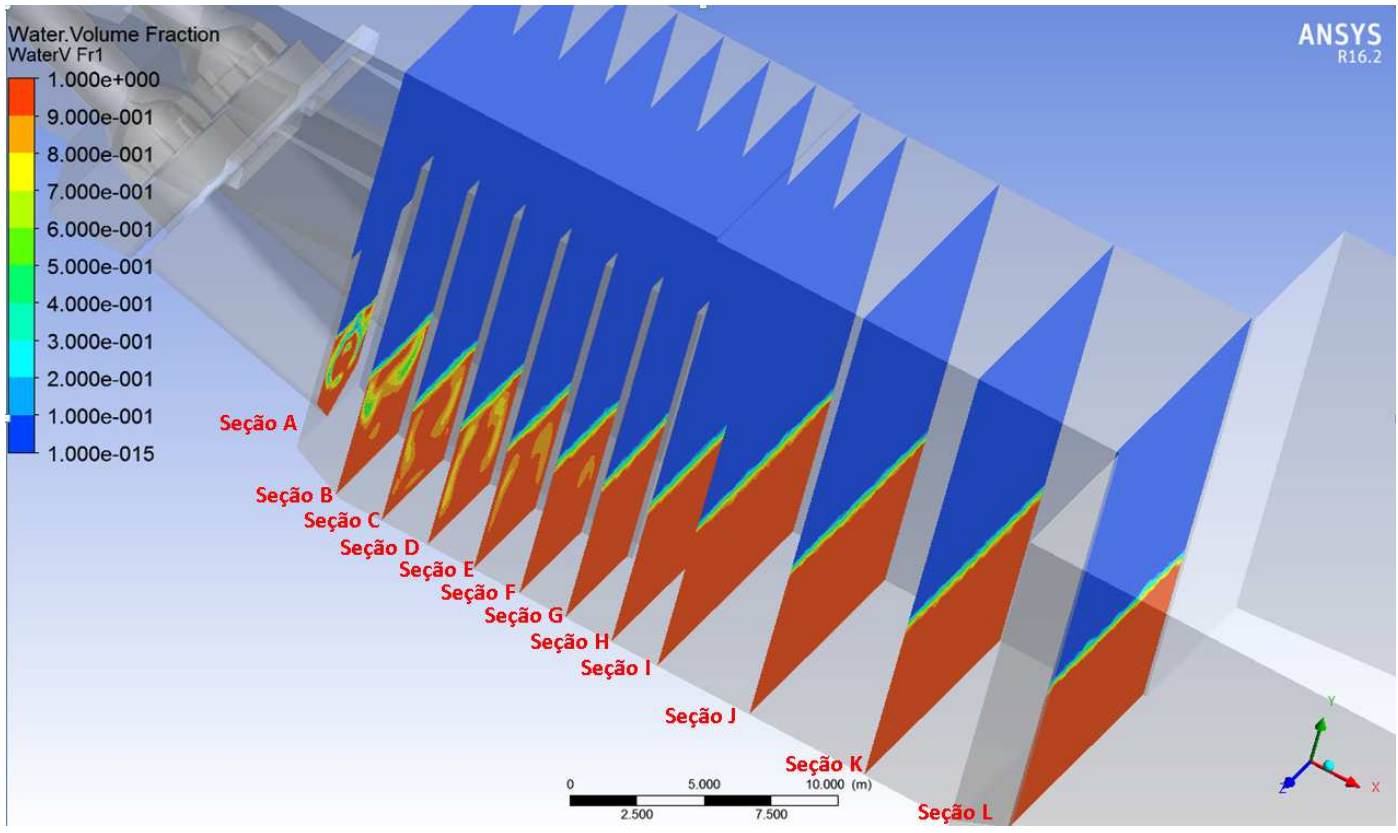

Figura 87. Fração de volume nas seções analisadas pelo número de Froude, $H / d=11,2$

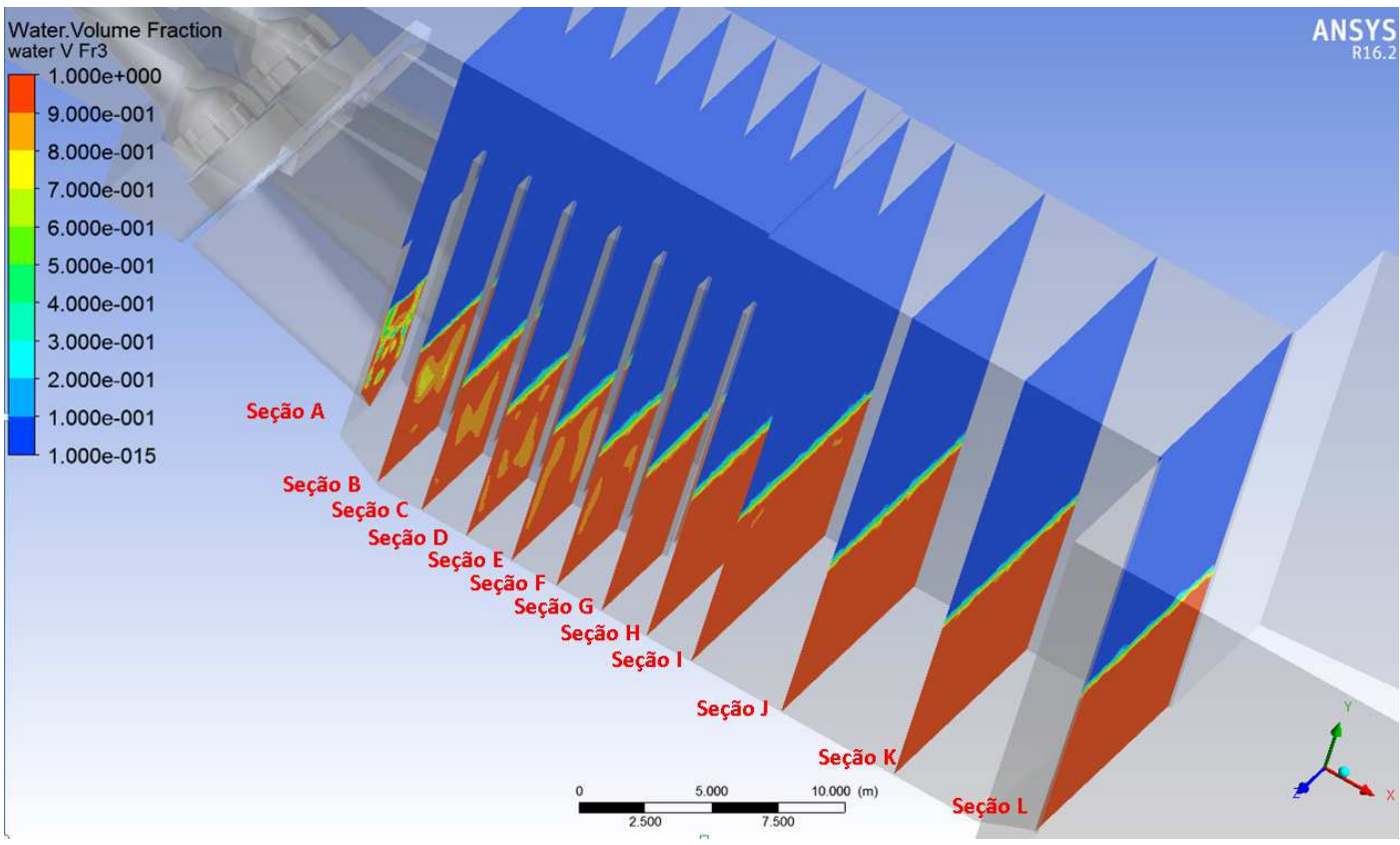

Figura 88. Fração de volume nas seções analisadas pelo número de Froude, $H / d=7,5$

A figura 85 mostra a fração de volume não uniforme ao longo da câmara de dissipação para a relação $H / d=20$, enquanto que na figura 86 a fração de volume assume formato mais 
uniforme para a relação $H / d=15$, tendo esta uniformidade acentuada para as demais relações $H / d$, vistas nas figuras 87 e 88 .

Conforme equação 1 a relação mais elevada de $H / d$ resulta em maior vazão, que consequentemente resulta em maior quantidade de movimento do jato incidente na câmara de dissipação. Desta forma, o jato empurra o volume de água da câmara para a jusante, provocando um ressalto hidráulico menos uniforme conforme mostrado nas figuras 85 e 86 .

A não uniformidade do ressalto hidráulico se associa a maior turbulência para operação da câmara de dissipação e também a profundidades muito rasas próximas à região de incidência do jato, que pode ser interpretada de forma local como um nível abaixo do nível sweepout, não sendo indicado para operação conforme explicado na seção 2.4. A uniformidade da distribuição da fração de volume ao longo da câmara dissipadora pode ser um indicativo de faixa operativa admissível, pois esta pode indicar boa distribuição de velocidades e provável baixo número de Froude, relacionado a ressaltos hidráulicos mais suaves.

Nas tabelas 16, 17, 18 e 19, o número de Froude foi calculado para cada seção indicada nas figuras de 85 a 88.

Tabela 16. Número de Froude ao longo da câmara de dissipação, $H / d=20$

\begin{tabular}{|c|c|c|c|c|}
\hline Seção & Posição no eixo x $(\mathrm{m})$ & $\begin{array}{c}\text { V seção } \\
(\mathrm{m} / \mathrm{s})\end{array}$ & $\mathrm{h}(\mathrm{m})$ & Froude $(-)$ \\
\hline A & 0 & 26.3 & 1.3 & 7.5 \\
\hline B & 2 & 10.1 & 2.7 & 2.0 \\
\hline C & 4 & 9.6 & 3.1 & 1.7 \\
\hline D & 6 & 8.3 & 3.5 & 1.4 \\
\hline E & 8 & 8.9 & 3.8 & 1.5 \\
\hline F & 10 & 8.7 & 3.9 & 1.4 \\
\hline G & 12 & 9.2 & 4.4 & 1.4 \\
\hline H & 14 & 9.7 & 5.0 & 1.4 \\
\hline I & 16 & 8.1 & 5.2 & 1.1 \\
\hline J & 20 & 7.0 & 6.7 & 0.9 \\
\hline K & 25 & 5.1 & 7.8 & 0.6 \\
\hline L & 31 & 4.3 & 7.7 & 0.5 \\
\hline
\end{tabular}


Tabela 17. Número de Froude ao longo da câmara de dissipação, $H / d=15$

\begin{tabular}{|c|c|c|c|c|}
\hline Seção & Posição no eixo x (m) & $\begin{array}{c}\text { V seção } \\
(\mathrm{m} / \mathrm{s})\end{array}$ & $\mathrm{h}(\mathrm{m})$ & Froude (-) \\
\hline A & 0.0 & 16.0 & 3.5 & 2.7 \\
\hline B & 2.0 & 5.7 & 4.5 & 0.9 \\
\hline C & 4.0 & 6.4 & 5.1 & 0.9 \\
\hline D & 6.0 & 6.6 & 5.7 & 0.9 \\
\hline E & 8.0 & 6.9 & 6.1 & 0.9 \\
\hline F & 10.0 & 7.0 & 6.5 & 0.9 \\
\hline G & 12.0 & 7.0 & 7.0 & 0.8 \\
\hline H & 14.0 & 6.2 & 7.4 & 0.7 \\
\hline I & 16.0 & 5.5 & 7.8 & 0.6 \\
\hline J & 20.0 & 5.2 & 7.7 & 0.6 \\
\hline K & 25.0 & 4.4 & 8.0 & 0.5 \\
\hline L & 31.0 & 4.1 & 7.5 & 0.5 \\
\hline
\end{tabular}

Tabela 18. Número de Froude ao longo da câmara de dissipação, $H / d=11,2$

\begin{tabular}{|c|c|c|c|c|}
\hline Seção & Posição no eixo x $(\mathrm{m})$ & $\begin{array}{c}\text { V seção } \\
(\mathrm{m} / \mathrm{s})\end{array}$ & $\mathrm{h}(\mathrm{m})$ & Froude $(-)$ \\
\hline A & 0.0 & 9.3 & 5.4 & 1.3 \\
\hline B & 2.0 & 4.2 & 5.9 & 0.6 \\
\hline C & 4.0 & 5.1 & 6.2 & 0.7 \\
\hline D & 6.0 & 6.7 & 6.2 & 0.9 \\
\hline E & 8.0 & 6.0 & 6.4 & 0.8 \\
\hline F & 10.0 & 5.8 & 6.8 & 0.7 \\
\hline G & 12.0 & 5.5 & 7.4 & 0.6 \\
\hline H & 14.0 & 4.9 & 7.4 & 0.6 \\
\hline I & 16.0 & 4.6 & 7.6 & 0.5 \\
\hline J & 20.0 & 4.4 & 7.9 & 0.5 \\
\hline K & 25.0 & 3.7 & 8.3 & 0.4 \\
\hline L & 31.0 & 3.2 & 7.7 & 0.4 \\
\hline
\end{tabular}


Tabela 19. Número de Froude ao longo da câmara de dissipação, $H / d=7,5$

\begin{tabular}{|c|c|c|c|c|}
\hline Seção & Posição no eixo x $(\mathrm{m})$ & $\begin{array}{c}\text { v seção } \\
(\mathrm{m} / \mathrm{s})\end{array}$ & $\mathrm{h}(\mathrm{m})$ & Froude $(-)$ \\
\hline A & 0.0 & 5.8 & 7.00 & 0.7 \\
\hline B & 2.0 & 3.13 & 7.42 & 0.4 \\
\hline C & 4.0 & 4.33 & 7.03 & 0.5 \\
\hline D & 6.0 & 4.89 & 6.83 & 0.6 \\
\hline E & 8.0 & 5.06 & 6.76 & 0.6 \\
\hline F & 10.0 & 4.79 & 7.05 & 0.6 \\
\hline G & 12.0 & 4.45 & 7.65 & 0.5 \\
\hline H & 14.0 & 3.93 & 7.71 & 0.5 \\
\hline I & 16.0 & 3.69 & 7.83 & 0.4 \\
\hline J & 20.0 & 3.43 & 8.10 & 0.4 \\
\hline K & 25.0 & 2.91 & 8.45 & 0.3 \\
\hline L & 31.0 & 2.5 & 7.60 & 0.3 \\
\hline
\end{tabular}

Analisando os números de Froude para todas as seções, independente da relação $H / d$, a maior parte da dissipação de energia ocorre dentro da câmara de dissipação, ou seja, em sua saída todos os números de Froude são subcríticos que representam escoamento fluvial.

Ainda assim, a diferença entre as simulações acima está na forma em que os números de Froude se distribuem ao longo da câmara de dissipação, ou seja, para as relações $H / d$ mais elevadas a redução do número de Froude ocorre bruscamente no início da câmara logo após as paredes convergentes.

Ainda que a maior parte de energia seja dissipada dentro da câmara para todas as relações $L / d$, chama a atenção os valores de velocidade de escoamento no final da câmara (seção $L$ ) obtidos pelo Ansys $C F X$, onde estes apresentam valores relativamente altos quando comparados com aqueles ao valor referente à relação $H / d=11,2$, ou seja, a de projeto. Isto pode ser interpretado como uma provável turbulência no escoamento, proveniente de recirculação das linhas de corrente, que resulta em energia residual no final da câmara.

De forma a complementar a análise da faixa operativa da câmara de dissipação, os estudos de perfil de velocidades na câmara de dissipação, perfil de pressões e análise de recirculação serão apresentados para todas as relações $H / d$. 


\subsubsection{Análise de Perfil de Velocidades e Pressão no Fundo da Câmara Dissipadora}

As figuras de 89 a 92 apresentam a distribuição de velocidades no fundo da câmara para cada relação $H / d$.

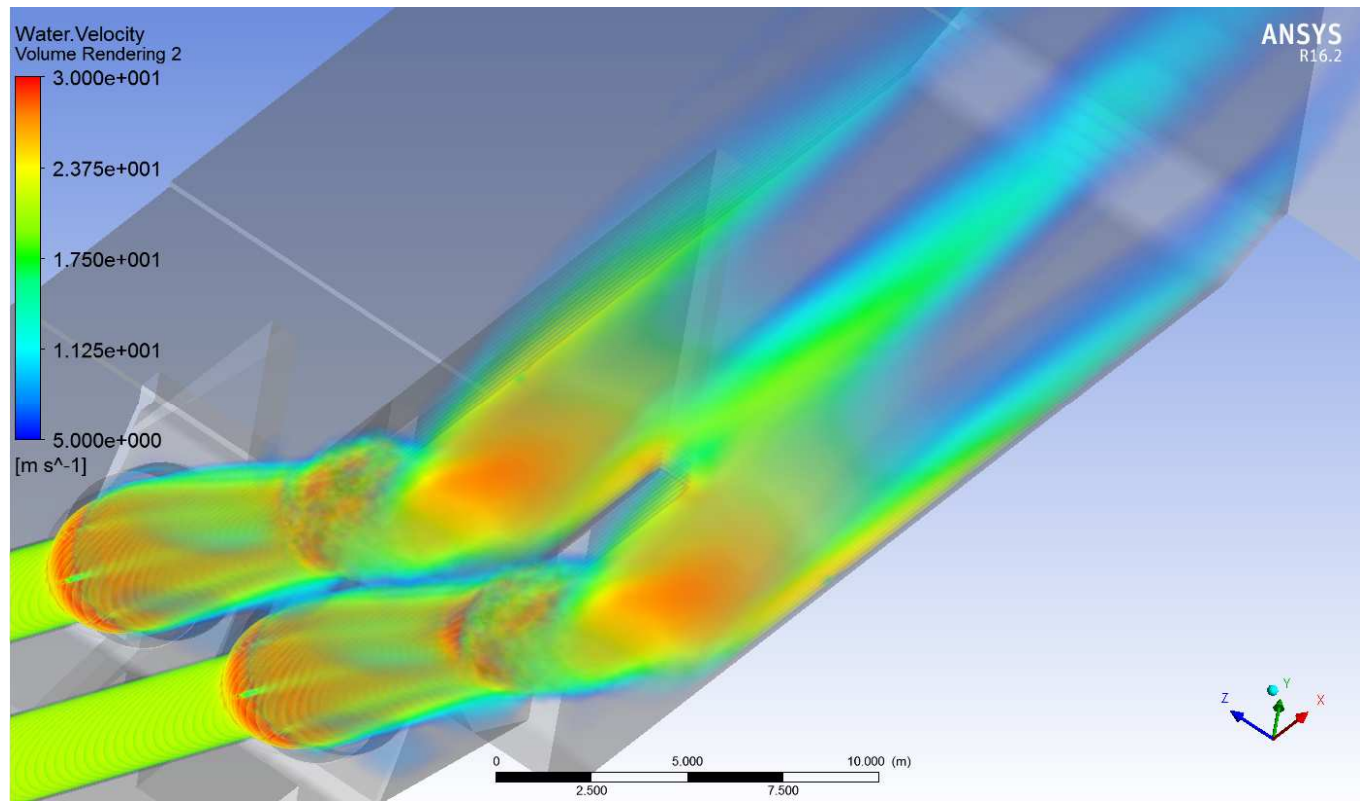

Figura 89. Velocidades de escoamento no fundo da câmara de dissipação , $H / d=20$

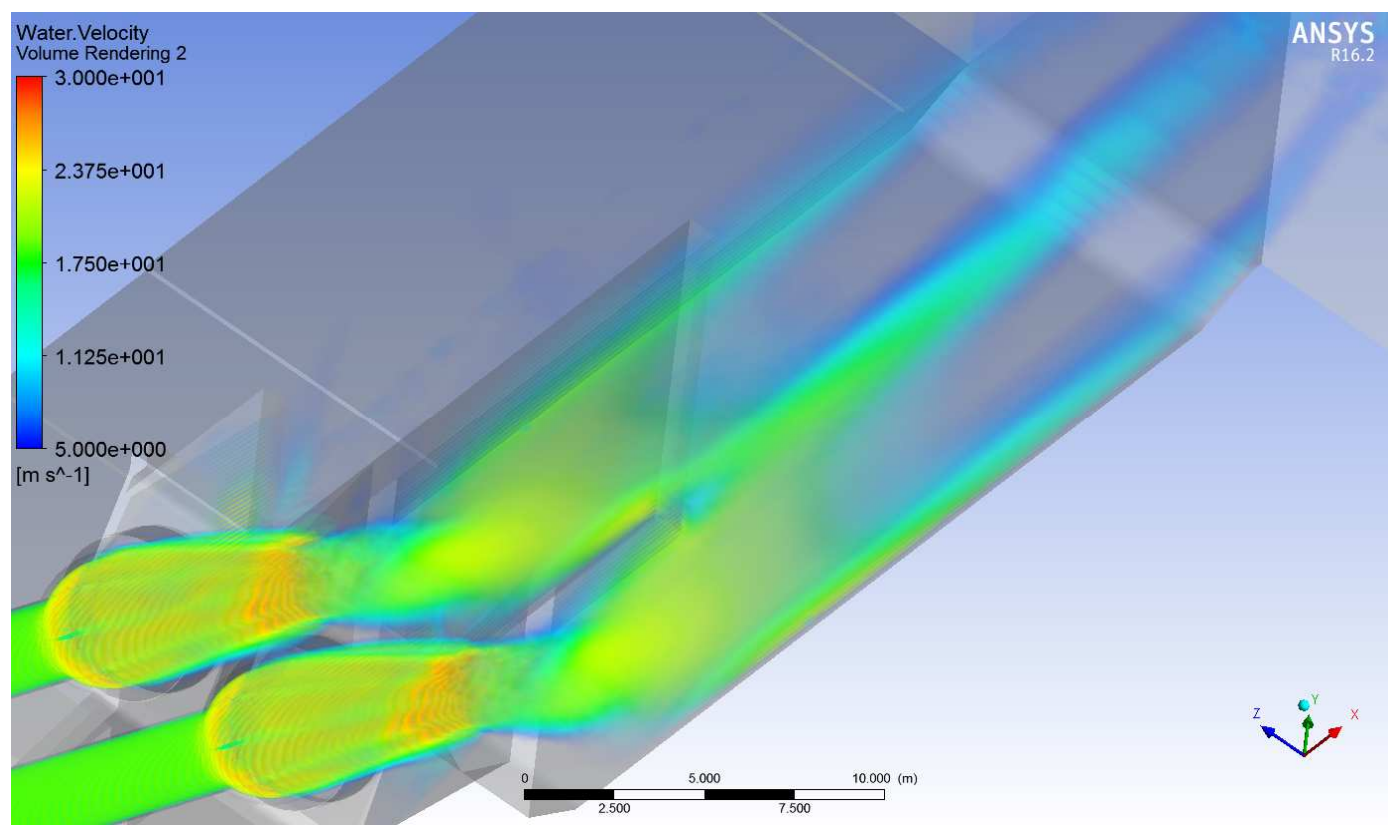

Figura 90. Velocidades de escoamento no fundo da câmara de dissipação , $H / d=15$ 


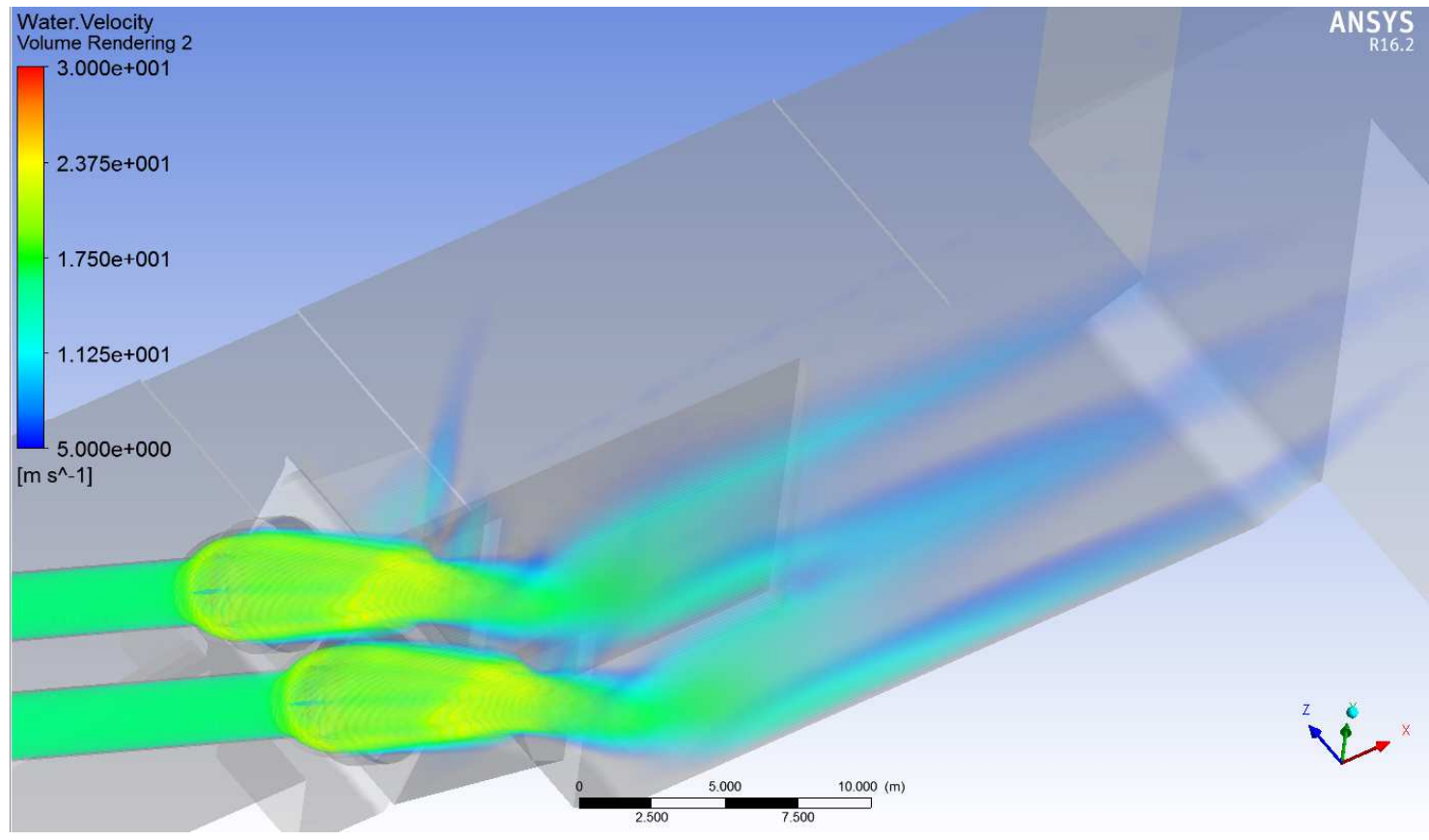

Figura 91. Velocidades de escoamento no fundo da câmara de dissipação , $H / d=11,2$

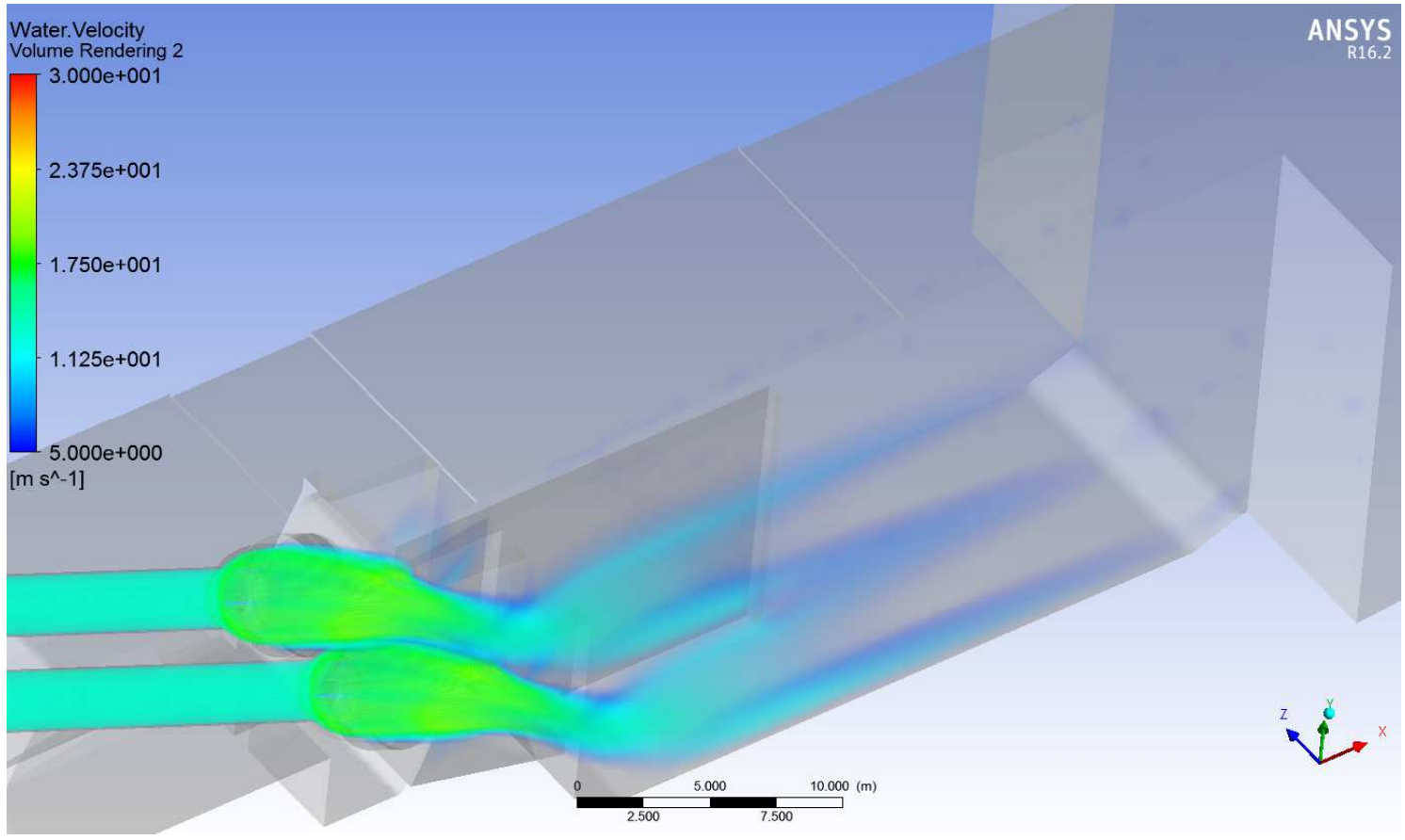

Figura 92. Velocidades de escoamento no fundo da câmara de dissipação , $H / d=7,5$ 
Conforme as figuras de 89 a 92 mostram, o perfil de velocidades incidentes no fundo da câmara de dissipação atinge valor máximo na ordem de $27 \mathrm{~m} / \mathrm{s}$ para a relação $H / d=20$, $22 \mathrm{~m} / \mathrm{s}$ para $H / d=15,18 \mathrm{~m} / \mathrm{s}$ para $H / d=11,2 \mathrm{e} 11 \mathrm{~m} / \mathrm{s}$ para $H / d=7,5$.

Considerando que a estrutura de concreto seja dimensionada para tais condições e tomando como referência as condições iniciais de projeto $(H / d=11,2)$, julga-se possível avaliar a possibilidade de operação do protótipo com $H / d=15$ porque a diferença de velocidades entre estas duas relações $H / d$ não parece distante.

Vale salientar que eventuais instabilidades de operação bem como erosão por destacamento devem avaliadas no ensaio de modelo.

A operação com $H / d=20$ mostrada na figura 89 indica grandes gradientes de velocidade que, em termos práticos tem maior chance de causar erosão por arraste na câmara de dissipação. Desta forma é aconselhável não operar nesta condição.

Para a relação $H / d=7,5$ mostrada na figura 92 não foram observadas restrições, exceto pela verificação da estabilidade de operação em modelo físico.

De forma análoga, a análise de pressões no fundo da câmara de dissipação é apresentada nas figuras de 93 a 96. 


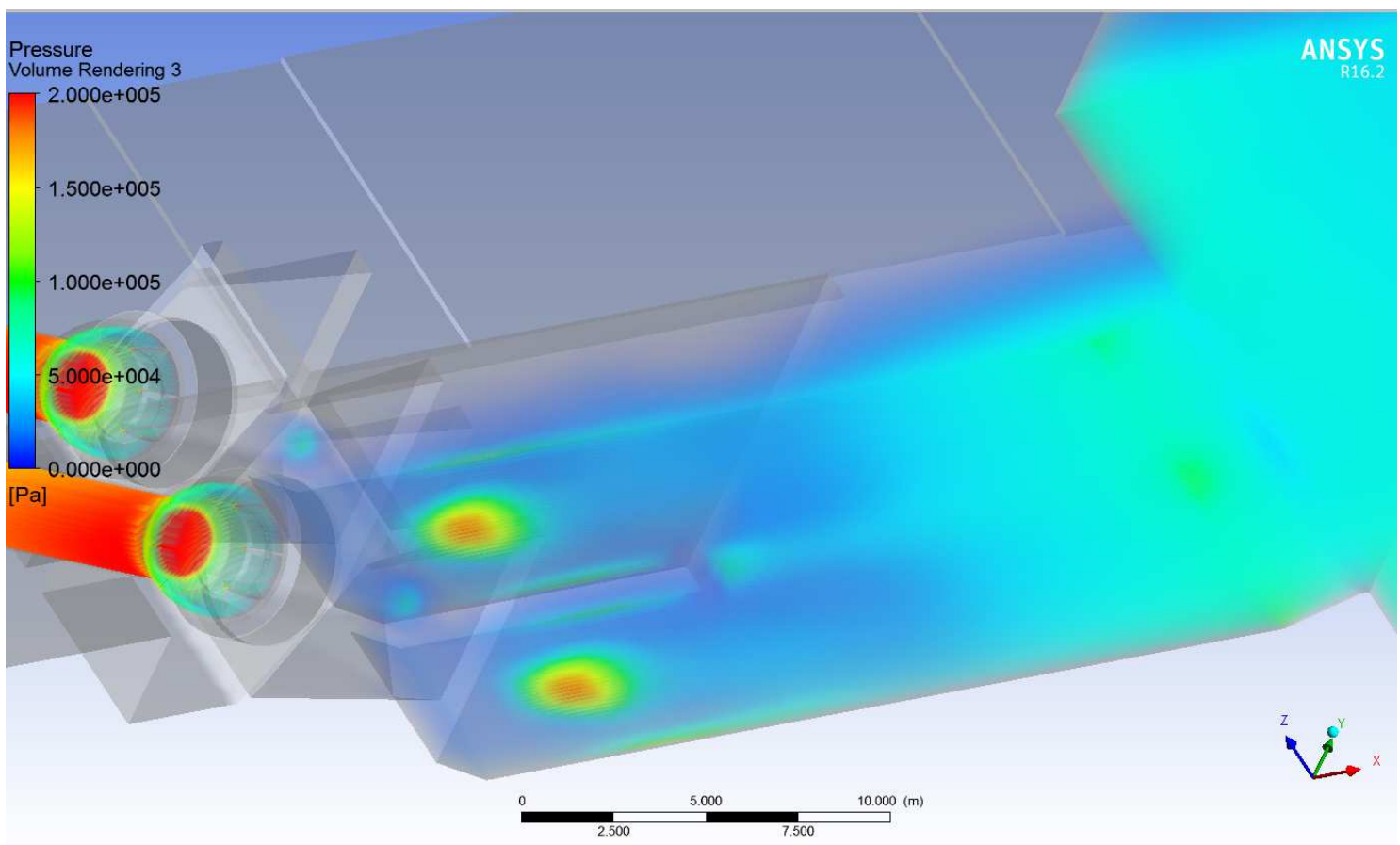

Figura 93. Pressões no fundo da câmara de dissipação , $H / d=20$

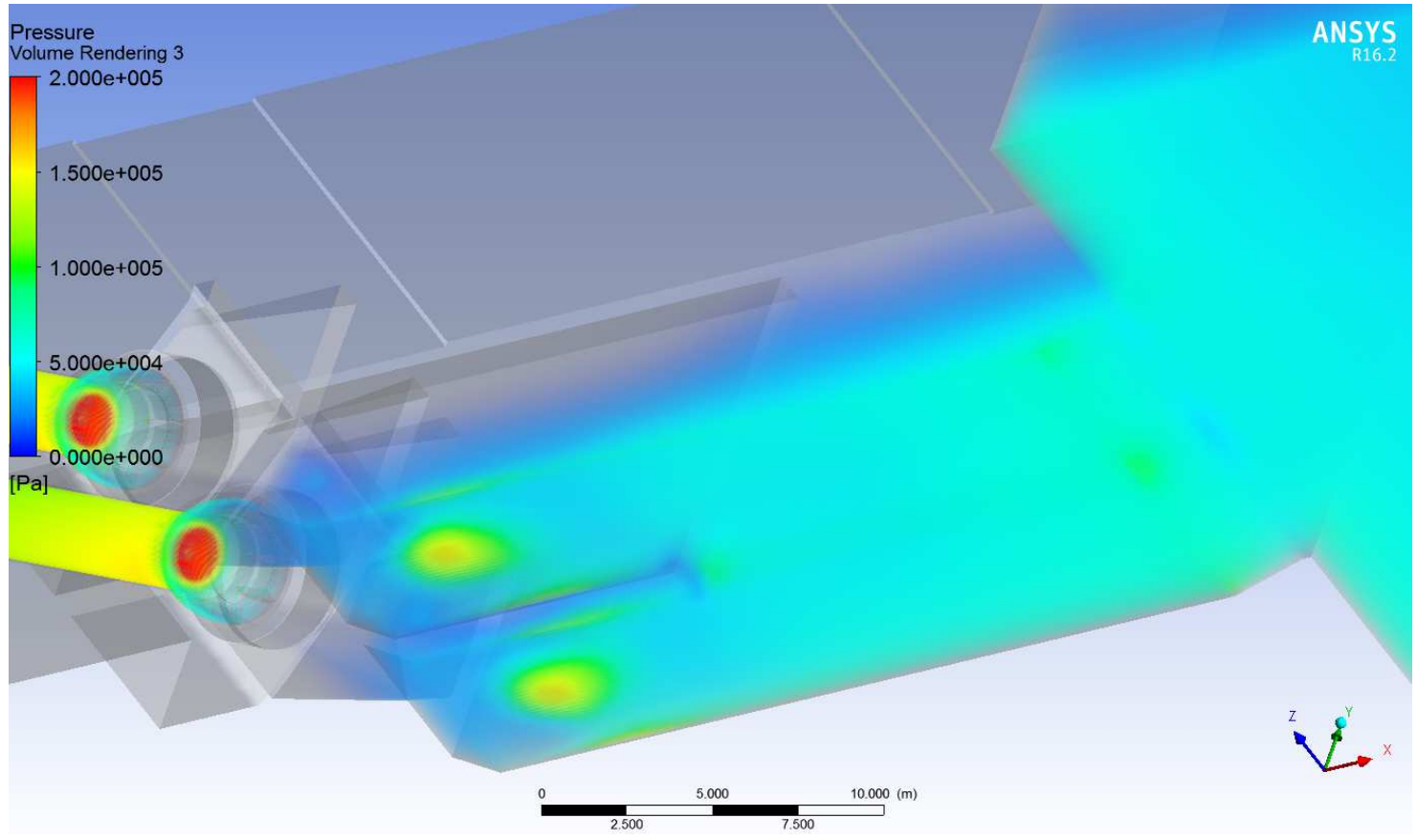

Figura 94. Pressões no fundo da câmara de dissipação , $H / d=15$ 


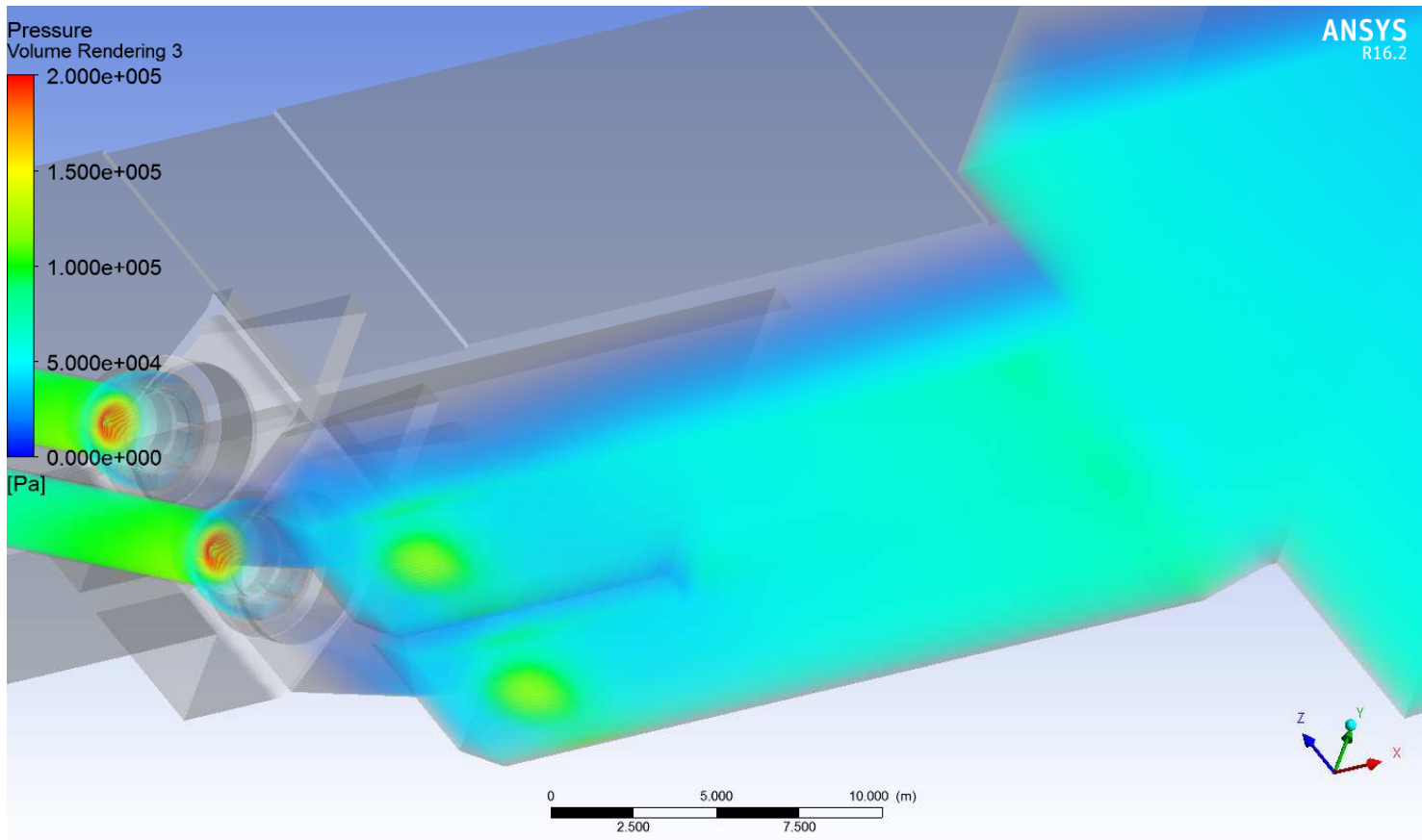

Figura 95. Pressões no fundo da câmara de dissipação , $H / d=11,2$

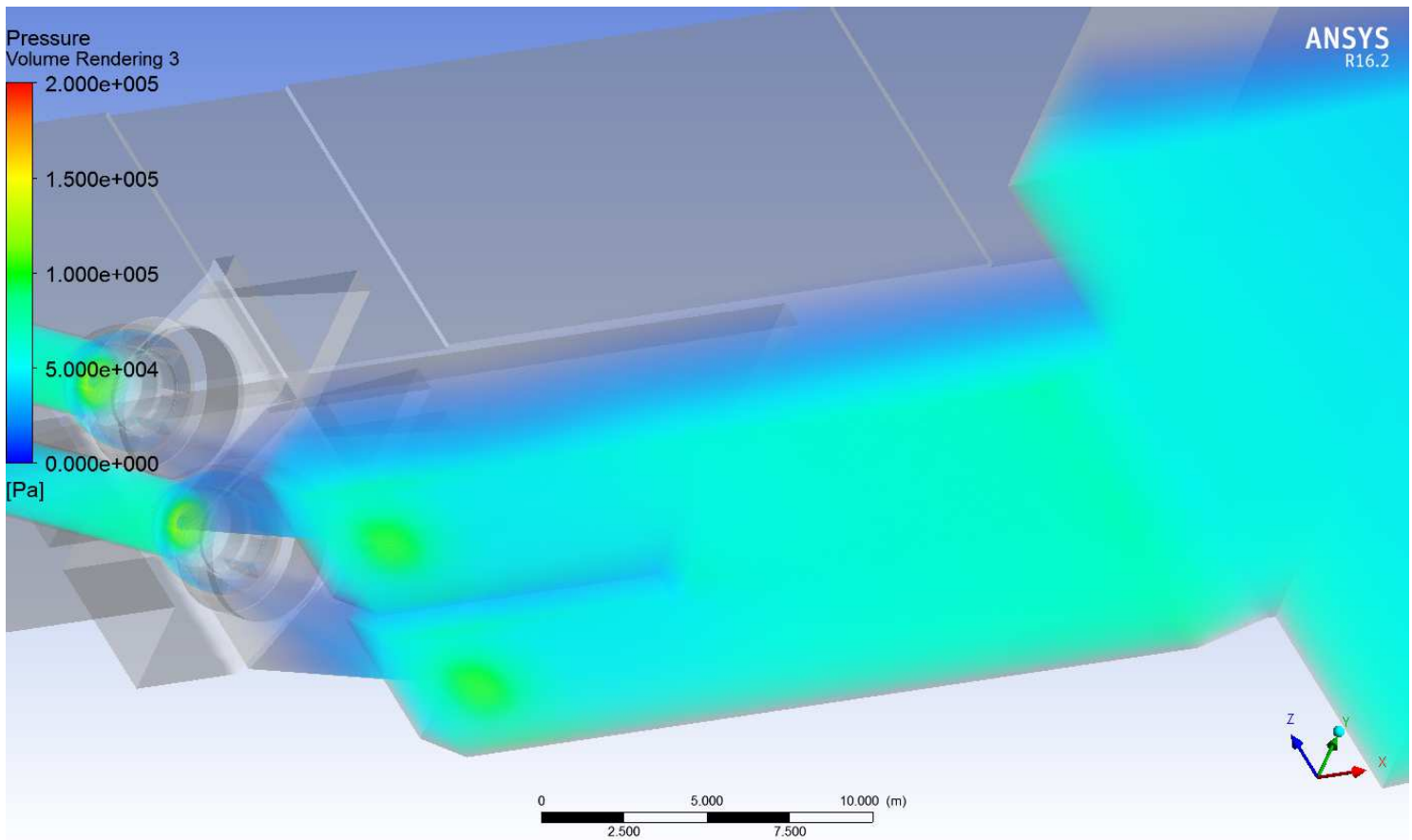

Figura 96. Pressões no fundo da câmara de dissipação , $H / d=7,5$ 
As figuras de 93 a 96 mostram que as magnitudes máximas de carga de pressão no fundo da câmara de dissipação são aproximadamente $19,5 \mathrm{~m}$ para $H / d=20,16,5 \mathrm{~m}$ para $H / d=15$, $14 \mathrm{~m}$ para $H / d=11,2$ e $12 \mathrm{~m}$ para $H / d=7,5$.

Nota-se que as cargas de pressão diferem de forma mais branda para relações $H / d \leq 15$. Isto porque para a relação $H / d \leq 15$ ocorre maior regularidade da fração de volume na região incidente do jato que, por consequência resulta em carga estática mais parecida com a relação de projeto $H / d=11,2$. Além disso, a superfície de água na região onde o jato incide permite maior amortecimento do mesmo.

Desta forma é possível sugerir testes em modelo físicos de forma a confirmar a operação para a $H / d=15$ como admissível.

Vale ressaltar que apesar da aparente normalidade de operação para a relação $H / d=7,5$, as simulações foram executadas em regime estacionário e não transitório. Assim devem-se levar em conta eventuais oscilações de pressão durante o ensaio de modelo físico, que podem contribuir para a erosão da estrutura quando o valor de pressão chega ao seu mínimo, induzindo o destacamento de material da estrutura dissipadora.

Ainda assim, a recirculação de fluxo deve ser analisada, pois esta pode contribuir para a erosão da câmara conforme explicado a seguir.

\subsubsection{Análise das Linhas de Corrente na Câmara Dissipadora}

Finalmente será analisada a questão de linhas de corrente, tendo em mente monitorar eventuais recirculações que possam trazer sólidos em suspensão do canal ou reservatório a jusante da câmara dissipadora para dentro da câmara, o que contribuiria para erosão da mesma.

As figuras de 97 a 100 mostram as linhas de corrente para as relações $H / d$ analisadas. 


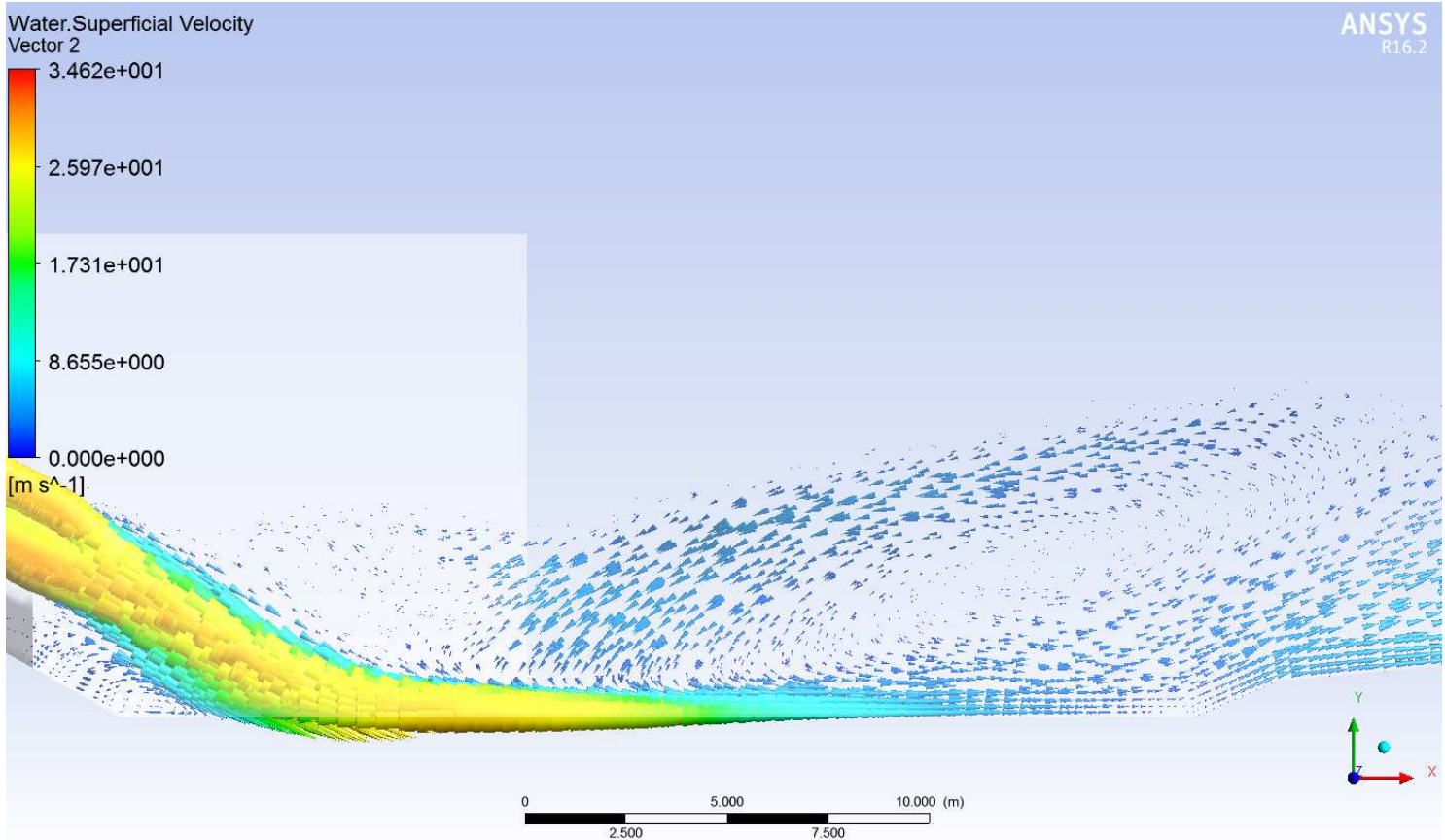

Figura 97. Linhas de corrente vetoriais no plano da válvula, $H / d=20$

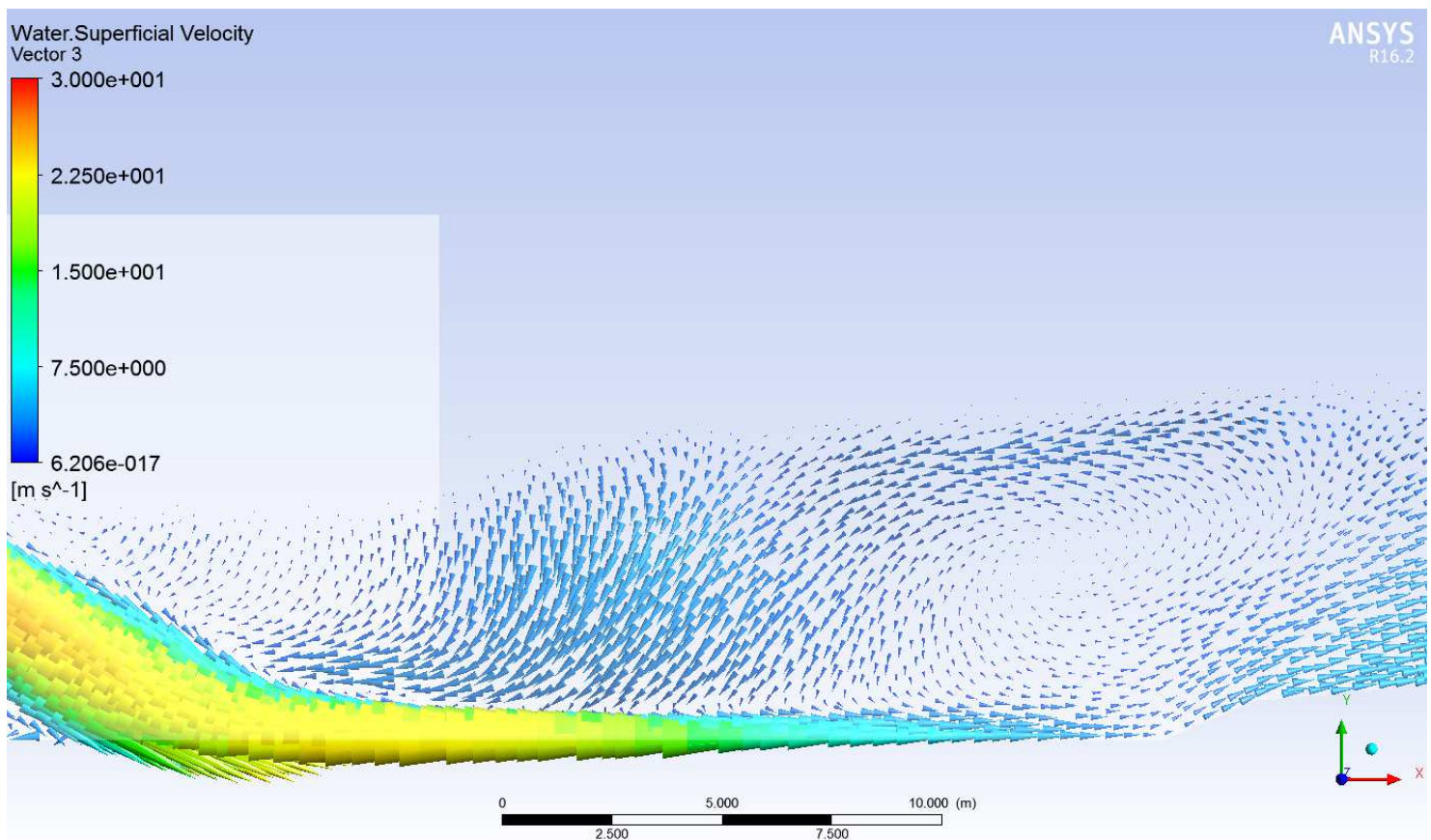

Figura 98. Linhas de corrente vetoriais no plano da válvula, $H / d=15$ 


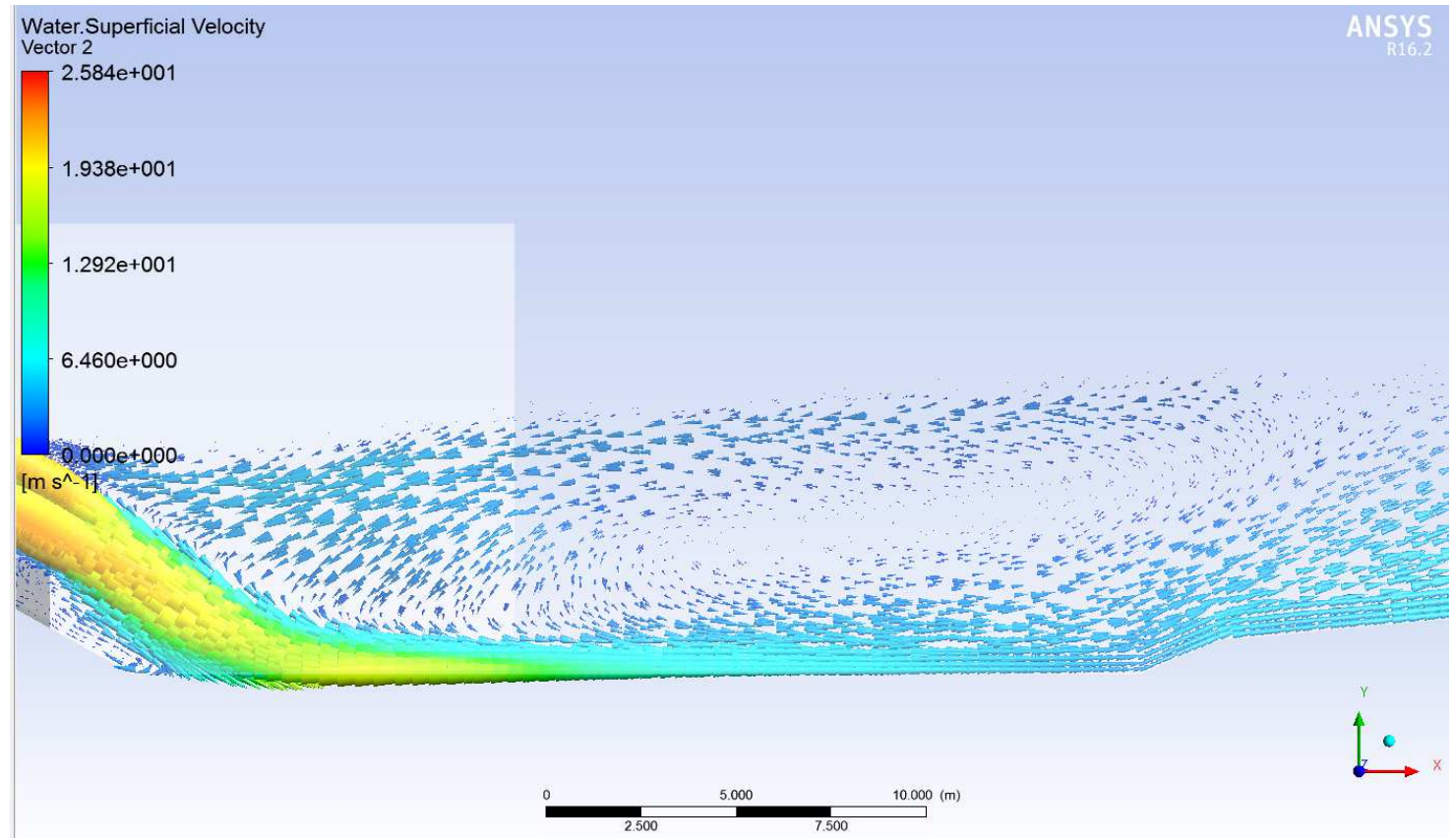

Figura 99. Linhas de corrente vetoriais no plano da válvula, $H$ / d =11,2

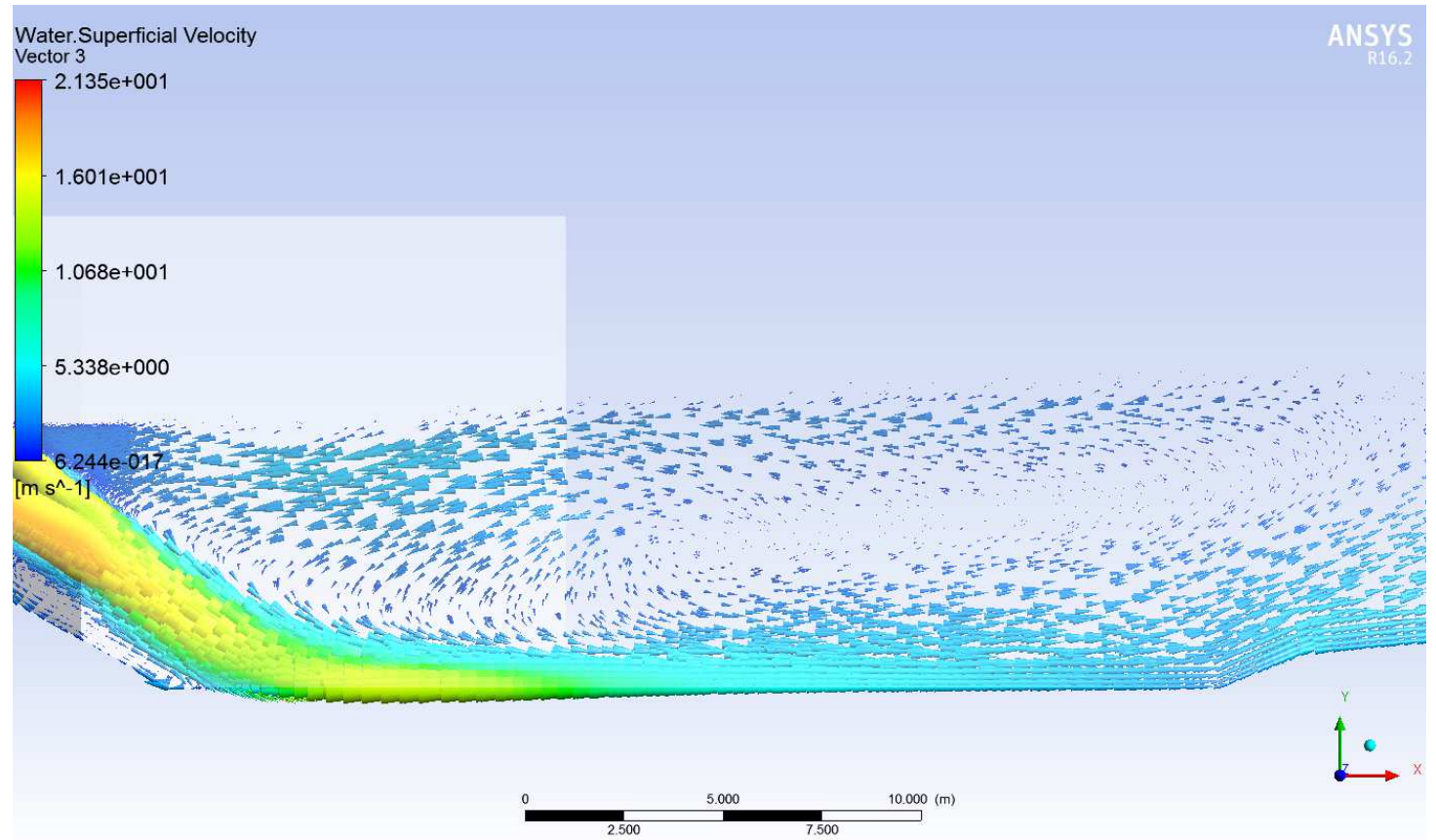

Figura 100. Linhas de corrente vetoriais no plano da válvula, $H / d=7,5$ 
Como pode ser observado nas figuras de 97 a 100, a recirculação se dá na parte superior do escoamento, o que já era esperado porque a incidência do jato na parte inferior da câmara de dissipação induz a recirculação de água na região mais próxima a superfície, formando então o ressalto hidráulico.

A diferença na forma do ressalto hidráulico para cada relação $H / d$ está no comprimento e profundidade da recirculação, ou seja, para as maiores relações $H / d$ o ressalto hidráulico apresenta comprimento menor e mais profundo, enquanto o oposto ocorre para as menores relações.

Desta forma, a diferença de comprimento da região de ressalto hidráulico é inversamente proporcional à velocidade de escoamento no fundo da câmara de dissipação, sendo esta proveniente da válvula dispersora.

Com relação à limitação de faixa operativa devido à recirculação, devem-se observar os vetores de velocidade (magnitude e direção do escoamento) na saída da parte inferior da câmara de dissipação.

Os vetores de velocidade citados acima não devem apresentar valores muito altos porque se estiverem mais alinhados com a horizontal, o escoamento poderá induzir erosão fora da câmara dissipadora, ou seja, no fundo do canal aberto ou reservatório. Ainda assim, se estes vetores fora da câmara retornam à câmara através da recirculação, também pode haver erosão dentro da câmara.

Além destes vetores de escoamento não deverem apresentar grandes magnitudes, não é aconselhável que estes estejam inclinados na vertical no sentido da superfície. Tal condição induziria o levantamento de sólidos do fundo do reservatório podendo ser levados para dentro da câmara de dissipação, aumentando as chances de erosão da mesma.

Em resumo, valores elevados de $H / d$ podem causar erosão fora (e talvez dentro) da câmara de dissipação enquanto seus baixos valores podem causar erosão por destacamento dentro da 
câmara de dissipação se o ângulo dos vetores de velocidades for muito inclinado para a superfície.

É observado que próximo ao fundo da saída da câmara de dissipação não os vetores de velocidade apresentam valores próximos a 4 e $6 \mathrm{~m} / \mathrm{s}$ para todas as relações de $H$ / $d$.

A profundidade da recirculação próxima à saída da câmara é maior para as maiores relações de $H / d$, resultando em maior inclinação para a superfície dos vetores de velocidade, o que aumenta as chances de entrada de sólidos trazidos do fundo do reservatório para a câmara de dissipação.

Referente às relações $H / d \geq 11,2$ é possível observar que o ressalto hidráulico tende a sair da câmara de dissipação, ou seja, a câmara de dissipação começa a ficar proporcionalmente pequena para o ponto operacional.

Para as relações $H / d \leq 11,2$, a profundidade da recirculação aparentemente não provocaria erosão apresentando um ressalto hidráulico mais suave.

Quanto às demais relações, estas podem ser verificadas em ensaio de modelo físico sendo que a relação $H / d=15$ tem maior chance de sucesso nos testes pois, sua profundidade de recirculação é bem menor que a apresentada pela relação $H / d=20$, o que sugere menor criticidade para erosão por arraste no fundo da câmara de dissipação. 


\section{CONCLUSÕES}

Este trabalho envolveu estudos sobre válvula dispersora com foco no escoamento na válvula Hollow-Jet e na câmara de dissipação de energia, envolvendo a calibração de um modelo numérico com base em um banco de dados de modelo físico da literatura existente.

A partir desta calibração foi possível estudar a faixa operativa da válvula e da câmara de dissipação, levando em conta a operação adequada do sistema, o que permitiu obter informações no sentido de proporcionar a tomada de decisão e planejamento da operação da estrutura dissipadora.

Na prática, devido aos períodos de cheia e estiagem, uma câmara dissipadora dificilmente operará 100 \% do tempo no ponto de operação de projeto, o que fundamenta a importância do estudo da faixa operativa do sistema que pode ser resumido na figura 101.

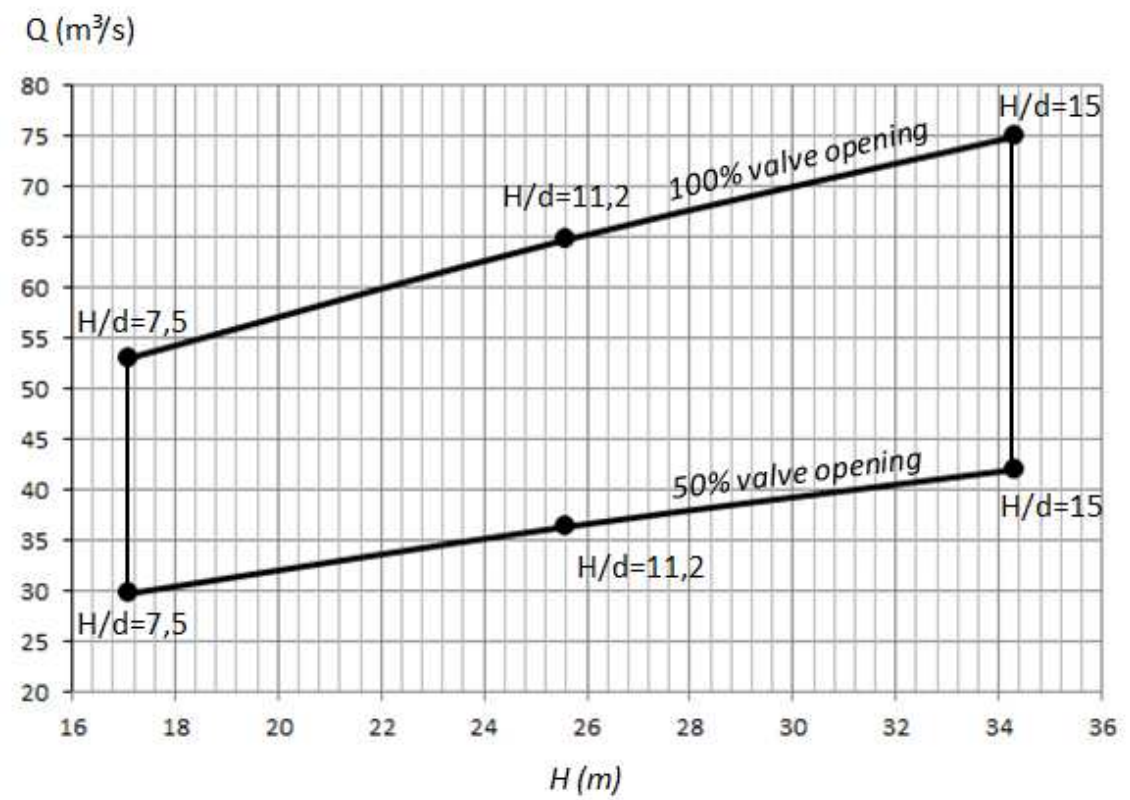

Figura 101. Faixa operativa da câmara dissipadora, queda líquida versus vazão de cada válvula 
Os resultados das simulações numéricas demonstraram a possibilidade de selecionar os casos onde a operação aparenta viabilidade, trazendo então maior assertividade para a realização dos ensaios em modelo físico. Assim, este trabalho permitiu concluir que a câmara dissipadora de Falcon Dam pode operar entre as razões 7,5 $\leq H / d \leq 15$, ou seja, esta câmara pode operar em condições diferentes das estabelecidas em projeto $(H / d=11,2$ e abertura de válvulas em $100 \%)$.

Adicionalmente, os resultados das simulações numéricas podem ser usados para a construção de um banco de dados em $C F D$, possibilitando analogias com outras simulações a serem realizadas no futuro. 


\section{REFERÊNCIAS BIBLIOGRÁFICAS}

- ANSYS - Customer Training Material, Introduction to Ansys CFX - Lecture 9 Advanced Physics, Pennsylvania, United States, 2010, p. 43-44.

- ANSYS - Lecture 7, Mesh Quality and Advanced Topics, Pennsylvania, United States, 2014. p. 10

- ANSYS, CFX Solver Modeling Guide Release 15.0, Pennsylvania, United States, 2013, p. 40.

- BUCK, B; JOHNSON, M; SHARP, Z. Improving Concrete Containment Structures Associated with Fixed-Cone Valves, Utah State University, 2011, p. 447.

- BUDO, et al, Stepped Spillway Flow - Comparison of Numerical And Scale Models, Belgrade University, 2013, p. 3-4.

- ELETROBRÁS, Critérios de Projeto Civil de Usinas Hidrelétricas, 2003, p. 79.

- ENVIROPRO, Submerged Discharge Valve, www.enviropro.co.uk, 2015

- GAO, et al, Three-dimensional hydrodynamic model of concrete tetrahedral frame revetments, China Three Gorges University, 2009, p. 1.

- GERDIN, L; KEIJSER, M.R, Numerical Study on Jet Flow Characteristics of High Head and Large Discharge Spillways, Uppsala Universitet, 2014, p. 20-21.

- HOOKSERVICE, Howell Bunger Valve, www.hookservice.eu, 2015

- LEWIN, Jack, Hydraulic Gates and Valves, London, Thomas Teldford, 1995, p. 76-77.

- MARGEIRSSON, Björn, Computational Modeling of Flow over a Spillway, Gothenburg, Chalmers University of Technology, 2007, pp. 4-6

- ORTIZ, J.P; Fundamentos da Turbulência de Escoamentos Incompressíveis Aplicados à Engenharia, 2010, sites.poli.usp.br/d/pme5213. 
- SILVA, M.R; Modelação Numérica 3D de escoamentos descarregadores de cheias com escoamento em superfície livre. Descarregador complementar de Salamonde, Técnico Lisboa, 2013, p. 33-34.

- UNITRACC.COM, Plunger Valve, www.unitracc.com, 2015

- URBAN DRAINAGE AND FLOOD CONTROL DISTRICT, Urban Storm Drainage Criteria Manual, 2016, Volume 2, Chapter 9, p. 13.

- USBR Engineering Monograph N²5, Hydraulic Design of Stilling Basins and Energy Dissipators, Denver, 1984, Section 8, p. 127-152.

- USBR Hydraulic Laboratory Techniques, Denver, United States Government Printing Office, 1980, Chapter 8, p. 125-126

- USBR Hydraulic Report No189, Tests on 24-inch Hollow-Jet Valve at Boulder Dam, Denver, 1945, p.23-24.

- USBR Hydraulic Report N²40, The Development of High-Head Outlet Valves, Denver, 1948, p. 13-14.

- USBR Hydraulic Report N²76, Hydraulic Model Studies of Falcon Dam, Denver, 1950, p. $72-97$.

- VERSTEEG, H.K \& MALALASEKERA, W, An Introduction to Computational Fluid Dynamics - The Finite Volume Method, Pearson Prentice Hall, Second Edition, 1995, p. 2$3: 35-37: 305-306$. 